\title{
Cenozoic evolution of the Campbell Plateau, Subantarctic New Zealand: Insights from sub-bottom profile data
}

By

Benjamin David Cathie

A thesis submitted in the partial fulfilment of the requirements for the degree of Master of Science in Geology

School of Geography, Environment and Earth Sciences

Victoria University of Wellington, New Zealand

2019

TE WHARE WĀNANGA O TE ŪPOKO O TE IKA A MĀUI

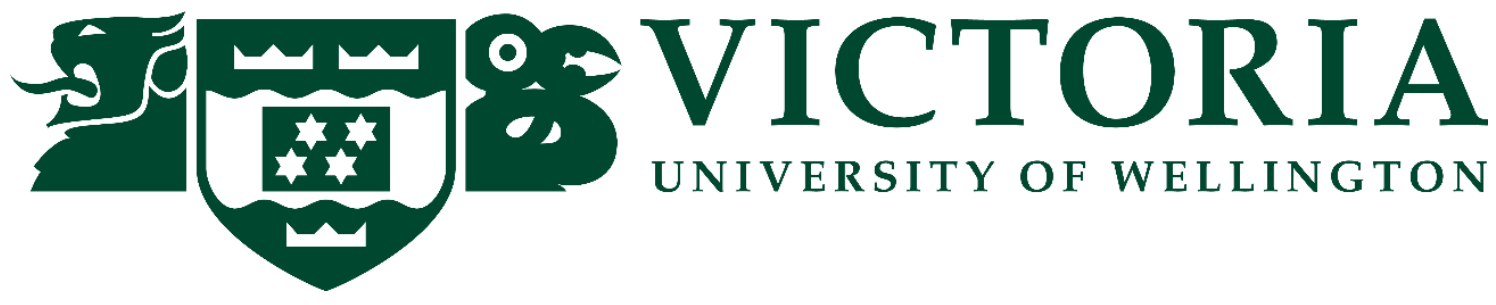




\section{$\underline{\text { Abstract }}$}

The Campbell Plateau represents $\sim 30 \%$ of the submerged continent of Zealandia and represents part of the Gondwana super-continent that began to break-up $98 \mathrm{Ma}$. The focus of this MSc thesis is to use sub-bottom, profile data collected in 2017 and 2018 from Campbell Plateau to improve our understanding of the Cenozoic evolution of the region. The sub-bottom profiles show a rugged basement overlain by a variety of sedimentary sequences and subsurface features such as volcanoes, onlap, and downlap surfaces as well as multiple unconformities that can be traced throughout the Cenozoic (65Ma). The sub-bottom profiles are compared to 2 drill cores; Ocean Drilling Program (ODP) site 1120 on the eastern side of the plateau and Deep Sea Drilling Program (DSDP) site 277 in the south. These drill cores indicate that the lithology from the Cretaceous onwards is predominantly biogenic calcareous sandstone and mudstone, which changes to nannofossil-rich oozes in the Miocene and foraminiferal oozes and nannofossil oozes dated early to late Pleistocene. The northern plateau appears to be relatively quiescent with thin, relatively uniform strata, only influenced by small reverse faults. Sedimentary deposits such as wedges and contourites are also evident in the central and north-western part of the study area. The southern plateau appears to be have been highly dynamic with onlap/downlap surfaces, interpreted as current scours, and erosional surfaces. There is a plateau-wide unconformity during the Pliocene, as derived from the nannofossils of the ODP1120 drill core, which appears to have been a large-scale erosional event. The Southern Ocean circulation, dominated by Antarctic Circumpolar Current, the Subtropical Front, and local wind-driven currents, are the main drivers of these lithological changes and plateau-wide sedimentological structures.

Previous interpretations of the sub-surface structure of the plateau are seen to be invalid in relation to this study, with the sub-surface seen to be relatively undeformed with only minor reverse faulting present. Areas of possible uplifted basement seen near Campbell Island also indicate that the Campbell Plateau has been through substantial erosion and deformation since its' separation from Gondwana $~ 98 \mathrm{Ma}$ and movement to its modernday position. 


\section{$\underline{\text { Acknowledgments }}$}

Firstly, I would like to thank my supervisors, Helen Bostock and Lionel Carter. Helen, thank you for the amazing amount of time and effort you have dedicated to editing this thesis and putting up with some silly questions I've asked at times, also giving me the two weeks at sea which I am very grateful for the opportunity and the help whilst there. Thank you also for the huge amount of encouragement and enthusiasm over the past year from yourself and Lionel. Lionel, I would also like to thank you for your time editing this thesis, having a laugh now and again, and your knowledge of both oceanography and the past sediment work in the area.

Thank you to the staff at the National Institute of Water and Atmospheric Research (NIWA) for allowing me access to their facilities for the duration of this thesis and help throughout the way, in particular, thank you to Susi Woelz for processing the subbottom profile data and your knowledge with Kingdom Suite and seismic interpretation, along with general guidance throughout. Thank you also to the crew of the RV Tangaroa for the hospitality during my time at sea, I'd also like that thank Alan Hart for help whilst at sea and for covering the other shift on the sub-bottom profiling.

I would also like to thank Max, Lockie and Jacob for your feedback and help with this thesis but also always finding ways to procrastinate at least a few times a day whenever I was in the office.

Finally, I would like to thank my parents and family for their endless support over the last year and throughout my entire education. 


\section{Table of Contents}

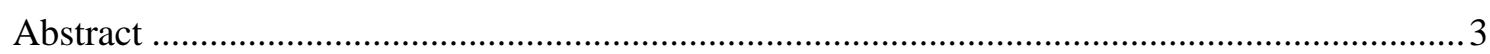

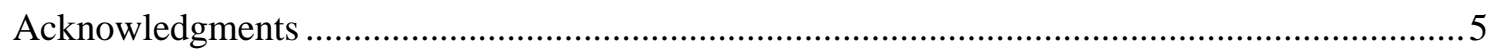

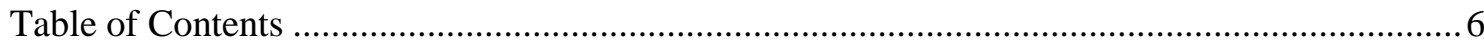

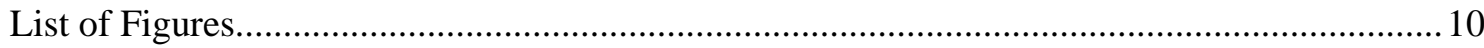

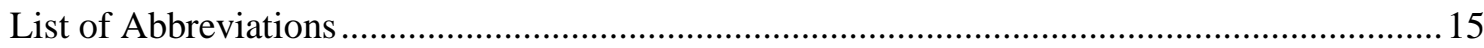

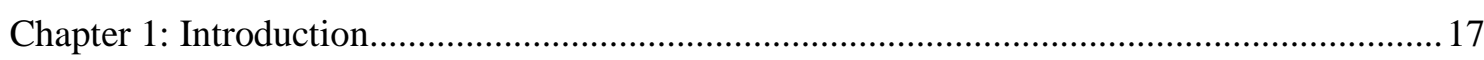

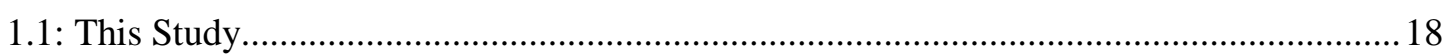

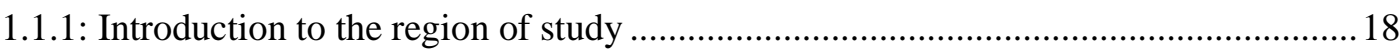

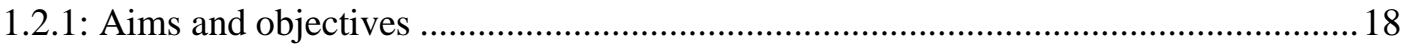

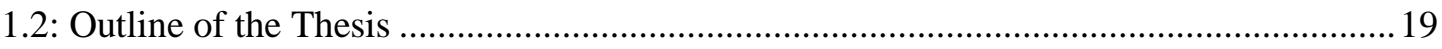

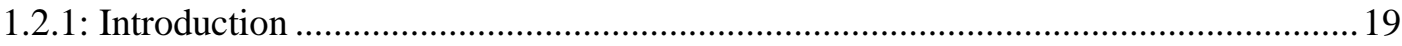

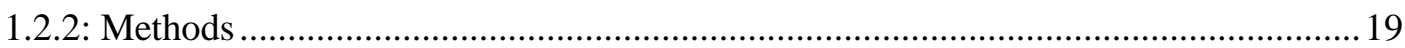

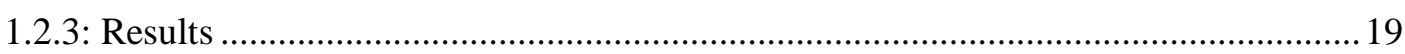

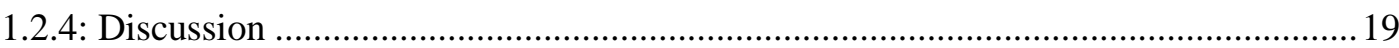

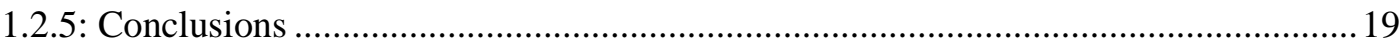

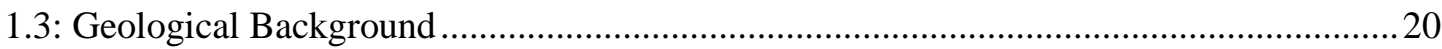

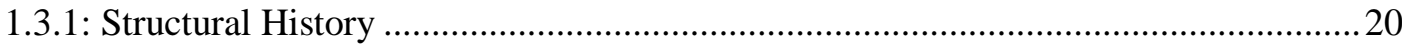

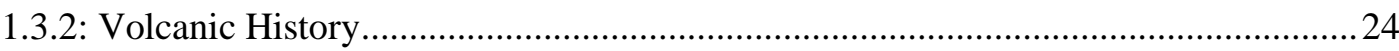

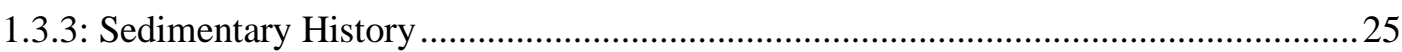

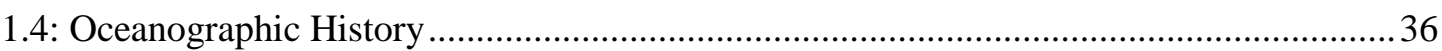

1.4.1: Paleoceanography of the Campbell Plateau .................................................................. 36

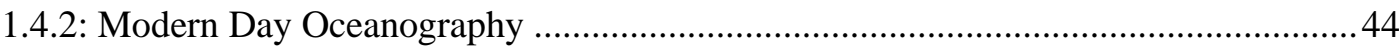

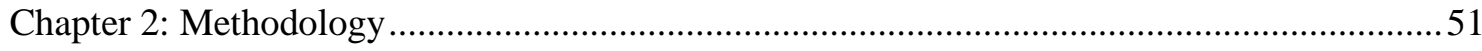

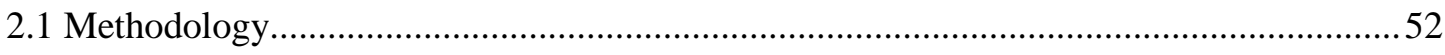

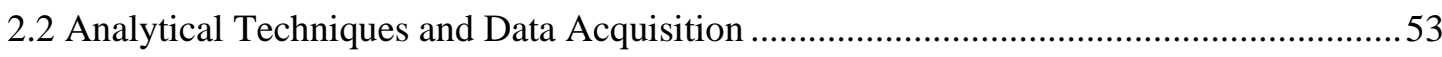

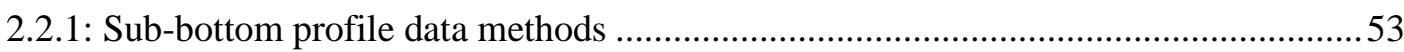

2.2.2: Damuth Scale and data description ......................................................................... 54

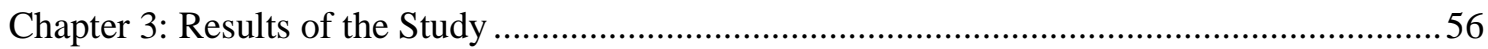

3.1: Line 1 (ODP1120 core site, eastern Campbell Plateau) .......................................................59

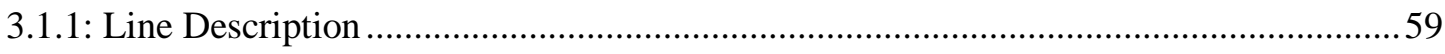

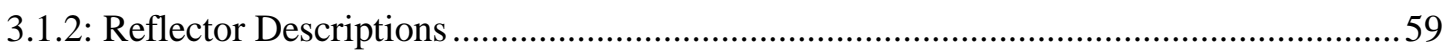

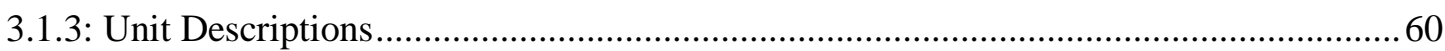

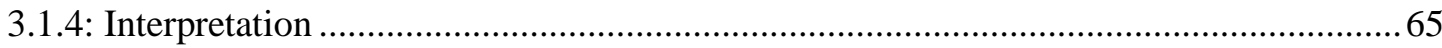

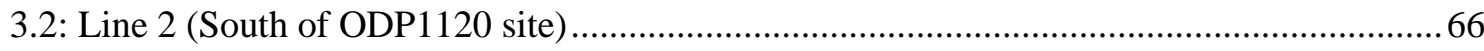

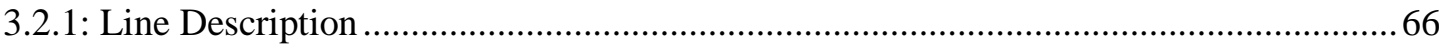

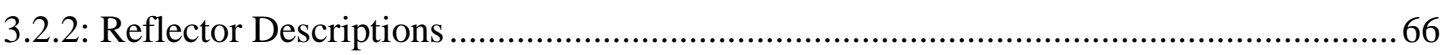




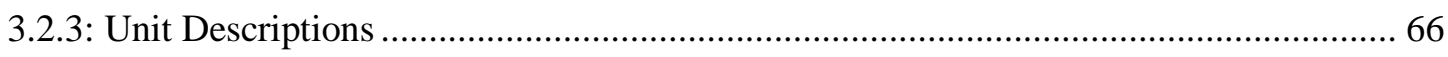

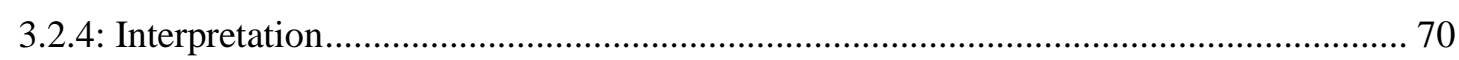

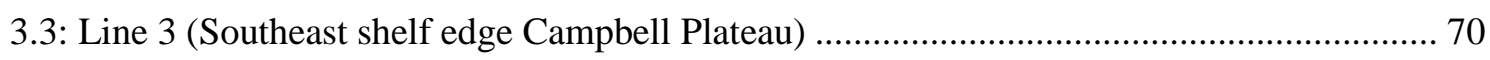

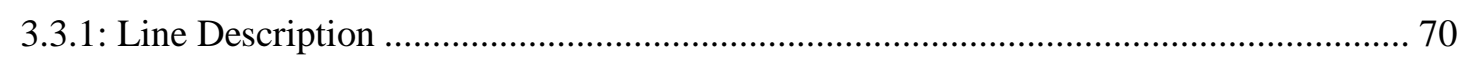

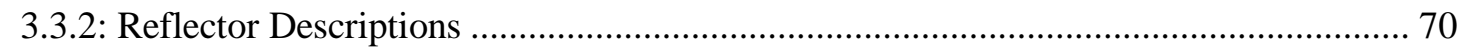

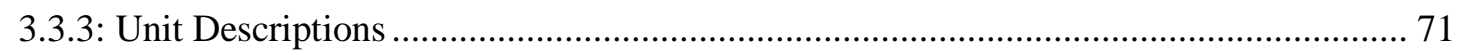

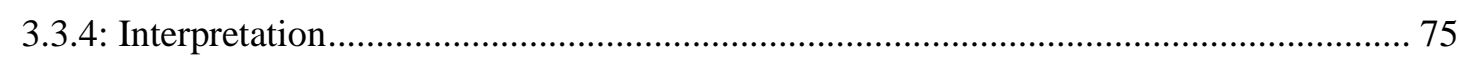

3.4: Line 4 (Eastern shelf edge of Campbell Plateau) ............................................................. 75

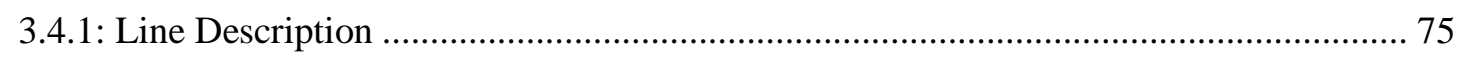

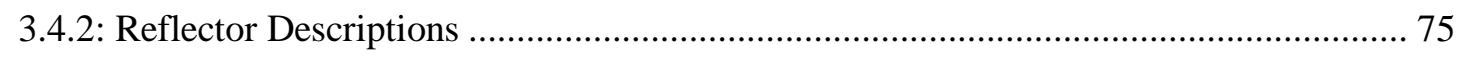

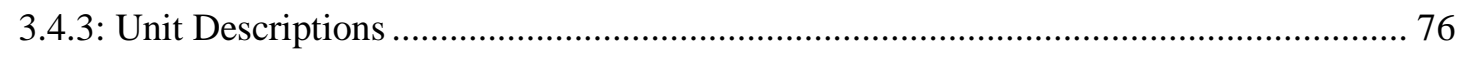

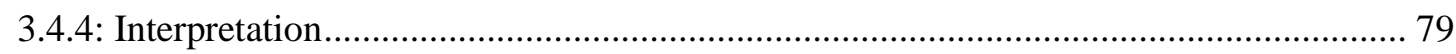

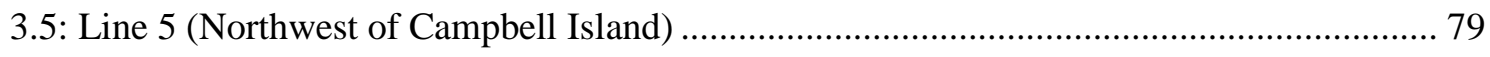

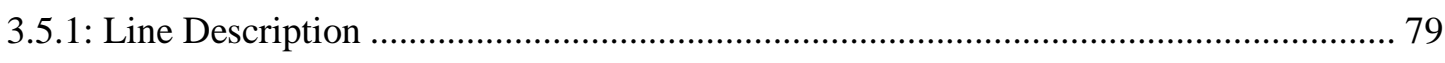

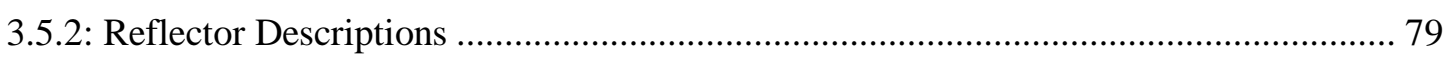

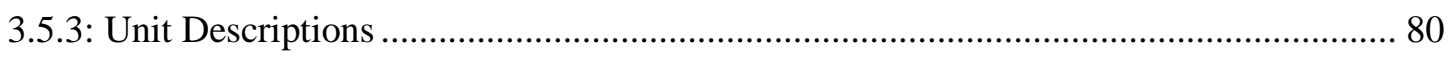

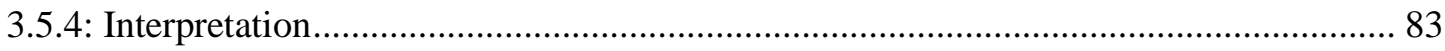

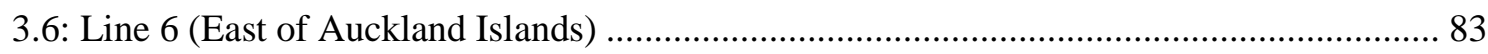

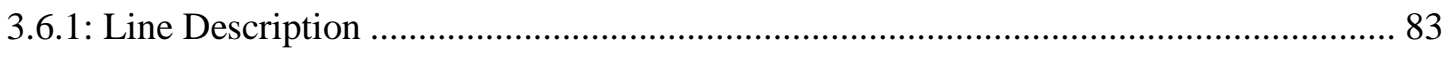

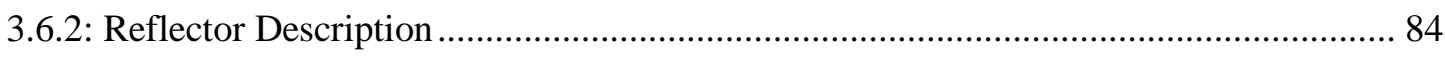

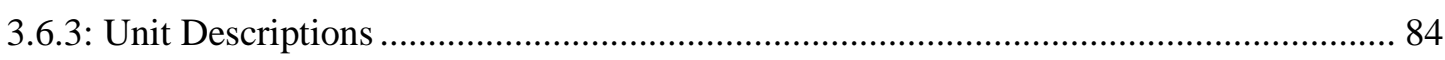

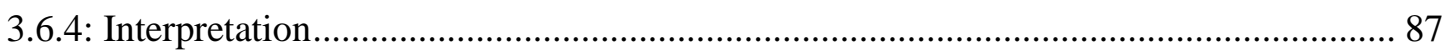

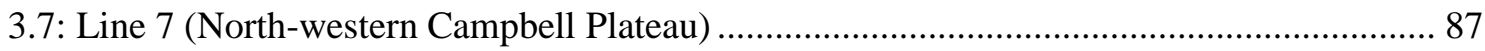

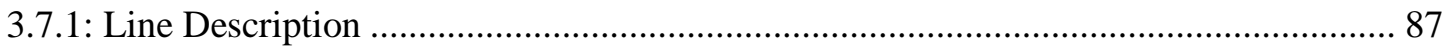

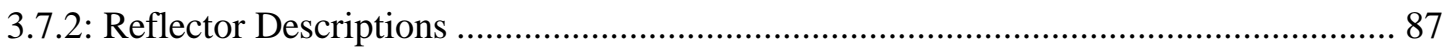

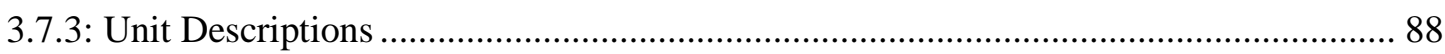

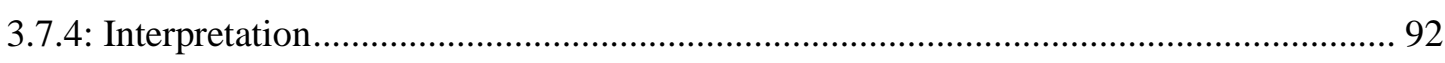

3.8: Line 8 (Northern Campbell Plateau, north of Pukaki Rise) .............................................. 92

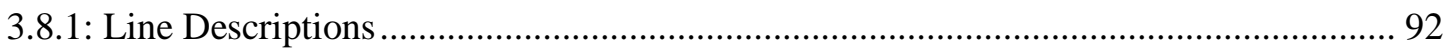

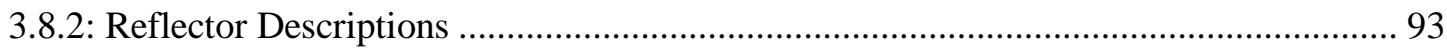

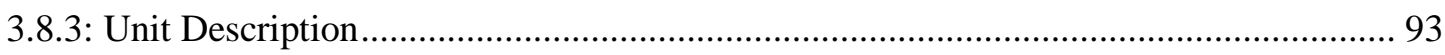

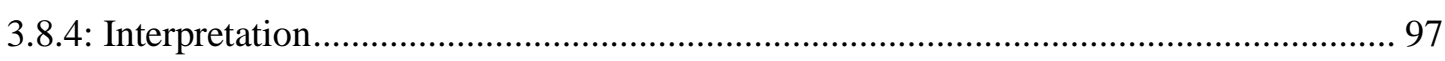

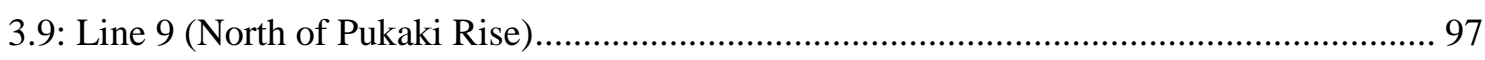

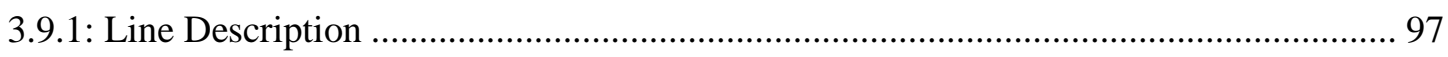

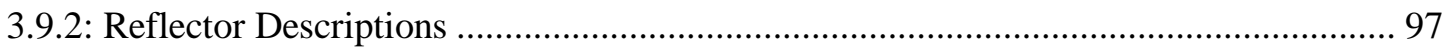

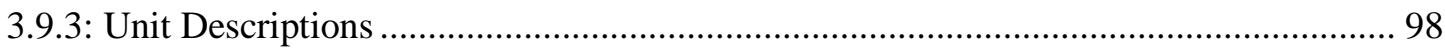

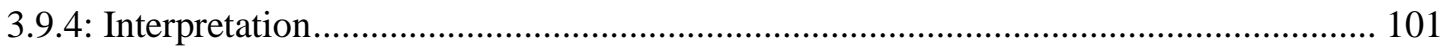

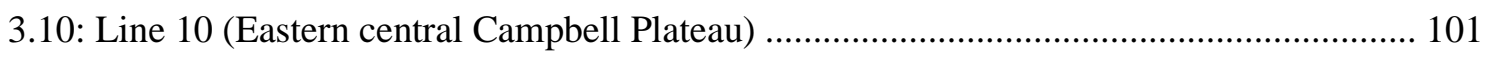

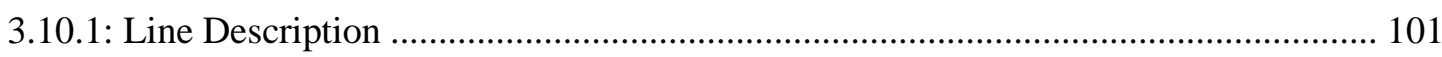




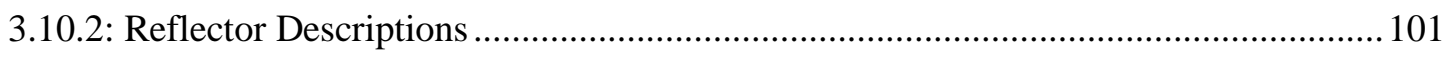

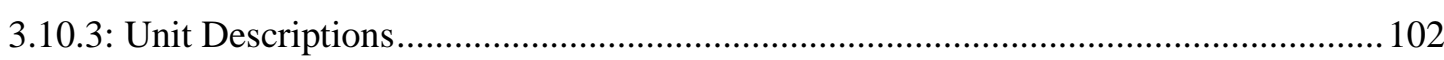

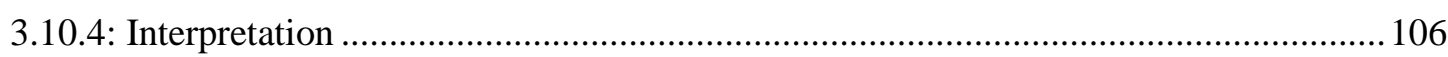

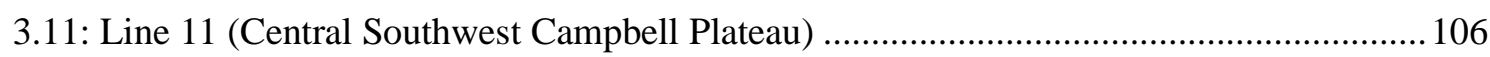

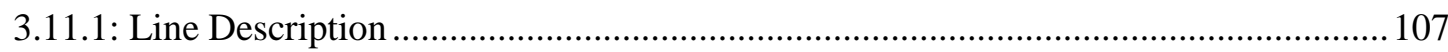

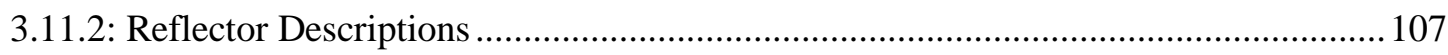

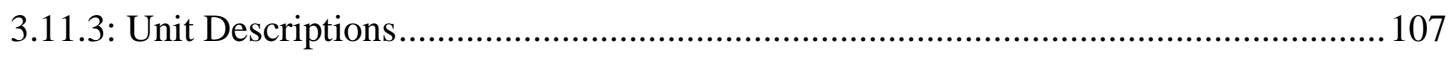

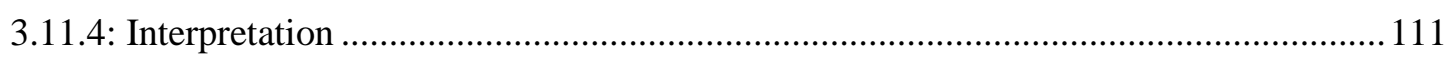

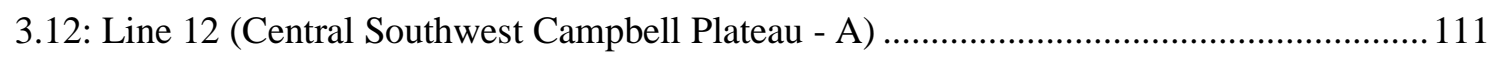

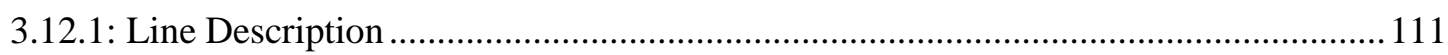

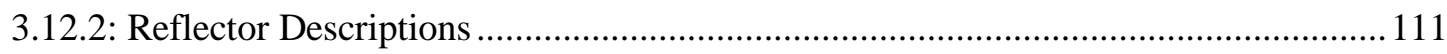

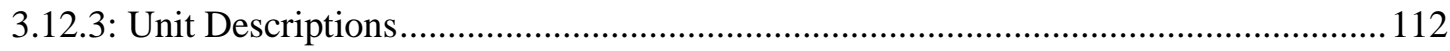

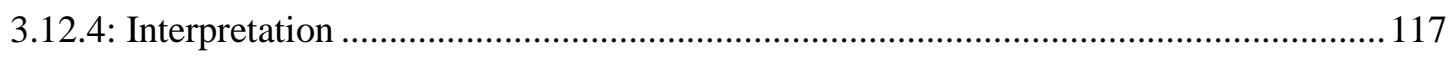

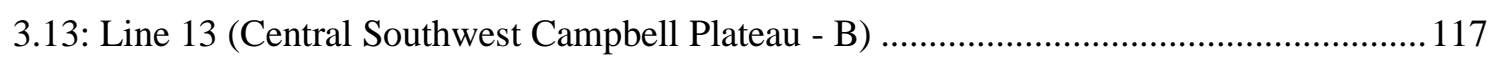

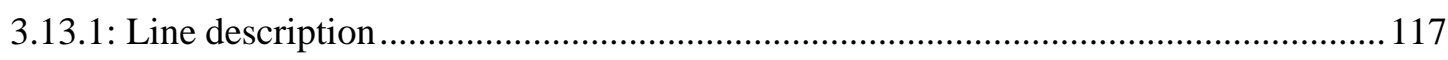

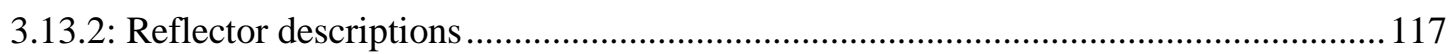

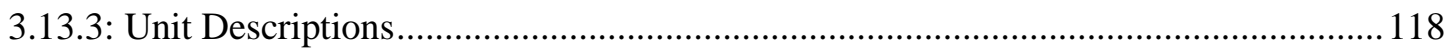

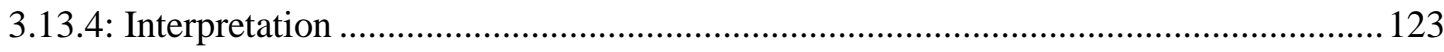

3.14: Line 14 (Central Southwest Campbell Plateau - C) ...................................................... 123

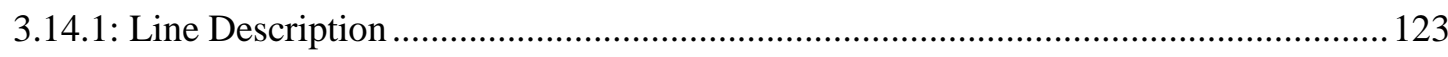

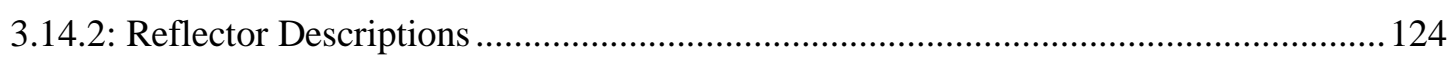

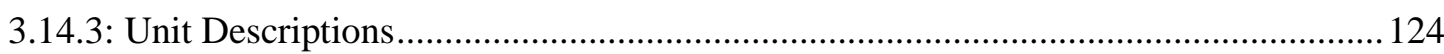

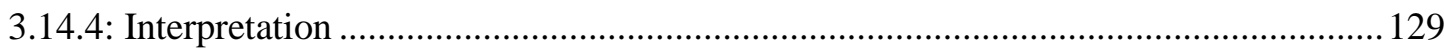

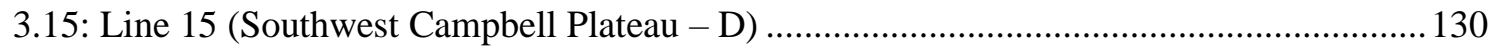

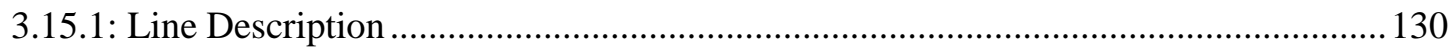

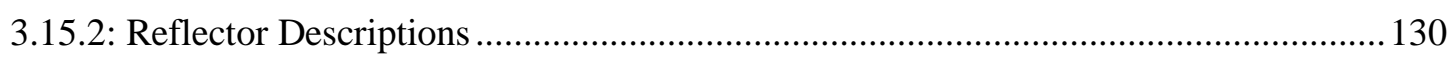

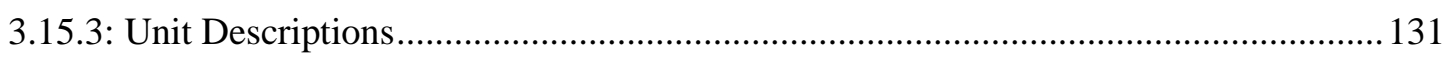

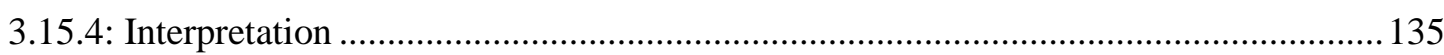

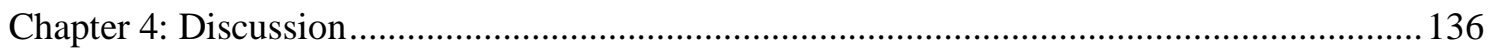

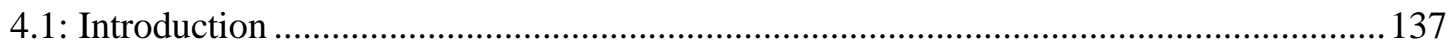

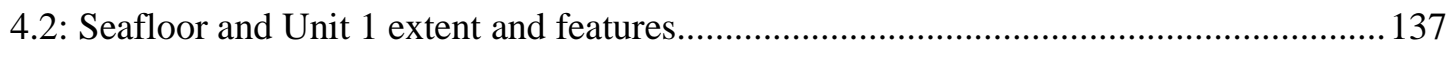

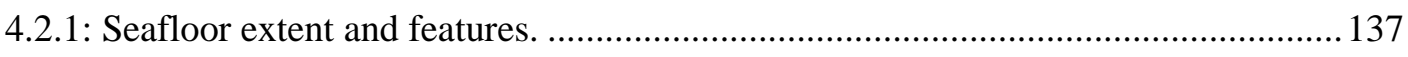

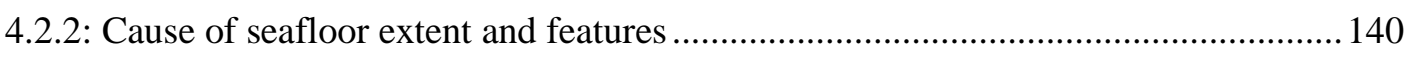

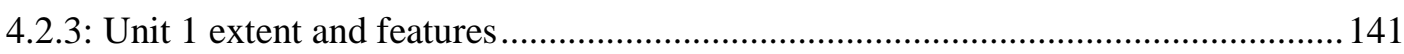

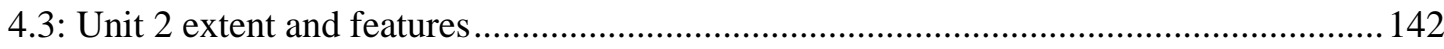

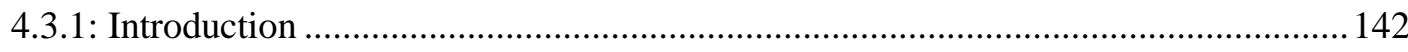

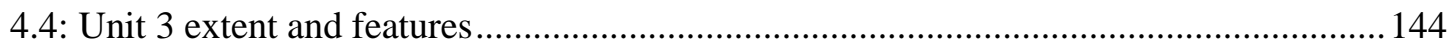

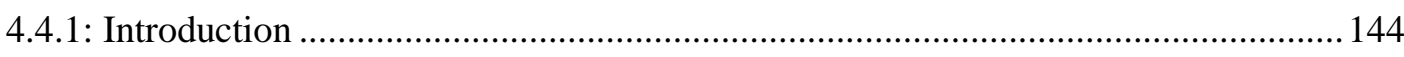

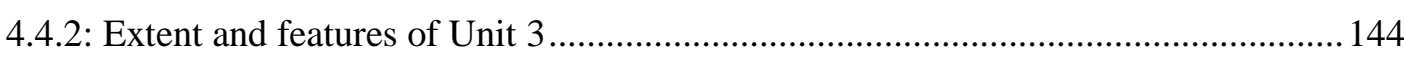


4.5: Structural Features of the Campbell Plateau Subsurface

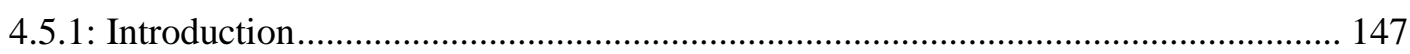

4.5.2 The subsurface structural geology of Campbell Plateau ....................................... 149

4.5.3 Extent and amplitude and timing of faulting....................................................... 150

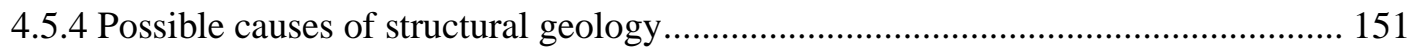

4.6: Features of subsurface Campbell Plateau .................................................................... 151

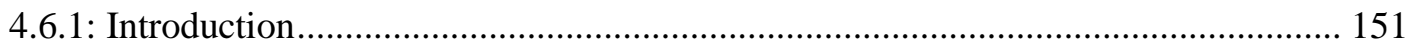

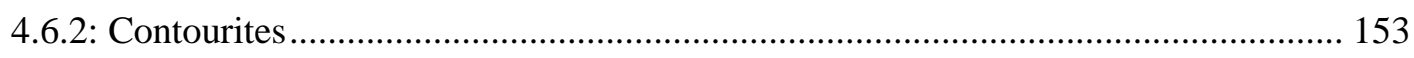

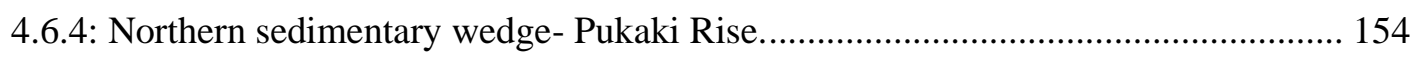

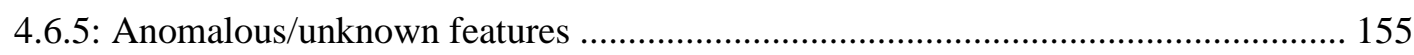

4.6.7: Southern and western features of the Campbell Plateau......................................... 156

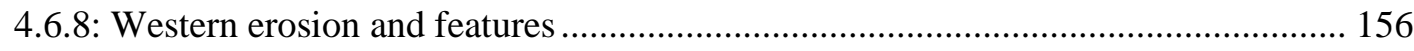

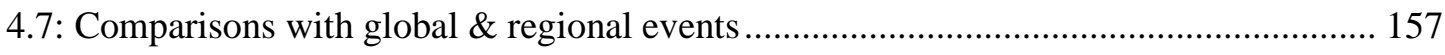

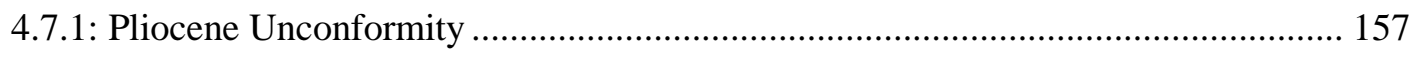

4.7.2: Subsurface Oligocene Campbell Plateau ............................................................ 161

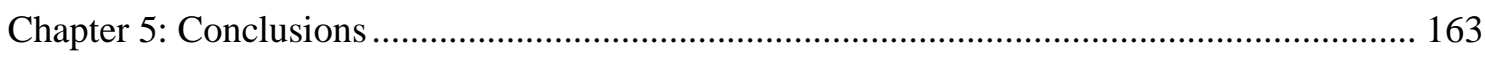

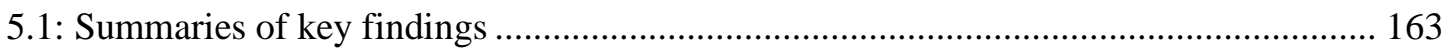

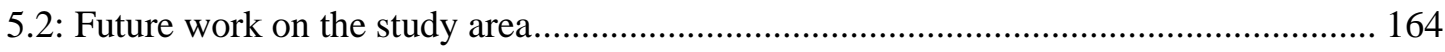

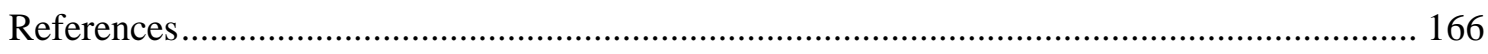




\section{List of Figures}

Figure 1.1: Paleo-reconstruction of New Zealand during the Late Cretaceous (from King., 2000).

Figure 1.2: Paleo-reconstruction of New Zealand during the Late Paleocene (From King., 2000).

Figure 1.3: Paleo-reconstruction of the Southern Ocean, a displaying plate tectonic and paleogeographic/paleoceanographic map from the Paleocene (From Nelson and Cooke., 2001)

Figure 1.4: Early interpretation of the Campbell Plateau's structural geology by Summerhayes (1969).

Figure 1.5: Compilation of DSDP sediment cores taken to the south of Campbell Plateau and in the southern section of the plateau. .26

Figure 1.6: Compilation of DSDP and ODP sediment cores taken to the north of Campbell Plateau and in the northern section of the plateau. .28

Figure 1.7: Map displaying locations of all major sediment and surface cores taken across the plateau. .29

Figure 1.8: Lithogenic flux map of modelled dust deposition during the LGM (from Durand et al., 2017)..... 30

Figure 1.9: Map of the early surface sediment extent map of the Campbell Plateau (from Summerhayes., 1969). 31

Figure 1.10: Maps of the modern percentages of carbonate over Campbell Plateau (published in Bostock et al., 2018). . .32

Figure 1.11: Maps of the modern percentages of gravel over Campbell Plateau (published in Bostock et al., 2018)....

Figure 1.12: Maps of the modern percentages of sand over Campbell Plateau (published in

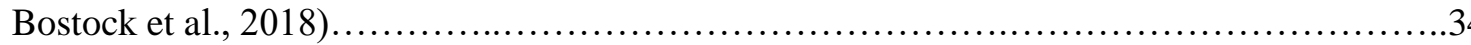

Figure 1.13: Maps of the modern percentages of mud over the Campbell Plateau (published in Bostock et al., 2018).

Figure 1.14: Maps of the modern abundances of nannofossils vs abundances during the MIS 5e (from Cortese et al., 2013)

Figure 1.15: Map of intensified STF during MIS 5e (from Duncan et al., 2016). .44

Figure 1.16: Map of the modern surface circulation around New Zealand and the Southern Ocean. .46

Figure 1.17: Ocean Data View temperature transect across the Campbell Plateau in a NE to SW direction outlining the primary water masses identified.

Figure 1.18: Map of the intermediate water masses seen as tracked by Argo Floats around New Zealand and the Southern Ocean. 48

Figure 1.19: Map of the deep and bottom water masses seen as tracked by Argo Floats around New Zealand and the Southern Ocean.... 
Figure 2.1: TOPAS echogram screen detailing the main components whilst taking sub-bottom profile data.

Figure 2.2: Display screen of IHS Kingdom interpretation screen, highlighting the ODP site 1120 core that has been used as the main seismic tie point for this study.....

Figure 2.3i-iv: Compilation of the varying Damuth echo type scales used to classify sub-bottom reflections.

Figure 3.1: Map displaying the sub-bottom profile lines used in this study, lines labelled are the lines used in the results as representatives for each main area of the study area. .58

Figure 3.2a: Uninterpreted seismic section of line 1, located on the eastern Campbell Plateau.

Figure 3.2b: Interpreted seismic section of line 1, with the line annotated with the features seen in each reflector and unit.

Figure 3.2c: Zoomed interpreted a seismic section of the centre of line 1, annotating the central amplitude low and features surrounding it.

Figure 3.3a: Uninterpreted seismic section of line 2, located on the eastern Campbell Plateau.

Figure 3.3b: Interpreted seismic section of line 2, the line is also annotated outlining the features and characteristics of each reflector and unit when necessary....

Figure 3.4a: Uninterpreted seismic section of line 3, located on the southeast shelf edge of the Campbell Plateau.

Figure 3.4b: Interpreted seismic section of line 3, annotated with the key features seen in each reflector and unit in this line.

Figure 3.5a: Uninterpreted seismic section of line 4, located on the southeast Campbell

Plateau.

Figure 3.5b: Interpreted seismic section of line 4, this line is annotated with key features that are seen in each reflector and unit in this line.

Figure 3.6a: Uninterpreted seismic section of line 5, located on the southeast Campbell Plateau, north of Campbell Island

Figure 3.6b: Interpreted seismic section of line 5, the line is annotated features and points of interest in each reflector, unit and major features of the line itself.

Figure 3.7a: Uninterpreted seismic section of line 6, located north of Auckland Island, on the southwest Campbell Plateau.

Figure 3.7b: Interpreted seismic section of line 6, the line is annotated with the few key features due to heavy erosion.

Figure 3.8a: Uninterpreted seismic section of line 7, the line is located in the northwestern section of the Campbell Plateau.

Figure 3.8b: Interpreted seismic section of line 7, annotation on this line outline the main features seen in the contourites in the northern section of the study area.

Figure 3.9a: Uninterpreted seismic section of line 8, located on the northern Campbell Plateau. 
Figure 3.9b: Interpreted seismic section of line 8, annotations on this line outline the main features seen in the large wedge structure in the lines' southern section.

Figure 3.10a: Uninterpreted seismic section of line 9, located on the northern Campbell Plateau, north of Pukaki Rise.

Figure 3.10b: Interpreted seismic section of line 9, annotations represent various changes in bedding amplitudes, thicknesses in the units as well as further erosional features.

Figure 3.11a: Uninterpreted seismic section of line 10, located on the eastern central Campbell Plateau. 104

Figure 3.11b: Interpreted seismic section of line 10, annotations on this line represent possible seafloor scouring and fluid escape structures.

Figure 3.12a: Uninterpreted seismic section of line 11, located on the southeast central Campbell Plateau.

Figure 3.12b: Interpreted seismic section of line 11, annotations here primarily represent erosional features and variations in bedding.

Figure 3.13a: Uninterpreted seismic section of line 12, located on the central southwest Campbell Plateau.

Figure 3.13b: Interpreted seismic section of line 12, annotations on this line represent pinch out points of units and faulting seen in this section.

Figure 3.14a: Uninterpreted seismic section of line 13, located on the central southwest Campbell Plateau.

Figure 3.14b: Interpreted seismic section of line 13, annotations on this line represent sections of possible biogenic gas, variations in bedding thickness and amplitude and also other possible structural features.

Figure 3.15a: Uninterpreted seismic section of line 14, located on the central southwest Campbell Plateau.

Figure 3.15b: Interpreted seismic section of line 14, annotations on this line represent possible bedding deformation by a possible intruding submarine volcano, along with points of further possible scouring.

Figure 3.15c: Zoomed schematic interpretation of line 14 and the possible depression of unit 2a near the possible central feature via erosion.

Figure 3.15d: Zoomed schematic interpretation of line 14 and the possible cause of depression of unit 2a near the possible central feature possibly due to a pressure difference.

Figure 3.16a: Uninterpreted seismic section of line 15, located on the central southwest Campbell Plateau.

Figure 3.16b: Interpreted seismic section of line 15, annotations on this line represent pinch out points of units against a plane of erosion.

Figure 4.1: Map displaying the various Damuth echo type classifications interpreted across the study area.

Figure 4.2: Isochron map of the mean thickness of unit 1 across the study area.

Figure 4.3: Isochron map of unit 2a showing its extent and variation of thickness across the study area. 
Figure 4.4: Isochron map of unit 3a, showing the unit's extent and thickness across the study

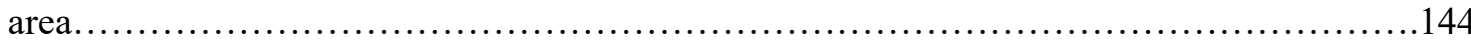

Figure 4.5: Isochron map of unit 3b, showing its extent and thickness across the study area.

Figure 4.6: Schematic of the impacts of submarine volcanism on sediments, through the banking up of sediments (A) or the intrusion of the volcano (B)...

Figure 4.7: Map displaying the locations of interpreted sub-surface faults in this study 148

Figure 4.8: Early structural interpretations of the Campbell Plateau by Summerhayes (1969)

Figure 4.9: Map displaying the various sub-marine features seen on the Campbell Plateau.

Figure 4.10: Map of the modern-day Southern Ocean circulation regime, with suggestions for possible paleo-currents during the LGM.

Figure 4.11: Circulation map of New Zealand during the LGM, with suggestions for current directions during this time period.

Figure 4.12: Schematic measured section compiling sediment cores taken on the plateau along with geological, volcanic and climatic/oceanographic events from the Southern Ocean tied to these cores by date.

\section{List of Tables}

Table 1: Table of the summary of Cenozoic oceanographic and climatic events to likely affect the Campbell Plateau's evolution and the resulting sediments.... 


\section{$\underline{\text { List of Abbreviations }}$}

AABW: Antarctic Bottom Water

AAIW: Antarctic Intermediate Water

ACC: Antarctic Circumpolar Current

CDW: Circumpolar Deepwater

DSDP: Deep Sea Drilling Project

DWBC: Deep Western Boundary Current

EAC: East Australian Current

I-P: Indonesian-Pacific Origin

Ka: Thousand of years ago

Kyr: Thousand years

LCDW: Lower Circumpolar Deep Water

LGM: Last Glacial Maximum

Ma: Millions of years ago

MBES: Multibeam Echosounder

MECO: Mid Eocene Climatic Optimum

MIS: Marine Isotope Stage

MPT: Mid Pleistocene Transition

NZSSO: New Zealand's Sector of the Southern Ocean

ODP: Ocean Drilling Programme

PETM: Paleocene-Eocene Thermal Maximum

PF: Polar Front

SAF: Subantarctic Front

SAMW: Subantarctic Mode Water

SAW: Subantarctic Water

SC: Southland Current

SEC: South Equatorial Current

SST: Sea Surface Temperature

STF: Subtropical Front

STW: Subtropical Waters

TO: Tasman Outflow

TVG: Time Variable Gain 
UCDW: Upper Circumpolar Deep Water

WE: Wairarapa Eddy 
Chapter 1: Introduction 


\section{1: This Study}

This study aims to undertake the rather ambitious goal of understanding the subsurface history of the Campbell Plateau based on the new TOPAS sub-bottom profile data that was taken on NIWA voyages TAN1703 and TAN1804. Previous geological work on the Campbell Plateau was primarily performed by Summerhayes (1969), who made the first general understanding of the region. Since then, several cores have been taken across the plateau. These cores include a variety of long $(<150 \mathrm{~m})$ ocean drill cores such as ODP1120 and DSDP227, along with a variety of short cores $(<5 \mathrm{~m})$ such as F106 and Y16 (Summerhayes, 1969; Carter, 2018). These cores have allowed for a limited insight into the subsurface of the Campbell Plateau. However, this study aims to take that sedimentary data and, in conjunction with the TOPAS sub-bottom profile data, trace sedimentary and structural features over the Plateaus to identify its evolution with reference to regional and global climatic and geological events during the Cenozoic.

\subsection{1: Introduction to the region of study}

The Campbell Plateau is a large submarine plateau located in Subantarctic New Zealand, approximately between latitudes $47-55^{\circ} \mathrm{S}$. The Plateau covers an area of $800,000 \mathrm{~km}^{2}$, most of which occurs between $500-1000 \mathrm{~m}$ below sea level. However, there are four islands (Campbell, Auckland, Bounty, Antipodes) that dot the surface of the plateau plus Pukaki Rise and Bounty Platform that rise to within $200 \mathrm{~m}$ of the sea surface (Mitchell et al., 2012).

\subsection{1: Aims and objectives}

This study aims to gain insight into the general sub-surface history of the sub-surface Campbell Plateau, regarding both structural and sedimentary regimes and how this compares to past studies on the plateau. The possible impacts of paleo-oceanography and the modern-day oceanography on the sub-surface sediments of the Campbell Plateau throughout the Cenozoic. The extent and causes of both known and potentially new unconformities in the sub-surface Campbell Plateau. 


\section{2: Outline of the Thesis}

\subsection{1: Introduction}

This section will go through the regional background of the Campbell Plateau both in terms of geological and oceanographic histories and past work completed on the plateau. In this chapter, there will also be an overview of the study along with the aims and objectives of the study.

\subsection{2: Methods}

This section will go into the equipment used when at sea and how it performs. This section will also cover the techniques used in the interpretation of the data and types of classifications of data types used.

\subsection{3: Results}

This section will include a selection of 15 sub-bottom profile lines that are representative of the various different sedimentation styles and features are seen in the sub-surface Campbell Plateau. These will include descriptions of reflectors and units interpreted as well as a brief interpretation of the potential causes of features seen in each line.

\subsection{4: Discussion}

The discussion will cover the extent of units interpreted in the study and likely causes for their variation throughout the plateau. It will also discuss possible linkages and causes to sub-surface features.

\subsection{5: Conclusions}

This will list the main points of the discussion and give further insights into further works needed into the Campbell Plateau to further the sub-surface/seismic studies of the area. 


\section{3: Geological Background}

\subsection{1: Structural History}

Campbell Plateau's geological history can be traced back to the original separation of the Zealandia continent from Gondwana approximately $98 \mathrm{Ma}$ ( King, 2000). This separation was caused by tectonic rifting of the Antarctic, New Zealand and Australian segments throughout the Late Cretaceous (Sutherland., 1999). Evidence of these rifting events is present in the two subbasins on Campbell Plateau: Campbell Basin and Pukaki Basin (Glasby \& Wright, 1990). Campbell Basin is a failed rift, controlled by linear normal faulting and lies northeast of Campbell Island (Glasby \& Wright, 1990).

Throughout Campbell Plateau's tectonic history, it has continued to undergo rotation, with the separation of Zealandia from Gondwana $98 \mathrm{Ma}$. Evidence from marine magnetic and satellite gravity data indicate that Campbell Plateau's southeastern margin and the southern margin of Chatham Rise were once attached to the northern margin of the West Antarctic Region of Marie Byrd Lands (Timm et al., 2010). After the break-up of Campbell Plateau from Marie Byrd Land ( 83-79 Ma), the focus of tectonic activity shifted to other areas of the southwestern sector of the Southern Ocean from 80-53 Ma being dominated by the seafloor spreading of the Tasman and South Pacific (Cook et al., 1999). The Campbell Plateau in the Late Cretaceous, however, is interpreted to be above sea level (King, 2000) and linked to the evolution of the Great South Basin (see figure 1.1), through the Late Cretaceous through to the Paleocene (55 $\mathrm{Ma})$. In the late Cretaceous, a regional marine transgression occurs across Zealandia occurring on eastern New Zealand at $\sim 80 \mathrm{Ma}$ and in the west at $\sim 67$ $65 \mathrm{Ma}$ in which Campbell Plateau is semi-submerged by the end of the Paleocene (55 Ma) (see figure 1.2 and 1.3). 


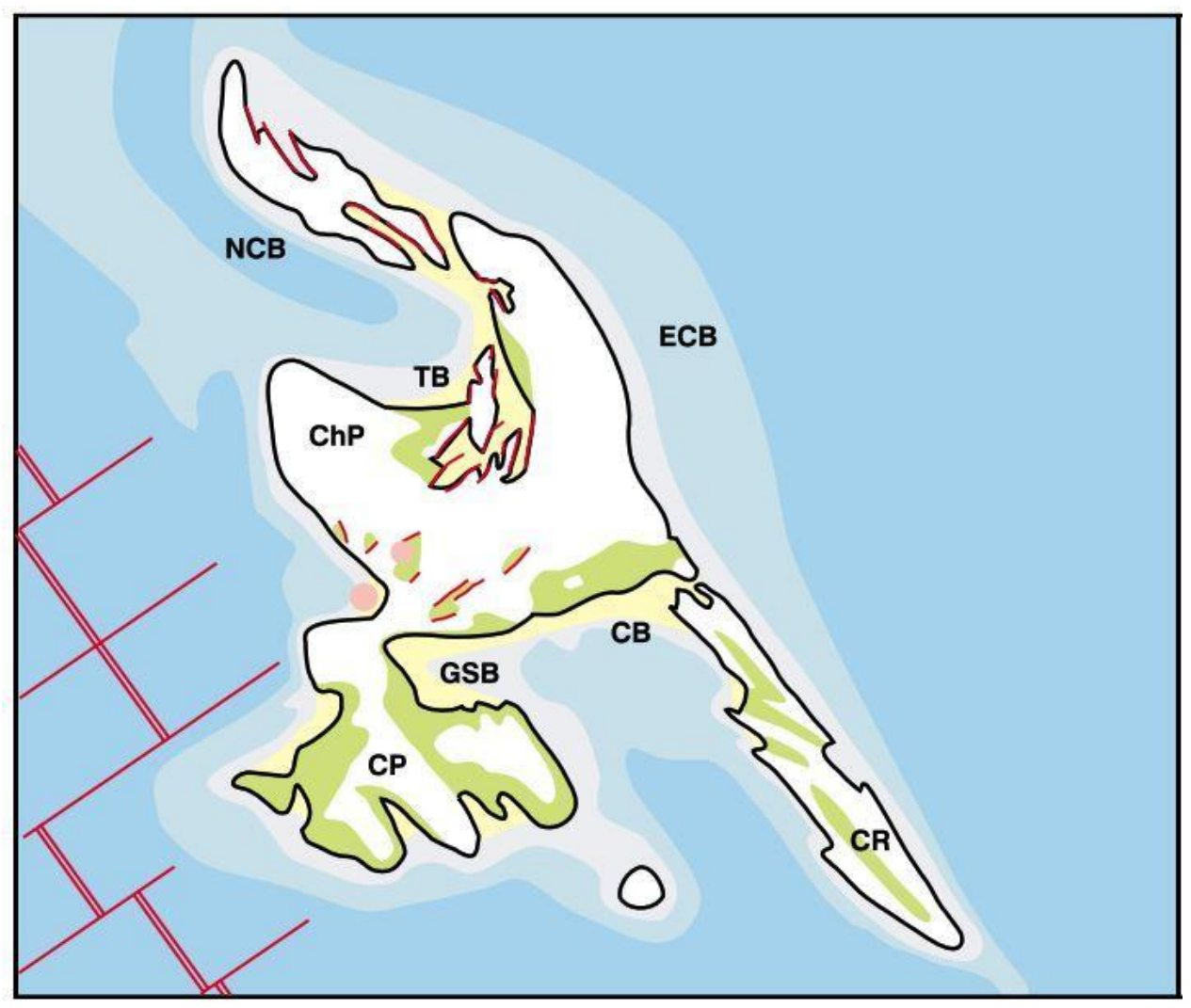

Figure 1.1: Paleogeographic reconstruction of New Zealand for the Late Cretaceous (65Ma) from King (2000), abbreviations relevant to this study are Great South Basin (GSB), Campbell Plateau (CP), and Chatham Rise (CR). (From King 2000).

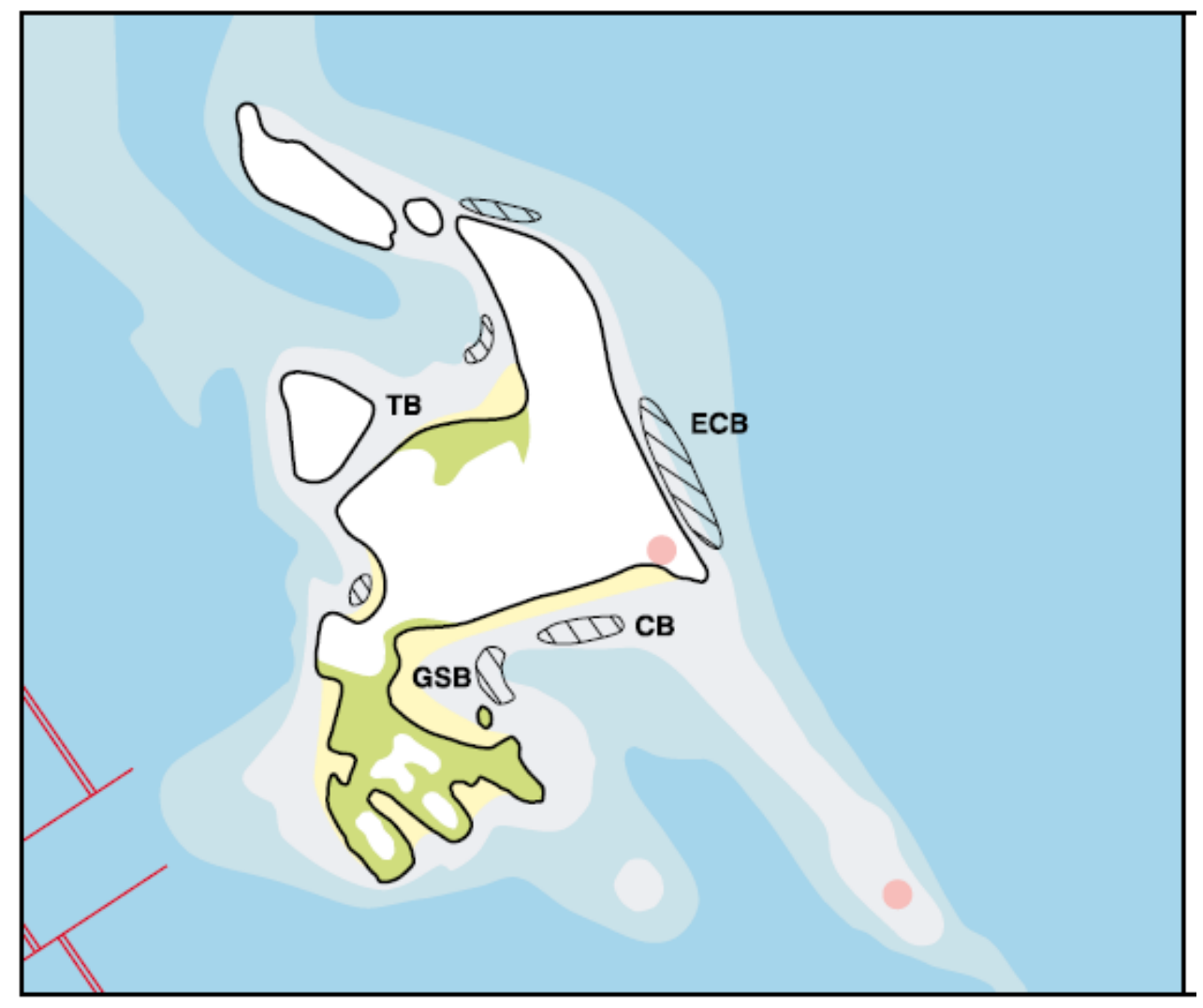

Figure 1.2: Paleogeographic reconstruction of New Zealand for the Latest Paleocene (55Ma) from King (2000), note that Campbell Plateau is mostly submerged. Abbreviations mentioned are Great South Basin (GSB), Canterbury Basin (CB), East Coast Basin (ECB) and Taranaki Basin (Taranaki Basin). (From King 2000). 


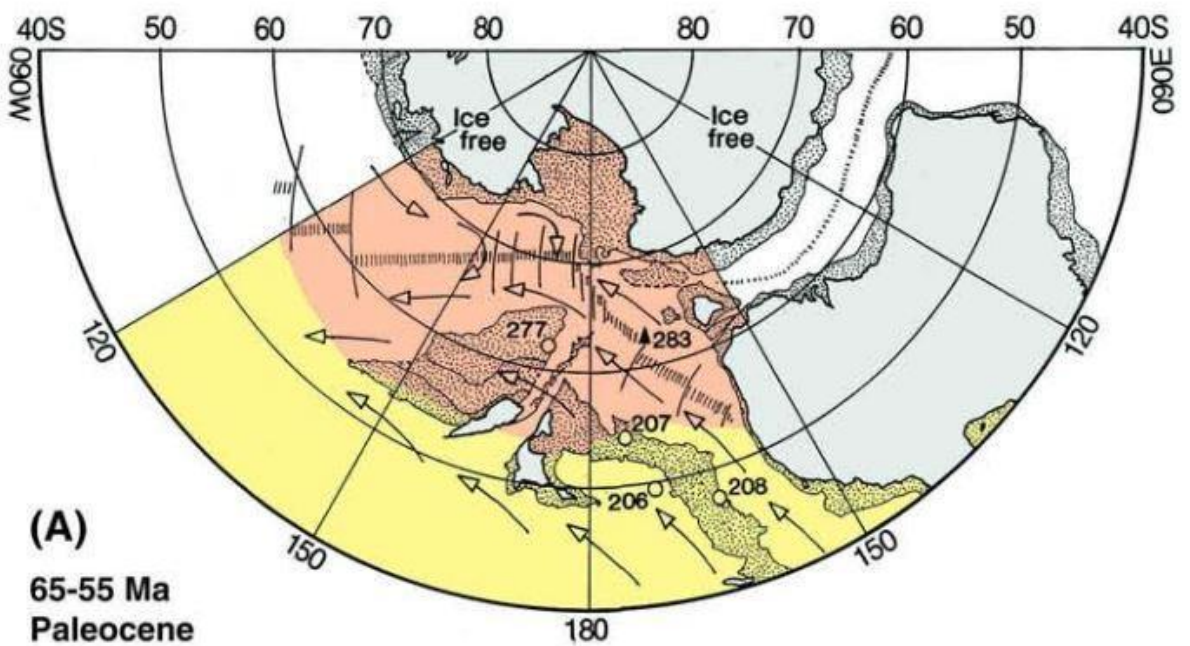

Figure 1.3: Paleogeographic reconstruction of the Southern Ocean during the Paleocene showing direction of water masses and paleolatitudes. The area highlighted in yellow indicates the area covered by subtropical water masses, with the area coloured in peach indicates the area covered by temperate waters (from Nelson and Cooke 2000).

However, some minor tectonic activity continued on the Campbell Plateau in the Late Eocene. During this period seafloor spreading rates in southern Zealandia were $\sim 15 \mathrm{~mm} / \mathrm{yr}$, this spreading then gradually went from extension to strikeslip motion during the Oligocene through to the Miocene (Cook et al., 1999). This motion would have moved Campbell Plateau to its current day position, with slight internal deformation also occurring due to this change. Through the Miocene to the present day (20-0Ma) the Campbell Plateau and the Antarctic spreading continued with only minor changes in the speed $(<15 \mathrm{~mm} / \mathrm{yr})$ and direction (Cook et al., 1999). Much of the geology and units of the Campbell Plateau are also found in the Great South Basin, this is seen in the EoceneOligocene limestone the Tuck Cove Formation, located on Campbell Island (Beggs., 1978).

The Great South Basin's evolution gives some insight into the structural evolution of Campbell Plateau. Great South Basin sits on the northwest of the Campbell Plateau. Based on Cook et al., (1999) correlation with seismic stratigraphy from the drilling of DSDP site 277 , it was suggested that the majority of the Campbell Plateau was formed during the mid-Cretaceous period of extensional tectonics across much of New Zealand's sedimentary basins. However, the proximity of the Australian and Pacific plate boundary close to Great South Basin has made much of the basin's Cretaceous history poorly understood due to the vast about of deformation occurring with the deformation associated with the separation of Gondwana and the subsequent deformation 
since the Cretaceous (King, 2000). The western margin of Campbell Plateau has been dated to have formed during the Late Eocene, which was a consequence of the formation of the proto-plate boundary of the Australian and Pacific tectonic plates (Cook et al., 1999). With the formation of the plate boundary throughout the Late Eocene further seafloor spreading occurred, creating the Emerald Basin and Solander Trough. The formation of these features caused a passive continental margin along the western Campbell Plateau.

The large-scale structural history of the Campbell Plateau can, therefore, be linked to the general structural evolution of Zealandia and is partly linked to the evolution of the Great South Basin. However, the detailed tectonic history of the Campbell Plateau has received little attention. Early work performed by Summerhayes (1969) used the bathymetry of Campbell Plateau to provide some insight into the generalised structural history of the region (see fig 1.4). Summerhayes (1969) interpreted a series of anticlines and synclines based on bathymetric highs and lows such as the Campbell and Pukaki Rises. Subsequent work suggests that the area was gently deformed throughout the Oligocene with the formation of volcanic centres such as Campbell Island and the Auckland Islands on the broad highs across the plateau (Katz, 1974). 


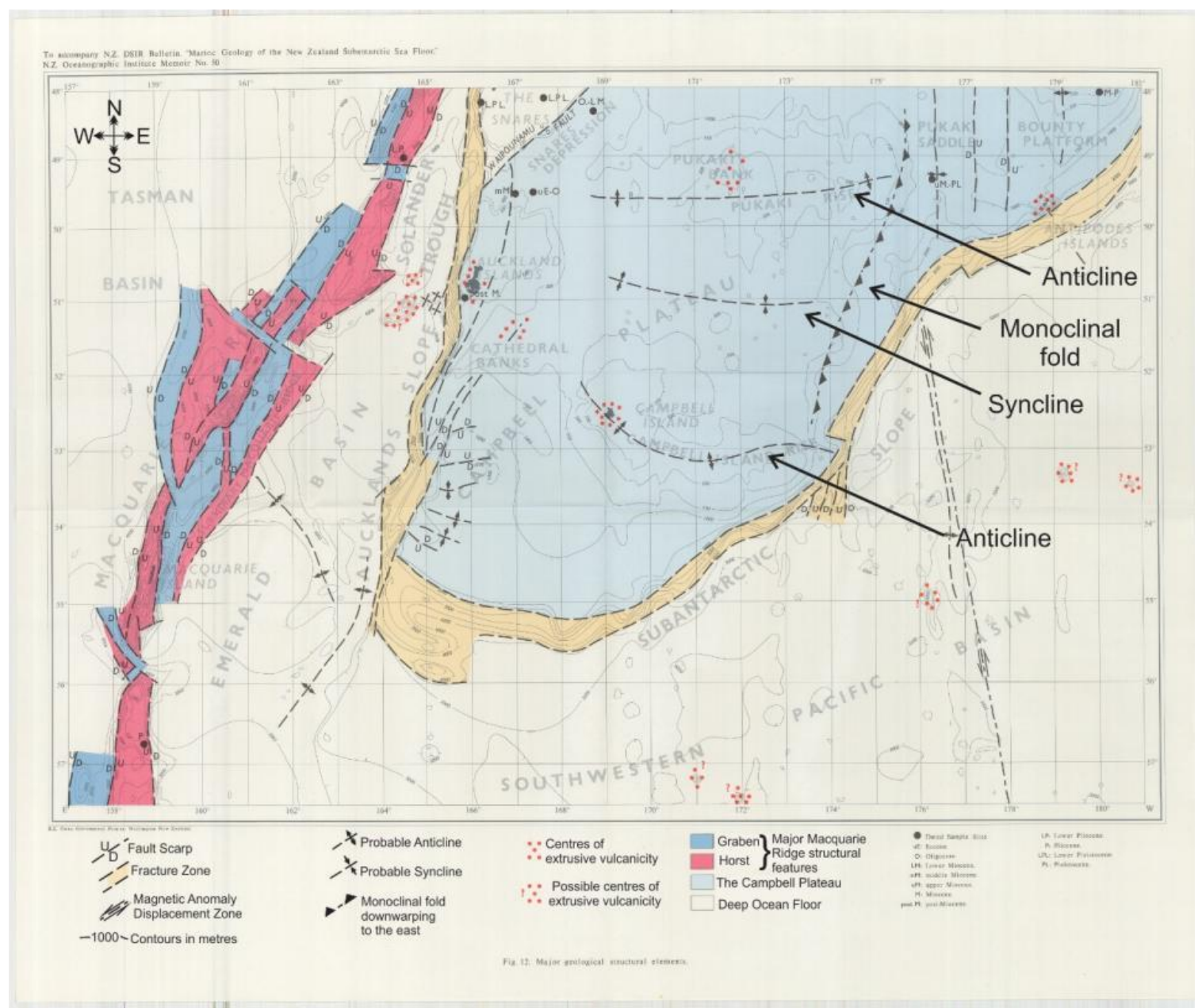

Figure 1.4: Early structural map of the Campbell Plateau as depicted by Summerhayes (1969). The area highlighted in light blue represents interpreted as the top of the plateaux. The area highlighted in light brown indicates the Campbell Plateau slope edge/deep ocean floor. The blue and red area to the west indicates the Macquarie Ridge structural features; with blue being graben structures and red being horst structures (this area is not included in this study). (Modified from Summerhayes., 1969)

\subsection{2: Volcanic History}

Campbell Plateau has been a centre of volcanic activity for much of the

Cenozoic, resulting in the formation of the several volcanic islands that dot the surface of the plateau. Evidence from Auckland, Campbell, and the Antipodes Islands show the pattern of volcanism moving eastward across the plateau with time (Adams, Morris, \& Beggs, 1979). On Auckland Island, volcanism was initiated in the Oligocene, with alkali basaltic and granite lithologies, with the oldest volcano being late Oligocene 24-26 Ma in age (Adams, 1983). The Menhir Gabbro, dated at $\sim 16 \mathrm{Ma}$ is representative of the Carnley Gabbro on Auckland Islands (Adams et al., 1979). On Campbell Island, the alkali olivine basalts exposed on the island have an age range of 11-6.5 Ma (Adams et al., 
1979). Further eastward the youngest volcanic rock recorded on the Antipodes Islands are 0.5-1 Ma (Adams, 1983).

\subsection{3: Sedimentary History}

The limited sub-surface seismic studies (Summerhayes, 1969) on the plateau in conjunction with onshore geological studies (Beggs, 1978: Oliver, Finlay, \& Fleming, 1950) give insight to the stratigraphy of the Campbell Plateau. For simplification of this, the Sedimentary History will be separated into three main sedimentary groupings: Cretaceous to Paleocene, Eocene to Miocene and the Pliocene through to the Holocene.

\subsubsection{1: Late Cretaceous to Paleocene (66-56Ma)}

The Late Cretaceous geology of the Campbell Plateau is recorded through the Complex Point Group, on Campbell Island. This Group primarily consists of low-grade schist basement, which is the basement rock of the Campbell Plateau (Beggs, 1978; Oliver, Finlay, \& Fleming, 1950). These well-foliated schists appear to be texturally comparable to the Haast Schist of eastern Otago in the South Island (Beggs, 1978; Bishop, 1974).

Above this schist basement rock the plateau also displays a possible marine transgression during the Cretaceous shown by a 30m thick interbedded terrigenous sandstone and mudstone unit known as the Garden Cove Formation on Campbell Island (Beggs, 1978). The Garden Cove Formation suggests, however, based on microplankton and pollen samples that the cross-bedded sandstones and the mudstones are of possibly an estuarine or near-shore facies (Wilson, 1967). Evidence of this is by the disparity between the DSDP 277 Paleocene facies and the Campbell Island Paleocene facies, which may reflect uplift of the exposed basement on Campbell Island during Miocene volcanism (see section 1.3.2: volcanic history). The Paleocene is recorded at DSDP site 277 (see figure 1.5). This borehole reached a depth of $462 \mathrm{~m}$ subsurface; this is the deepest borehole drilled on Campbell Plateau (Kennett et al., 1973). The borehole encountered four units, of which the deepest was Late Paleocene in age. The $>22 \mathrm{~m}$ Late Paleocene section was made up of nannofossil chalk with chert, clay, and pyrite (Kennett et al., 1973). The presence of nannofossil chalk shows that Campbell Plateau was submerged throughout the Paleocene, at least on the western Plateau, and is 
potentially the start of a marine transgression across much of Zealandia (Mortimer et al., 2014).

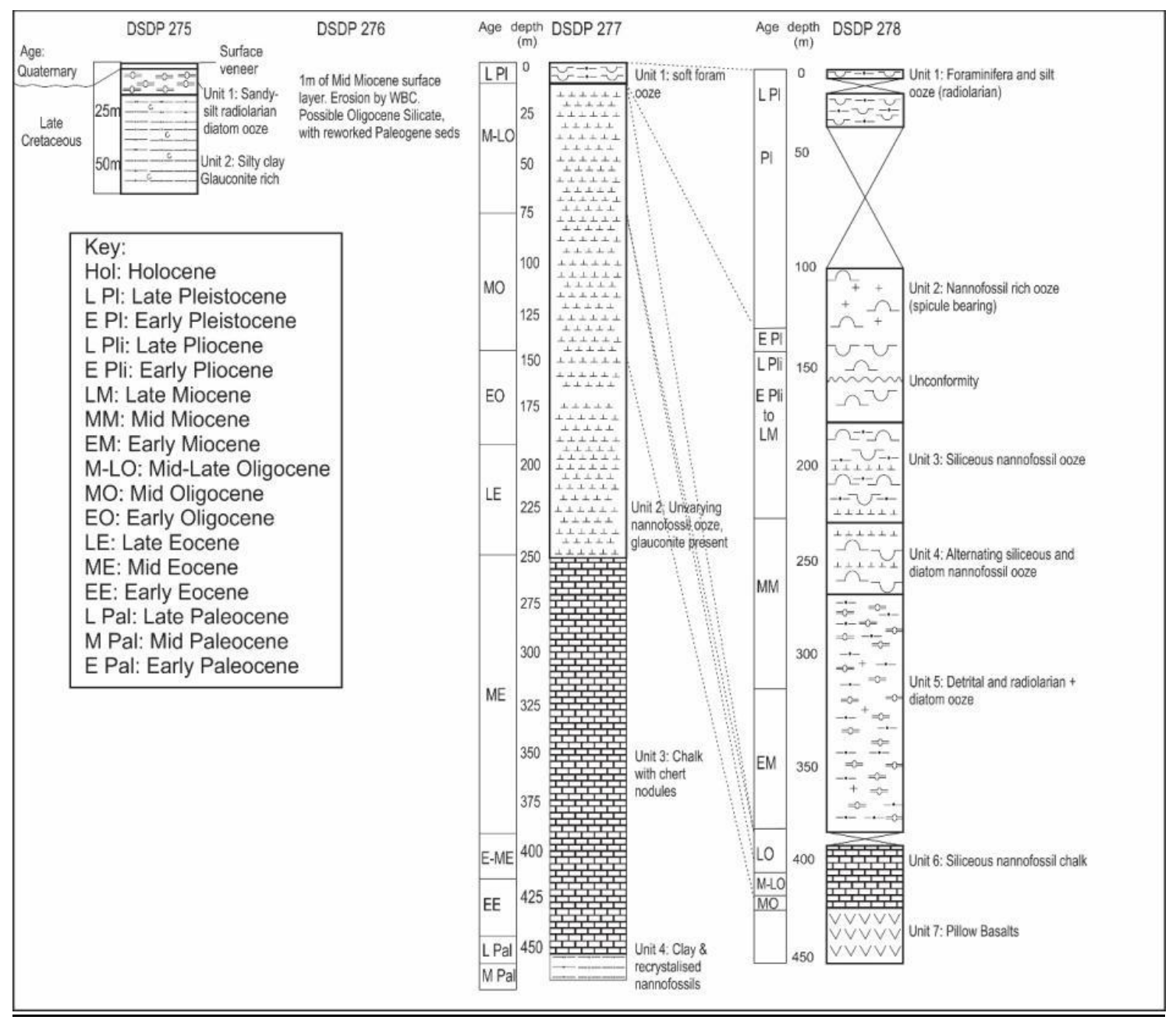

Figure 1.5: Core logs of the southern DSDP cores from Campbell Plateau. All sedimentary cores are modified from, see figure 1.7 for locations. (modified from (J. P. Kennett et al., 1975a, 1975b, 1975c; Kennett, 1975))

\subsubsection{2: Eocene (56-33.9 Ma)}

Based off the findings in DSDP 277, the Eocene on Campbell Plateau is much the same as the Paleocene and is made up of nannofossil chalk but is significantly thicker reaching 208m (see figure 1.5, DSDP277 unit 3). Evidence from benthic foraminifera in the Paleocene/Eocene sediments suggests that Campbell Plateau was a fully marine environment, with the indications that it was at lower to middle bathyal water depths throughout the Eocene (Hollis, 1997; Hollis et al., 2015). The nannofossil chalk discovered in the Eocene section of DSDP 277 has also been linked to the onshore Tucker Cove Limestone of the Campbell Island Group (Kennett et al., 1973). This gives further evidence that Campbell Plateau was fully marine which is consistent with the marine transgression that occurred throughout the Paleocene and Eocene across Zealandia (King, 2000). 


\subsubsection{3: Oligocene (33.9-23.03 Ma)}

During this period Campbell Plateau remained submerged, and there is evidence that large areas of Zealandia were also submerged (King, 2000) due to global eustatic sea levels being 55 m higher than modern day levels (Miller et al., 2008). The Oligocene is represented worldwide, including Campbell Plateau and other parts of Zealandia, by limestone deposits. The Oligocene is present on Campbell Plateau at core sites DSDP 277 and at DSDP 278 in the Lower Emerald Basin (Fig. 1.7). In core DSDP 277 the Oligocene sediments are $231 \mathrm{~m}$ of unvarying nannofossil ooze together with two intervals of glauconite-bearing sandstone at $125 \mathrm{~m}$ and $244 \mathrm{~m}$ (Fig. 1.5) (Kennett et al., 1973). The presence of glauconite in the unit suggests a low sedimentation rate across Campbell Plateau during this time. A major event that occurred during the Oligocene was the Marshall Paraconformity, which is interpreted to be associated with the opening of the Pacific Sector of the Southern Ocean, this spreads from the Canterbury Basin down toward the Campbell Plateau (Fulthorpe, Carter, Miller, \& Wilson., 1996). The Marshall Paraconformity has been interpreted to have been deposited during a sea-level high stand and period of maximum transgression (Fulthorpe et al., 1996).

The Tucker Cove Limestone persists throughout the Eocene through to the Oligocene on Campbell Island. As previously stated this limestone is dated from the Eocene through to the Oligocene, suggesting a fully transgressive marine environment (Beggs, 1978). This section of the Tucker Cove Limestone is well exposed, 100m above modern sea level (Beggs., 1978). This exposure may be linked to local uplift during the Campbell Island Miocene volcanism. The Oligocene is also present on Auckland Island through the volcanism during this period (see Section 1.1.2)

\subsubsection{4: Miocene (23.03-5.33 Ma)}

During this period, there are several major tectonic shifts (see section: 1.3.1). Lithologies from this period are represented onshore, but the Miocene was not encountered on western Campbell Plateau at DSDP 277 (Kennett et al., 1973). However, the Miocene is present and relatively continuous on the eastern edge of Campbell Plateau at ODP 1120 as well as in further afield sites such as DSDP 594, south of the Chatham Rise (Figs 1.7). Miocene sediments at these sites were predominantly calcareous biogenic ooze, up to $96 \%$ carbonate (see figure 1.6), with relatively constant sedimentation from $20-5 \mathrm{Ma}$ (Carter et al., 1999). This abundance of biogenic ooze could be linked to the increasing warm subtropical conditions in the Early Miocene (Jenkins, 1993). 
The Early Miocene is not present in the Campbell Island sequence (Beggs, 1978), possibly indicating this section was eroded at this time due to uplift associated with volcanism during the Oligocene and Miocene. The only Miocene aged material seen on Campbell Island is volcanic and Upper Miocene in age, this is represented through the alkali basalts (see volcanic section 1.3.2).

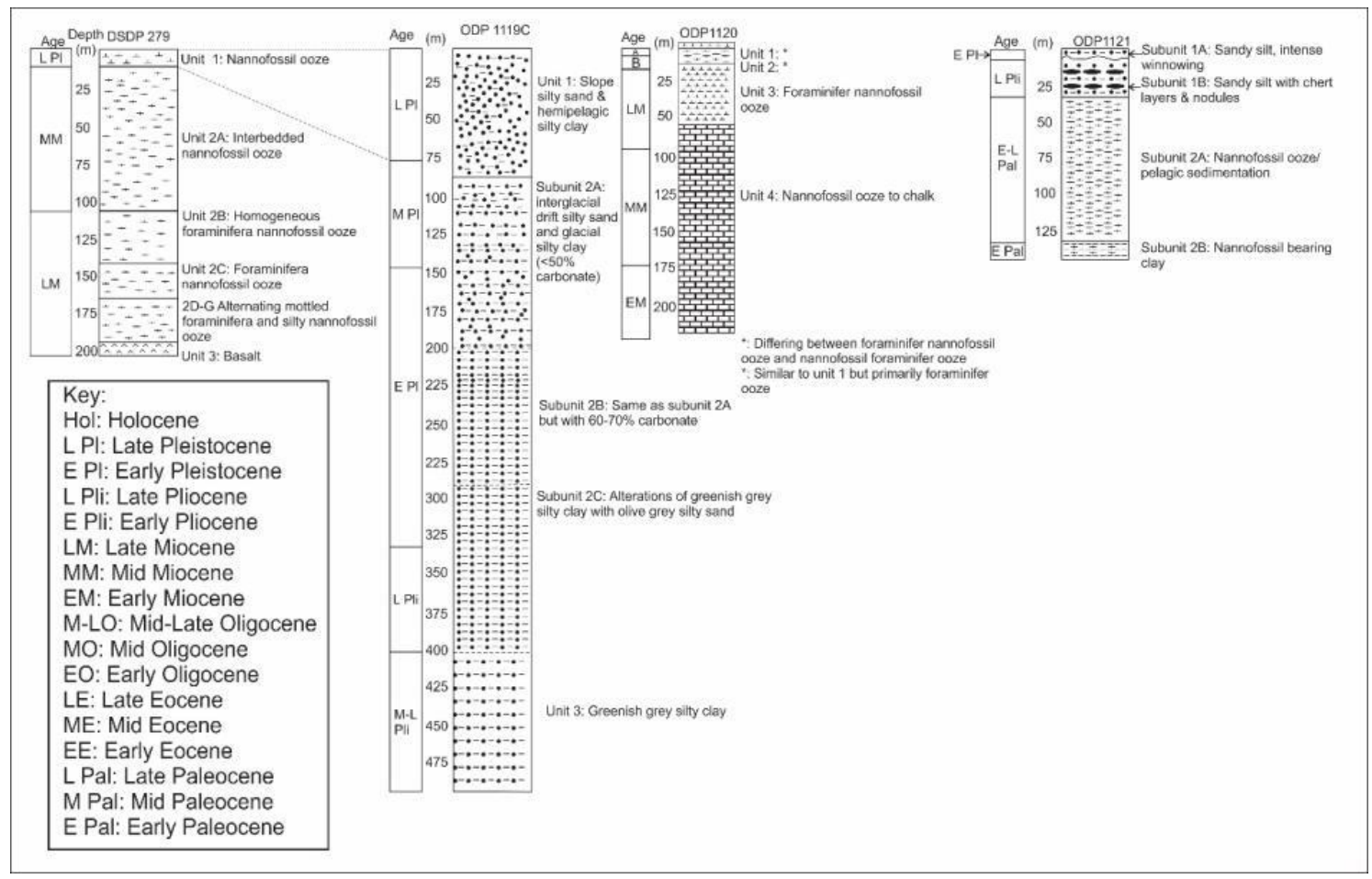

Figure 1.6: Core logs of the northern cores of Campbell Plateau and the surrounding region, both DSDP and ODP sites see figure 1.7 for locations

\subsubsection{5: Pliocene-Pleistocene (5.33Ma to $11.7 \mathrm{Ka}$ )}

The Pliocene is not present on the Campbell Plateau and is only found in the DSDP 594 core in the Bounty Trough, where $470.4 \mathrm{~m}$ of nannofossil ooze and chalk from Late Miocene to Pliocene, overlain by $169.1 \mathrm{~m}$ of alternating pelagic and hemipelagic deposits of late Pliocene to Pleistocene age (Kennett et al., 1975). 


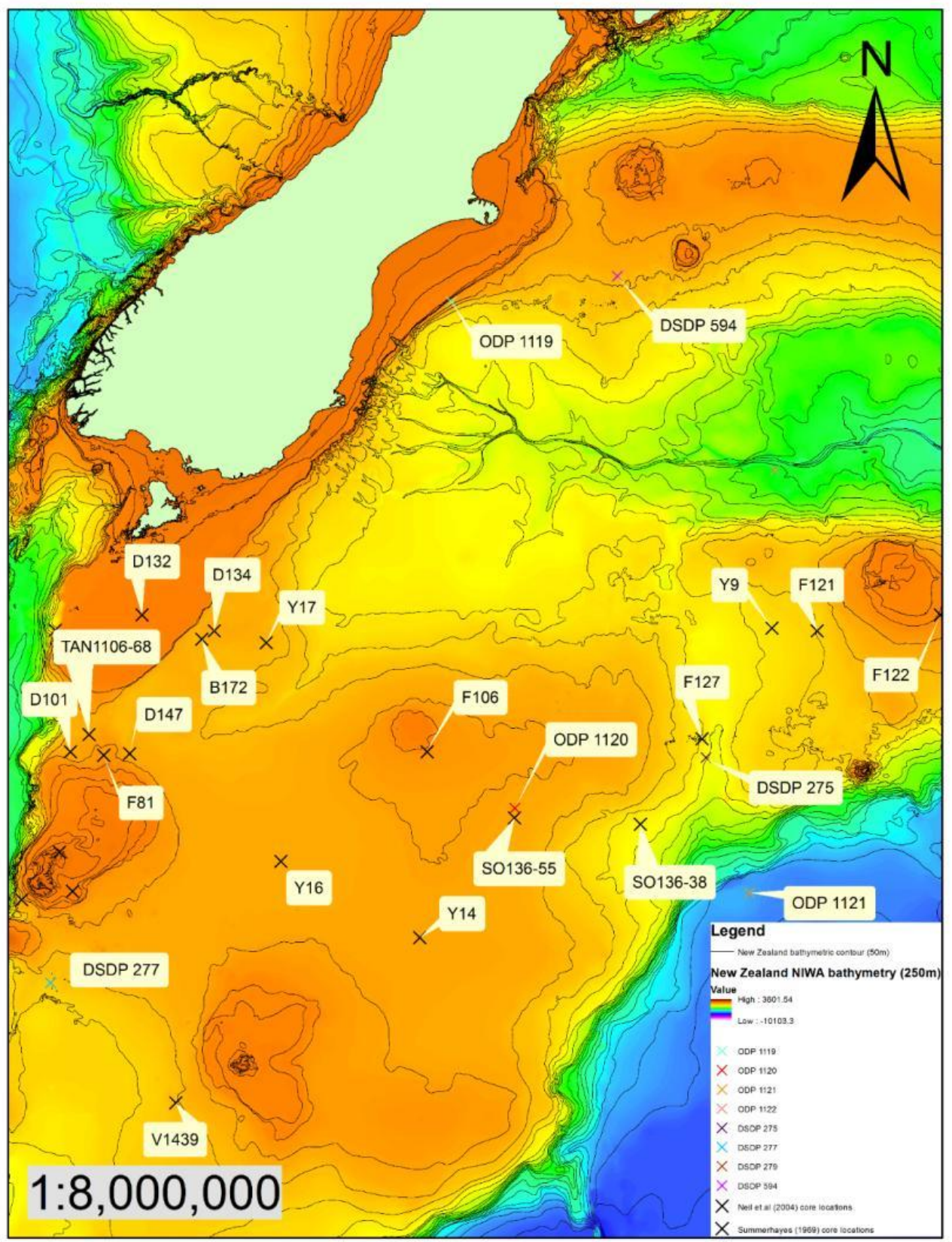

Figure 1.7: Localities of sediment cores taken across Campbell Plateau from 1969 to 2000

The Pleistocene $(2.58 \mathrm{Ma}-11.7 \mathrm{ka})$ was a period dominated by glacial and interglacial cycles. On Campbell Plateau, the Pleistocene is comprised of alternating nannofossil and foraminiferal oozes (Carter et al., 2000; Summerhayes, 1969). The traditional deposition during glacial and interglacial cycles in the rest of New Zealand sees the deposition of nannofossils and carbonates during interglacial periods and the glacial periods dominated by hemipelagic sediments. This occurs in a modified form on Campbell Plateau where 
nannofossil ooze deposited during the interglacial periods whereas foraminiferal ooze containing varying amounts of terrigenous sediment - depending upon proximity to terrigenous sediment pathways - deposited during the glacials (Carter et al., 2000). The increase in terrigenous sediment during the glacials (e.g. the Last Glacial 27-18 ka) is due to the glacial climates favouring erosion, due to depleted vegetation, extensive glaciation across the South Island and strengthened winds enhanced dust input from local and Australian sources (Hesse, 1994) (see figure 1.8). Despite the influx of terrigenous material from glacial New Zealand, Campbell Plateau sedimentation rates remained low $\left[0.5 \mathrm{~g} /\left(\mathrm{cm}^{2} \mathrm{ka}\right)\right.$ (L Carter et al., 2000) reflecting the location of the Plateau distant from prominent fluvial sources and associated channel extensions which led mainly into Bounty Trough. This increased dust supply, however, did not lead to an increase in phytoplankton production.

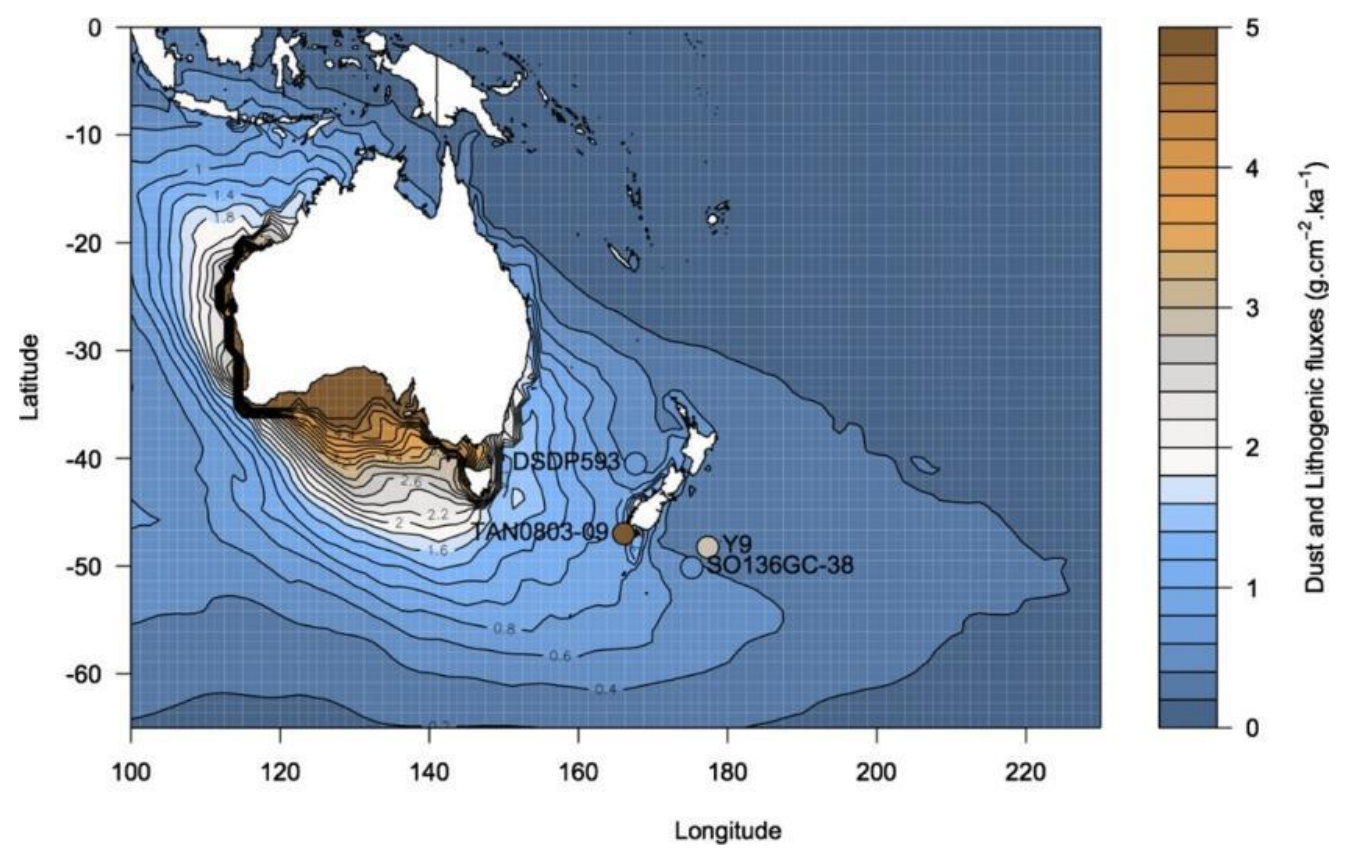

Figure 1.8: Map of the lithogenic flux of sediment of modelled dust deposition during the LGM (from Durand et al., 2017) 


\subsubsection{6: Modern sediments}

The modern sediments on Campbell Plateau were first assessed by Summerhayes (1969), which involved the broad mapping of the Plateau's surface both onshore and offshore. This was attained from 134 surface sediment samples across Campbell Plateau, and from 17 cores (see fig 1.7 and 1.9).

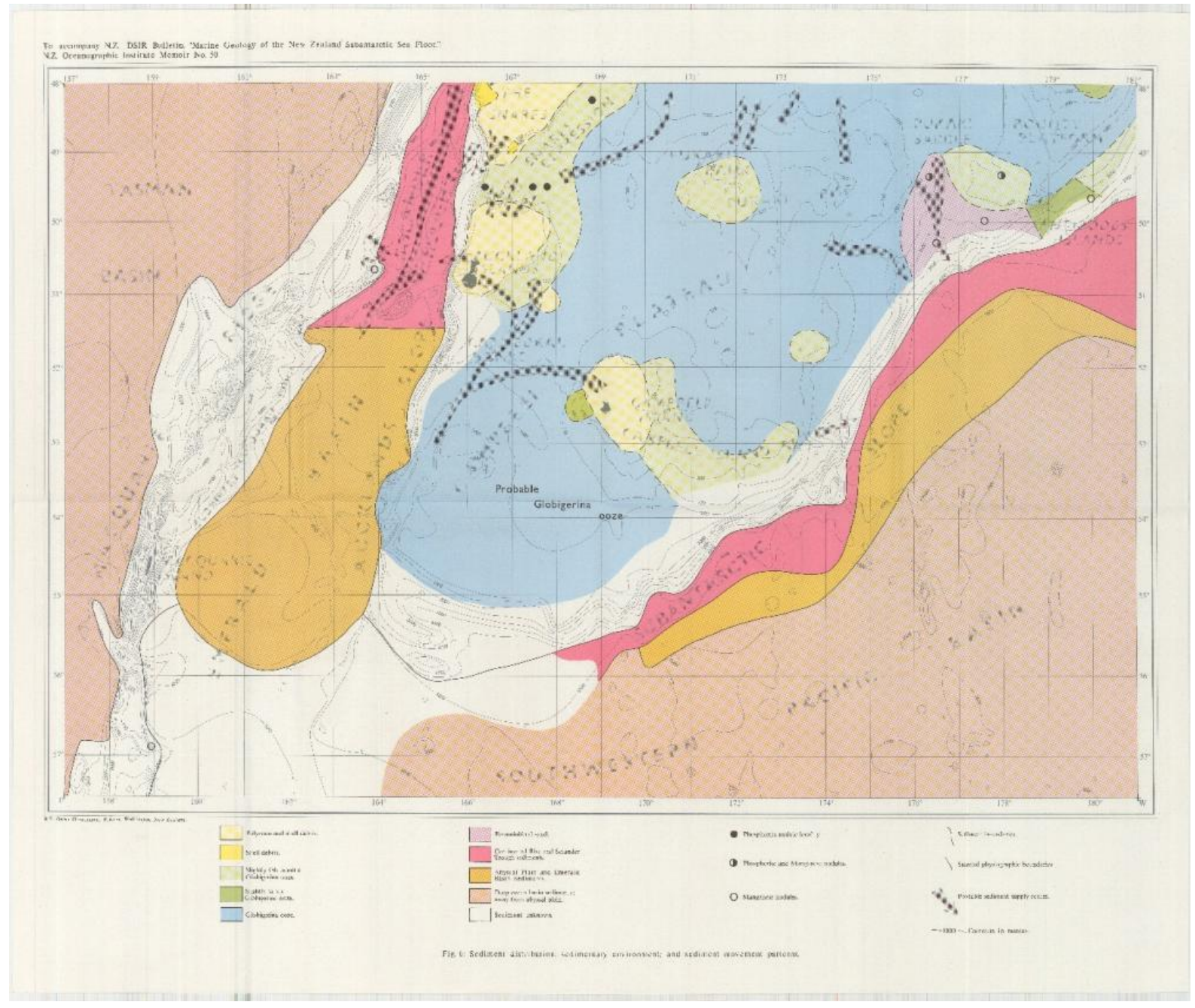

Figure 1.9: Early surface sediment extent map of Campbell Plateau (from Summerhayes., 1969)

From the work performed by Summerhayes (1969) much of the deeper parts of the central plateau ( $>500 \mathrm{~m}$ water depth) are covered in Globigerina-rich ooze. Shallow areas around Auckland and Campbell Islands are slightly sandy or very sandy Globigerina oozes with very high carbonate content, up to 83 to $92 \%$, suggesting this has had little sedimentation since MIS 1 and MIS 5 respectively (Carter et al., 2000; Neil et al., 2004), whereas island shelves $(<120 \mathrm{~m}$ depth) are dominated by bryozoan and molluscan shell debris. The sediment and surface samples collected by Summerhayes (1969) revealed many of Globigerina ooze and sand samples contained glauconite and occasionally with 
phosphorite (see Appendix). There is very little terrigenous material present on the Plateau today due to the lack of rivers flowing into the region, although there may be some terrigenous sediment within the vicinity of the islands.

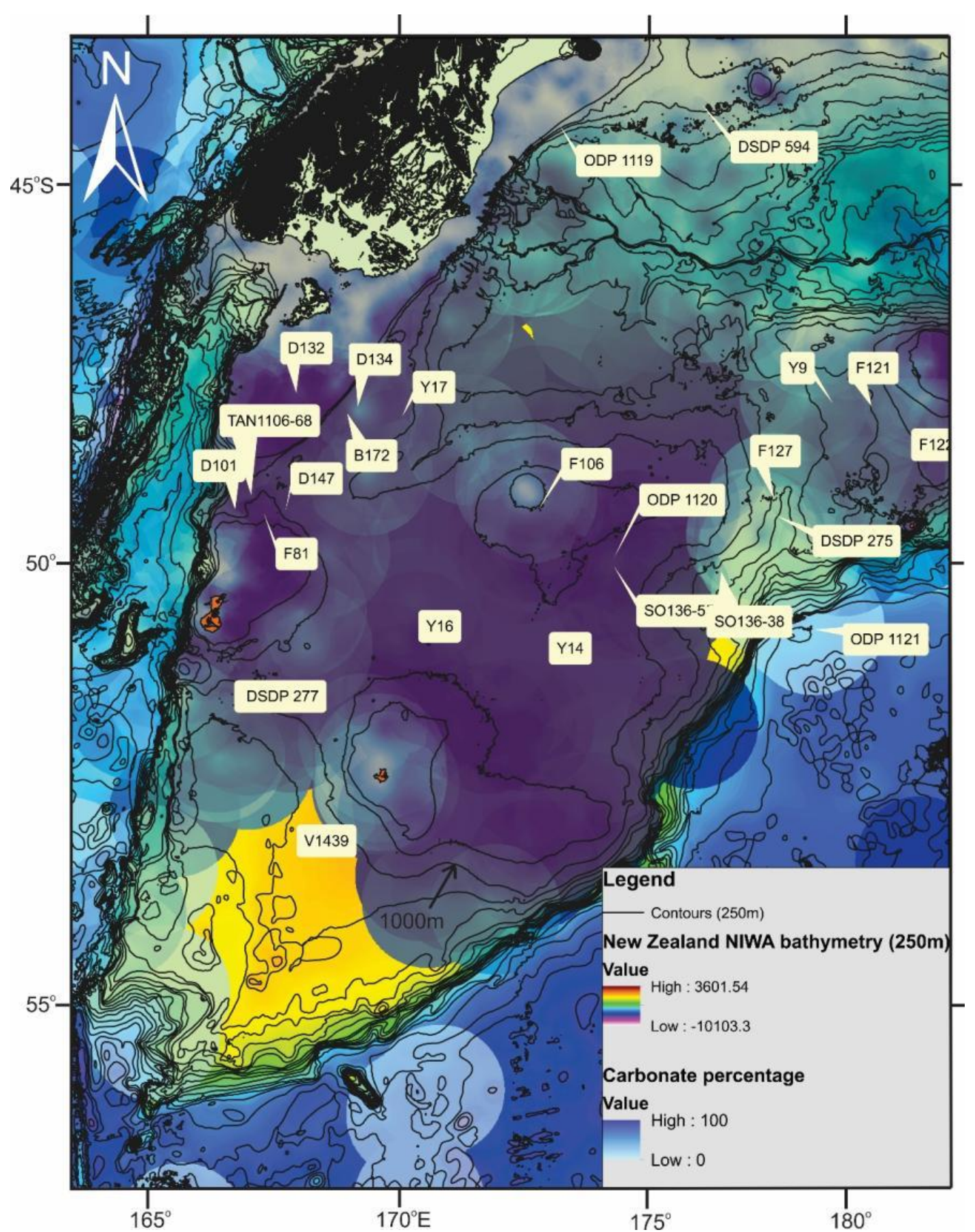

Figure 1.10: Modern-day sediment percentages carbonate over Campbell Plateau, 1000m contour indicated by the arrow (data from nzSEABED, published in Bostock et al., 2018)

Recent work by Bostock et al., (2018) uses all the data for the region and has plotted up the percentage of gravel, sand, mud, and carbonate for the Plateau (see figures 1.10, 
1.11 1.12 and 1.13). Prominent sediments are calcareous sand or calcareous biogenic sand comprised of foraminifers, which agrees with the work of Summerhayes (1969).

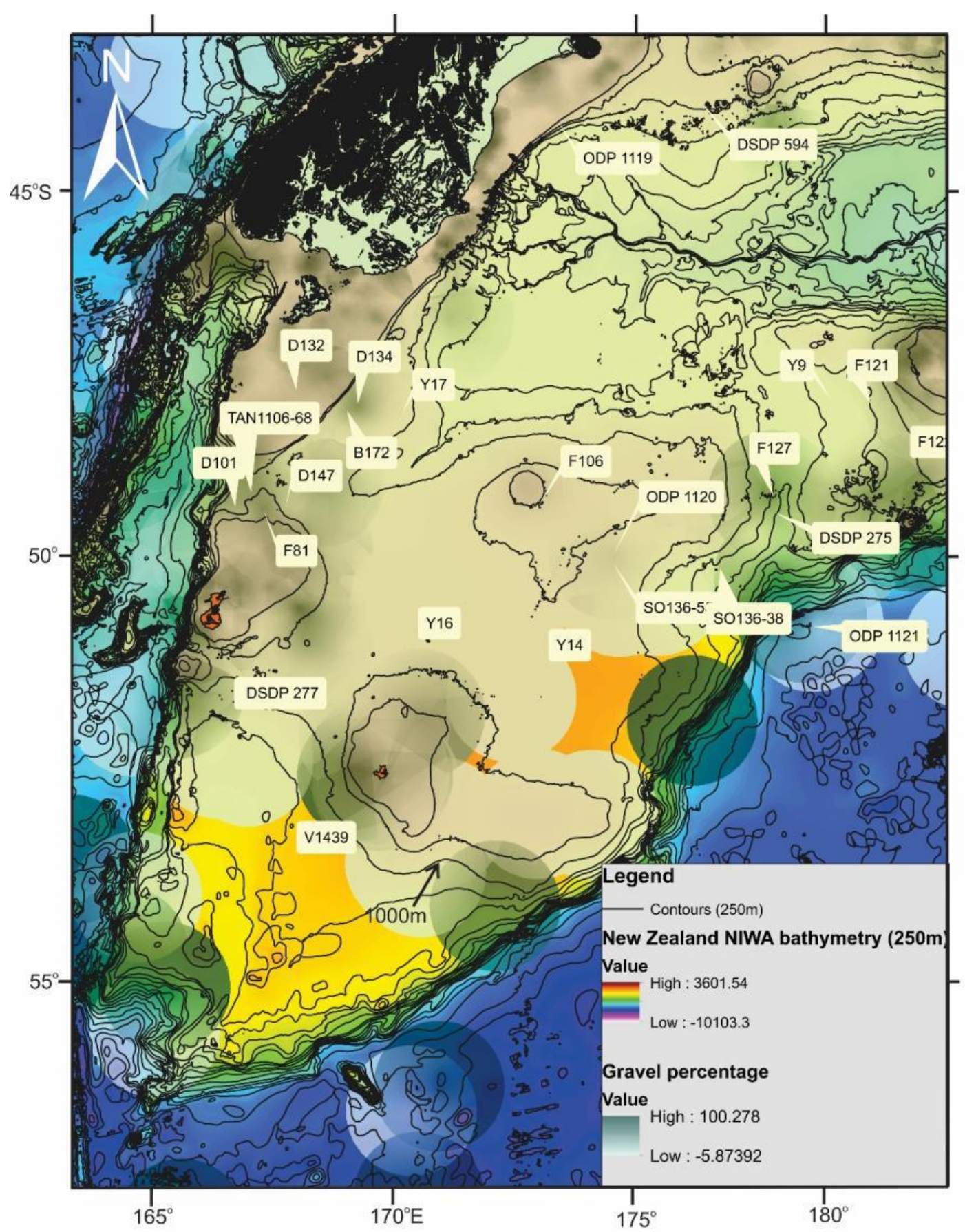

Figure 1.11: Modern-day sediment percentages gravel over Campbell Plateau, 1000m contour indicated by the arrow. (data from nzSEABED, published in Bostock et al., 2018)

The highest percentages of sand occur near or around the volcanic islands; Campbell and Auckland, whereas fine-grained carbonate ooze, prevails in the deeper sections of the Plateau. The modern-day biogenic supply of carbonate is primarily calcareous nannoplankton and pelagic foraminifers (Carter et al., 2000). Today, the Southland Current and strong southerly induced storms transport river-derived sediment 
northeastward along the shelf thus bypassing the Plateau and adjacent Bounty Trough. Local hot spots of terrigenous sand and gravel are derived from the islands.

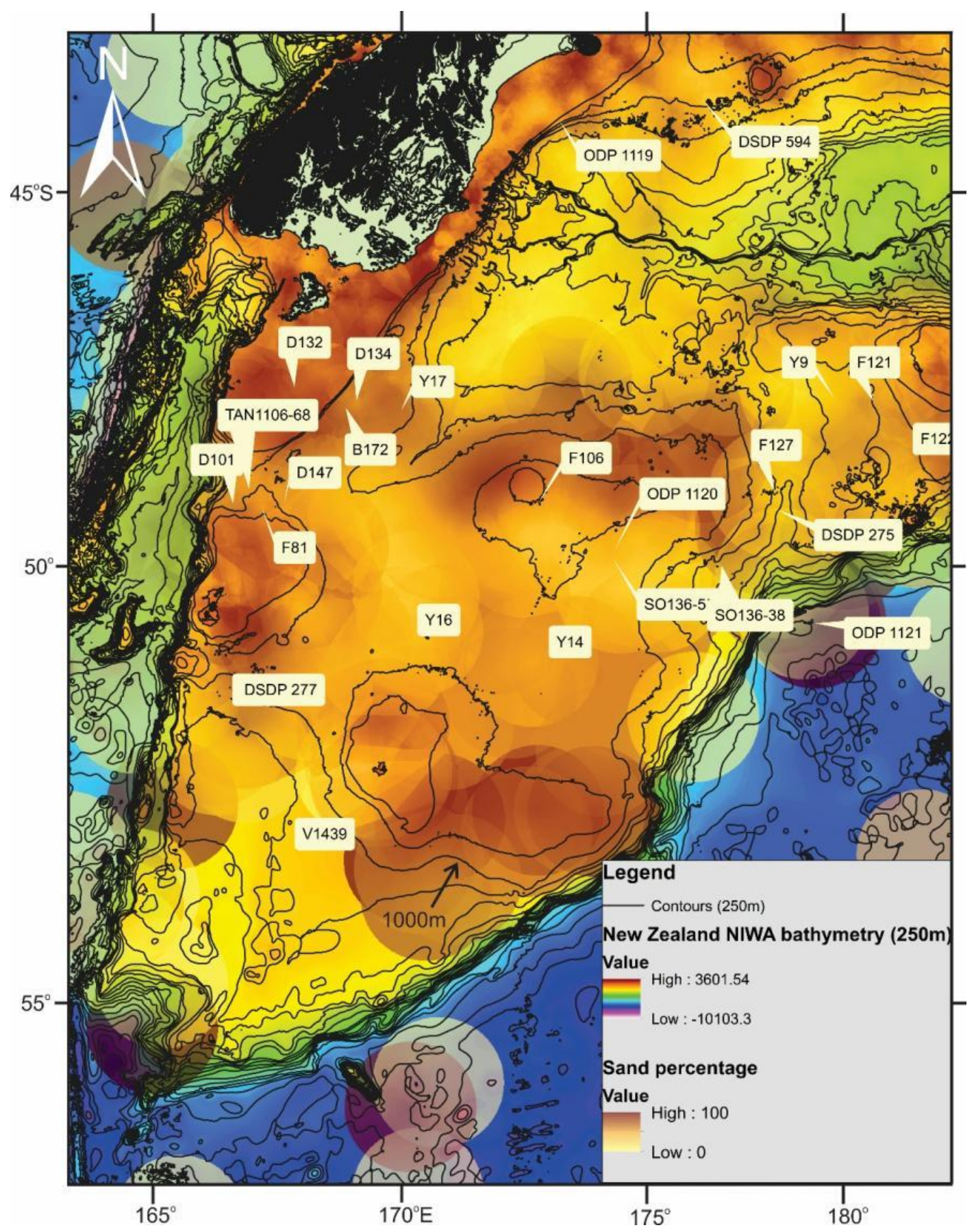

Figure 1.12: Modern-day sediment percentages of sand over Campbell Plateau, 1000m contour indicated by the arrow. (data from nzSEABED, published in Bostock et al., 2018) 


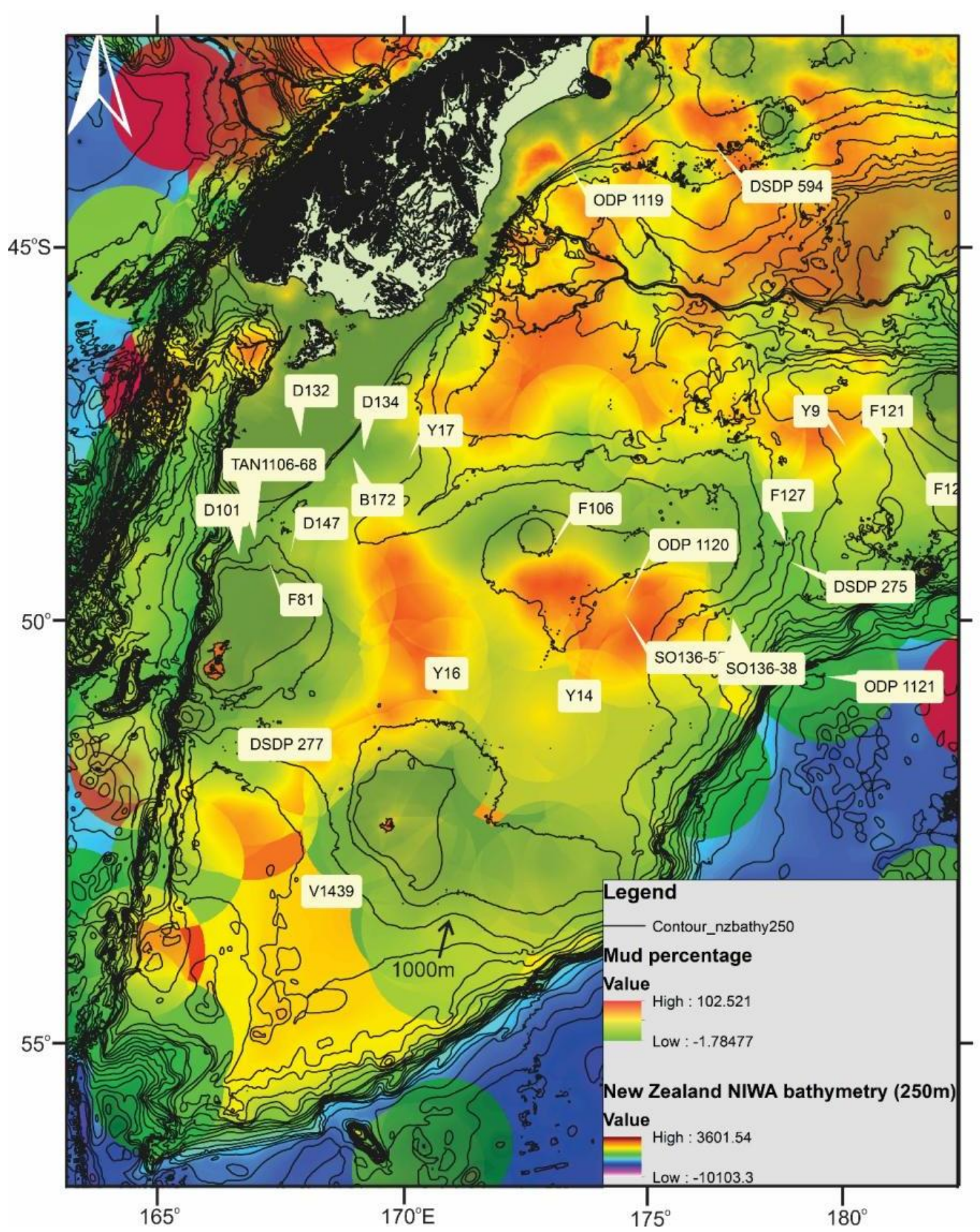

Figure 1.13: Modern-day sediment percentages of mud over Campbell Plateau, 1000m contour indicated by the arrow. (data from nzSEABED, published in Bostock et al., 2018) 


\section{4: Oceanographic History}

\subsection{1: Paleoceanography of the Campbell Plateau}

The palaeoceanographic record for the Campbell Plateau can be traced through the Cenozoic. The record is heavily influenced by the tectonic movements of continents and the separation of super-continents. These tectonic movements and the development of the current day oceanic setting were previously described by Nelson and Cooke (2001) using DSDP sites located in New Zealand's sector of the Southern Ocean (NZSSO). Using the sediment patterns from these cores, and ages/constraints placed by stable oxygen isotopes and microfossil/planktic foraminifera there are seven main events (time periods) of activity: Paleocene, Early-early Middle Eocene, Late Middle-Late Eocene, Oligocene, Early-early Middle Miocene, Late Middle-Late Miocene and the Present day. Below is a summary of the sediments and the oceanographic understanding of these different time periods (see Table 1), building on the original review of Nelson and Cooke (2001). 
Table 1: Oceanographic and climatic events throughout the Cenozoic period that likely affected the evolution of the Campbell Plateau. Primary sediments present give an indication of the sea level and ocean conditions at time of deposition. (Modified from Nelson and Cooke, 2001).

\begin{tabular}{|c|c|c|c|c|c|c|}
\hline $\begin{array}{c}\text { Time } \\
\text { Sections }\end{array}$ & $\begin{array}{c}\text { Primary } \\
\text { Sediments } \\
\text { Present }\end{array}$ & $\begin{array}{c}\text { Antarctic } \\
\text { Ice Sheets } \\
\text { present }\end{array}$ & $\begin{array}{c}\text { Surface } \\
\text { Currents }^{1}\end{array}$ & $\begin{array}{c}\text { Current } \\
\text { Gateways }\end{array}$ & $\begin{array}{l}\text { Oceanic } \\
\text { Fronts }\end{array}$ & $\begin{array}{c}\text { Major } \\
\text { Climatic } \\
\text { Events }\end{array}$ \\
\hline $\begin{array}{l}\text { Paleocene } \\
(65-55 \mathrm{Ma})\end{array}$ & Calcareous & No & Warm (I-P) & $\begin{array}{c}\text { Tasmanian } \\
\text { closed } \\
\text { Drake closed }\end{array}$ & None & $\begin{array}{l}\text { Paleocene- } \\
\text { Eocene } \\
\text { Thermal } \\
\text { Maximum }\end{array}$ \\
\hline $\begin{array}{c}\text { Eocene (56- } \\
\text { 33.9Ma) }\end{array}$ & Calcareous & $\begin{array}{c}\text { No in Early } \\
\text { to Middle } \\
\text { Eocene, } \\
\text { growing in } \\
\text { Mid to Late } \\
\text { Eocene }\end{array}$ & $\begin{array}{c}\text { Early to Late } \\
\text { - Warm (I-P) } \\
\text { Latest } \\
\text { Eocene - } \\
\text { Cool (Ant) }\end{array}$ & $\begin{array}{c}\text { Tasmanian } \\
\text { closed } \\
\text { Drake closed } \\
\text { during Early } \\
\text { to Late } \\
\text { Eocene. } \\
\text { Tasmanian } \\
\text { leaking } \\
\text { West } \\
\text { Antarctic } \\
\text { open during } \\
\text { Latest } \\
\text { Eocene. }\end{array}$ & $\begin{array}{c}\text { No fronts } \\
\text { until proto- } \\
\text { STF in } \\
\text { Latest } \\
\text { Eocene }\end{array}$ & $\begin{array}{c}\text { Eocene } \\
\text { Thermal } \\
\text { Maximum } \\
\text { Early Eocene } \\
\text { Climatic } \\
\text { Optimum } \\
\text { Mid Eocene } \\
\text { Climatic } \\
\text { Optimum }\end{array}$ \\
\hline $\begin{array}{c}\text { Oligocene } \\
(33.9-23.03 \\
\text { Мa) }\end{array}$ & $\begin{array}{l}\text { Terrigenous- } \\
\text { siliceous } \\
\text { Calcareous- } \\
\text { siliceous } \\
\text { Calcareous }\end{array}$ & $\begin{array}{c}\text { East - } \\
\text { Present } \\
\text { West - No }\end{array}$ & $\begin{array}{l}\text { Cold (Ant) } \\
\text { Cool (Ant) } \\
\text { Warm (I-P) }\end{array}$ & $\begin{array}{c}\text { Tasmanian } \\
\text { open } \\
\text { West } \\
\text { Antarctic } \\
\text { open } \\
\text { Drake } \\
\text { leaking }\end{array}$ & $\begin{array}{c}\text { AAPF } \\
\text { proto-SAF } \\
\text { proto-STF }\end{array}$ & $\begin{array}{l}\text { Onset of } \\
\text { permanent } \\
\text { ice sheets, } \\
\text { widespread } \\
\text { glaciation }\end{array}$ \\
\hline $\begin{array}{c}\text { Neogene } \\
(23.03-2.5 \\
\mathrm{Ma})\end{array}$ & $\begin{array}{c}\text { Terrigenous- } \\
\text { siliceous } \\
\text { Siliceous- }\end{array}$ & $\begin{array}{c}\text { Early to Mid } \\
\text { - East } \\
\text { Neogene } \\
\text { Present, } \\
\text { West not. }\end{array}$ & $\begin{array}{l}\text { Cold (Ant) } \\
\text { Cool (Ant) } \\
\text { Warm (I-P) }\end{array}$ & $\begin{array}{c}\text { Early to } \\
\text { Middle } \\
\text { Neogene - } \\
\text { Tasmanian } \\
\text { open }\end{array}$ & $\begin{array}{c}\text { Early to } \\
\text { Middle } \\
\text { Neogene - } \\
\text { AAPF } \\
\text { proto-SAF }\end{array}$ & $\begin{array}{l}\text { Miocene } \\
\text { Climatic } \\
\text { Optimum } \\
\text { Mid } \\
\text { Miocene }\end{array}$ \\
\hline
\end{tabular}




\begin{tabular}{|c|c|c|c|c|c|c|}
\hline $\begin{array}{c}\text { Time } \\
\text { Sections }\end{array}$ & $\begin{array}{c}\text { Primary } \\
\text { Sediments } \\
\text { Present }\end{array}$ & $\begin{array}{l}\text { Antarctic } \\
\text { Ice Sheets } \\
\text { present }\end{array}$ & $\begin{array}{c}\text { Surface } \\
\text { Currents }^{1}\end{array}$ & $\begin{array}{c}\text { Current } \\
\text { Gateways }\end{array}$ & $\begin{array}{l}\text { Oceanic } \\
\text { Fronts }\end{array}$ & $\begin{array}{c}\text { Major } \\
\text { Climatic } \\
\text { Events }\end{array}$ \\
\hline & $\begin{array}{l}\text { calcareous } \\
\text { Calcareous }\end{array}$ & $\begin{array}{c}\text { Mid to Late } \\
\text { Neogene - } \\
\text { Both Ice } \\
\text { Sheets } \\
\text { present }\end{array}$ & & $\begin{array}{c}\text { West } \\
\text { Antarctic } \\
\text { closed } \\
\text { Drake open } \\
\text { Indonesian } \\
\text { restricted. } \\
\text { Mid to Late } \\
\text { Neogene - } \\
\text { Tasmanian } \\
\text { open } \\
\text { Drake open }\end{array}$ & $\begin{array}{c}\text { proto-STF. } \\
\text { Mid to Late } \\
\text { Neogene - } \\
\text { AAPF } \\
\text { SAF } \\
\text { STF }\end{array}$ & $\begin{array}{c}\text { Transition } \\
\text { (SST } \\
\text { decrease of } \\
\text { 6-7 C) }\end{array}$ \\
\hline $\begin{array}{l}\text { Pliocene and } \\
\text { Pleistocene } \\
\text { glacial } \\
\text { periods ( } 2.5 \\
\text { Ma - } 21 \mathrm{Ka})\end{array}$ & $\begin{array}{c}\text { Terrigenous- } \\
\text { siliceous } \\
\text { Siliceous- } \\
\text { calcareous } \\
\text { Calcareous }\end{array}$ & $\begin{array}{l}\text { Both West } \\
\text { and East } \\
\text { Present - } \\
\text { Extended }\end{array}$ & $\begin{array}{c}\text { Cold (Ant) } \\
\text { Cool (Ant) } \\
\text { Warm (I-P): } \\
\text { Not present } \\
\text { on CP }\end{array}$ & $\begin{array}{l}\text { Tasmanian } \\
\text { open } \\
\text { Drake open }\end{array}$ & $\begin{array}{l}\text { AAPF } \\
\text { SAF } \\
\text { STF }\end{array}$ & $\begin{array}{c}\text { Last Glacial } \\
\text { Maximum } \\
\text { Mid Pliocene } \\
\text { Cooling }\end{array}$ \\
\hline $\begin{array}{l}\text { Pliocene and } \\
\text { Pleistocene } \\
\text { inter-glacial } \\
\text { periods } 2.5 \\
\text { Ma - } 18 \mathrm{Ka} \text { ) }\end{array}$ & $\begin{array}{c}\text { Terrigenous- } \\
\text { siliceous } \\
\text { Siliceous- } \\
\text { calcareous } \\
\text { Calcareous } \\
\text { (Enhanced) }\end{array}$ & $\begin{array}{l}\text { Both West } \\
\text { and East } \\
\text { Present - } \\
\text { Reduced }\end{array}$ & $\begin{array}{l}\text { Cold (Ant) } \\
\text { Cool (Ant) } \\
\text { Warm (I-P) }\end{array}$ & $\begin{array}{c}\text { Tasmanian } \\
\text { open } \\
\text { Drake open }\end{array}$ & $\begin{array}{l}\text { AAPF } \\
\text { SAF } \\
\text { STF }\end{array}$ & $\begin{array}{l}\text { Increase in } \\
\quad \text { SST } \\
\text { Increase in } \\
\text { carbonate } \\
\text { production }\end{array}$ \\
\hline
\end{tabular}

${ }^{1}$ I-P, Indonesian Pacific origin; Ant, Antarctic origin

\subsubsection{1: Paleocene Oceanography}

Paleocene sediments are primarily described from DSDP site 277 located on the Central Campbell Plateau (see figure 1.7). DSDP 277 at its deepest section (472.5m) penetrated Middle Paleocene sediments with a thickness of $\sim 20 \mathrm{~m}$. It was primarily made up of nannofossil chalk and ooze, which persisted through for $35 \mathrm{Ma}$ to the Oligocene showing a uniform environment (Kennett et al., 1975).

The DSDP 277 Paleocene sediments were reassessed by (Hollis et al., 2015) who discovered the Paleocene-Eocene boundary, along with the Paleocene-Eocene Thermal 
Maximum (PETM), which is one of the southernmost recordings of this event. The PETM was a global event when temperatures rose by $5-6^{\circ} \mathrm{C}$ about $\sim 56 \mathrm{Ma}$ and lasted for $\sim 220$ kyr (Hollis et al., 2015). The foraminifera and $\mathrm{Mg} / \mathrm{Ca}$ data showed that intermediate water had peak temperatures of $\sim 19^{\circ} \mathrm{C}$ and whereas surface waters had peak temperatures of $\sim 32^{\circ} \mathrm{C}$. In these $45 \mathrm{~m}$-thick sections, the sediments were generally a greenish-white to greenish-grey nannofossil chalk, with increased clay content in the upper Paleocene (Hollis et al., 2015).

This time-period also shows that both Drake Passage (South America and Antarctica) and the Tasmanian Gateways (South Tasman Rise and Antarctica) were closed with an icefree Antarctica (Abreu \& Anderson, 1998; Nelson \& Cooke, 2001; Wise, 1991; Zachos et al., 2001). Through this period sedimentation rates were low $(1 \mathrm{~cm} / \mathrm{ka})$, with areas of local upwelling having restricted sections of biosiliceous oozes (Nelson \& Cooke, 2001). Oxygen isotope data also suggest that the Southern Ocean during the Paleocene was well stratified (Barron et al., 1991). Planktic foraminifera from DSDP 277 suggests that NZSSO was affected by undifferentiated subtropical waters from the northwest to northeast with a possible warm subtropical and cool subtropical transition zone at 50$55^{\circ} \mathrm{S}$ paleolatitude (Jenkins, 1993). Also, there was no evidence for any oceanic frontal systems occurring in the area during the Paleocene (Nelson \& Cooke, 2001).

\subsubsection{2: Eocene Oceanography}

The Eocene (55 Ma-37 Ma) saw a period of global warmth and the transition from a global "Greenhouse" to a global "Icehouse". This is expressed through the several climatic optimums when substantial depletions in $\delta 180 \%$ occurred. These rises were the Eocene Thermal Maximum: $\sim 53.7 \mathrm{Ma}$, the Early Eocene Climatic Optimum: $\sim 52.6 \mathrm{Ma}$ to $50.3 \mathrm{Ma}$, and the Mid Eocene Climatic Optimum: $40 \mathrm{Ma}$ (Zachos et al., 2008). The significance of these warming trends throughout this epoch is the relation it potentially has to sediment deposition and oceanographic patterns affecting the Campbell Plateau during this time. Due to these increased periods of warmth saw minimal ice accumulations in the Arctic and Antarctica (Greenwood \& Wing, 1995; Huber et al., 2004; Markwick, 1998; Zachos et al., 2001; Zachos., et al 1993). This lack of ice accumulation was also in part due to the closure of the Tasman Gateway and the Drake Passage.

During the Eocene, the palaeoceanography was heavily influenced by the closure of the Tasman Gateway and the Drake Passage. This, in turn, caused warm surface currents, 
little or no ice over Antarctica for much of the Eocene, and no oceanic fronts (Nelson \& Cooke, 2001) (see table 1).

\subsubsection{3: Oligocene Oceanography}

The Oligocene encompasses the most dramatic changes on the Campbell Plateau and the Southern Ocean. The largest changes were brought about through the tectonic events that led to the opening of the Drake Passage and the Tasmanian Gateway. Opening of these seaways started the well-established global cooling and the onset of Antarctic glaciation and establishment of permanent ice sheets over the continent (Kennet 1977, 1978, 1980; Miller et al., 1991; Nelson and Cooke, 2001). As stated previously by Zachos et al. (1994) this glaciation witnessed and Southern Ocean SST reduction by $2-6^{\circ} \mathrm{C}$. During this period of intense change, it is suggested that of proto-fronts established across the Campbell Plateau and the Southern Ocean (Nelson and Cooke, 2001).

\subsubsection{4: Neogene Oceanography}

This period of 23-2.5 Ma, encompassing the Miocene and Pliocene epochs, saw the first evidence of an unhindered Antarctic Circumpolar Current (ACC) in which both the Tasmanian gateway and Drake gateway were fully open (Campbell S. Nelson \& Cooke, 2001). The increase in the flow of the ACC, leading to a series of widespread unconformities/hiatuses in the Late Oligocene and Early Miocene. The Early Miocene saw a general warming trend across the Southern Ocean and the development of the protoSTF. This warming marked a general shift to higher SST's around $16 \mathrm{Ma}$ (Shakleton \& Kennett, 1975).

Throughout the Middle Miocene (25-15 Ma) the Southern Ocean continued to extend with the increase and expansion of the ACC and other polar and subpolar fronts. However, foraminifera collected at DSDP sites 279 and 594 shows a substantial increase in sub-tropical species of foraminifera suggesting an intensification of some frontal systems.

This period has been strongly influenced by glacial and interglacial cycles, which primarily affected changes in sea level, SST and strength/location of oceanic fronts and currents. There are several cores across Campbell Plateau that have a record of Pleistocene sediments: ODP 1120, Y9, Y14, Y16, Y17, V1439, SO136-38, MD97-2109. These cores show that the Pleistocene is primarily nannofossil ooze, up to $60-93 \%$ 
carbonate. The Pleistocene section thickness is approximately $10 \mathrm{~m}$; in ODP 1120 it a maximum thickness of $11.2 \mathrm{~m}$, whereas core SO136-38 encountered at least $4 \mathrm{~m}$ of fine sand foraminifera ooze (Thiede et al., 1998).

\subsubsection{5: Oceanography of the glacial periods}

The glacial periods of the Pleistocene and Pliocene on Campbell Plateau were accompanied by lower SSTs (Weaver et al.,1998). That suggests that during the Last Glacial Maximum (LGM), which occurred $21 \mathrm{Ka}$, global SST's were a minimum of $\sim 3.2^{\circ} \mathrm{C}$ cooler than the present. SSTs showed large fluctuations with winter SST's of 1 to $3^{\circ} \mathrm{C}$ and summer SST's of $\sim 6^{\circ} \mathrm{C}$ (Bostock et al., 2015; Duncan et al., 2016; Weaver et al., 1998). There is evidence that the Antarctic winter sea ice may have extended as far as $55^{\circ} \mathrm{S}$, just to the south of Campbell Plateau for several months of the year (Weaver et al., 1998; Nelson and Cooke 2001; Crosta et al., 2004). The associated drop in SST and northward expansion of sea ice during the winter increased the likely hood of Antarctic icebergs reaching the plateau and there is evidence for increased concentrations of icerafted debris (IRD) during the last two glacials (Carter et al., 2002). This IRD presence showed that icebergs over the last $200 \mathrm{kyr}$ arrived periodically onto the Plateau with the biggest pulse occurring at the MIS 7/6 transition at $~ 180-190 \mathrm{ka}$. The largest amount of IRD was found in the Pukaki Saddle, with the lowest amounts being on the central Campbell Plateau (Carter et al., 2002). In contrast, interglacial periods such as MIS 5e were marked by little IRD deposition, on the Plateau presumably reflecting warmer SST's that caused iceberg melting closer to Antarctica (Lionel Carter, Neil, \& Northcote, 2002; Watkins, Ledbetter, \& Huang, 1982).

Glacial periods also impacted frontal systems on or peripheral to Campbell Plateau namely, changes in the STF (Subtropical Front), SAF (Subantarctic Front) and PF (Polar Front). The STF changed dramatically throughout the glacial and inter-glacial cycles. This is based on paleo-SST data from plankton foraminifera from cores across the Plateau (Bostock et al., 2015). These SST reconstructions suggest that the STF did not influence the northwest Campbell Plateau during the glacials, and this area was overlain with Subantarctic Surface Water (Bostock et al., 2015).

This variation of glacial ocean fronts also affected the PF and the SAF. As these are deep reaching components of the ACC, they are bathymetrically controlled by the Plateau. This bathymetric constraint was further increased with the northward expansion of sea ice and the westerly windstorm belt which further intensified the ACC against the Plateaus 
margins. Intensification caused the thermal isolation of the interior water masses on the Campbell Plateau, which were warmer compared to waters of the ACC fronts. The ACC, however, increased its flow through Pukaki Saddle to contribute to an incursion of cold water to the South Island and northwards to East Cape (Neil et al., 2004). Thus, part of the northern Plateau was also thermally isolated, leaving warmer Subantarctic Mode Water on the central plateau to circulate in a weak anticlockwise gyre.

Away from the plateau and the complex bathymetry east of New Zealand, there is evidence for northward migrations of the main oceanographic fronts including the STF (Bostock, Barrows, et al., 2013; Sikes et al., 2009); SAF and PF (Barrows et al., 2000; Nelson et al., 1994; Nelson et al., 2000; Nelson \& Cooke., 2001; Nelson et al., 1993; Weaver et al., 1998). Thus, the STF did not sit over the northwest of the plateau during the glacial (Bostock et al., 2013b), but it remained over the Chatham Rise to the north due to topographic control (Sikes et al., 2002).

\subsubsection{6: Oceanography of the interglacial periods}

MIS 5e was a period similar to the present day's warming world., The work performed by Duncan et al., (2016), based off data acquired from core ODP 1120C, shows that during MIS 5e (120-130 ka) the climate was slightly warmer than now (see figure 1.14 and 1.15). This warming is evidenced from data from coccolithophore and foraminifera which saw mean annual SST for MIS 5e $0.9-1.8^{\circ} \mathrm{C}$ warmer (Cortese et al., 2013; Duncan et al., 2016). Throughout MIS 5e, ODP $1120 \mathrm{C}$ recorded an increased influx of subtropical water, which together with atmospheric warming, led to much SSTs up to $4^{\circ} \mathrm{C}$ above the Holocene mean temperature. That a thermally stratified upper ocean favoured coccolithophore production (Duncan et al., 2016). This led to the deposition of nannofossil ooze across Campbell Plateau. As modern conditions move closer to those of MIS 5e conditions $\left(\sim 2^{\circ} \mathrm{C}\right.$ warmer), it is likely that Campbell Plateau will continue to be dominated by enhanced nannofossil sedimentation (Duncan et al., 2016). 

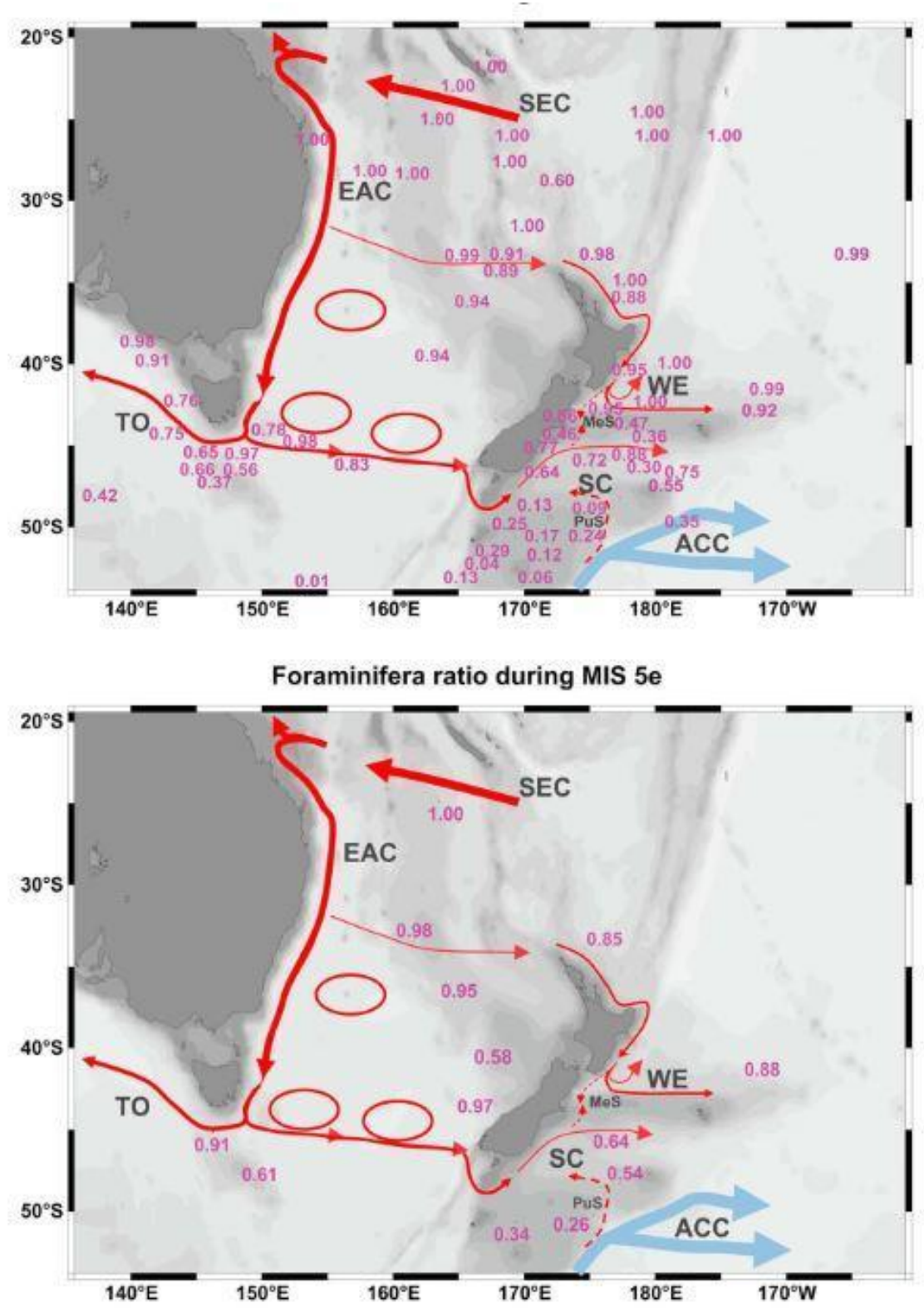

Figure 1.14: Modern (top panel) and MIS 5e (bottom panel) relative abundances, with the ratios representing the contribution to subtropical to subantarctic water masses. (from Cortese et al., 2013) 


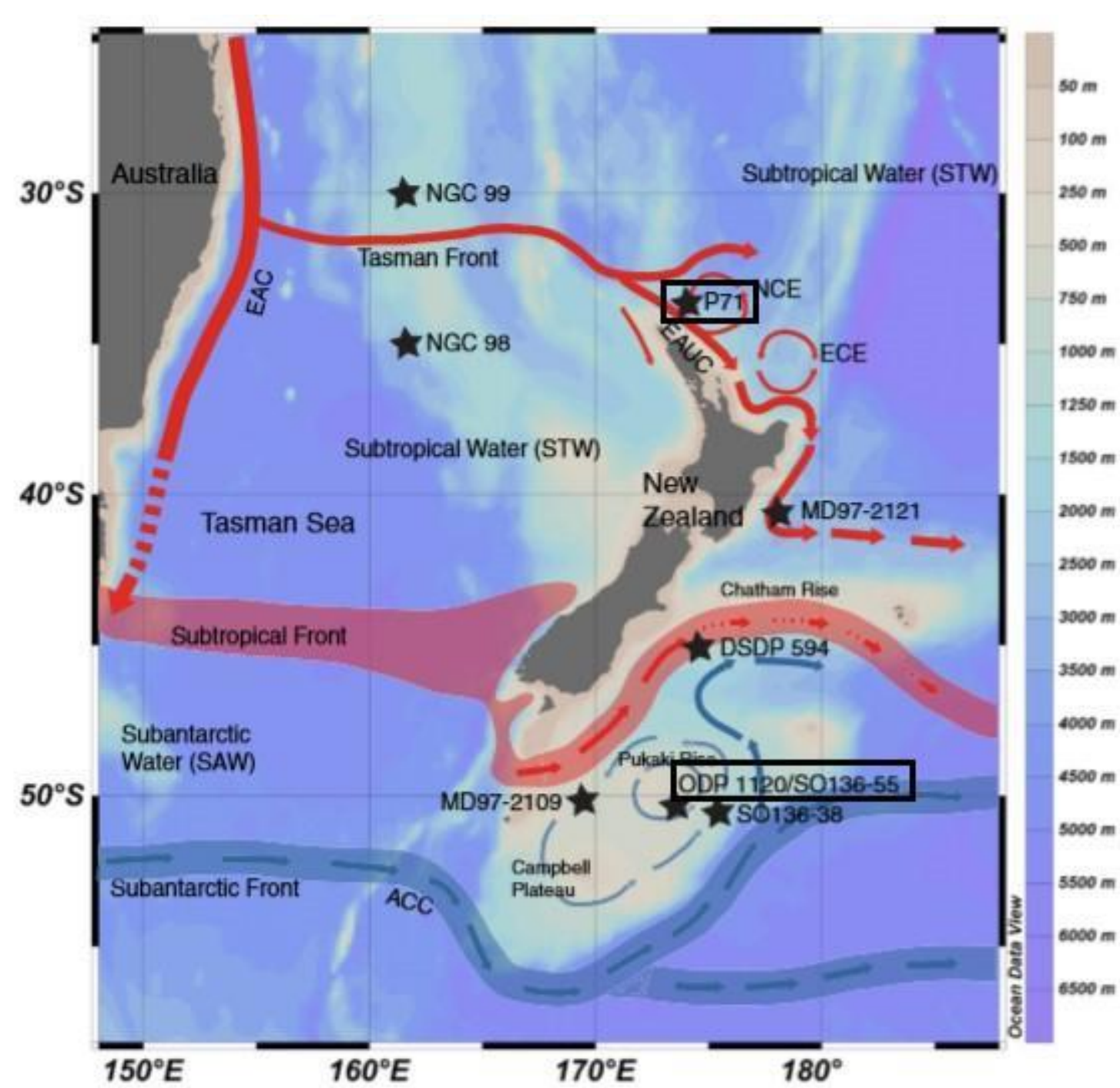

Figure 1.15: Map of modern ocean circulation the subtropical component of which would have intensified in MIS5e to transport more subtropical water to southernmost New Zealand and the Campbell Plateau. Core locations as used in Duncan et al., 2016, cores mentioned above are boxed. (Modified from Duncan et al., 2016)

\subsection{2: Modern Day Oceanography}

The present-day oceanography of the Subantarctic Campbell Plateau is dynamic and is heavily influenced by the plateau's topography. This oceanography has however changed throughout the Cenozoic with the movements of both plate tectonics/continents and changing ocean circulation and global climate. This section will discuss the previous work developed on the present-day Southern Ocean and Subantarctic region of New Zealand to understand how these impact the Campbell Plateau. 


\subsubsection{1: Surface Waters and Fronts}

As noted previously, the Plateau topographically controls the position of the Subtropical Front (STF) and the Subantarctic Front (SAF). The STF is the northern boundary to the Sub-Antarctic region and separates the northern warm, nutrient-poor and salty Subtropical Waters (STW) from the southern cool, nutrient-rich and less saline Subantarctic Waters (SAW) (Belkin \& Gordon, 1996; Bostock, Barrows, et al., 2013; Deacon, 1937; Nodder \& Northcote, 2001; Orsi, Whitworth III, \& Nowlin Jr, 1995). The STF is forced south around southern New Zealand and enters the Campbell Plateau from the Solander Trough at Snares Gap (Smith et al, 2013). Here the STF is locally known as the Southland Current (SC) and transports both STW and SAW (Sutton, 2003). The SC flows along the northwestern edge of the plateau, along the edge of the continental shelf of the South Island (see figure 1.16).

The SAF makes up the northern boundary of the Antarctic Circumpolar Current (ACC). Upstream of the plateau the SAF is split into 3 branches as it flows through the Macquarie Ridge (Sokolov et al, 2006), but as the SAF hits the steep topography of the western side of the Campbell Plateau, these branches merge into one and flow southeast around the plateau (Belkin \& Gordon, 1996; Forcén-Vázquez et al., 2018; Gille, 2003; Orsi et al., 1995; Sokolov \& Rintoul, 2007; Stanton \& Morris, 2004). 


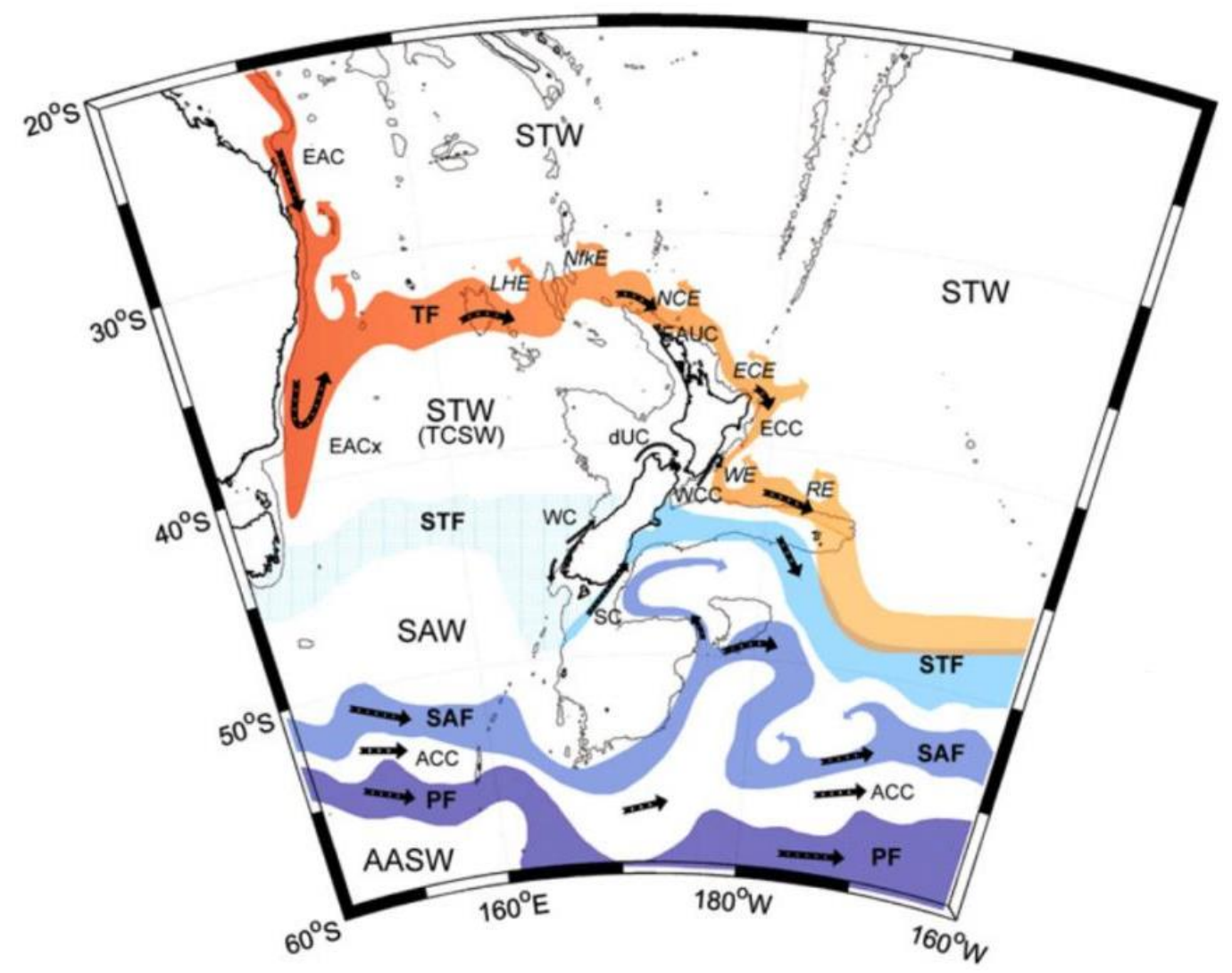

Figure 1.16: Modern day surface circulation schematic around New Zealand. Colours represent the differing temperatures of the flows, with red being the warmest and dark blue being the coldest. Acronyms relevant to this study is Subtropical Front (STF), Southland Current (SC), Subantarctic Water (SAW), Subantarctic Front (SAF) and the Antarctic Circumpolar Current (ACC). (Chiswell, Bostock, Sutton, \& Williams, 2015)

\section{Mode and Intermediate Waters}

The intermediate depth ( 500-1500m) water bodies that affect Campbell Plateau are the AAIW (Antarctic Intermediate Water) and the SAMW (Subantarctic Mode Water). Both affect the plateau in different manners. The SAMW is typically found at $450-750 \mathrm{~m}$ water depth but can be generated in much shallower areas. It is identified by a thermostad with a range of $8-9^{\circ} \mathrm{C}$ (see figure 1.17) and is oxygen-rich (Bostock et al.,, 2013; M. McCartney, 1977; M. S. McCartney, 1982; Rintoul \& England, 2002). However, on Campbell Plateau, it is seen to be slightly cooler $\left(<8^{\circ} \mathrm{C}\right)$ and less saline $(<34.45)$ (ForcénVázquez et al., 2018; Morris et al., 2001; Rintoul \& Bullister, 1999). In the summer months, SAMW is found below the upper $100 \mathrm{~m}$ of the stratified water column. In Autumn SAMW is located at 200-500 m water depth (Forcén-Vázquez et al., 2018), of which the SAMW found on the Campbell Plateau forms is still unclear. Initial studies suggested it formed through deep wintertime mixing over the Plateau (Bostock, Sutton, et al., 2013). However, recent work has suggested that it forms just north of the SAF and flows onto the plateau (Forcén-Vázquez et al., 2018). 


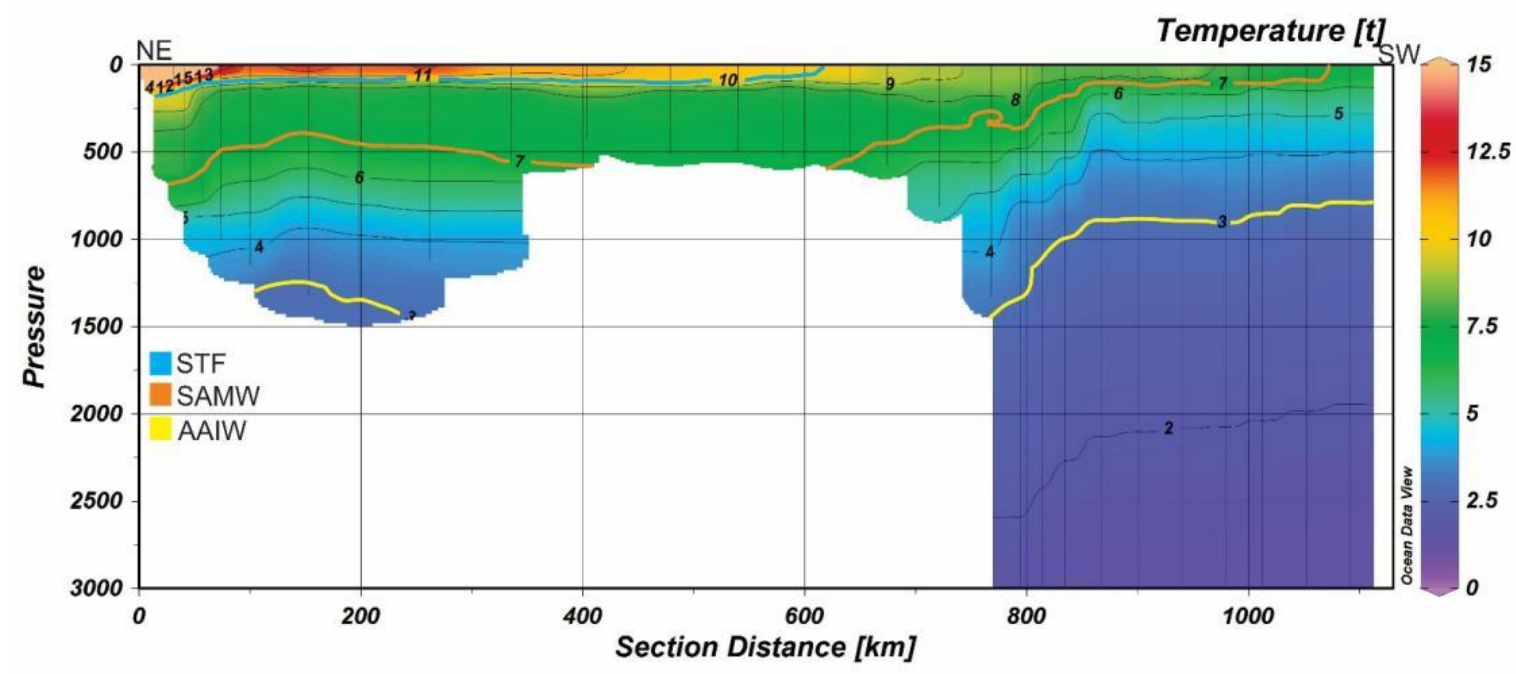

Figure 1.17: Transect from the NE to SW of the Campbell Plateau showing the water masses present. Yellow showing the temperature boundary of the AAIW, Orange showing the temperature boundary of the SAMW, and Cyan showing where the STF is present in this area of the Campbell Plateau.

AAIW is found at depths of between $500-1500 \mathrm{~m}$ and is identified by a salinity minimum of $~ 34.5$ psu (Bostock, Sutton, et al., 2013). Bostock et al (2013a) suggest that there are four distinct subtypes of AAIW in the South Pacific Ocean, three of which are found in the New Zealand region. The Southern Ocean subtype of the AAIW (subtype 4) is evident southeast of New Zealand and Argo float data show that it flows around the southern flank of Campbell Plateau and through the Pukaki Trough (see figure 1.18) (Bostock et al., 2013b). 


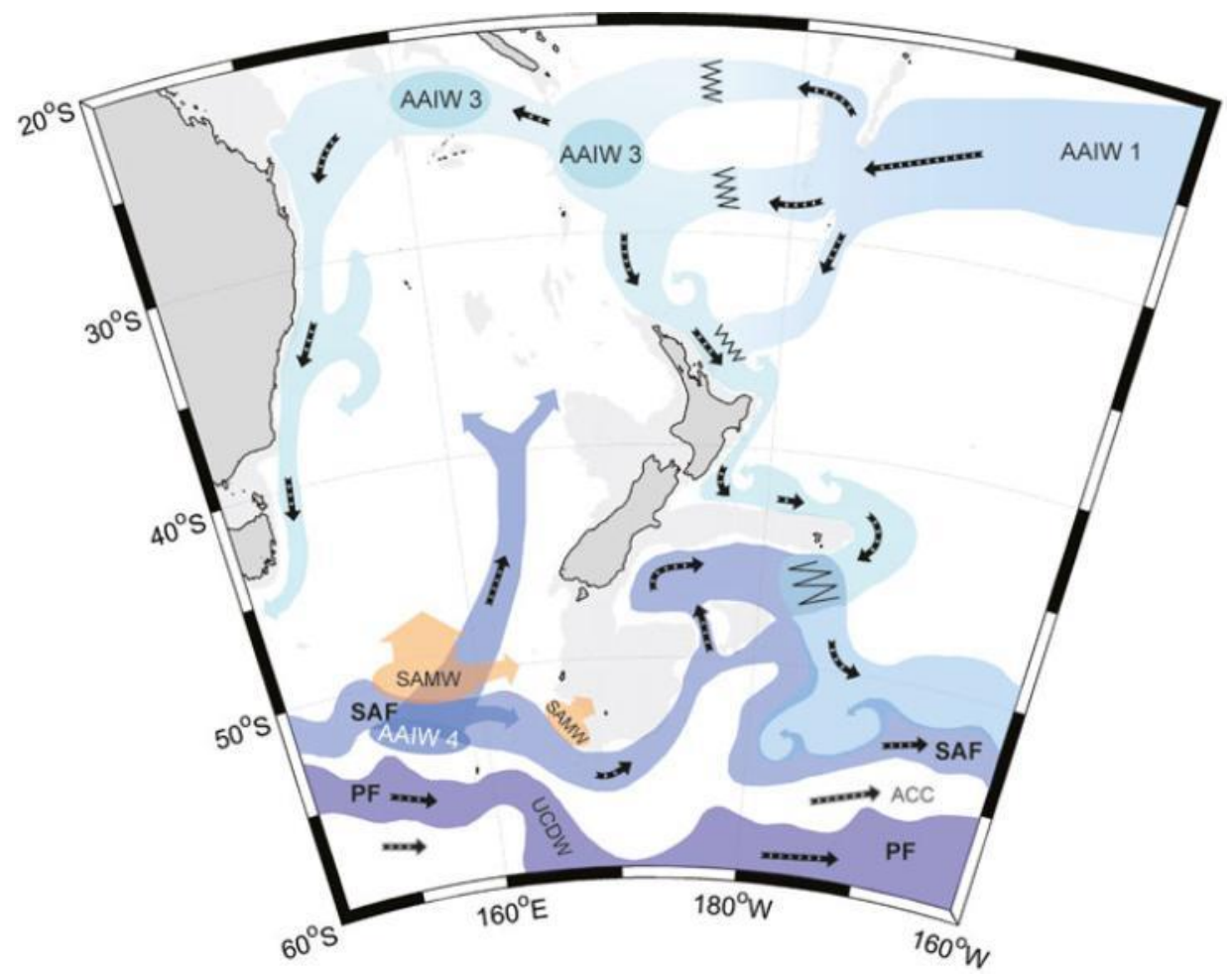

Figure 1.18: Schematic of intermediate water circulation around the Campbell Plateau from Argo float data (from Chiswell et al., 2015)

\section{Bottom and Deep Waters}

While these water masses are not found overlying the Campbell Plateau, they flow around the southern and eastern flanks of the Plateau as part of the Deep Western Boundary Current (DWBC) (see figure 1.19), which is the main flow of deep water (>2000m deep) into the Pacific region (Chiswell et al., 2015; Whitworth III et al., 1999). The deepest of these bodies is Antarctic Bottom Water (AABW), which has a temperature range of $0.8^{\circ} \mathrm{C}$ to $2^{\circ} \mathrm{C}$, salinity ranging from $34.6 \mathrm{psu}$ to $34.7 \mathrm{psu}$, a neutral density of $\gamma \eta>28.27 \mathrm{~kg}$ $\mathrm{m}^{-3}$, and is found deeper than $4000 \mathrm{~m}$ (Chiswell et al., 2015; Orsi et al., 1995). This water originates from the Antarctic continental shelf is thought to have several source regions (Chiswell et al., 2015; Ohshima et al., 2013). The main source region for the AABW south of New Zealand is suggested to be the Ross Sea (McCave, Carter, \& Hall, 2008). Situated above this bottom water is the Circumpolar Deep Water (CDW), which is split into two layers; upper (UCDW) being found $1450 \mathrm{~m}$ to $2500 \mathrm{~m}$ water depth, and lower (LCDW), between 2500m and the AABW (Orsi et al., 1995). 


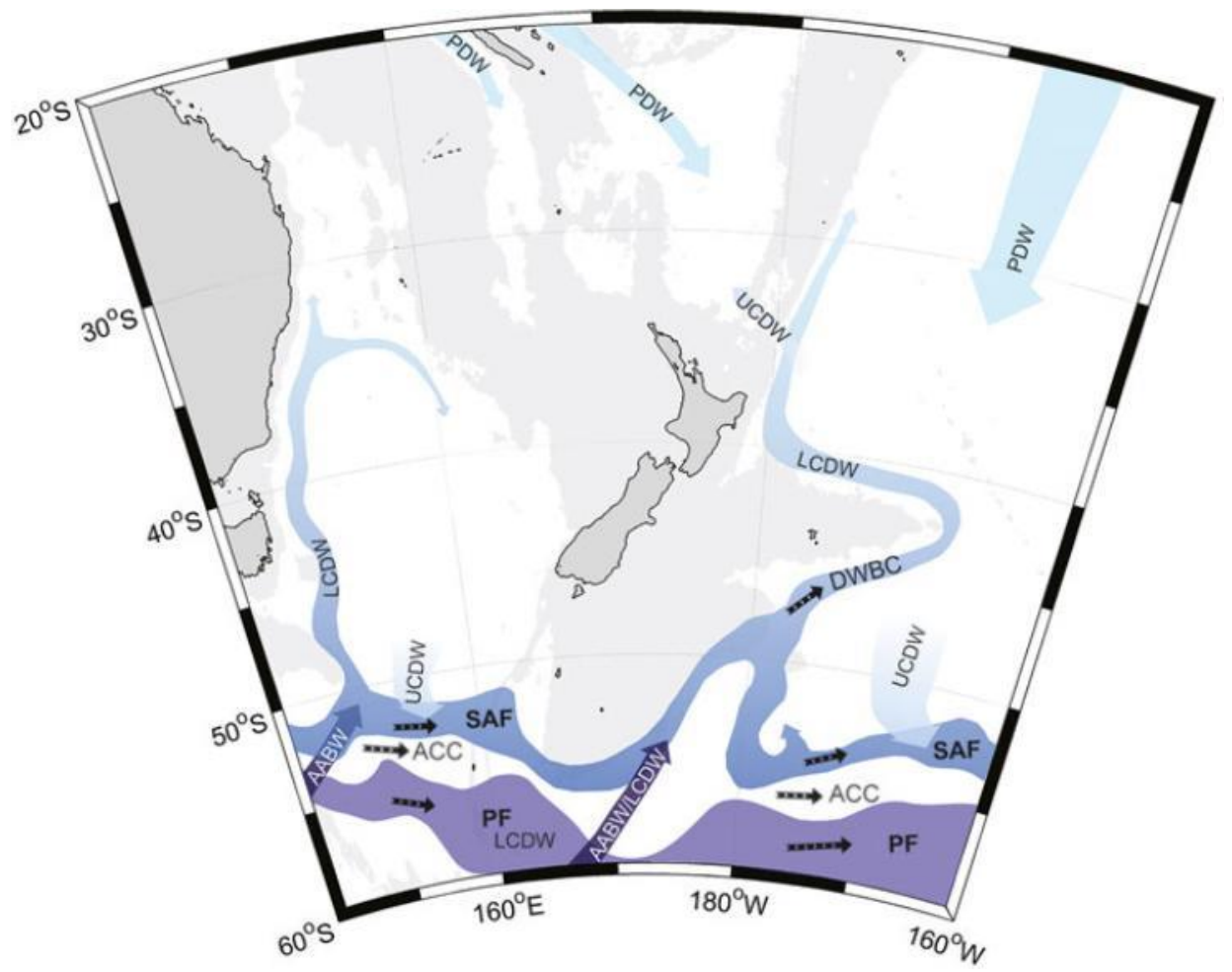

Figure 1.19: Schematic of deep and bottom water circulation around the Campbell Plateau and southern New Zealand based on hydrographic data. See Bottom and Deep-Water section for further detail. (From Chiswell et al., 2015). 
Chapter 2: Methodology 


\subsection{Methodology}

This study involved the use of the Kongsberg parametric sub-bottom profiler known as the TOPAS PS 18. The TOPAS acquires high-resolution seismic reflection data, enabling the assessment of shallow sub-bottom structure up to decimetre scale. Acquisition of the data for this project was attained on two separate voyages on the NIWA Research Vessel Tangaroa; TAN1703 and TAN1804, on March 2017 and April 2018, respectively.

Both voyages were physical oceanography focussed to deploy and recover moorings to understand the flow of water on and off the plateau; this constrained the location of the seismic tracks that were acquired in the study and the timing of data acquisition. For example, throughout the TAN1804 voyage, there were instances where the sub-bottom profiler was stopped due to a stoppage in the mooring recovery, along with periods of bad weather, which caused the vessel to seek cover around the southern side of the Auckland Islands for nearly 24hrs. These periods of bad weather and stoppages caused the data set to show higher levels of noise and periods of disjointedness between seismic traces (see figure 3.1 in Results for map of seismic lines).

Seismic reflection is an important tool for assessing the sub-surface profile of areas of interest. Seismic reflection works using sound wave propagation through a medium. The behaviour of the sound waves through the medium (e.g., distortion, reflection) is controlled by the physical properties of the material (e.g., density). Variable frequencies are utilised depending on factors such as the wave travel time, density of the material it is going through, and the travel time to the receiver (Lowrie, 2007).

The purpose of the using a sub-bottom profile in this study rather than conventional seismic is primarily due to the chirp system used by the profiler which gives it a relatively high frequency range of $15-21 \mathrm{kHz}$, with a primary beam width of $\sim 3.5 \mathrm{deg}$, a penetration capability of $>200 \mathrm{~m}$ and in a water depth of more than $3,800 \mathrm{~m}$ (Kongsberg, 2018). The TOPAS transmitter and receiver are mounted on the base of the RV Tangaroa and travelled at a speed of $\sim 10$ knots; an example of the profiler in survey mode can be seen in figure 2.1. The chirp system allows for high resolution, low noise sub-bottom data, which provides a nearly constant resolution with depth. As also, the majority of the sediment on the plateau is nannofossil ooze, which is relatively unconsolidated sediment, which in turn will reduce the density of the material due to the associated increase in porosity. This increase in porosity is also linked to the bulk 
compressibility of the sediment, which is associated with the density of the sediment (LeBlanc, Mayer, Rufino, Schock, \& King, 1992).

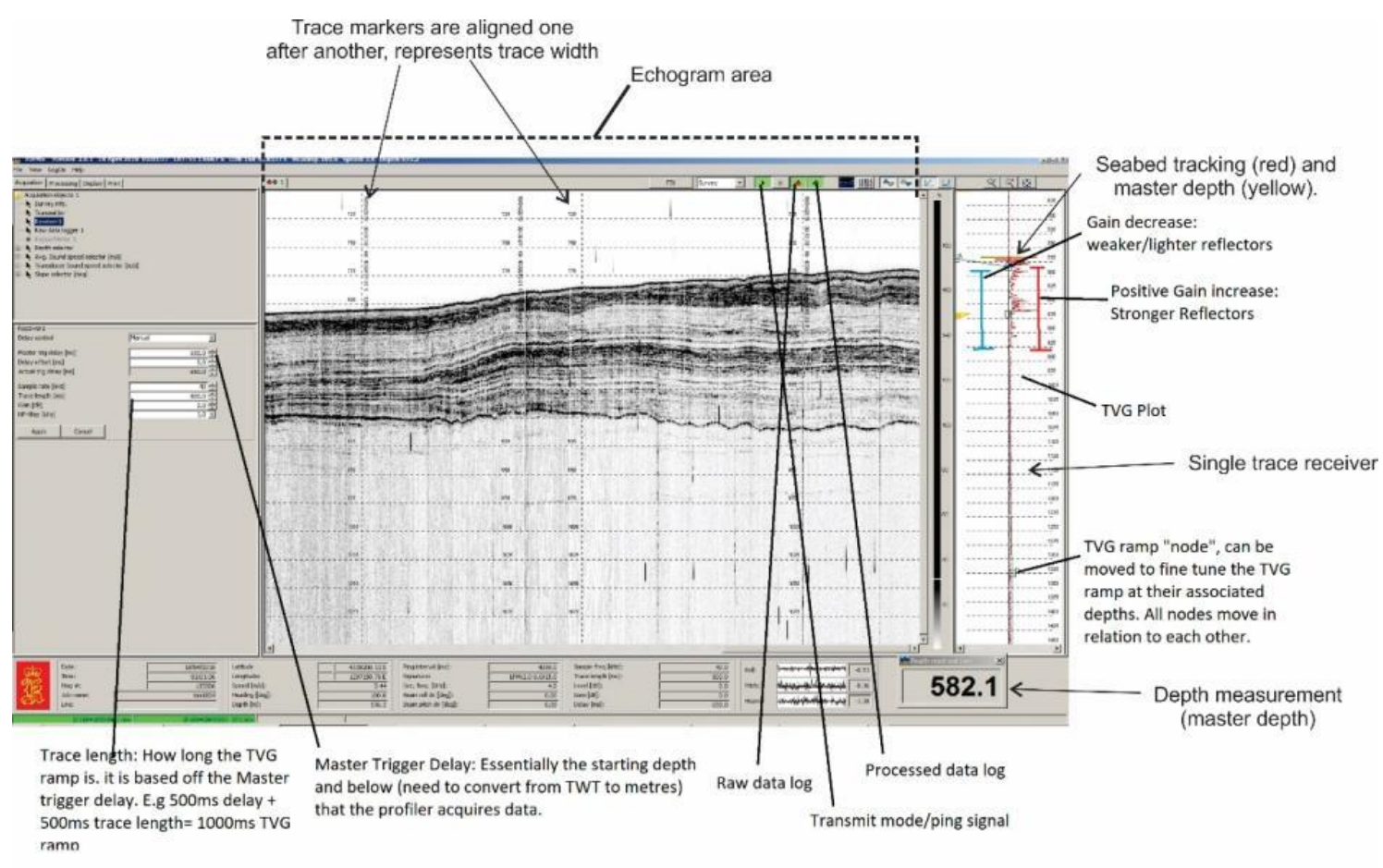

Figure 2.1: Annotated TOPAS echogram area whilst in survey mode, annotating each component of the acquisition screen and its purpose from TAN1804.

\subsection{Analytical Techniques and Data Acquisition}

\subsection{1: Sub-bottom profile data methods}

Sub-bottom profiler data was acquired in SEG-Y format from voyages TAN1703 and TAN1804 which underpinned the mapping a substantial part of the Plateau. This was imported into the interpretation software: IHS Kingdom Suite, Susi Woelz from NIWA then processed this data. Overall, the data was of good quality, allowing for the generation of thickness maps across the Campbell Plateau where enough sediment was present.

This sub-surface data was then tied to the few boreholes that were drilled on Campbell Plateau with emphasis on ODP1120, this was done using the Kingdom Suite Well Explorer software to help with picking of horizons (see figure 2.2) 


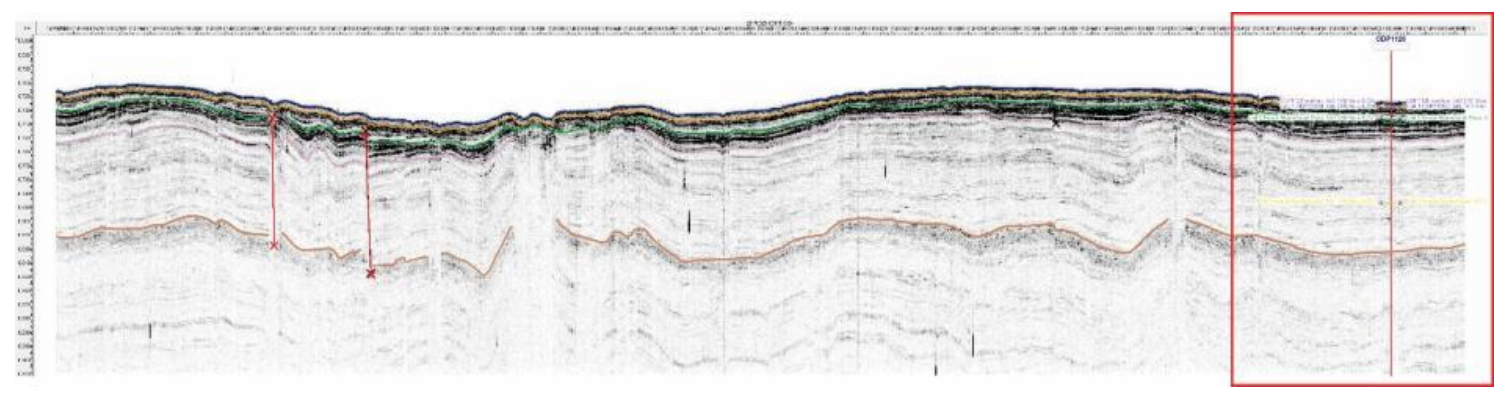

Figure 2.2: Example of interpreted sub-bottom profile line 20170329103515_000 with ODP1120 borehole in HIS Kingdom Suite (see area outlined in red), from TAN1703.

\subsection{2: Damuth Scale and data description}

The Damuth scale created by John E. Damuth in 1975 is a method of describing characteristics of bottom echoes in sub-bottom profile data. His descriptions are based on $3.5 \mathrm{kHz}$ profiles. The echoes were divided into two main types: distinct, class 1 and indistinct, class 2 (see figure 2.3i-iv), with their associated subtypes (Damuth, 1975). Within these two categories of echoes, a further subclass was discovered for each type. The purpose of these echo characteristics was to allow for the further insight into the lithology type, any geological or sedimentary structures, and possible geomorphic or microphysiography features present within the top $\sim 200 \mathrm{~m}$ of the seafloor (Damuth, 1975). The Damuth scale is ideally used in conjunction with other data sources such as sediment cores and seabed photographs to ground truth seismic structures and enhance their interpretive value. This approach will be repeated on Campbell Plateau using piston core ODP1120. 


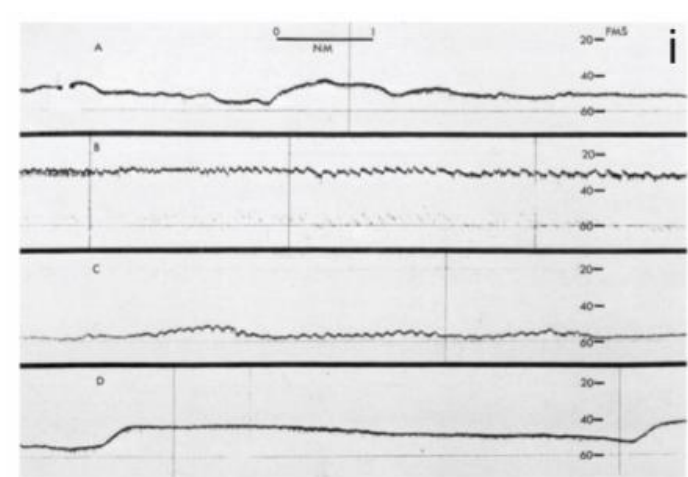

Figure 2.3-i: Damuth echo type 1A. These are sharp bottom echoes with no apparent sub-bottom reflector. This is then broken into several sub categories: $1 A-A$ $1 A-B, 1 A-C$ and $1 A-D$ (modified from Damuth, 1975).

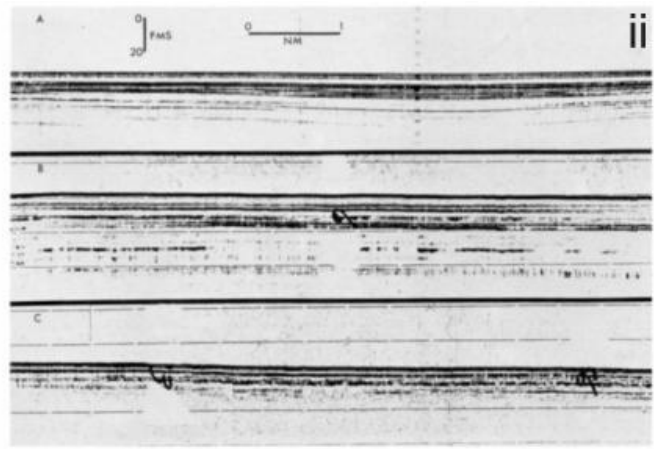

Figure 2.3-ii: Damuth echo type 1B. These are distinct, continuous, sharp bottom echoes with continuous, sharp, parallel sub-bottom reflectors that can stretch over tens to hundreds of kilometres. These are also broken into sub categories: $1 \mathrm{~B}-\mathrm{A}$, 1B-B and 1B-C (modified from Damuth, 1975).

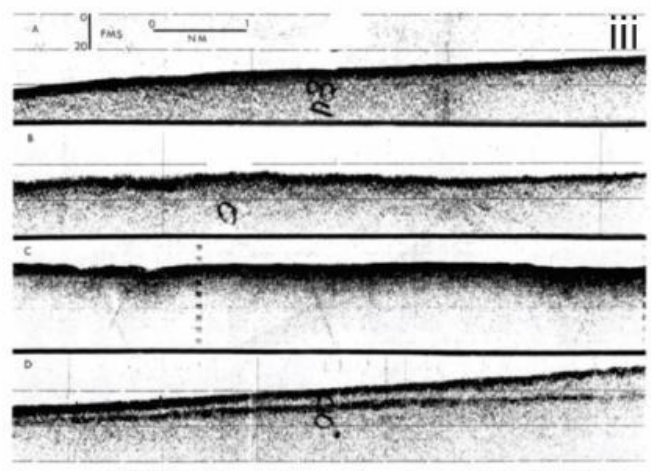

Figure 2.3-iii: Damuth echo type 2A-1. These are indistinct, very prolonged, fuzzy bottom echoes with no apparent bottom reflectors or an occasional converging sub-bottom reflector (see sub category D) which wedges out over a few kilometres. This is also broken up into sub categories: $2 \mathrm{~A}-1 \mathrm{~A}, 2 \mathrm{~A}-1 \mathrm{~B}, 2 \mathrm{~A}-1 \mathrm{C}$ and 2A-1D (modified from Damuth, 1975).

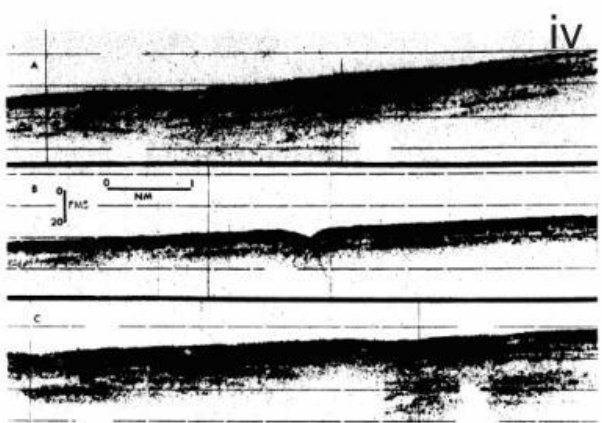

Figure 2.3-iv: Damuth echo type 2A-2. These are indistinct, semi-prolonged bottom echo with zones of semi-prolonged, discontinuous, parallel sub-bottom reflectors which alternate with zones of intermittent "mushy" sub-bottom reflectors. These are also broken into sub categories: $2 \mathrm{~A}-2 \mathrm{~A}, 2 \mathrm{~A}-2 \mathrm{~B}, 2 \mathrm{~A}-2 \mathrm{C}$ and $2 \mathrm{~A}-2 \mathrm{D}$ (modified from Damuth, 1975) 


\section{Chapter 3: Results of the Study}


This chapter will cover the main results of the study, this includes detailed descriptions of 15 TOPAS sub-bottom profile seismic lines that cover the variations seen on the Campbell Plateau. These variations include the different types of features seen on the Campbell Plateau, the variations of the units seen within these TOPAS seismic sections and the interpretations/reasoning for these changes.

These results will be outlined by first, giving a description of the seismic lines location and general characteristics. A description of the reflectors interpreted and traced in the lines will then be made with their general characteristics and features. Next will follow, will be the description of the units interpreted from these reflectors and the characteristics and features seen within these. Finally, to conclude every seismic section there will be an interpretation of the events that led to the sub surfaces current state, with reference to the possible formation of features and events seen. All measurements of thickness and depth are to be taken as a minimum, as these were approximate conversions using the minimum velocity of $1540 \mathrm{~ms}^{-1}$ measured at ODP site 1120 (Carter et al., 1999). 


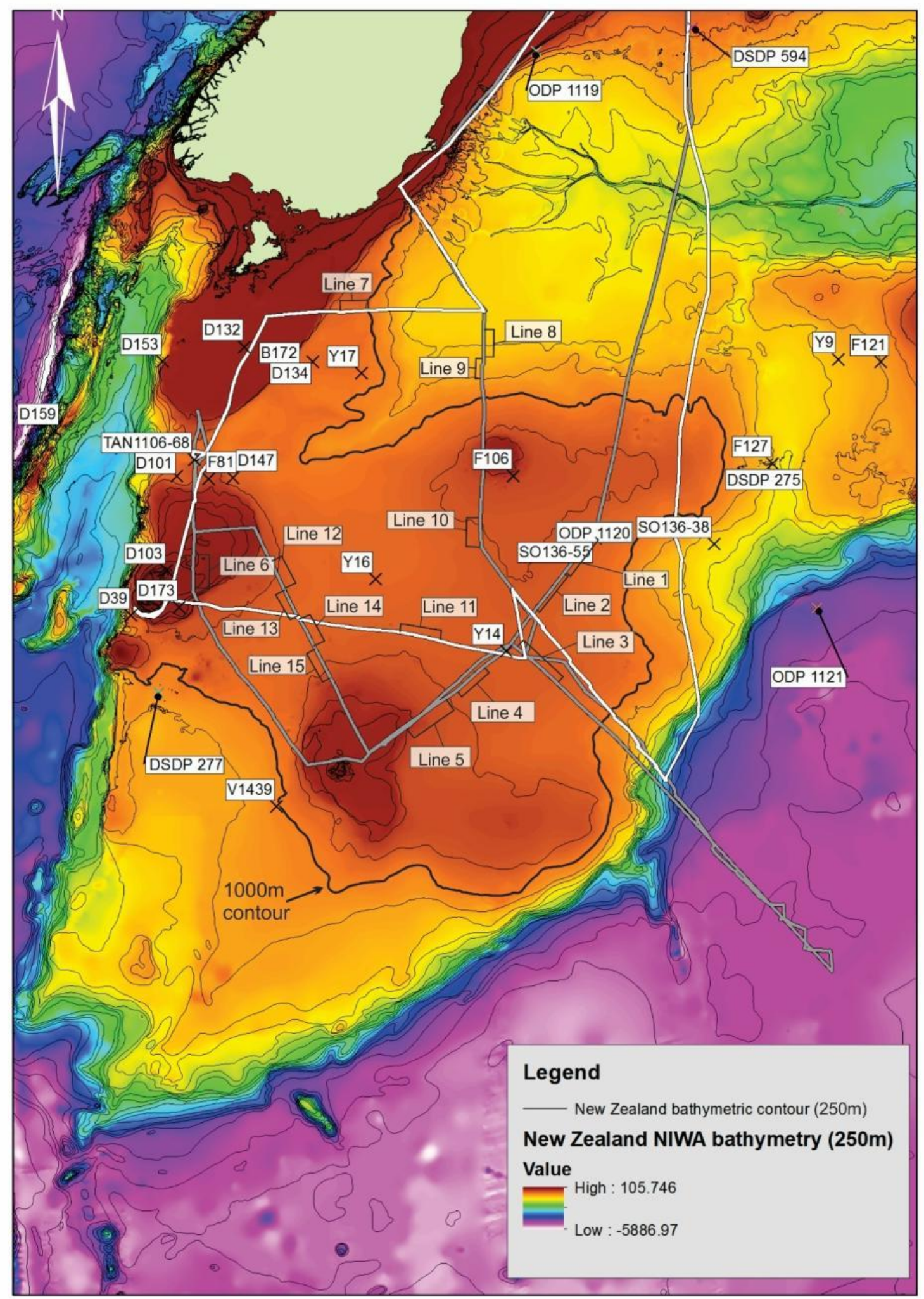

Figure 3.1: Map of sub-bottom profile lines, representative of the main features of the Campbell Plateau sub-surface, along with the deep sea and surface sediment cores were taken on and in the vicinity of the plateau. Note the bolden line represents the $1000 \mathrm{~m}$ contour line. The white lines represent the sub-bottom profile lines taken in 2018 and the grey represent lines taken in 2017. 


\section{1: Line 1 (ODP1120 core site, eastern Campbell}

\section{Plateau)}

\subsection{1: Line Description}

Sub-bottom profile line 1 located across the eastern centre of the Campbell Plateau trends north to south (see fig 3.1). The line is characterised to a depth of 0.910 milliseconds two-way time (TWT) and can be broken approximately into three vertical parts based off the seismic character. The lowest third, which is predominantly low amplitude material that increases in undulation with depth and with a decrease in the lateral continuity of the layers (see figure 3.2b). The middle third has a slight increase in amplitude across the section, along with having more defined bedding. The final upper third has higher amplitude/stronger reflectors that have more gentle undulations. The spacing of the undulations is closer together, in the southern section of the line (see area outlined in fig $3.2 \mathrm{~b}$ ).

\subsection{2: Reflector Descriptions}

Seafloor (Blue reflector): This is moderately undulating, is strongly reflective (an amplitude that varies from $\sim 1.00$ to $\sim 0.4 \mathrm{~A}$. The seafloor displays a Damuth scale of $1 \mathrm{~B}-$ B (see methods section part B). There are a variety of minor dips along the surface (see figure 3.2a: point A) which has a TWT depth of $\sim 0.003$.

Orange reflector: This has a high amplitude that is slightly undulating along with being laterally continuous. Begins at a depth of 0.715 TWT. The reflectors pattern generally follows the bathymetry of the seafloor. The amplitude of this reflector varies from $\sim 0.8$ at the strongest to $\sim 0.5$ along the horizon top.

Green reflector: This is a moderate to weak strength reflector $(\sim 0.15$ to $\sim 0.45$ amplitude), this horizon shows a similar undulating pattern to the orange reflector, however it is laterally discontinuous and disjointed. This reflector has a TWT depth of $\sim 0.730$ to 0.755 at its deepest section. 
Pink reflector: Moderately undulating, laterally discontinuous a weak to moderate reflector (see figure 3.1c). The reflector is located at a depth of between $\sim 0.745$ to $\sim 0.740$ TWT.

Brown reflector: This is horizon is a weak reflector ( $\sim 0.15$ to $\sim 0.02$ amplitude), that is moderately undulating, laterally discontinuous and segmented by faults. There is a large break in discontinuity (see figure $3.2 \mathrm{~d}$ ) this break is steep sided, going from $\sim 0.849$ to $\sim 0.815$ TWT at its steepest.

\subsection{3: Unit Descriptions}

Unit 1 (Blue to orange reflector): This Unit between the blue and orange reflectors displays general low amplitude ( 0.2 to $0.4 \mathrm{~A}$ ) across much of the Unit. Both the top and bottom reflectors of the unit are moderately undulating. Overall, the unit is the thinnest of all in the section, having a thickness of $\sim 0.005$ TWT or $\sim 9 \mathrm{~m}$.

Unit 2 a (Orange to green reflector): This Unit has a variety of features throughout, has a thickness that is $\sim 0.010-0.020$ TWT (see figure 3.2c). The reflectors present in this generally moderately to weakly defined that generally follows the bathymetry of the seafloor. The amplitude of this unit varies from $\sim 0.8$ at the strongest to $\sim 0.5$ along the horizon top. Within the unit, there is the presence of a consistent very low amplitude bed (0.003) that is $\sim 0.003$ TWT thick (see figure 3.2c). These low amplitude reflector thins in and out along the slight changes in slope and bathymetry (thins to $\sim 0.002$ TWT). Bedding throughout this unit is generally patchy (could be due to variation in reflection strength). There is also a dominant high amplitude bed ( 0.70-0.78), which is $\sim 0.003$ TWT thick. Throughout the unit, there is also the presence of possible chaotic reflectors within the beds.

Unit $2 b$ (Green to pink reflector): This unit has a maximum thickness of $\sim 0.020$ TWT and an average thickness of $\sim 0.007$ TWT, which is seen to pinch out (see figure $3.2 \mathrm{~b}$, point A), to a minimum of $\sim 0.001$ TWT. Unit 3 also has lenses of disjointed, high amplitude reflectors that has been segmented by faults (see figure $3.2 \mathrm{~b}$ ), the amplitude of these beds varies in amplitude ( $\sim 1.00$ to $\sim 0.45)$, which are generally located $\sim 0.003$ to $\sim 0.004$ TWT below the horizon top (see figure 3.2b). Faults intersect this Unit at points B and C (see figure 3.2b). This Unit also displays two distinct beds throughout that vary in thickness with bed A having a maximum thickness of $\sim 0.004$ TWT (see figure 3.2c) and thinnest in the south with a thickness of $\sim 0.001$ TWT (see figure $3.2 \mathrm{c}$ ). 
Bed B, which is located directly below bed A, has a maximum thickness of 0.003 TWT and is thinnest at 0.001 TWT.

Unit 2c (Pink to brown reflector): This Unit has faint to weak bedding ( $\sim 0.40$ to $\sim 0.10$ amplitude). Beds are generally laterally continuous (apart from when segmented by faulting). Chaotic bedding is present with amplitude varying from $\sim 0.2$ to $\sim 0.10$ (see figure 3.2b, point A). Unit thickness is uniform ( 0.081 to $\sim 0.075$ TWT). There is a loss of amplitude within the Unit below the chaotic bedding (see figure 3.2b, point D), this change is subtle at $\sim 0.02$ to $\sim 0.03$. A probable major bed located in the middle of unit that is located $\sim 0.760$ TWT or $\sim 0.025$ below the horizon top, this Unit has an average thickness of $\sim 0.010$ TWT. The most prominent example of this Unit is in the south of the section (see figure $3.2 \mathrm{~b}$, point E). Faulting in this unit is also prominent with the largest offset being 0.007 TWT (see figure $3.2 \mathrm{~b}$, outlined by point E).

Unit $3 a$ (Brown reflector and below): This unit is faintly bedded with a fuzzy/chaotic reflector that has very faint bedding (max. amp. 0.12), this varies over a depth of $\sim 0.820$ to $\sim 0.850$ (see figure $3.1 \mathrm{~b}$ marked by point $\mathrm{F}$ ). The largest fault offset seen in this unit, having an offset of $\sim 0.010$ TWT (see figure $3.2 \mathrm{~b}$, highlighted in blue). A very faint possible cone-like structure in the northern section of the line $(\sim 0.18$ to 0.09 amplitude), a low spot in the amplitude just above this (< 0.04) (see figure 3.2b, see point $A$, unit 1). 


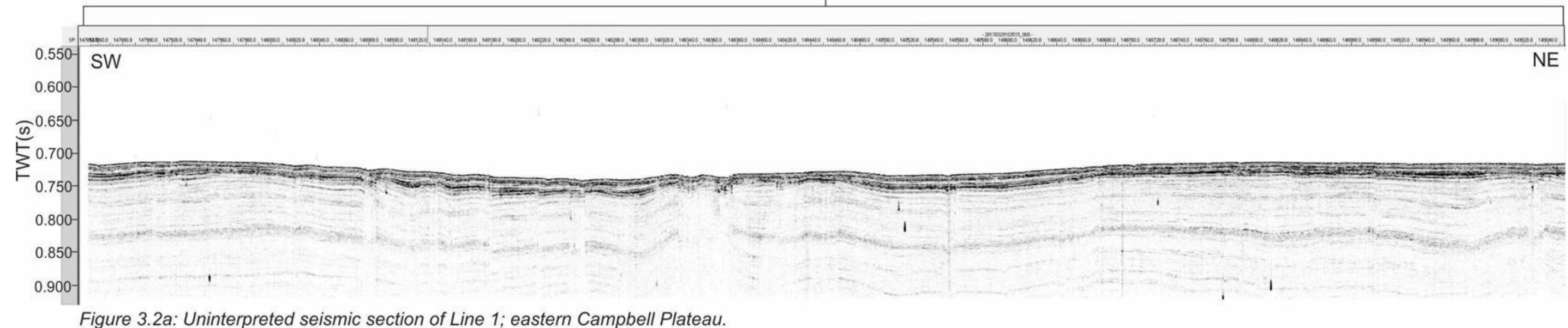

Figure 3.2a: Uninterpreted seismic section of Line 1; eastern Campbell Plateau.

$\sim 38 \mathrm{~km}$

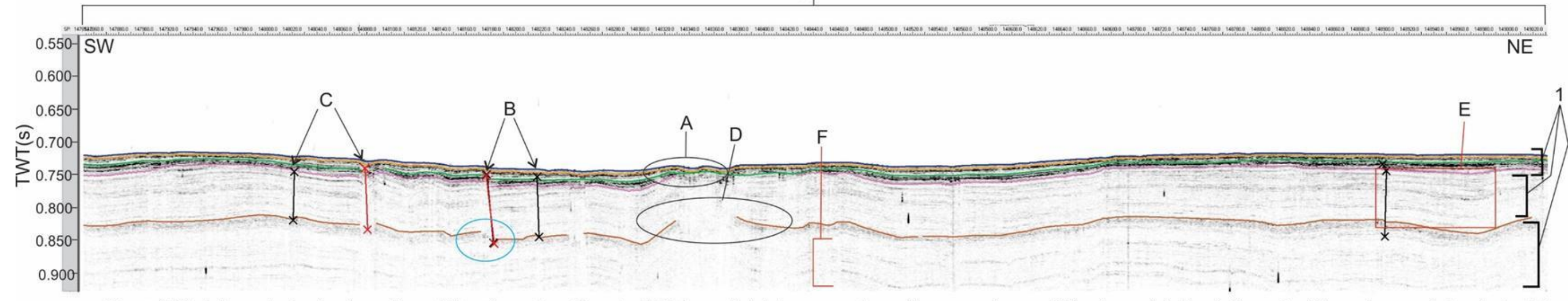

Figure 3.2b: Interpreted seismic section of Line 1; eastern Campbell Plateau. Point A represents seafloor scouring and thinning point of unit $2 \mathrm{~b}$ against $2 \mathrm{a}$ and area of chaotic bedding increase in bedding amplitude in unit $2 \mathrm{c}$. Point $\mathrm{F}$ represents bedding seen in unit $2 \mathrm{~d}$. Point 1 represents the three sections of seismic character the line can be approximately broken into. 


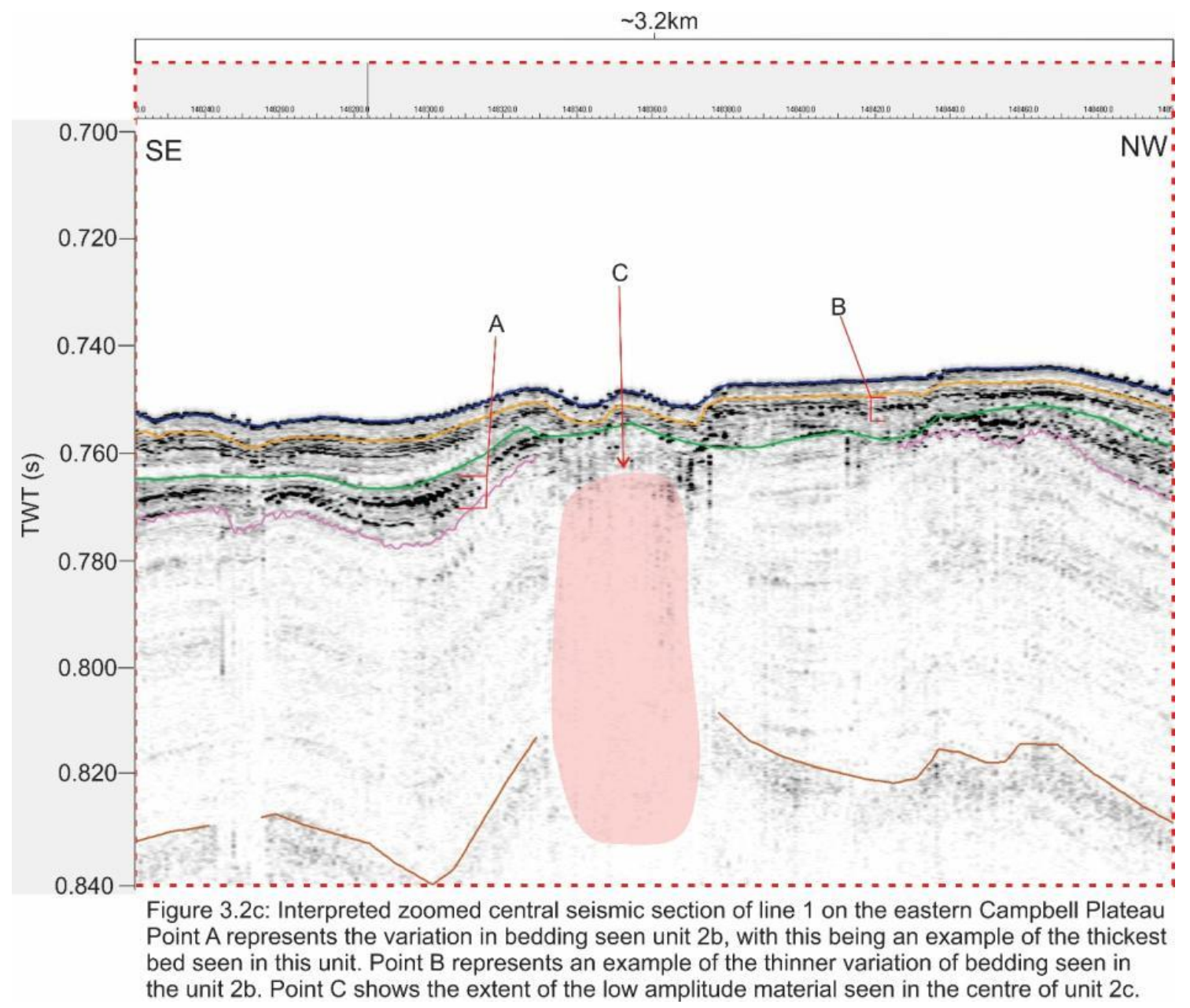




\subsection{4: Interpretation}

This section appears to be broken into three distinct sections; a strong reflecting upper section, a thicker slightly weaker reflecting and slightly undulating middle section and a weak moderately undulating lower section (see figure 3.2b). Unit 1 lies uniformly across the surface of this section. This unit is Pleistocene in age based on the ODP 1120 drill core and another nearby cores SO136-55, which displays several quaternary glacial/interglacial cycles (Neil et al., 2004). Below this unit 1, there is evidence of erosion prior to the deposition of unit 1 , as the orange reflector sits directly over the green reflector at the location labelled A (see figure 3.2c), this is presented by the this is further supported by the ODP1120 drill core ages. Based on ODP1120 core ages of these Units can be estimated; Unit 3a is likely to be late Early to Middle Miocene in age, Unit 2a is likely to be mid-Middle Miocene, Unit 2 is likely to be Late Miocene in age and Unit 1 is Pleistocene in age (2.58Ma to present). Faulting throughout the section appears to be older than Unit 1 but younger than Unit 2a due to there being no penetration into Unit 1, suggesting the faulting occurred sometime during the Late Miocene due to it penetrating all but the most upper Units. Other possible structures within this section include a possible fluid escape structure inside Unit 2c (see figure $3.2 b$ ). This structure appears to have formed after the deposition of unit $2 c$ and $2 b$ due to the possible fluid interacting with these two units, causing a drop-in amplitude. The closest age for this event is that it occurred sometime during the earliest Late Miocene due to the thinning interaction with unit $2 \mathrm{a}$ which is deposited possibly during the Latest Miocene. Further possible small-scale fluid escape structures are seen aligned with surface dips on the seafloor (see figure $3.2 \mathrm{a}$ and $3.2 \mathrm{~b}$ ). The thinning and thickening of beds in unit $2 \mathrm{a}$ is likely a small-scale erosional feature rather than effects caused by changes in sediment supply. This is due to much of the sediment across Campbell Plateau being nannofossil ooze which already has a very low sedimentation rate. The exact style of faulting is unknown due to no cross-cutting seismic lines. In the southern section of the line compression is seen to be further enhanced through the presence of normal faulting and evident from the vertical offset in the seismic reflectors. 


\section{2: Line 2 (South of ODP1120 site)}

\subsection{1: Line Description}

This line is located on the eastern central section of Campbell Plateau (see figure 3.1), going NNE to SSW direction. The line approximately starts at $\sim 0.700$ TWT depth down to 920 TWT. The line can be generally split into two sections: a strong amplitude top quarter of the section and a lower amplitude three-quarters of the section which is less defined. Overall, the section is lightly undulating across its length.

\subsection{2: Reflector Descriptions}

Seafloor (Blue reflector): Is a strong reflector ( 0.9A) that is gently undulating across its length, it displays minor scouring along its surface (see figure 3.3b, point $\mathrm{A}$ ). The reflector has a Damuth scale of 1B-B. The reflector begins at a depth of $\sim 0.700$ TWT.

Orange reflector: Is a strong reflector ( 0.8 to $0.9 \mathrm{~A})$ that is gently undulating, the same pattern of light scouring that is present in the overlying blue reflector. The reflector begins at depth of $\sim 0.705$ TWT.

Green reflector: This moderately strong reflector ( 0.7 to $0.9 \mathrm{~A})$ is gently undulating across its length. The reflector begins at a depth of $\sim 0.715$ TWT.

Pink reflector: Is a moderate reflector (0.5 to $0.7 \mathrm{~A})$, that is moderately undulating; in the northern section of the reflector there is a possible small fault that causes an offset of $\sim 0.005$ TWT.

\subsection{3: Unit Descriptions}

Unit 1 (Blue to Orange reflector): This unit is generally seen to be of low amplitude across its length with the Unit displaying very faint patchy reflectors throughout (see figure $3.3 \mathrm{~b}$, point B). Central there is a slight scour that affects both the top and bottom reflector, giving a slight depression in the unit (see figure 3.3b, point A). The unit's overall thickness is thin, having a thickness of $\sim 0.002$ TWT.

Unit 2 a (Orange to Green reflector): This unit has generally moderate to high amplitude beds ( 0.6 to $0.8 \mathrm{~A})$ that are relatively consistent across the unit with some possible thinning of the beds to the south (see figure $3.3 \mathrm{~b}$ point $\mathrm{C}$ ); however, there is a slight increase in bed thickness to the south, increasing to $0.01 \mathrm{TWT}$. The unit has an approximate thickness of $\sim 0.008$ TWT across the unit. 
Unit $2 b$ (Green to Pink reflector): Unit $2 \mathrm{~b}$ has the most variation of all units, having the bedding that varies from relatively high amplitude: $\sim 0.7 \mathrm{~A}$ to having a lower moderately strength reflectors $\sim 0.4$ to $0.5 \mathrm{~A}$ (see figure $3.3 \mathrm{~b}$, point $\mathrm{D}$ ). The reflectors within the unit are also slightly undulating across the length, with slightly stronger undulation in the north (see figure 3.3b, point D). The focus point of this unit, however, is the bottom reflector where a fault intersects the reflector. The fault offset is approximately $\sim 0.005$ TWT (see figure 3.3b, point E). 
$\sim 14 \mathrm{~km}$

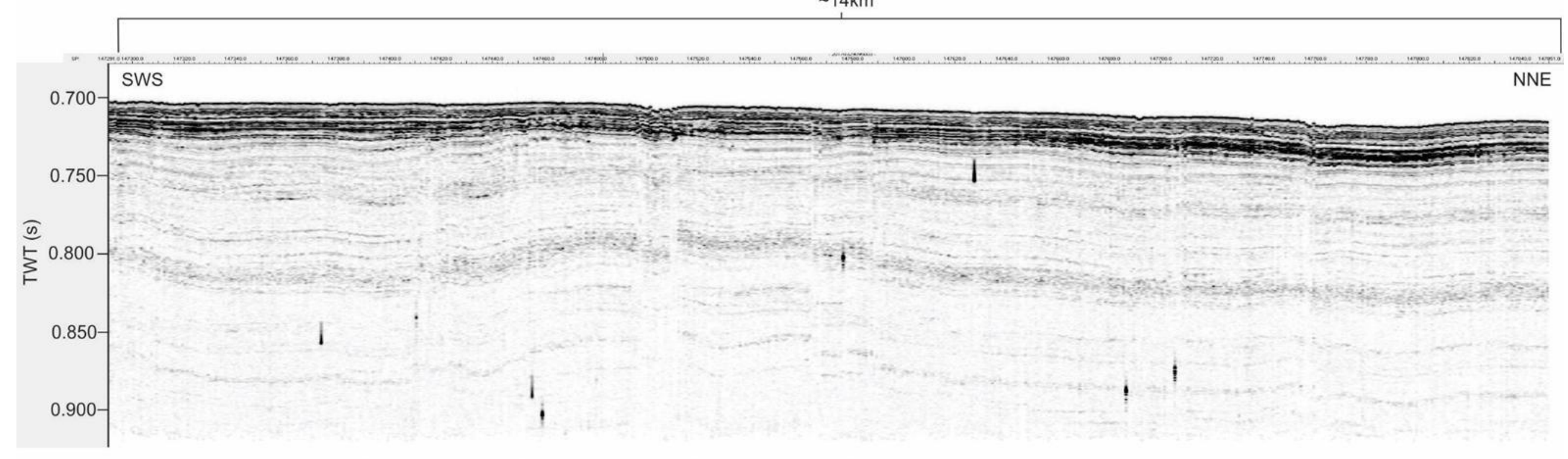

Figure 3.3a: Uninterpreted seismic section of line 2, eastern Campbell Plateau.

$\sim 14 \mathrm{~km}$

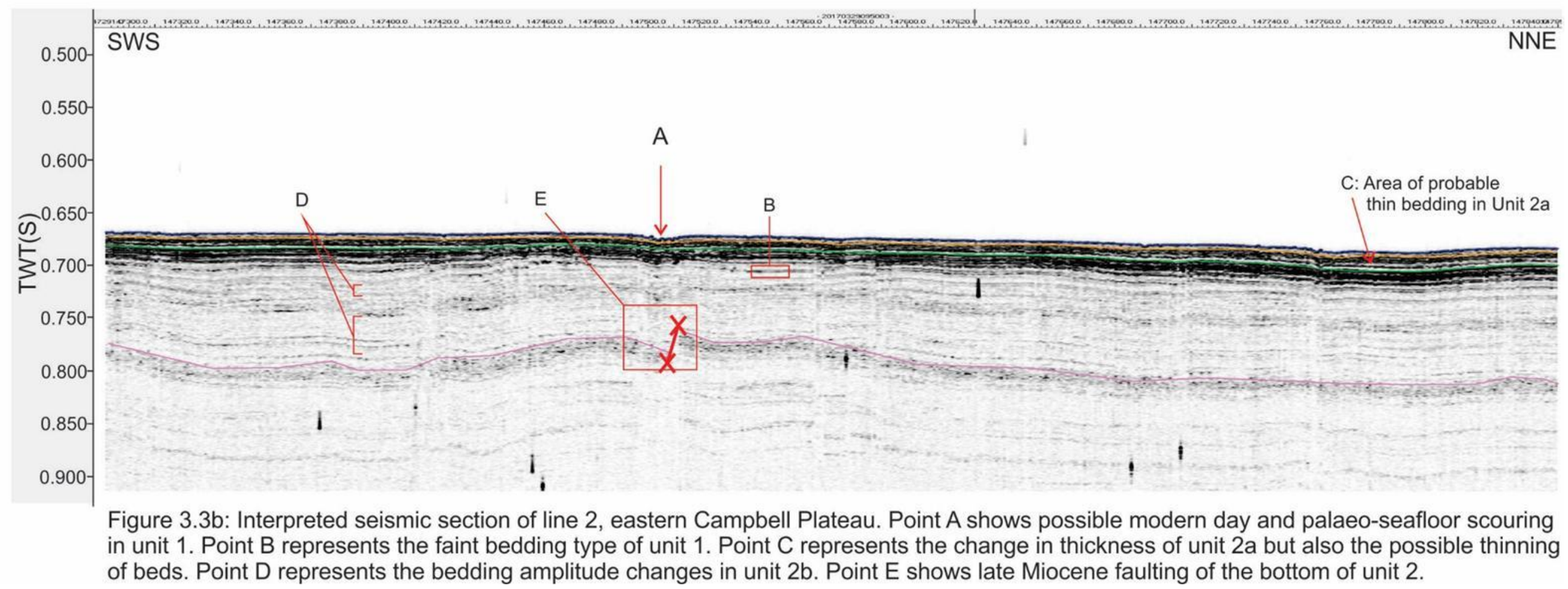




\subsection{4: Interpretation}

Line 2 displays Units that have been subjected to little deformation throughout their deposition, the line can be broken down two sections of differing amplitudes, with the top 0.025 TWT being generally higher amplitude material ( 0.7 to $0.9 \mathrm{~A})$, with the remainder 0.25 TWT being fainter bedding and having slightly more undulation. The stratigraphy of this line can be directly linked to the ODP1120 core on line 1 immediately to the north. From this connection, it can be made that unit 1 is likely Late Pleistocene in age and is largely made up of calcium carbonate suggested by cores SO136-55 and Y14 and F108 (Neil et al., 2004). This can be further shown in the nearby surface core: F108 (see figure 3.1). The F108 surface core shows that the top $205 \mathrm{~cm}$ of sediment near Pukaki Rise is $90.5 \%$ carbonate and is predominantly Globigerina ooze (see Appendix, Sediment Sample Types: below 500m). Unit 2a is likely the continuation of unit 2 seen in the ODP1120 core, this puts the unit at an age of Miocene and having a lithology that is dominated by foraminifera nannofossil ooze (Carter et al., 1999). Because of this linkage to ODP1120, this Unit also represents the unconformity found in ODP1120 between units' 1 and 2 . Unit $2 b$ is likely the continuation of unit 3 in the ODP1120 core, this then suggests that the lithology is similar in nature to unit 1 (Carter et al., 1999). The faulting interpreted in unit $2 \mathrm{~b}$ most probably occurred after deposition and due to the fault penetrating the upper layers it can be assumed that this occurred during the late Miocene. This is ascertained through ODP1120 unit 3 being dated a late Miocene in age (Carter et al., 1999).

\section{3: Line 3 (Southeast shelf edge Campbell Plateau)}

\subsection{1: Line Description}

Line 3 is located near the southeast edge of Campbell Plateau in approximately $500 \mathrm{~m}$ water depth and in an NW to SE orientation (see figure 3.1). This line is generally broken up into two sections: a high amplitude top section with strong reflectors and weak amplitude half with weaker patchy reflectors.

\subsection{2: Reflector Descriptions}

Seafloor (Blue reflector): Is a strong reflector $(\sim 1.00 \mathrm{~A})$ that has little undulation and begins at a depth of $\sim 0.690$ TWT. The seafloor in this area is like others in the vicinity 
having possible small-scale current scours along the surface (see figure 3.4b, point A), the seafloor also has a Damuth scale of 1B-B.

Orange reflector: Is a moderate to a strong reflector (ranging from $\sim 0.33 \mathrm{~A}$ to $\sim 0.71 \mathrm{~A}$ ), it is lightly undulating, laterally continuous and begins at a depth of 0.695 TWT.

Green reflector: Is a moderate strength reflector ( $0.5 \mathrm{~A})$, with little undulation throughout, it begins at a depth of $\sim 0.715$ TWT and is laterally continuous.

Pink reflector: This is a moderate to a weak reflector ( $\sim 0.02 \mathrm{~A}$ to $0.3 \mathrm{~A})$, it is lightly to moderately undulating throughout, laterally continuous and begins at a depth of $\sim 0.780$ TWT.

Brown reflector: is a very faint reflector (up to $\sim 0.11 \mathrm{~A}$ ) that begins at a depth of $\sim 0.830$ TWT. This reflector is lightly undulating and laterally continuous throughout.

\subsection{3: Unit Descriptions}

Unit 1 (Blue to orange reflector): This unit is well bedded throughout with reflectors being relatively well defined, having an amplitude of $\sim 0.24 \mathrm{~A}$ and a general thickness of $\sim 0.005$ TWT. Much of this unit is well defined and laterally continuous.

Unit 2 a (Orange to green reflector): This unit is seen to be more faintly reflecting than the upper unit with the units' top being more undulating. On the centre of the picked horizon, there is a possible sag present, which has a depth change of 0.011 TWT (see figure $3.4 \mathrm{~b}$, point B), with further small-scale sags throughout the unit. The reflectors within this unit is generally faint (up to 0.24A) and thin and patchy (only up to 0.002 TWT thick). Throughout, there are anomalously high amplitude ( $\sim 0.6 \mathrm{~A})$ reflectors (see figure $3.4 \mathrm{~b}$, point $\mathrm{C}$ ), reflectors are better defined in the north.

Unit $2 b$ (Green to pink reflector): The unit displays generally faint/weak patchy reflectors having a general maximum amplitude of $\sim 0.24 \mathrm{~A}$, however thickness of this interpreted unit is relatively consistent at $\sim 0.09$ TWT. The unit also displays the similar sag is seen in the previous unit, however, is more rounded and only has a depth change of 0.01 TWT (see figure $3.4 \mathrm{~b}$, point $\mathrm{D}$ ). reflectors in this unit follows a similar trend to other units, with it being more defined in the north of the unit.

Unit 2c (Pink to brown reflector): A faint unit that is lightly undulating to the edges of the line becoming moderately undulating in the centre of the line. The main feature of this unit is the central structure, which rises to $\sim 0.830$ TWT and has a slight increase in 
amplitude to $\sim 0.3 \mathrm{~A}$ (see figure $3.4 \mathrm{~b}$, point E). Overall, this unit, however, displays little penetration past the top reflector. 
$\sim 31.2 \mathrm{~km}$

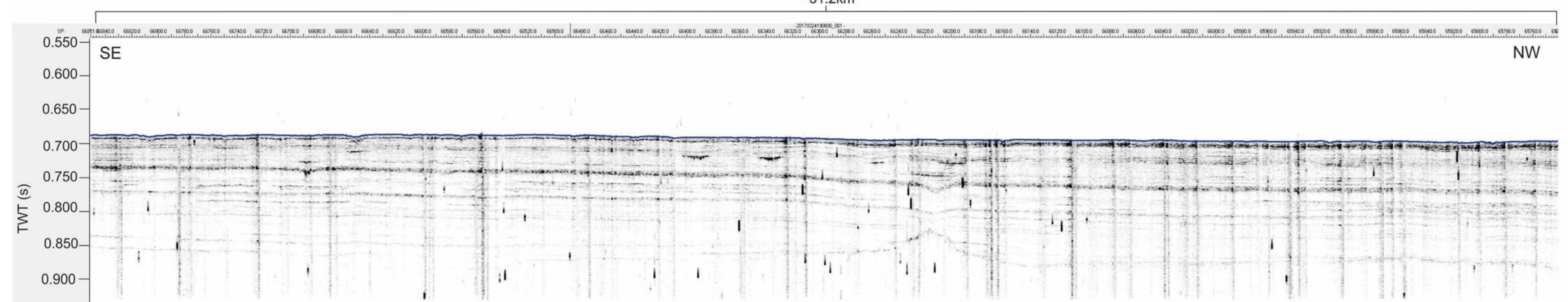

Figure 3.4a: Uninterpreted seismic section line 3, southeast shelf edge Campbell Plateau.

$\sim 31.2 \mathrm{~km}$

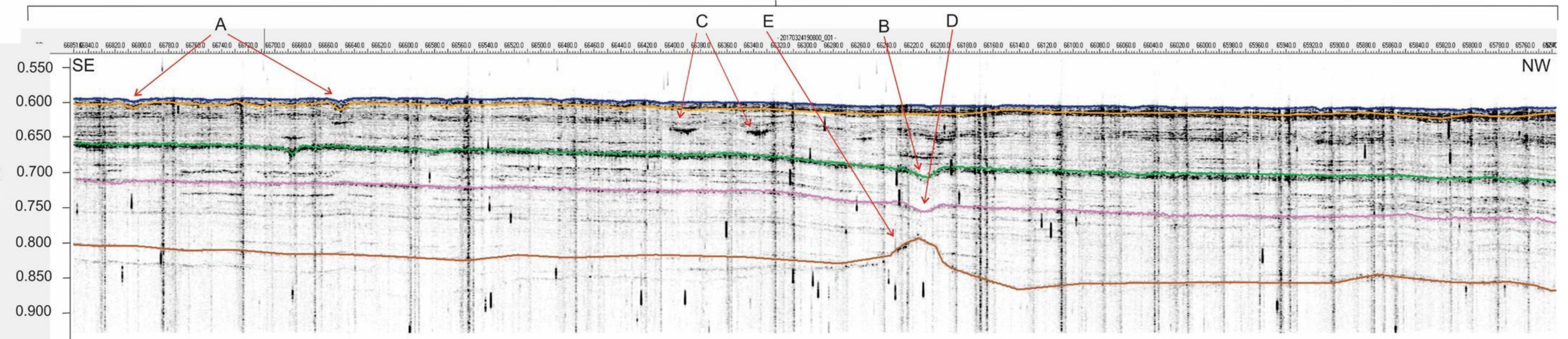

Figure 3.4b: Interpreted seismic section of line 3, southeast shelf edge Campbell Plateau. Point A represents modern day and palaeo-seafloor scours in unit 1. Point B represents a possible sediment sag within unit 2a. Point $C$ represents examples of several high amplitude material lenses within unit 2a. Point $D$ represents further possible sediment sags in unit $2 b$.

Point $E$ represents a possible fluid or gas escape structure within unit $3 a$. 


\subsection{4: Interpretation}

In this line, there is also a series of possible sediment infill structures that are located underneath a slight high at the base of unit 2c. This could be possible evidence of smallscale gas pockets, due to a drop in amplitude surrounding these lows, this could further indicate that the high at the base of unit $2 \mathrm{c}$ is possibly a small-scale gas escape structure. These features may also represent persistent erosion of an area via ocean currents since the deposition of the middle section of this line, with the slight high was seen in unit $2 \mathrm{c}$ being a slight basement high.

\section{4: Line 4 (Eastern shelf edge of Campbell Plateau)}

\subsection{1: Line Description}

Line 4 is located on the eastern shelf edge of Campbell Plateau (see figure 3.1). The section begins at a depth of 0.690 TWT and is approximately in $500 \mathrm{~m}$ of water and goes from SE to NW direction. The lines' units are largely planar in nature, the line can be generally broken down into two sections: the high amplitude well-defined top, then the lower section comprised of low amplitude patchy reflectors.

\subsection{2: Reflector Descriptions}

Seafloor (Blue reflector): This is a strong reflector $(\sim 1.00 \mathrm{~A})$ that has little undulation and begins at a depth of $\sim 0.690$ TWT. The seafloor in this area is like others in the vicinity having possible small-scale current scours along the surface (see figure $3.5 \mathrm{~b}$ ), the seafloor also has a Damuth scale of 1B-B.

Orange reflector: Is a moderate to a strong reflector (ranging from $\sim 0.33 \mathrm{~A}$ to $\sim 0.71 \mathrm{~A}$ ), it is lightly undulating, laterally continuous and begins at a depth of 0.695 TWT.

Green reflector: Is a moderate strength reflector $(\sim 0.5 \mathrm{~A})$, with little undulation throughout, it begins at a depth of $\sim 0.715$ TWT and is laterally continuous.

Pink reflector: This is a moderate to a weak reflector ( $\sim 0.02 \mathrm{~A}$ to $0.3 \mathrm{~A})$, it is lightly to moderately undulating throughout, laterally continuous and begins at a depth of $\sim 0.780$ TWT.

Brown reflector: This is a very faint reflector (up to $\sim 0.11 \mathrm{~A}$ ) that begins at a depth of $\sim 0.830$ TWT. This reflector is lightly undulating and laterally continuous throughout. 


\subsection{3: Unit Descriptions}

Unit 1 (Blue to orange reflector): In this unit, a series of low amplitude reflectors $(\sim 0.09 \mathrm{~A})$ is present throughout the unit with a relatively consistent thickness of $\sim 0.004$ TWT (see figure 3.5b, point A). Overall, the reflectors in this unit are well defined and laterally continuous, however, are overall relatively thin.

Unit 2 a (Orange to green reflector): The main feature of this unit is the one consistent main series of reflectors in the centre of the unit, which has a thickness of 0.12 TWT and general thickness of $\sim 0.008$ TWT. Reflectors however apart from this very welldefined section is generally faint throughout, having an amplitude of $\sim 0.02 \mathrm{~A}$. In the west of the section there is possible infilling due to a probable paleo-scour in the lower section of the unit (see figure $3.5 \mathrm{~b}$, point $\mathrm{B}$ ).

Unit $2 b$ (Green to pink reflector): This is the thickest of all units, having a thickness of $\sim 0.065$ TWT. Overall, the main features of this unit are that there is little penetration with faint and patchy reflectors throughout, with the strongest reflection being an amplitude of $\sim 0.2 \mathrm{~A}$ (see figure $3.5 \mathrm{~b}$, see point $\mathrm{C}$ ).

Unit 2c (Pink to brown reflector): The unit has very faint reflectors with little overall subsurface features with the maximum amplitude of the reflectors being $\sim 0.03 \mathrm{~A}$. Reflectors within this unit is also laterally discontinuous (see figure $3.5 \mathrm{~b}$, point $\mathrm{D}$ ) 


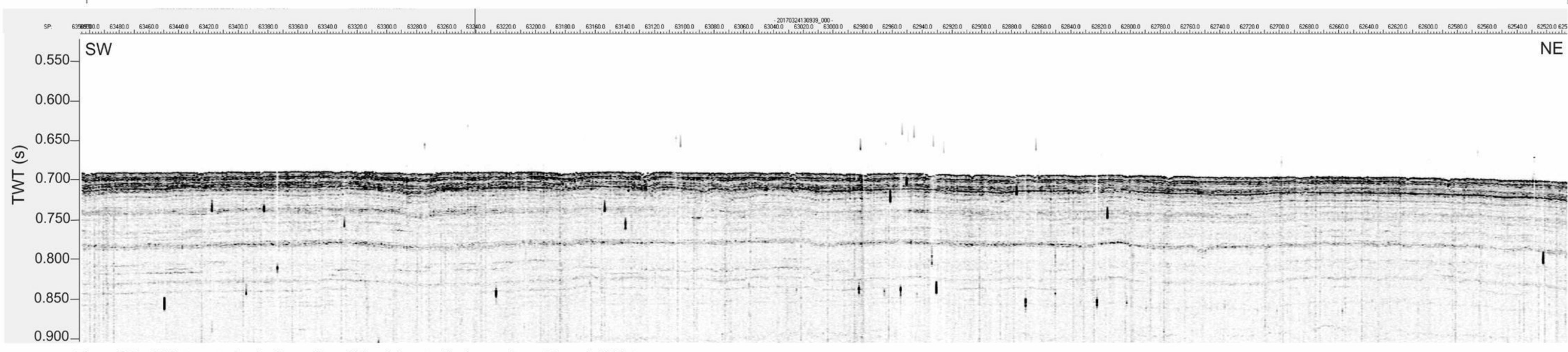

Figure 3.5a: Uninterpreted seismic section of Line 4, located in the southeast Campbell Plateau.

\section{$\sim 27 \mathrm{~km}$}

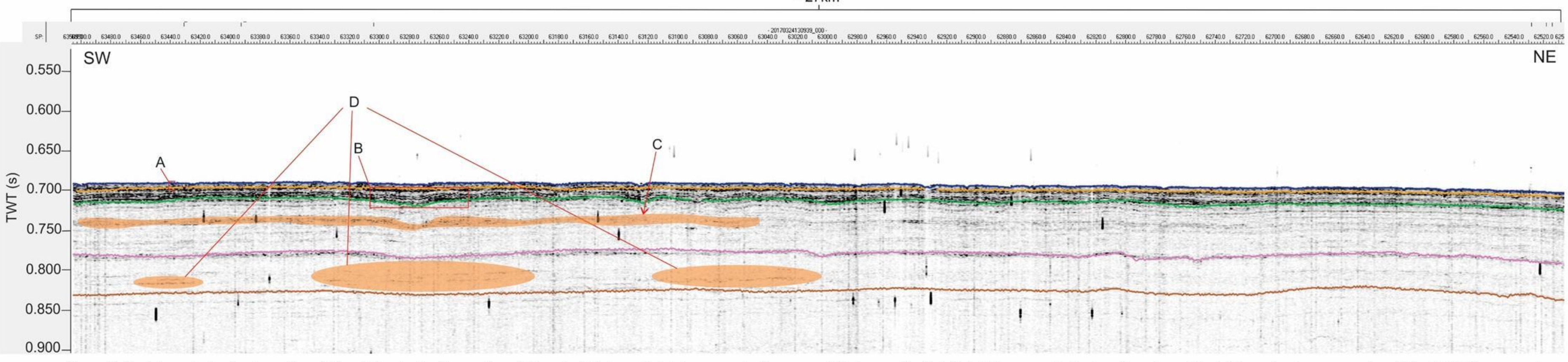

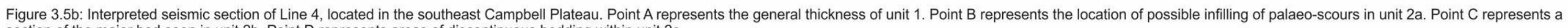
section of the major bed seen in unit $2 \mathrm{~b}$. Point $\mathrm{D}$ represents areas of discontinuous bedding within unit $2 \mathrm{c}$. 


\subsection{4: Interpretation}

This seismic section has generally seen little deformation to the strata during and after deposition. This would indicate that this area of the plateau has remained relatively quiescent compared to the surrounding lines suggesting that possibly the eastern shelf edge of the plateau had little in The age of these Units can be attained through the linkages with nearby seismic lines which have been tied to ODP1120. Unit 2c is possibly Early to Middle Miocene in age. Unit $2 \mathrm{~b}$ is possibly Middle to mid-Late Miocene. Unit 2a is likely Late Miocene and unit 1 is Pleistocene in age, also supported by core Y14.

\section{5: Line 5 (Northwest of Campbell Island)}

\subsection{1: Line Description}

Line 5 is in the northwest of Campbell Island (see figure 3.1) and is in approximately $500 \mathrm{~m}$ water depth with the seafloor starting at a depth of $\sim 0.555$ TWT. The high amplitude of the uplifted unit in the middle of the line distinguishes the line.

\subsection{2: Reflector Descriptions}

Seafloor (Blue reflector): This is seen as a craggy strong reflector ( 0.93-1.0A), lightly undulating, seafloor scour in the south of the Unit, goes from a depth of 0.555 TWT to 0.567 TWT, with several smaller scours in the north (see fig 3.6b, point A). The seafloor in this area has a Damuth scale of 1B-A.

Orange reflector: Is a moderate strength reflector (up to $\sim 0.55 \mathrm{~A}$ ) that is moderately undulating throughout and generally follows the same pattern as the above reflector, this reflector varies in depth from $\sim 0.557$ to $\sim 0.642$ TWT.

Green reflector: This reflector is a light to a moderate strength reflector $(\sim 0.41 \mathrm{~A})$ that is highly laterally discontinuous and is found at TWT of $\sim 0.610$ to $\sim 0.655$.

Pink reflector: This reflector is a light reflector $(\sim 0.15 \mathrm{~A})$ that is very lightly undulating and is very laterally discontinuous. and is found at TWT of $\sim 0.600$ to 0.670 .

Brown reflector: This very strong reflector $(\sim 0.5$ to $1.0 \mathrm{~A})$ is highly undulating across its entire length and is found at TWT of $\sim 0.615$ to 0.720 . 
Purple reflector: Is a moderate reflector ( $\sim 0.3$ to $0.4 \mathrm{~A})$ that is light undulating and is largely laterally discontinuous, separated by the possible volcanic or bedrock high in the centre of the line.

\subsection{3: Unit Descriptions}

Unit 1 (Blue to orange reflector): This unit displays faint bedding throughout ( 0.07A), however, this could possibly be subunits. The unit is also seen to be eroded in the south due to the seafloor scouring (see figure $3.6 \mathrm{~b}$, point $\mathrm{A}$ ).

Unit $2 a$ (Orange to green reflector): This unit displays little bedding and structure, it also has evidence of seafloor scouring (see figure 3.6b, points A \& B), with a slight discontinuity along with the orange reflector due to heavy surface scouring of the seafloor (see figure 3.6b, point A). The bottom of the unit displays the most variability with a possible high amplitude lens or drape that is $\sim 0.44 \mathrm{~A}$ in strength (see figure $3.6 \mathrm{~b}$, point C).

Unit $2 b$ (Green to pink reflector): This unit has very faint bedding in its most prominent section (see figure 3.6b, point D) that has a low amplitude of ( 0.04 to $0.35 \mathrm{~A}$ ), apart from this faint bedding, there is little other structure.

Unit 2c (Pink to brown reflector): This unit exhibits a large change in height in the centre of the line where it rises from 0.653 TWT to 0.622 TWT. This rise is possibly volcanic in nature due to the very high amplitude ( 0.8 to $1.00 \mathrm{~A})$ at depth, also due to the lack of faults seen surrounding this high, rule out the possibility of it being a basement rock high (See figure 3.6b, point D). In the north of this unit, there is the evidence of faint bedding (up to $\sim 0.4 \mathrm{~A}$ ) throughout the unit, this appears to possibly fine upslope and then reappear past the high amplitude rise to the south (see figure $6 \mathrm{~b}$, points E).

Unit $3 a$ (Brown to purple reflector): This unit is separated into two parts, split by the possible volcanic high in the centre of the line. The unit displays faint bedding (up to $\sim 0.4 \mathrm{~A}$ ) upslope to the NNW (see figure 3.6, point F), with no apparent bedding to the SSE. 

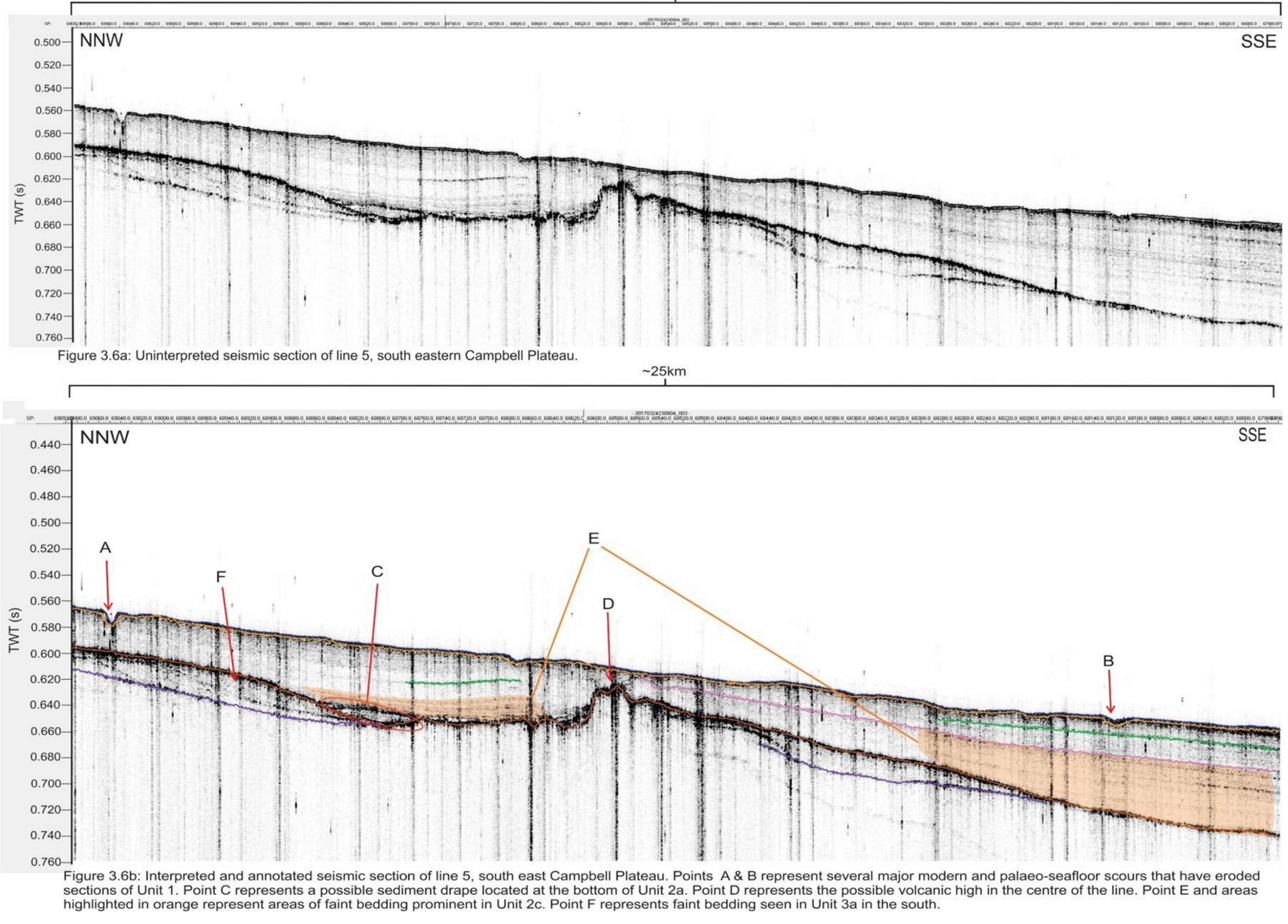


\subsection{4: Interpretation}

This section displays the possible nature of the sub-surface volcanism or basement bedrock of Campbell Plateau. The section appears to have the possible uniform deposition, with little influence of deformation from tectonic processes, however, this could be likely due to the lack visibility due to the low amplitude within the units this also remains uncertain. The units in this line can be linked to the nearby surface core D173 to the NW of this line (see figure 3.1). These linkages to the nearby surface core D173 taken by Summerhayes (1969), that unit 1 is likely Globigerina ooze, however, this has not been dated.

The first feature to form in this line was likely the centre volcanic feature, due to the nature of the sediment deposition and the distribution of possible volcanic material. However, this feature may also represent elevated bedrock, with the high amplitude likely attributed erosion, with the high itself possibly representing a hiatus. The possible volcanic feature is shown through the spread of high amplitude material across the line and the deposition of the beds near the possible volcano suggest that this feature formed first, and the sediments were deposited over top and around it. With the line's proximity to Campbell Island, the age of this volcano could be linked to the inception of the late Miocene volcanism that led to the formation of alkali olivine basalts (Adams et al., 1979), which in turn have led to the formation of this structure.

\section{6: Line 6 (East of Auckland Islands)}

\subsection{1: Line Description}

Line 6 is located to the east of Auckland Islands in the western section of Campbell Plateau (see figure 3.1). The line is in relatively shallow water at $\sim 150 \mathrm{~m}$ water depth. The line overall displays little penetration past the seafloor with much of the penetration to lower units seen in areas where sediment is preserved. 


\subsection{2: Reflector Description}

Seafloor (Blue reflector): This is a very strong reflector $(\sim 0.8$ to $1.0 \mathrm{~A})$ that is moderately undulating throughout. The reflector displays a Damuth scale of $1 \mathrm{~B}-\mathrm{A}$ and appears to be heavily eroded throughout.

Orange reflector: This is a strong very shallow reflector $(\sim 0.8 \mathrm{~A})$. This follows closely the blue reflector. This reflector is highly undulating and laterally discontinuous, being only present in the central sections of the line.

Green reflector: This is moderately strong to a strong reflector ( $\sim 0.7$ to $0.8 \mathrm{~A})$ that is also moderately undulating; however, it is slightly more laterally continuous where present. This reflector follows a similar pattern to the prior layer with it only being present in sections where sediment is preserved.

\subsection{3: Unit Descriptions}

Unit 1 (Blue to orange reflector): This unit is very thin, with a maximum thickness of $\sim 0006$ TWT. This unit is also very discontinuous and heavily eroded throughout (see figure $3.7 \mathrm{~b}$, points $\mathrm{A}$ and $\mathrm{B}$ ). In the northern section of the unit, the unit pinches out against the top reflector (see figure $3.7 \mathrm{~b}$, point $\mathrm{C}$ ). The fact that the unit is only present where sediment is preserved suggests that there has been heavy erosion around the Auckland Islands throughout much of the Pleistocene.

Unit 2 a (Orange to green reflector): This unit also follows a similar trend to that of the above unit with the unit being largely discontinuous and undulating. This unit is slightly thicker were present at $\sim 0.01$ TWT at thickest. Although this unit does show slightly more laterally continuity, where present. This unit has possible patchy beds within it that are of highly reflective material (see figure $3.7 b$, point $\mathrm{D}$ ). 


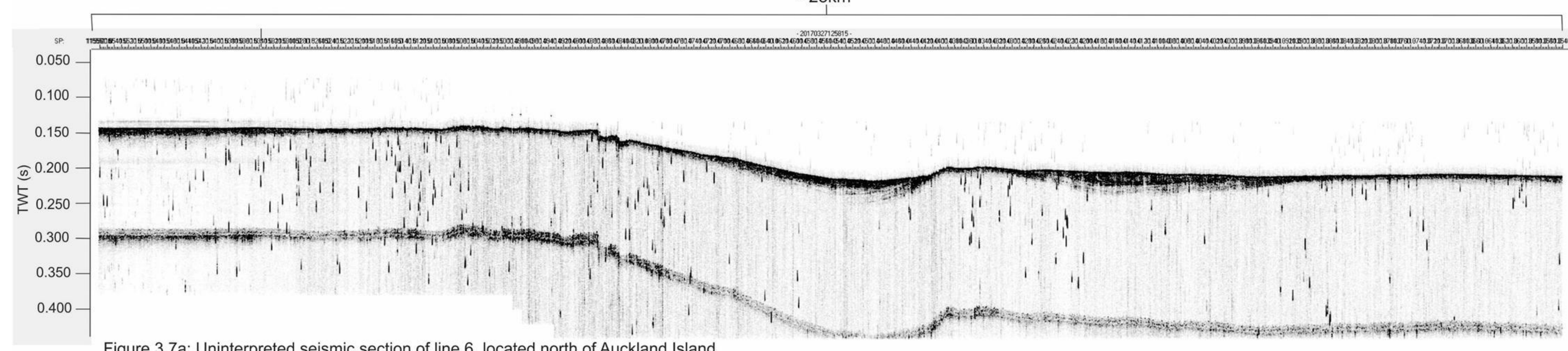

Figure 3.7a: Uninterpreted seismic section of line 6, located north of Auckland Island.

$\sim 25 \mathrm{~km}$

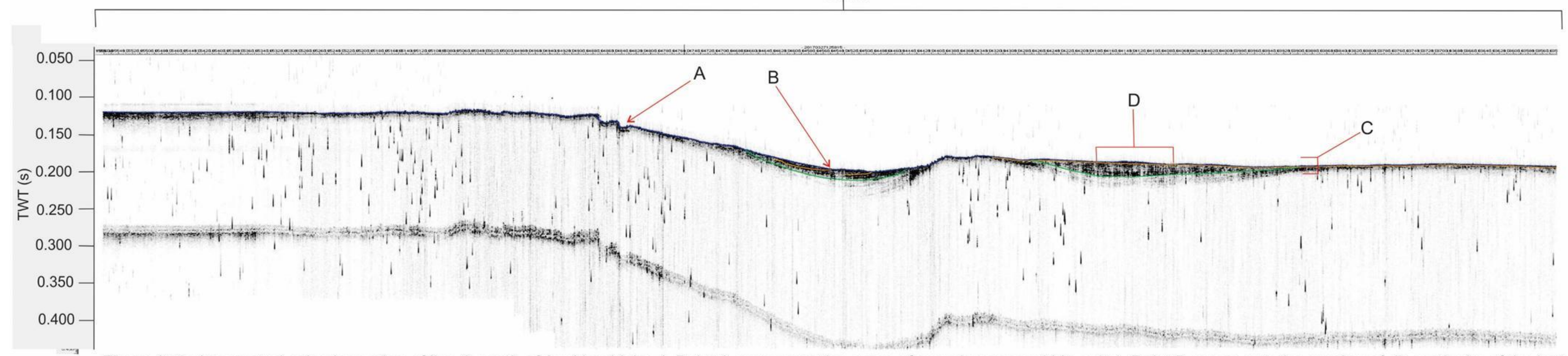

Figure 3.7b: Interpreted seismic section of line 6, north of Auckland Island. Point A represents the areas of scouring seen within unit 1 . Point B represents the erosion of discontinuity of the bottom reflector of unit 1. Point $\mathrm{C}$ represent the pinch out point of unit 1. Point $\mathrm{D}$ represents the possible patchy bedding represented in Unit 2. 


\subsection{4: Interpretation}

This section displays what is characteristic of the seismic sections in areas close to the several islands that dot the surface of the Campbell Plateau. This line shows the extent of the erosion in these areas, suggesting that since the expulsion of these islands throughout the Miocene. The pinching of sediments in units 1 and 2 suggest that topographic control or due to intense erosion of sediment. The erosion of the units is further shown due to the position of the line relative to ocean current positions both paleo and modern day.

\section{7: Line 7 (North-western Campbell Plateau)}

\subsection{1: Line Description}

Sub-bottom profile line 7 is in the north-west section of Campbell Plateau, approximately $120 \mathrm{~km}$ to the south-east of Stewart Island. The segment is located off the continental shelf; it exhibits heavy erosion through the stepped appearance given in the seafloors' expression and the subsurface. In each of these steps, there is evidence of where sediment is built up where erosion is very apparent. This line located at a depth that varies from $\sim 0.83$ TWT at the shallowest, to a deepest of $\sim 1.07$ TWT at the bottom of the slope.

\subsection{2: Reflector Descriptions}

Seafloor (Blue reflector): The seafloor in this area displays the characteristics that are somewhat typical of the rest of the Campbell Plateau, a strong reflector $(\sim 0.7 \mathrm{~A})$ that is light to moderately undulating. Throughout the seafloor, there is evidence of high amounts of erosion (see figure $3.8 \mathrm{~b}$ ); the seafloor in this section has a Damuth scale of 1B-C.

Orange reflector: This reflector is seen as a moderate strength reflector ( $\sim .5$ amplitude at the highest), that is high to moderately undulating in the west to changing to rolling light undulations in the eastern part of the section.

Green reflector: This is a moderate to weak strength reflector $(\sim 0.3 \mathrm{~A})$, it is located at depth of $\sim 0.85$ TWT in the west, going down to a depth of $\sim 1.060$ TWT in the far eastern edge of the slope. 
Pink reflector: This is a moderate to a weak patchy reflector $(\sim 0.2 \mathrm{~A})$, it begins at a depth of $\sim 0.880$ TWT in the west, in the east having the deepest depth of $\sim 1.080$ TWT.

Brown reflector: Is a very patchy and segmented reflector, its reflective strength varies from moderate to strong and is moderately undulating where present. It is present across the whole segment; however only where seismic penetration allows (see fig 3.8b, point A) varies from a depth of $\sim 1.08 \mathrm{TWT}$ on the western slope edge and then down to a maximum of $\sim 1.195$ TWT on the eastern slope.

Purple reflector: This is a very faint reflector ( $0.2 \mathrm{~A}$ at highest) that is intermittent throughout the line and has little undulation throughout.

\subsection{3: Unit Descriptions}

Unit 1 (Blue to orange reflector): This unit is located at a depth that varies from $\sim 0.840$ TWT at the highest, down to $\sim 1.07$ TWT downslope at the lines deepest section. In the western section of the line, unit 1 appears to mount a very low reflective material then thins and pinches out against the seafloor and unit 2 (see figure $3.8 \mathrm{~b}$, point $\mathrm{B}$ ). The eastern section of this line displays unit 1 as mounting the sedimentary feature and following the change in slope. Within these sedimentary structures, unit 1 appears to have consistent thin bedding with the highest amplitude being $\sim 0.3 \mathrm{~A}$ and the highest thickness being of $\sim 0.002$ TWT. The strength of the reflector also stays relatively the same ( 0.2A-0.4A) and follows a similar pattern of erosion to the seafloor.

Unit 2a (Orange to green reflector): This unit has little undulation in the western section and is distinctly planar in the western section, it then pinches out against unit 1 in the west (see figure 3.8b, point $\mathrm{C}$ ). The eastern section displays the trend like upper units with it following sedimentary structures and the structure of the area downslope and is overall laterally discontinuous across the entire section. Bedding within this unit varies in strength and style, in the west the bedding is weaker ( 0.15A-0.2A) and more planar, whereas in the east the bedding style is heavily influenced by the bathymetry and sedimentary structures. This influence is shown through the beds having a more rolling nature and a slight increase in amplitude across the beds (up to $\sim 0.35 \mathrm{~A}$ ). Due to the planar nature of the unit in the west, it is inferred to be a possible erosional surface due to the scouring of the lower layer. This unit appears to have patchy and chaotic bedding throughout the western section that has an amplitude variation of $\sim 0.3 \mathrm{~A}$ to 0.01A, potential lenses of higher reflective material (see figure 3.8b, point D). 
Unit $2 b$ (Green reflector to pink reflector): This unit shows little undulation throughout the section; it varies from east to west. In the west, the layer is planar, pinches out against the unit 1 , and is located at the top of the slope (see figure $3.8 \mathrm{~b}$, point $\mathrm{E}$ ). However, in the east unit $2 \mathrm{~b}$ mounts the sedimentary structures and follows the pattern of bathymetry downslope (see figure $3.8 \mathrm{~b}$ ). Bedding in the eastern section of the segment where it is preserved in the sedimentary structures, the unit is laterally discontinuous across the entire segment.

Unit 2c (Pink reflector to brown reflector): This unit has variation between the western and eastern sections of the unit. On the western section, the strength of the reflector is moderate in strength and patchy. There is the possibility of possible fluid escape structures, due to the positioning of possible pot marks on the seafloor (see figure $3.8 \mathrm{~b}$, point $F$ ). On the eastern downslope section of this segment unit $2 b$ strength varies from weak to strong in reflection strength, it is also part of a possible erosional surface under a possible contourite deposit (see figure $3.8 \mathrm{~b}$, point $\mathrm{G}$ ).

Unit $3 a$ (Brown to purple reflector): This unit has little subsurface reflectors, the prevalent feature in this unit is two possible fluid escape structures on the western slope edge that is in line with the upper possible fluid escape structures that extend to the surface and sees an amplitude change of $\sim 0.1 \mathrm{~A}$ to $0.01 \mathrm{~A}$ in the possible structure 
$\sim 37 \mathrm{~km}$

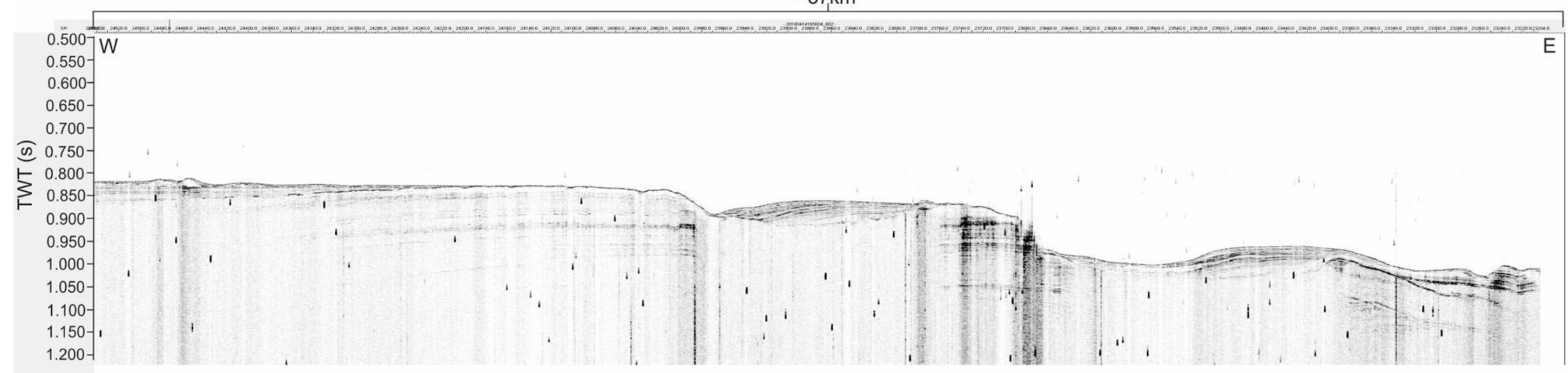

Figure 3.8a: Uninterpreted seismic line 7, northwest Campbell Plateau.

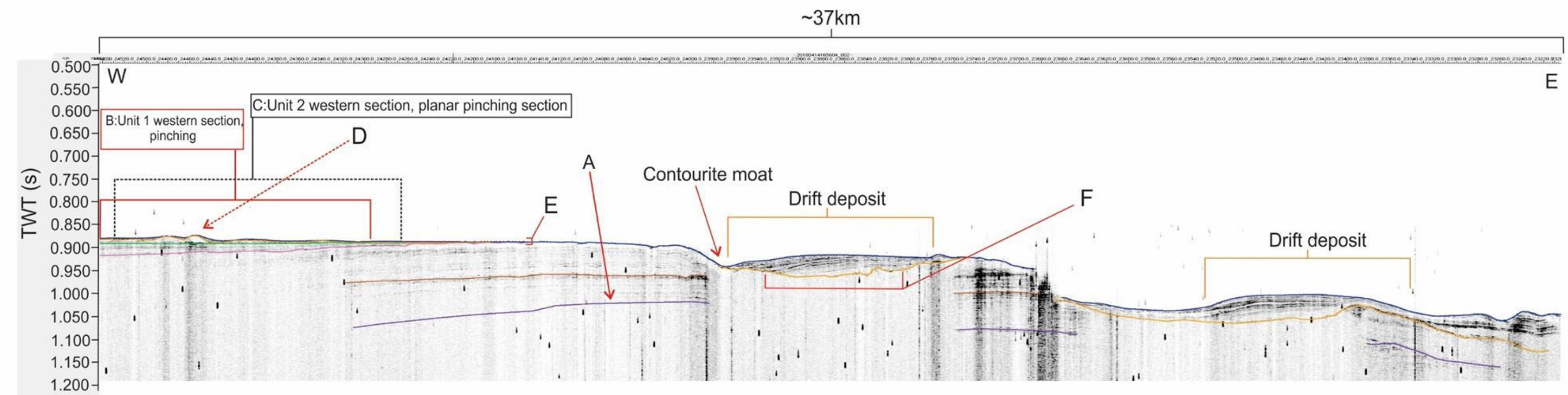

Figure 3.8b: Interpreted seismic line 7, NW Campbell Plateau. Point A represents example of where the purple reflector is present. Point B represents the pinch out of unit 1. Point $C$ represents the pinch out of unit 2. Point $D$ represents area of highly reflective material in unit 2. Point $E$ represents the pinch out area of unit $2 \mathrm{a}$. Point $\mathrm{F}$ represents the possible erosional surface attributed to unit $2 \mathrm{~b}$. 


\subsection{4: Interpretation}

Throughout this section, there is very clear evidence of heavy erosion across the entire length. The stepped nature follows the bathymetry, however on the west of the segment is more planar with several possible small-scale pot marks in the seafloor, these occur where near-surface sub-surface units are not present.

This segment shows a large amount of variation in both through sedimentary controls and possible oceanographic controls. This segment appears to have gone through several cycles of change with firstly soon after the deposition of the Units in this segment there was possible compression happened due to the presence of undulation within the units on a variety of scales. Unit $2 \mathrm{a}$ and $2 \mathrm{~b}$ appear to be eroded at different stages, with unit $2 b$ being near fully eroded throughout much of the segment, this then led to the deposition then erosion of unit 2a. The erosion of unit $2 \mathrm{a}$ also appears to have been eroded in a " $u$ " shaped fashion, which then had the deposition of the upper units above this, which were also subject to erosion. The style of the erosion upper three units varies from across the segment, the style of sedimentation that has been deposited on top of unit $2 \mathrm{~b}$ in the centre and eastern edge of the segment is indicative of contourite deposits (see Chapter 1 for reference). The style of contourites seen in this segment are likely analogues of small patch drift deposits due to their rather short nature, being $\sim 10 \mathrm{~km}$ at longest, that are likely calcareous sandy or calcareous bioclastic contourites (Stow \& Faugères, 2008) due to the nature of the surrounding sediment and bedding style of the contourites. The width and general geometry of these contourites, however, are unknown due to the lack of a crossing seismic line.

\section{8: Line 8 (Northern Campbell Plateau, north of $\underline{\text { Pukaki Rise) }}$}

\subsection{1: Line Descriptions}

Line 8 is in the northern section of Campbell Plateau, to the south of Pukaki Rise (see figure 3.1). Line 8 is in the central northwest of the Campbell Plateau in approximately $1500 \mathrm{~m}$ water depth. It is located at a depth of 1.698 TWT to the seafloor and can be characterised by the large sediment wedge/ onlap surface that intersects the subsurface, on a large slope. The sediment wedge is higher in amplitude compared to the 
sedimentary packages that are above and below it. This line has little undulation throughout.

\subsection{2: Reflector Descriptions}

Seafloor (Blue reflector): Is a strong reflector ( 0.8 to $1 \mathrm{~A})$, that is lightly undulating throughout the entire section. The depth of this reflector varies from $\sim 1.807$ TWT upslope to 1.698 TWT downslope. The reflector displays a Damuth scale of 1B-A, with the reflector also displaying slight erosion on the upper slope (see figure $3.9 \mathrm{~b}$ ).

Orange Reflector: This is a strong to moderate strength reflector (0.79A to $0.5 \mathrm{~A})$, has little undulation, following a similar pattern to the blue reflector, it is also laterally continuous. The reflector begins at a depth of $\sim 1.7$ TWT.

Green Reflector: This is a moderate to a weak strength reflector ( $\sim 0.27$ to $0.4 \mathrm{~A})$, that begins at a depth of 1.708 TWT. The reflector is moderately undulating downslope and is laterally continuous.

Pink Reflector: This reflector is a moderate strength reflector $(\sim 0.7 \mathrm{~A})$ that begins at a depth of $\sim 1.1710$ TWT. The reflector is seen to have stronger undulations in the upslope north section and becomes more planar to the south.

\subsection{3: Unit Description}

Unit 1 (Blue to orange reflector): This unit has a generally low amplitude (0.2 to $0.4 \mathrm{~A})$ that slightly thickens downslope; changing from $~ 0.005$ TWT thickness upslope to $\sim 0.010$ TWT thickness downslope, the unit is also laterally continuous across the section. There appears to be quite a lot of possible interbedding with substantial alternating light and moderate amplitudes (see figure 3.9b, point A) that are more prevalent in the downslope section. This unit also sees more deformation upslope, with possible small-scale folds or compaction (see figure 3.9b, point B).

Unit 2 a (Orange to green reflector): Unit $2 \mathrm{a}$ is the thinnest of all units present in this line, having a relatively consistent thickness of $\sim 0.005$ TWT across its' entire length. Reflectors within this unit is very faint to not being present at all, suggesting a very low amplitude unit ( 0.1 to $0.2 \mathrm{~A})$ that is massive or is very finely bedded. Unit 2 a displays similar structural characteristics as unit 1; with it being more planar downslope, more deformed upslope, with possible small-scale folds, and paleo-scours (see figure 3.9b, point B). 
Unit $2 b$ (Green to pink reflector): Unit $2 \mathrm{~b}$ is the thickest all units seen in this section, with the thickest section being an onlap surface (see figure $3.9 \mathrm{~b}$, see the area highlighted in blue), having a thickness $<0.7$ TWT downslope. The bedding in this unit is very variable upslope and downslope. Upslope in this unit shows bedding this is generally moderately to faintly bedded ( 0.3 to $0.6 \mathrm{~A})$, with the bedding visible being constrained by the thickness (see figure $3.9 \mathrm{~b}$, point $\mathrm{B}$ ). Downslope unit $2 \mathrm{~b}$ the amplitude changes are large, with the most notable changes being attributed to increases in amplitude, thickness and number of possible beds. The amplitude changes show an increase in strength in the onlap surface to increase to 0.7 to $0.9 \mathrm{~A}$ (see figure $3.9 \mathrm{~b}$, point $\mathrm{C}$ ). Within the onlap surface, is a relatively large low amplitude bed that displays a thickness of $\sim 0.007$ TWT (see figure $3.9 \mathrm{~b}$, point $\mathrm{D}$, outlined in red). 
$\sim 29 \mathrm{~km}$
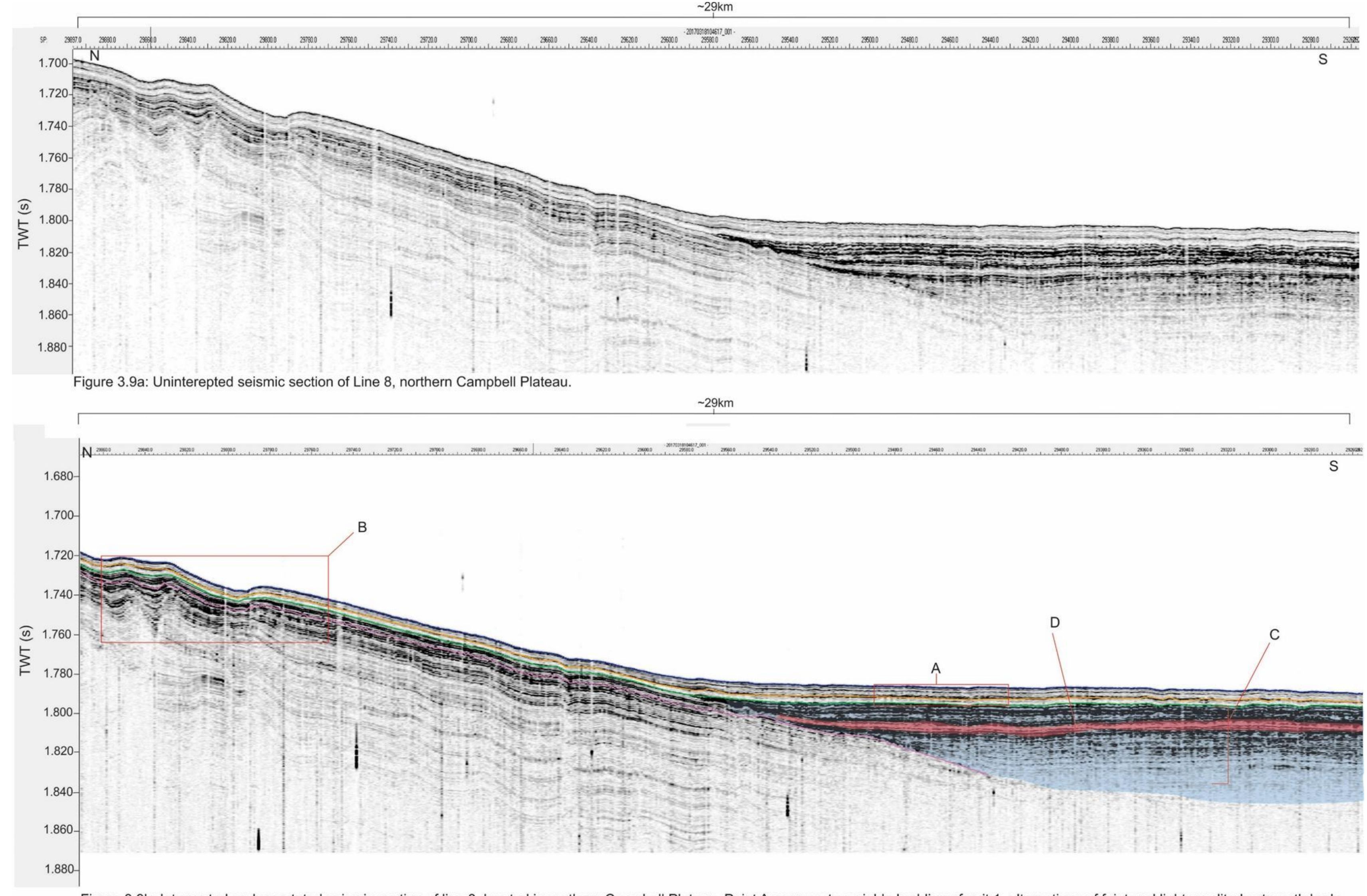

Figure 3.9b: Interpreted and annotated seismic section of line 8, located in northern Campbell Plateau. Point A represents variable bedding of unit 1, alternations of faint and light amplitude strength beds. Point $B$ represents the deformation and possible compression seen in unit $1,2 a$ and $2 b$. Point $C$ represents the bedding variability seen in the onlap surface. 


\subsection{4: Interpretation}

The nearest cores to this line are surface core F106 and ODP1120 (see figure 3.1 for localities), from ties to these cores it can be assumed that the age of unit 1 when tied to these cores, can be dated at approximately Pleistocene in age. This age is attained through the unit being tied to unit 1 in ODP1120 dated to Pleistocene in age, being made up of foraminifera nannofossil ooze (Carter et al., 1999). Core F106, collected by Summerhayes (1969) was dated to an age of Pliocene to Pleistocene and was made up of primarily globigerina ooze. Units $2 \mathrm{a}$ and $2 \mathrm{~b}$ in line 8 can possibly be tied to unit 3 in the ODP1120 core, giving an age of late Miocene. The descriptions given in this report also align with units $2 \mathrm{a}$ and $2 \mathrm{~b}$ descriptions particularly in the upslope portions of the units. In the upslope sections of line 8 , units $2 \mathrm{a}$ and $2 \mathrm{~b}$ display similar characteristics to the core samples of ODP1120 unit 3; with unit 3 is described as a weakly bedded ooze, which is comparable to that of possible faint to little bedding throughout much of unit $2 \mathrm{a}$ and the upslope portion of unit $2 \mathrm{~b}$.

\section{9: Line 9 (North of Pukaki Rise)}

\subsection{1: Line Description}

Line 9 is located directly North of Pukaki Rise . in approximately 1200m water depth (see figure 3.1). The section is primarily consists of faint beds that vary with intensity and thickness with an increase in slope. Much of the reflectors are well defined and continuous across the length of the line.

\subsection{2: Reflector Descriptions}

Seafloor (Blue reflector): Is a strong reflector $(\sim 1 \mathrm{~A})$ that has little undulation. There are small-scale channels in the south of the section (see figure 3.10b); the unit varies in depth from 1.684 TWT to 1.694 TWT and has a Damuth scale of 1B-1.

Orange reflector: This unit is strong to a moderate reflector ( 0.4-0.8A) that is lightly undulating and begins at a depth of $\sim 1.515$ TWT.

Green reflector: Is a moderate to weak strength reflector ( $\sim .2$ to $0.7 \mathrm{~A})$ that is very lightly undulating throughout, is laterally continuous.

Pink reflector: Weak reflector ( 0.02 to $0.1 \mathrm{~A})$ that is slightly undulating. The reflector has little penetration past the horizon top, 


\subsection{3: Unit Descriptions}

Unit 1 (Blue to orange reflector): Throughout this unit, there is patchy bedding with variable amplitude ( 0.05A to $0.71 \mathrm{~A})$, the channels formed from the seafloor above have also caused the partial erosion of the area immediately below the channel (see figure 3.10b). The thickness of the unit is relatively consistent being $\sim 0.020$ TWT thick across the section. Bedding in this unit is variable with bedding in the north being generally more defined and more laterally continuous; however, there is little amplitude change between north and south in this variation.

Unit 2 a (Orange to green reflector): This unit has lateral variability with thickness changes to the south (see figure 3.10b) with it thinning to the south going from $\sim 0.020$ TWT at the thinnest to $\sim 0.060 \mathrm{TWT}$. In the south of the section, there is generally better-defined beds, with more chaotic beds past the main seafloor channel. There is possible evidence of uplift or erosion past the seafloor channel. The most defined beds in this unit are generally $\sim 0.007$ TWT thick, with the presence of high amplitude lenses $(\sim 0.55 \mathrm{~A})$ (see figure $3.10 \mathrm{~b})$.

Unit $2 b$ (Green to pink reflector): This unit is overall relatively well bedded however there is slight penetration in the northern and southern ends of the line with faint bedding present with an amplitude up to $\sim 0.22 \mathrm{~A}$ (see figure $3.10 \mathrm{~b}$ ). The northern beds, where all units are thinner, have a slightly lower amplitude of $\sim 0.18 \mathrm{~A}$. In the centre of the unit however, there is little evidence for bedding due to lack of penetration.

Unit 2c (Pink reflector onwards): This unit is very faint overall ( 0.1A), displaying pockets of faint bedding throughout, which is more prevalent in the northern and southern sections of the unit (see figure 3.10b, points D1 and D2). 


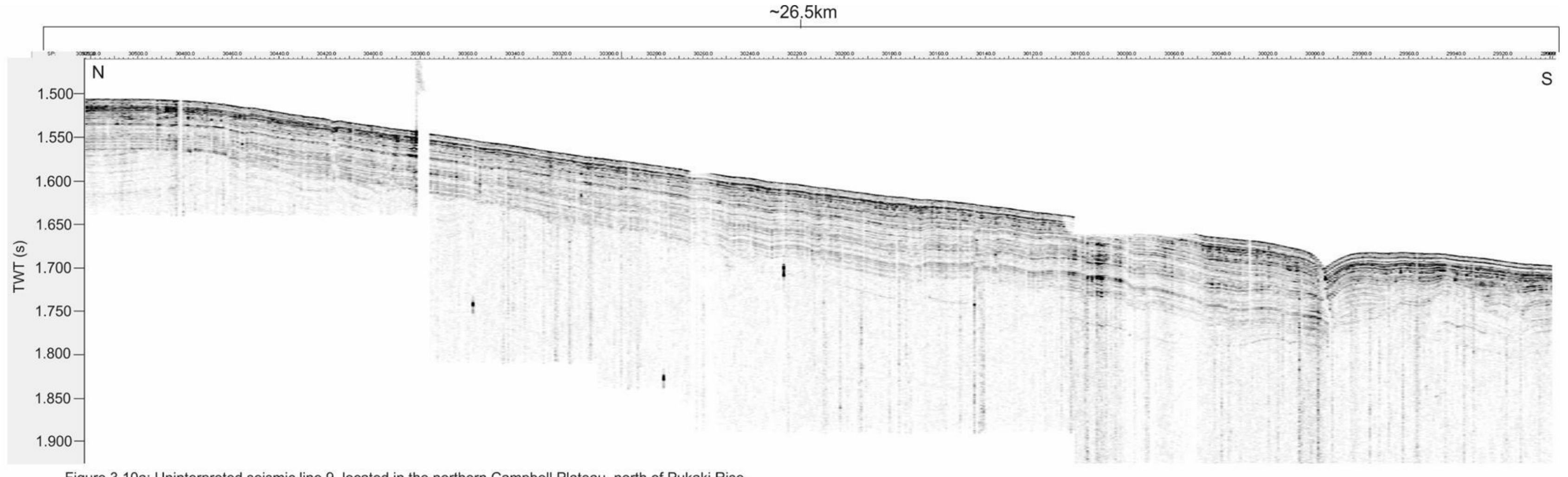

Figure 3.10a: Uninterpreted seismic line 9, located in the northern Campbell Plateau, north of Pukaki Rise

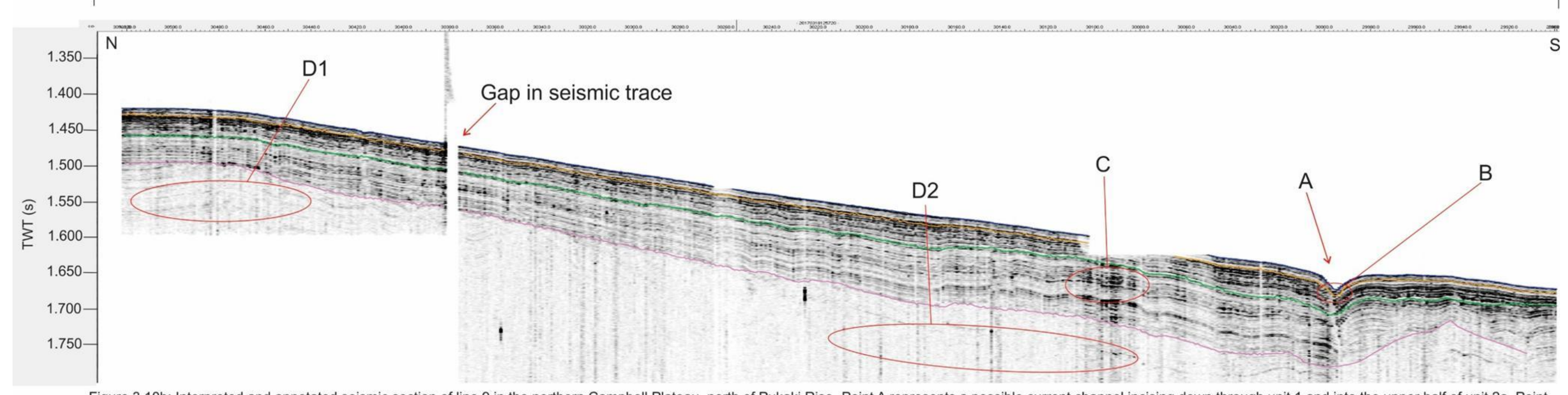

Figure 3.10b: Interpreted and annotated seismic section of line 9 in the northern Campbell Plateau, north of Pukaki Rise. Point A represents a possible current channel incising down through unit 1 and into the upper half of unit 2a. Point general faint bedding seen in unit $2 \mathrm{c}$ in the north and south respectively. 


\subsection{4: Interpretation}

This section has seen the classic deposition of sediments, with unit 2 being the oldest and the seafloor being the youngest. With ties to nearby lines, the ages of these sediments can be estimated: unit 2 being possibly Middle Miocene in age, unit 1a being possibly Late Miocene or Pleistocene in age, unit 1 is likely Pleistocene when tied with nearby seismic lines, borehole ODP1120 and the surface core F106. The evidence of the higher amplitude layers within unit $2 \mathrm{~b}$ suggest possible pockets of densely packed sediment. Throughout the line, there is clear evidence of surface erosion on all layers, particularly the seafloor. Given the proximity of the line to Pukaki rise, this may well be due to the circulation of the Pukaki Gyre.

\subsection{0: Line 10 (Eastern central Campbell Plateau)}

\subsection{1: Line Description}

Line 10 is located along eastern central Campbell Plateau and is $32 \mathrm{~km}$ in length, the line is located in $\sim 500 \mathrm{~m}$ water depth (see figure 3.1 ). The line exhibits classical sedimentation with little structural deformation, each of the horizons picked has visible swallow scouring, as per the conditions at the time of deposition.

\subsection{2: Reflector Descriptions}

Blue reflector: A strong reflector $(<1.00 \mathrm{~A})$, slightly to moderately undulating across its length, begins at a depth of approximately has a Damuth scale of 1B-B

Orange reflector: A strong reflector to moderate reflector in patches (0.4 to $0.8 \mathrm{~A})$, moderately undulating, laterally continuous.

Green reflector: Is a moderate strength reflector (0.6A), moderately undulating across its length, laterally discontinuous.

Pink reflector: A moderately strong to a strong reflector (0.6 to $0.9 \mathrm{~A})$, that is lightly undulating, and is laterally continuous across its length. 
Brown reflector: A strong reflector (0.8 to $1.00 \mathrm{~A})$, that is moderate to strongly undulating (increased in the Western end), is laterally continuous throughout the section.

Purple reflector: Is a weak to a moderately patchy reflector ( 0.2 to $0.5 \mathrm{~A})$, moderately undulating, is laterally discontinuous across the entire section.

\subsection{3: Unit Descriptions}

Unit 1 (Blue to orange reflector): This unit begins at a depth of approximately 0.725 TWT and ends at 0.735 TWT at its lowest point, giving the unit an approximate thickness of $\sim 0.010$ TWT. The unit is faintly bedded throughout and has a relatively low amplitude within the unit ( $\sim 0.2$ to $0.4 \mathrm{~A})$ on the beds. Throughout the unit, there are several scours that have affected the top and bottom of the unit in the same pattern (see figure 3.11b, points A and B). Scouring within this unit is stronger on the western section of the unit.

Unit 2 a (Orange to green reflector): This unit begins at a depth of $\sim 0.730$ TWT down to a depth of $\sim 0.735$ TWT. The top of the unit is well defined; however, the bottom of the unit is very discontinuous and broken. The overall the unit has little bedding and is dominantly low amplitude material ( 0.2A) throughout. In the eastern section there are possible fluid escape structures in the lower section of the unit (see figure $3.11 \mathrm{~b}$, point C).

Unit $2 b$ (Green to pink reflector): Unit $2 \mathrm{~b}$ begins at a depth of $\sim 0.735$ TWT down to 0.760 TWT. Within the unit there is faint and patchy bedding throughout that varies in amplitude from moderate strength at $\sim 0.7 \mathrm{~A}$ to $\sim 0.3 \mathrm{~A}$ (see figure $3.11 \mathrm{~b}$, point $\mathrm{D}$ ). A high amplitude bed is seen in the middle section of the unit that has an amplitude of $\sim 0.7 \mathrm{~A}$ (see point $\mathrm{E}$ on figure 3.11b). In the eastern section of the unit, there are two areas of lower amplitude material that has an amplitude of $\sim 0.3 \mathrm{~A}$ and penetrates the horizon top (see figure $3.11 \mathrm{~b}$, point $\mathrm{C}$ ). Overall, the unit has discontinuous bedding that is faint in sections.

Unit 2c (Pink to brown reflector): This unit begins at a depth of $\sim 0.760$ TWT (Pink reflector) down to $\sim 0.815$ TWT (brown reflector). This unit has the most well defined beds and is the thickest (at $\sim 0.055$ TWT). Within the unit, there is a split of high amplitude ( $\sim 0.8)$ upper beds and a faint amplitude $(\sim<0.3)$ lower beds (see figure 3.11b, point F) which is present throughout the entire unit. The higher amplitude bed has a thickness of $\sim 0.020$ TWT, with the lower bed having a thickness of $\sim 0.018$ TWT. In 
the east of the section there are possible small-scale sediment waves that are approximately 0.015 TWT in size and $~ 0.007$ TWT in individual size (see figure $3.11 \mathrm{c}$, inset of figure 3.11b). The Unit overall has two distinct beds in the upper and lower sections of the beds with these beds gently to moderately undulating, with undulations increasing in strength on the eastern section of the unit.

Unit $3 a$ (Brown to purple reflector): This unit begins at a depth of $\sim 0.815$ TWT (brown reflector) down to a depth of $\sim 0.835$ TWT (purple reflector), giving it an approximate thickness of $\sim 0.020$ TWT or $\sim 30 \mathrm{~m}$. The unit is generally consists of low amplitude material ( 0.1 to $0.3 \mathrm{~A})$ across its length, has very faint and patchy bedding and little structure throughout (see figure 3.11b). The horizon top exhibits several shallow scours that is present amongst all horizons in this line. 


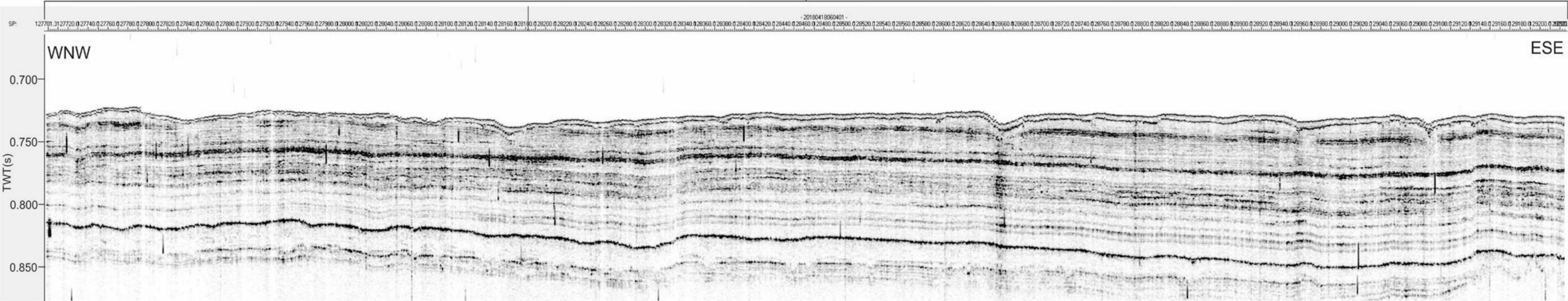

Figure 3.11a: Unannotated seismic section of line 10, eastern central Campbell Plateau.

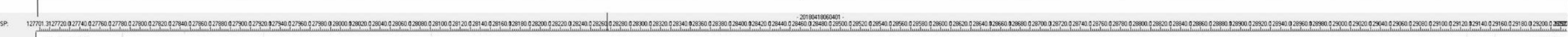
WNW

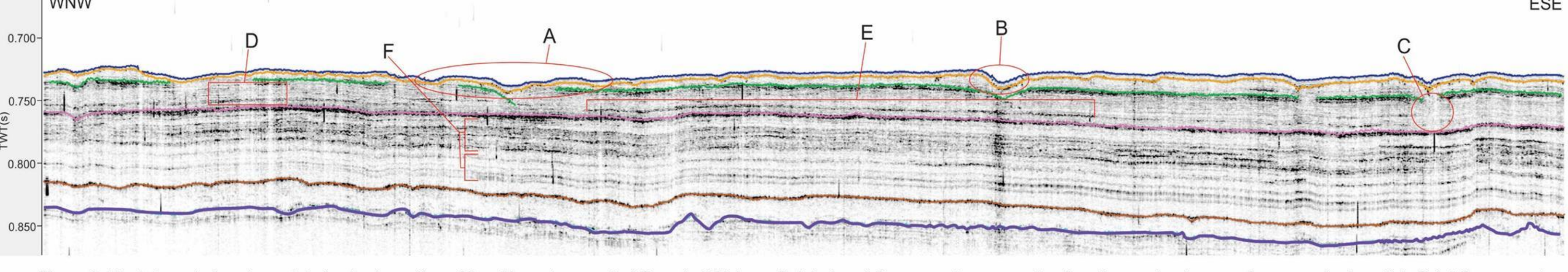

Figure 3.11b: Interpreted and annotated seismic section of line 10, eastern central Campbell Plateau. Points $A$ and $B$ represent an example of modern and palaeo-seafloor scouring in unit 1. Point C represents a characteristics that are indicative of a possible fluid escape structure in unit $2 a$. Point $D$ represents the style of bedding present in unit $2 b$. Point $E$ represents a dominant high amplitude bed within unit $2 b$. Point $F$ represents the bedding variation seen in unit $2 c$. 


\subsection{4: Interpretation}

The age of these units can be inferred from the ties to prior seismic lines that have been in turn tied to the ODP1120 to the NW of this line. With reference to the nearby surface cores Y14: $186 \mathrm{~cm}$ of sediment and Y16: $299 \mathrm{~cm}$ of sediment (see figure $3.1 \mathrm{for}$ localities). These two surface cores allow the age and sediment type of unit 1 to be inferred to be late Pleistocene in age, this is further shown by the age of unit 1 in the ODP1120 core. The lithology of this unit can also be inferred from cores Y14, Y16 and ODP1120, showing that it is primarily foraminifera bearing nannofossil ooze (Carter et al., 1999). Unit 2a is like that of ODP1120 unit 2, being early Pleistocene in age, and made up of foraminifera bearing nannofossil ooze. Unit $2 b$ is likely linked to ODP1120 unit 3 , due to the unit being primarily weakly bedded ooze, which could be inferred to be the faint/patchy reflectors interpreted to be present in unit $2 \mathrm{~b}$. Due to this correlation, it can be inferred that unit $2 b$ is likely late Miocene in age (Carter et al., 1999). Units 2c and 3a, when linked to ODP1120, suggest they are linked to unit 4 and possibly unit 3 . The lithology of both units $2 \mathrm{c}$ and $3 \mathrm{a}$ are likely foraminifera bearing nannofossil ooze, with the age of these units varying between Early to Late Miocene.

This line is a section that has seen a relatively moderate amount of deformation across its length, with more deformation to the south. Most units are conformable, with the exception to the top reflector of unit $2 \mathrm{~b}$. It appears unit $3 \mathrm{a}$ has had the most deformation, especially to the south, with the units above that becoming slightly more planar as the units get younger. This decrease in deformation suggests that deformation was strongest prior to the deposition of unit $3 \mathrm{a}$, suggesting that deformation occurred after in the Late Miocene or after. After this Miocene deformation, deformation appeared to slow with much of it being possibly attributed to seafloor scouring after deposition. However, all units in the south appear to have been slightly deformed more than what is seen in the north of the section.

\subsection{1: Line 11 (Central Southwest Campbell Plateau)}




\subsection{1: Line Description}

This line is located in the central south plateau, it has a length $38 \mathrm{~km}$ in the west by east direction (see figure 3.1). The line is generally undulating across the length, with to the east the line becomes thinner and slightly less undulating to the east with the change in slope. Much of the reflectors in this line are moderate strength in amplitude ( 0.3 to 0.7A). Possible bedding in the units interpreted here is well defined in the second and fourth units. In the eastern section of the line where the slope increases, there is the possibility of a sediment wedge in the last interpreted unit.

\subsection{2: Reflector Descriptions}

Seafloor (blue reflector): This strong reflector (0.8 to $1.00 \mathrm{~A})$ is light to moderately undulating across the length of the line, with undulations slightly increasing to the east with the increase in slope. The reflector has a Damuth scale of 1B-B.

Orange reflector: This reflector is also a relatively strong reflector ( 0.8 to $0.9 \mathrm{~A})$ that follows a similar pattern of undulation to the previous reflector, with the reflector becoming more undulating to the east with the increase in slope. This reflector is also laterally continuous.

Green reflector: Is a light reflector $(\sim 0.3 \mathrm{~A})$ that is lightly undulating that increases in undulations to the east. This reflector is also laterally continuous throughout.

Pink reflector: This reflector is quite faint (0.01 to $0.2 \mathrm{~A})$, it is more lightly undulating than previous reflectors, with it as well following a similar trend to other reflectors with it being influenced by the increase in slope.

Brown reflector: This is a relatively moderate strength reflector ( $\sim 0.3$ to $0.5 \mathrm{~A})$ it is lightly undulating across the length of the line; the reflector is also laterally continuous. Light pink reflector: This reflector is a faint reflector $(0.01$ to $0.2 \mathrm{~A})$ that is light to moderately undulating. The reflector follows the opposite pattern to the previous reflectors, with the reflector going downward, with the increase of slope to the east. The reflector is also laterally continuous.

\subsection{3: Unit Descriptions}


Unit 1 (Blue to orange reflector): This unit is generally faint $(0.02$ to $0.3 \mathrm{~A})$ with little or faint bedding throughout. The unit is seen to have a relatively constant thickness of $\sim 0.005$ TWT or $\sim 7 \mathrm{~m}$. The unit also appears to have a possible low amplitude (0.01 to $0.1 \mathrm{~A})$ central bed that is continuous across the unit.

Unit 2 a (Orange to green reflector): This unit is also generally faint throughout; the unit also appears to pinch out against itself at the western and eastern edges of the line (see figure 3.12b). The possible bedding in this unit is quite faint and thin, with bedding only being visible where the sediment is thickest $(\sim 0.006$ TWT or $\sim 9 \mathrm{~m})$. This unit thins too $<0.001 \mathrm{TWT}$ or $<1 \mathrm{~m}$ near the edges of the line.

Unit $2 b$ (Green to pink reflector): This unit has two distinct halves: an upper higher amplitude ( 0.3 to $0.6 \mathrm{~A}$ ) with rather distinct patchy bedding that has a thickness of $\sim 0.025 \mathrm{TWT}$ or $38.5 \mathrm{~m}$ thick. The lower half of the unit is a bed that is $\sim 0.01 \mathrm{TWT}$ or $\sim 15 \mathrm{~m}$ in thickness, this half is generally fainter ( $\sim 0.02$ to $0.3 \mathrm{~A})$ with less defined beds. The unit becomes thinner upslope, with the unit thinning to a thickness of $\sim 0.002$ TWT or $\sim 3 \mathrm{~m}$.

Unit 2c (Pink to brown reflector): This is a relatively faint unit overall (0.01 to 0.3A), with the bedding, is generally faint with patches of moderate strength beds ( 0.02 to $0.4 \mathrm{~A})$. The thickness of this unit is $\sim 0.023 \mathrm{TWT}$ or $\sim 35 \mathrm{~m}$ across much of the western section of the unit, with the unit becoming thinner upslope to the east to a thickness of $\sim 0.008$ TWT or $\sim 12 \mathrm{~m}$.

Unit $3 a$ (Brown to purple reflector): This is the thickest of all reflectors, having a maximum thickness of over $\sim 0.152$ TWT or over $\sim 234 \mathrm{~m}$, the unit also has consistent bedding throughout, with the upper bedding of the unit being generally stronger amplitude (0.5 to $0.7 \mathrm{~A}$ ) than the lower half of the unit. The upper bed in this unit also follows a similar pattern to that of the upper units in this line. The upper bed has a thickness change of $\sim 0.020$ TWT or $\sim 30 \mathrm{~m}$ at its thickest in the western section of the line, thinning up to 0.005 TWT or $\sim 7 \mathrm{~m}$ thickness to the east with the increase in slope. 


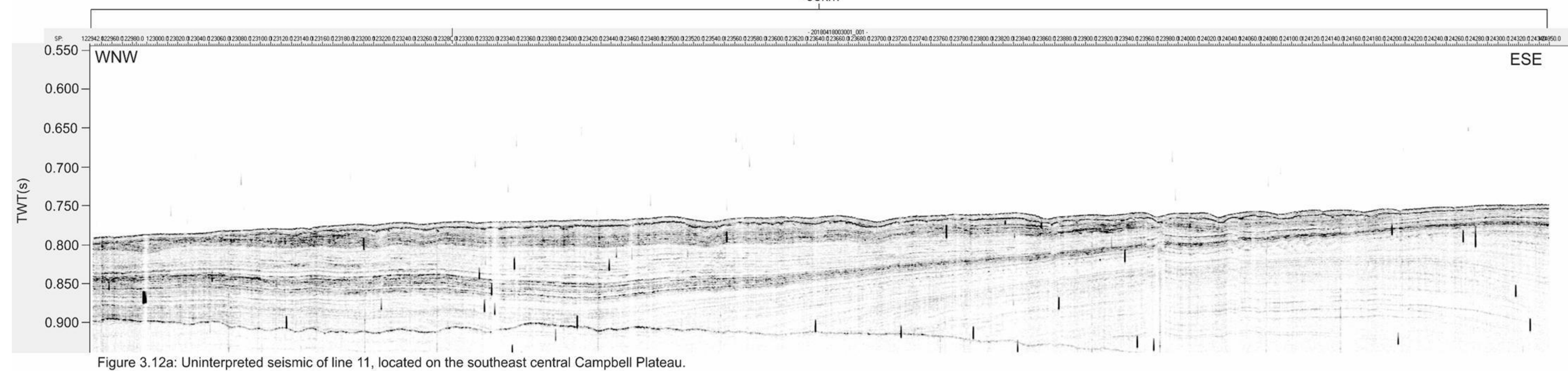

$\sim 38 \mathrm{~km}$

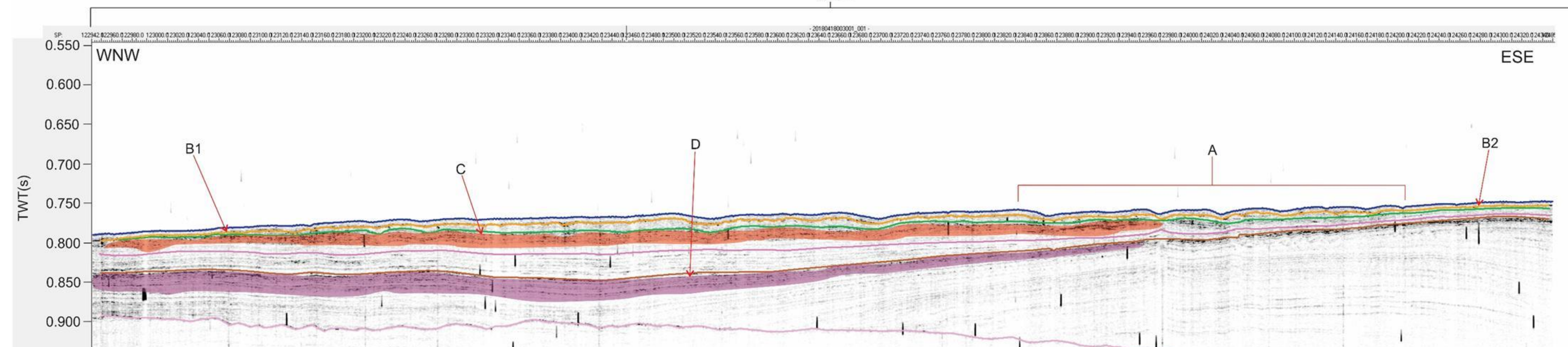

Figure 3.12b: Interpreted seismic of line 11, located on the southeast central Campbell Plateau. Point A shows the increase in possible scouring to the SE at the top of unit 1. Points B1 and B2 show the pinch ends of unit 2a in both the NW

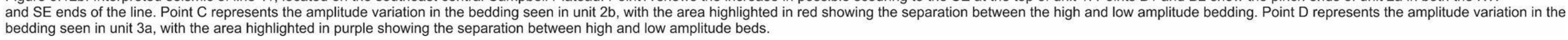




\subsection{4: Interpretation}

The units in this line appear to have little deformation throughout, as is seen with all units appear to be deposited along the central Campbell Plateau, with the exception to the bottom of unit $3 b$ (the light pink reflector). Units $3 a, 2 c$ and $2 b$ appear to be deposited under similar conditions due to the shared characteristics of each unit in terms of their profiles. The outlier to this is unit $2 \mathrm{a}$, in which both ends of the unit are seen to pinch out against each other. The nature of unit 1 and the nature of its bottom reflector (orange reflector) suggest that it may be an erosional surface, this is in part due to the pinching nature of the immediately below unit $2 \mathrm{a}$.

\subsection{2: Line 12 (Central Southwest Campbell Plateau -} $\underline{\mathrm{A})}$

\subsection{1: Line Description}

Line 12 is located across central southwest Campbell Plateau, to the east of the Auckland Islands (see figure 3.1). The line is orientated in an NW to SE direction, with the NW section following the slope up towards the shelf edge of the Auckland Islands. The line is generally made up of relatively thick sedimentary sequences, having a total thickness of sediment up to $\sim 0.070$ TWT or $\sim 107$ to $114 \mathrm{~m}$ of total sediment cover thinning upslope. At the NW edge of the line, there is a strong amplitude high, which may represent either a volcanic structure or basement high. At this strong amplitude structure, the bottom five reflectors appear to merge and follow up the edge of the structure. Bedding within the line is moderately defined with a moderate amount of deformation seen throughout the reflectors/units via faulting.

\subsection{2: Reflector Descriptions}

Seafloor (Blue reflector): This is a strong reflector (0.8 to $1.00 \mathrm{~A})$, that is moderately undulating across its length. The reflectors' profile is highly influenced by the bathymetry of the area and the slope of the nearby Auckland Islands. 
Orange reflector: This is a strong reflector $(0.7$ to $0.8 \mathrm{~A})$, it is moderately undulating and following a similar profile to that of the seafloor and is laterally continuous. The reflector is also influenced by the strong amplitude structure to the NW by being pushed upward.

Green reflector: The green reflector is a moderately strong reflector ( 0.6 to $0.7 \mathrm{~A})$ that is also moderately undulating across its length. The reflector is discontinuous due to being cut by faults in the SE, having an offset of $\sim 0.010$ TWT or $\sim 15 \mathrm{~m}$ (see figure $3.13 \mathrm{~b}$, point A), and being penetrated by two further (likely normal) faults in the centre of the line. The offset seen in these faults is minor compared to the previous, with offsets of $\sim 0.004$ TWT or $\sim 6 \mathrm{~m}$ and $\sim 0.003$ TWT or $\sim 4.5 \mathrm{~m}$ (see figure $3.13 \mathrm{~b}$, point B1 and B2 respectively).

Pink reflector: This reflector is a moderate strength reflector (0.5 to $0.6 \mathrm{~A})$, that is light to moderately undulating across its length. The reflector is laterally discontinuous; several faults cut across it (see figure 3.13 b points A, B1 and B2). The southern fault is seen to have the largest offset, with an offset of 0.008 TWT or $\sim 12 \mathrm{~m}$.

Brown reflector: This is a moderate strength slightly patchy reflector (0.4 to $0.6 \mathrm{~A})$, that is slight to moderately undulating across its length, the reflector is also laterally discontinuous across its length. In the SE section of the reflector, there is faulting that is seen to have an offset of $\sim 0.011$ TWT or $\sim 16 \mathrm{~m}$.

Purple reflector: This is a light to a moderate reflector (0.4 to $0.7 \mathrm{~A})$, it is moderately to highly undulating and is largely discontinuous. The reflector is also penetrated by the faults seen in the other reflectors however is less evident in the SE, and more prominent in the central section of the line having an offset of $\sim 0.005$ TWT or $\sim 7 \mathrm{~m}$.

Light brown reflector: This is a light to a moderate reflector (0.4 to $0.6 \mathrm{~A})$ it is moderately undulating across its length. The reflector is discontinuous across its length. The reflector also is not penetrated by faults.

\subsection{3: Unit Descriptions}

Unit 1 (Blue to orange reflector): This unit is faintly bedded and has a slight variation in thickness with change in slope. The unit is slightly thicker throughout the centre of the unit, having an approximate thickness change of $\sim 0.002$ TWT or $\sim 3 \mathrm{~m}$ along the SE and NW edges of unit to 0.007 TWT or $\sim 10 \mathrm{~m}$ in the centre of the line. The unit appears to also be faintly bedded throughout, with the beds being most continuous where 
sediment thickness is at its highest. In the NW, the bottom of the reflector (the orange reflector) appears to pinch out against the seafloor (the blue reflector).

Unit 2 a (Orange to green reflector): Unit 2 is a unit that has chaotic bedding in much of the upper half of the unit and with the lower half being generally faint to little bedding. The units' thickness is generally thinning upslope to the NW, with the unit thinning to $\sim 0.01$ TWT or $15.4 \mathrm{~m}$ from a thickness of 0.015 TWT or $\sim 23 \mathrm{~m}$ (see figure $3.13 \mathrm{~b}$ point, points $\mathrm{C} 1$ and $\mathrm{C} 2$ respectively).

Unit $2 b$ (Green to pink reflector): This unit has the most well defined bedding of all units in this line. The bedding in this unit varies with slope and sediment thickness, being the most well defined and thickest in the SE, with the unit having a thickness of $\sim 0.016$ TWT or $\sim 24 \mathrm{~m}$. This unit and its bedding then thin upslope to $\sim 0.004$ TWT or $\sim 6 \mathrm{~m}$. The unit is faulted throughout, with the SE portion of the unit having the largest offset of $\sim 13 \mathrm{~m}$. Faulting within the middle section of the line there is also faulting present, in which this section is the having offset of $\sim 5 \mathrm{~m}$ within the unit.

Unit 2c (Pink to brown reflector): This unit has a thickness ranging from $\sim 0.01$ TWT or $\sim 15 \mathrm{~m}$ to $\sim 0.005$ TWT or $\sim 7.7 \mathrm{~m}$, it follows the same general thickness patterns as the all other units in this section, with the unit thinning upslope to the NW. The unit is also cut by the same faults as previous units, with the offset of the largest $\sim 14 \mathrm{~m}$. The bedding within this unit is also generally faint and weakly bedded throughout, with much of the bedding being present in the SE section of the line, in the centre of the line the unit there is minimal or faint bedding throughout the central section of the unit (see figure 3.13b, point $\mathrm{D})$. This bedding changes to more prominent, starting to reappear to the NW, having an increased amplitude to $\sim 0.7$ to $0.8 \mathrm{~A}$ however appears to be discontinuous throughout. The unit also follows the same trend as other units with the unit pinching out at the NW slope edge against the strong amplitude high.

Unit 3 a (Brown to purple reflector): This unit is relatively disjointed compared to previous units with the bottom reflector of the unit being discontinuous and generally faint across the line. The unit itself generally displays faint bedding (0.2 to $0.3 \mathrm{~A})$. Unit $3 \mathrm{a}$ is cut by the southern fault, as is the same with all other above units, with the offset in this unit being $\sim 11.8 \mathrm{~m}$. The offsets seen in the central area of faulting is not prominent compared to that of the other units. This is similar to the above units, this unit also pinches out against along the NW slope edge against the strong amplitude high. 
Unit $3 b$ (Purple to light brown reflector): The final unit in this line is the most disjointed off all lines with both top and bottom reflectors being largely discontinuous. Within the unit, there is also evidence of hyperbolic structures that vary in amplitudes from $\sim 0.4 \mathrm{~A}$ to $0.7 \mathrm{~A}$ (see figure $13 \mathrm{~b}$, point $\mathrm{E}$ ). This unit is the only unit where the SE fault does not influence in the unit, however, in the two central faults seem to be only influencing the top half of the unit by deforming the top reflector. The unit is also pinching out in the NW as is similar to all other above units 

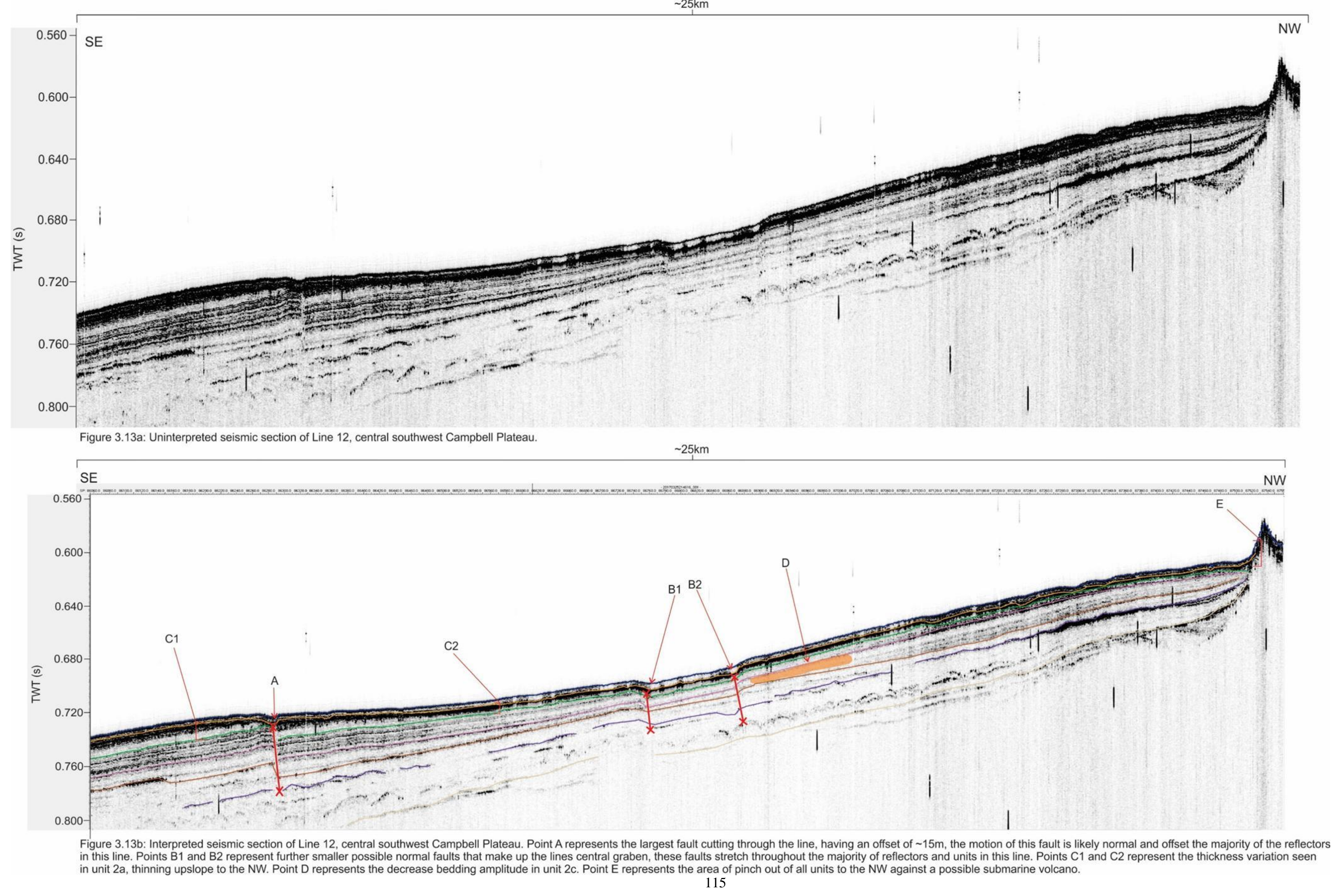


\subsection{4: Interpretation}

This line shows a lot of variability between all units, although there is one similar feature combining them all. The pinching out of units $3 b, 3 a, 2 c, 2 b$ and $2 a$ suggests that these units were deposited first then the intrusion of the strong amplitude high occurred. This event likely occurred before the deposition of unit 1 , due to the unit appearing to bank up against the structure. Due to the age of unit 1 being tied to the same age of unit 1 ODP1120, it can be estimated to be Pleistocene in age. The age of the other units in the line can be linked to other units in the area with much of units being tied back to units that have been tied to ODP1120. These other units can be estimated to be within the Miocene Epoch, suggesting that the strong amplitude structure is at least Miocene or younger. The strong amplitude structure could possibly be volcanic in nature; this is due to the lack of faulting surrounding the immediate area possibly ruling out a basement high. The strong amplitude hyperbolic structures are possibly mega-ripples or sand waves; however, there is little evidence to support this other than form factor.

\subsection{3: Line 13 (Central Southwest Campbell Plateau - $\underline{\text { B) }}$}

\subsection{1: Line description}

Line 13 is located to the SE of the Auckland Islands, and is $~ 30 \mathrm{~km}$ long and is located on the NW slope of the Auckland Islands shelf (see figure 3.1). This line is generally seen to be filled with low amplitude sections that cut through much of units. The reflectors in this line are also constrained by the bathymetry of the slope and distribution of possible biogenic gas placement throughout the line.

\subsection{2: Reflector descriptions}

Seafloor (blue reflector): Is a strong reflector (0.8 to $1.0 \mathrm{~A})$ that is moderately undulating, with undulations being stronger in the NW and becoming less strong to SE upslope. The reflector is also seen to have more evident seafloor scouring to the NW (see figure $3.14 \mathrm{~b}$, point $\mathrm{A}$ ). 
Orange reflector: This reflector is a strong reflector $(0.7$ to $0.9 \mathrm{~A})$ that is moderate to highly undulating, with undulations being stronger in the NW then becoming weaker to the SE following the slope up. The reflector is also laterally continuous across the line.

Green reflector: The maroon reflector is a moderately strong reflector (0.6 to 0.9A), that is moderately undulating following the same trend as previous reflectors with the undulations being generally stronger in the SE and then weakening to the NW. The reflector is also seen to be laterally continuous across the line length.

Pink reflector: This reflector is a moderate strength reflector $(0.5$ to $0.7 \mathrm{~A})$ that is moderately undulating across the line. The undulation pattern follows the same pattern as the previous layers, with increased strength undulations to the SE with it becoming weaker to the NW. The reflector is continuous across the length of the line.

Brown reflector: Is a moderate to faint reflector $(0.3$ to $0.5 \mathrm{~A})$ that is high to moderately undulating. The reflector is largely discontinuous being broken into several parts and is the most broken to the SE. The longest continuation of the reflector occurring to the NW. These broken sections appear to be broken by the low amplitude pockets that come up through much of the reflectors in this line.

Purple reflector: This is weak to a moderate reflector $(0.3$ to $0.5 \mathrm{~A})$ that is high to moderately undulating, with the pattern of undulation being like that of previous reflectors with the SE being the most undulating and disjointed with the NW becoming more planar in nature. The same low amplitude material that has caused the disjointing of the previous reflectors also affects this reflector.

Light brown reflector: The pink reflector is primarily strong to a faint reflector $(0.2$ to $0.8 \mathrm{~A}$ ) with the strength of the reflector increasing with the increase in slope to the NW. The reflector is highly undulating throughout and laterally continuous where present.

\subsection{3: Unit Descriptions}

Unit 1 (Blue to orange reflector): This unit is faintly bedded with possible chaotic bedding throughout (see fig $3.14 \mathrm{~b}$, point $\mathrm{A}$ ). The unit has a relatively uniform thickness of $\sim 0.005$ TWT or $\sim 7 \mathrm{~m}$, however, this slightly varies with undulations. The unit appears to mantle the lower units of the line. The unit is slightly thicker to the SE where undulations are generally stronger. 
Unit 2a (Orange to green reflector): This is the thinnest of all units with much of the unit having a thickness of $\sim 0.002$ TWT or $\sim 3 \mathrm{~m}$ across a large portion of the line. The unit is seen to thicken and thins across the unit with the thickest section of the unit being to the SE with a thickness of $\sim 0.01 \mathrm{TWT}$ or $\sim 15 \mathrm{~m}$. The bottom reflector of this unit appears to be the most undulating. The bedding in this unit is seen to be most prominent in the SE where the sediment is thickest; the bedding seen within this unit is mainly patchy and possibly slightly chaotic in nature.

Unit $2 b$ (Green to pink reflector): This unit is largely discontinuous and is seen to be one of the more heavily influenced units by the potential biogenic gas that has caused the separation of this unit. The unit is heavily influenced in the central SE section of the line, within this section there is a "V" like structure where the unit is possibly heavily influenced by this gas upwelling (see figure 3.14b, point B). Past this structure, the deformation weakens with the unit becoming slightly less deformed and thinning upslope to $\sim 0.004$ TWT or $\sim 6 \mathrm{~m}$ thickness.

Unit 2c (Pink to brown reflector): This is the thickest of all units and displays the thickest units of bedding throughout the line, having approximate total thicknesses of 0.055 TWT or $\sim 84.7 \mathrm{~m}$. Bedding within this unit is also one of the better defined with the unit, with much of the bedding being faint, however distinct beds can be traced in some sections (see figure $3.14 \mathrm{~b}$, point $\mathrm{C}$ ). Within the central section of much of the unit, a section of low amplitude bedding ( 0.1 to $0.3 \mathrm{~A}$ ) that is $\sim 0.021$ TWT or $\sim 32 \mathrm{~m}$ thick (see figure $3.14 \mathrm{~b}$, point $\mathrm{D}$ ). This low amplitude bed separates the unit into two different bedding types, with this separation being between the upper chaotic/patchy bedding mainly seen in the upper part of the unit and the faint lower bedding of the unit (see figure 3.14b, point E1 \& E2 respectively). This unit also follows the similar trend to the other units to the NW with the unit thinning upslope; however, the bedding is largely not present and/or has become largely low amplitude material.

Unit $3 a$ (Brown to purple reflector): This unit has the most well defined bedding of all units seen in this line, with bedding being seen across all sections of the line. This unit is also one of the most discontinuous with much of the reasons for the discontinuous layers is due to the intrusion of low amplitude material between the lower three units of this line. Bedding within this unit is seen range from moderate to low amplitude ( 0.2 to 0.5A). In the SE edge of the unit, the unit is very disjointed and chaotic with little overall structure. In the central NE to the NE end of the line the unit is seen to pinch out against unit $3 b$ (see figure $3.14 b$, point $F$ ) then re-emerge following the slope up. On the 
$\mathrm{NE}$, slope bedding is still visible in the unit, which is a unique feature of this unit when compared to other units in this line.

Unit $3 b$ (Purple to light brown reflector): This unit is predominantly a mixture of chaotic bedding and faint bedding (see figure 3.14b, points G1 and G2 respectively) the unit is highly discontinuous overall. Key features of this unit are the possible faint conical shaped structure in the centre of the unit, represented by the bottom light brown reflector and the pinching of the unit against itself (see figure 3.14b, point $\mathrm{H} 1$ and $\mathrm{H} 2$ respectively). 
$30 \mathrm{~km}$

D. SE

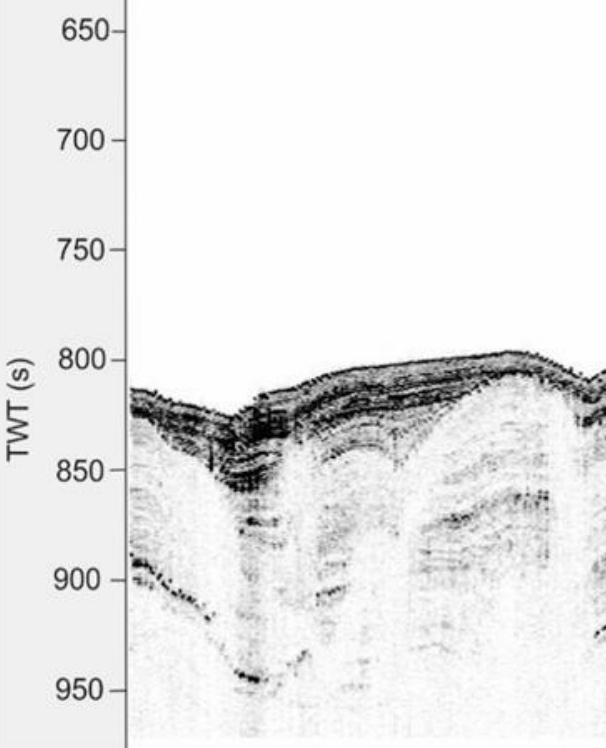

Figure 3.14a: Uninterpreted seismic of line 13 on the Central Southwest Campbell Plateau.

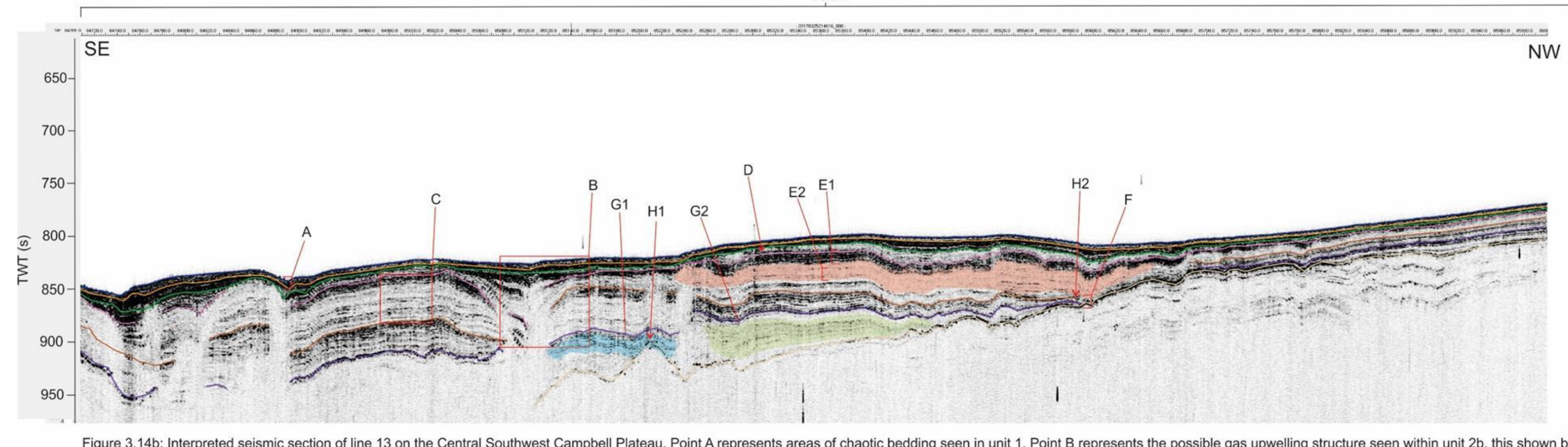

Figure 3.14b: Interpreted seismic section of line 13 on the Central Southwest Campbell Plateau. Point A represents areas of chaotic bedding seen in unit 1. Point $B$ represents the possible gas upwelling structure seen within unit $2 \mathrm{~b}$, this shown by the large "V" like low amplitude structure. Point $\mathrm{C}$ represents the general faint bedding seen in the SE section of unit $2 \mathrm{C}$. Point $\mathrm{D}$ represents a prominent section of low amplitude bedding that is highly deformed within unit $2 \mathrm{C}$. Points E1 and E2 2 increase in slope. Points $\mathrm{G} 1$ and $\mathrm{G} 2$ represent examples of faint chaotic bedding that is predominantly seen in unit $3 \mathrm{~b}$. Points $\mathrm{H} 1$ and $\mathrm{H} 2$ represent two separate features within unit $3 \mathrm{~b}$; $\mathrm{H} 1$ shows a possible faint submarine volcano or bathymetric
intic high. $\mathrm{H} 2$ represents the $\mathrm{NW}$ end of unit $3 \mathrm{~b}$ pinching out against itself. 


\subsection{4: Interpretation}

The main features of this line are the presence of the low amplitude material that is seen to be cutting through the lower three units of this line. Due to the nature of this sediment is primarily made up of nannofossil ooze, it could be possibly assumed that the cause of this discontinuity is due to the release of biogenic gas up through the layers caused a drop-in amplitude and giving the appearance of the discontinuity of units and beds within this line. The "V" shaped structure in the centre of the line is likely a possible sag or fluid escape structure. This sag formation is possibly due to a former gas deposit/pocket that was present in the unit, which has shifted due to possible pressure differences. This event and the flow of possible biogenic is assumed to have occurred prior to the deposition of units 1 and 2 a due to the lack of evidence of gas within these units.

\subsection{4: Line 14 (Central Southwest Campbell Plateau - $\underline{\text { C) }}$}

\subsection{1: Line Description}

This line is the third of the seismic sections that are in the central SW section of the Campbell Plateau (see figure 3.1). Is orientated in an NW to SE orientation, with the SE section of the line slightly increasing in slope to SE following up to the Campbell Island shelf edge. The line can be characterised by having clear bedding and being defined by the central amplitude structure in the middle of the line.

This line has generally well-bedded units that are undulating lightly to moderately and increasing/becoming more deformed to towards the central high amplitude structure. The key features of this line are the influence of the high amplitude structure on units and the deformation of the units closer to the structure. 


\subsection{2: Reflector Descriptions}

Seafloor (Blue reflector): This strong reflector ( 0.8 to $1.0 \mathrm{~A})$ is lightly undulating across the length of the line. In the centre of the line, there is a possible sag or scours present (see figure $3.15 \mathrm{~b}$, point A). The reflector has a Damuth scale of 1B-C.

Orange reflector: This reflector has a strong amplitude (0.8 to $1.0 \mathrm{~A})$, that is generally lightly undulating across the length of the line. The reflector has a similar profile to that of the blue reflector, with the reflector having a similar undulation style and the having a central sag or scour point. The reflector is also laterally continuous across the line.

Green reflector: This reflector is a moderate strength reflector ( 0.6 to $0.8 \mathrm{~A})$, that is light to moderately undulating. The reflector becomes more widely undulating closer to the central high amplitude structure. The reflector is also laterally discontinuous, being the first reflector that is interrupted by the central structure.

Pink reflector: This reflector is a patchy moderate to high strength reflector that has pockets of high amplitude material (0.6 to 0.9A). The reflector is also moderately to lightly undulating, with the NW side of the reflector having stronger undulations than the SE where the undulations appear to be lighter in strength. The reflector is also laterally discontinuous with the reflector being also interrupted by the central high amplitude structure, with this it appears the reflector also possibly pinches out against the green reflector on the NW section of the line (see figure $3.15 \mathrm{~b}$, point $\mathrm{B}$ ).

Brown reflector: The brown reflector is a faint to light reflector ( 0.1 to $0.4 \mathrm{~A})$ that is slightly undulating. The reflector is largely discontinuous, with much of it being present on the NW side of the line.

\subsection{3: Unit Descriptions}

Unit 1 (Blue to orange reflector): This unit is the thinnest of all units, having a thickness of $\sim 0.007$ or $\sim 10 \mathrm{~m}$ across much of the unit, with the exception to this being on the NW section of the line. In the NW there are slightly thicker pockets of sediment where undulations have increased, with the largest having a thickness of $\sim 0.015$ TWT or $\sim 23 \mathrm{~m}$ (see figure $3.15 \mathrm{~b}$, point $\mathrm{C}$ ). The unit is seen to have generally patchy bedding throughout, with the only consistent bedding being seen in the deeper sediment patches.

Unit 2 a (Orange to green reflector): This unit's thickness varies, becoming thicker towards the centre. In the NW of the unit the thickness varies from $\sim 0.01 \mathrm{TWT}$ or $\sim 15$ 
at the edge of the line, increasing to $\sim 0.03$ TWT or $\sim 46 \mathrm{~m}$ thickness near the centre of the line (see figure $3.15 \mathrm{~b}$, point D1 and D2 respectively). As the unit is discontinuous, the SE portion of the line is slightly thinner, having a thickness of $\sim 0.008$ TWT or $\sim 12 \mathrm{~m}$ thickness at the SE edge of the line at its thinnest and up to $\sim 0.042$ TWT or $\sim 64 \mathrm{~m}$ thickness at its thickest at the centre of the line (see figure 3.15, points E1 and E2 respectively). The bedding in this unit is split into two sections; a lighter amplitude upper layer and a stronger more defined bottom unit (ranging from $\sim 0.3 \mathrm{~A}$ and through to $0.7 \mathrm{~A}$ respectively). The split between these units appears to occur closer to the centre of the line, at the NW section of the line the bedding goes from chaotic at the edge of the unit, through to more defined bedding in the centre of the unit. The bottom reflector of this unit also displays several sags throughout both the NW and SE sides of the unit (see figure 3.15b, points F1, F2 and F3). The SE section of the unit has the more slightly deformed beds with a significant sag feature present in near the centre of the line (see figure 3.15 b, point $G$ ). The SE section of the line generally displays similar patterns to the NW section; however, the bedding is better defined and slightly more undulating across the length.

Unit $2 b$ (Green to pink reflector): This unit is also laterally discontinuous, and is separated by the central high amplitude structure. The bedding in this unit is generally faint to moderately strong, with much of the unit being generally a low amplitude $(\sim 0.3$ to $0.4 \mathrm{~A}$ ) overall, compared to that of the surrounding units. Bedding within this unit is generally laterally continuous and varies from faint to relatively high amplitude (from 0.2 to $0.7 \mathrm{~A}$ ). The unit displays slight depression and high along with the bottom reflector of the unit in the NW section of the line (see figure 3.15b, points $\mathrm{H} 1$ and $\mathrm{H} 2$ respectively). The unit appears to pinch out on itself near the centre of the line against the central structure, then reappearing on the SE side of the section. In the SE section of the unit, the bedding is generally seen to be similar amplitude strength but slightly less undulating in nature.

Unit 2c (Pink to brown reflector): This unit has a variable thickness that thins inwards, going from $\sim 0.32$ TWT or $\sim 49 \mathrm{~m}$ thick to $\sim 0.019$ TWT or $\sim 29 \mathrm{~m}$ thick near the centre of the line. This unit is the most discontinuous of all units, with the bottom reflector (brown reflector) of this unit being only seen on the NW side of the line. The unit is impacted by the separation caused by the central structure. Bedding within this unit can be broken up into two sections, with the unit having stronger amplitude top beds ( 0.7A) in the top half of the unit, with the lower half having lower amplitude beds 
( $\sim 0.3 \mathrm{~A})$. The bedding in this unit is generally seen to be slightly undulating and is well defined. 


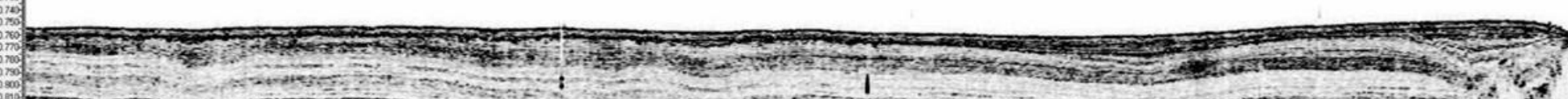

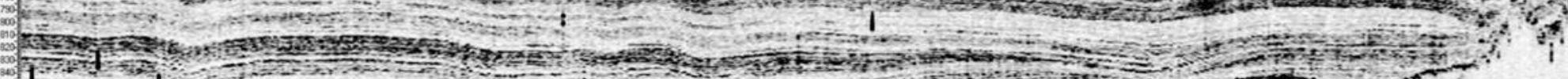

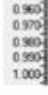

Figure 3.15a: Uninterpreted seismic section of line 14, central SW Campbell Plateau.

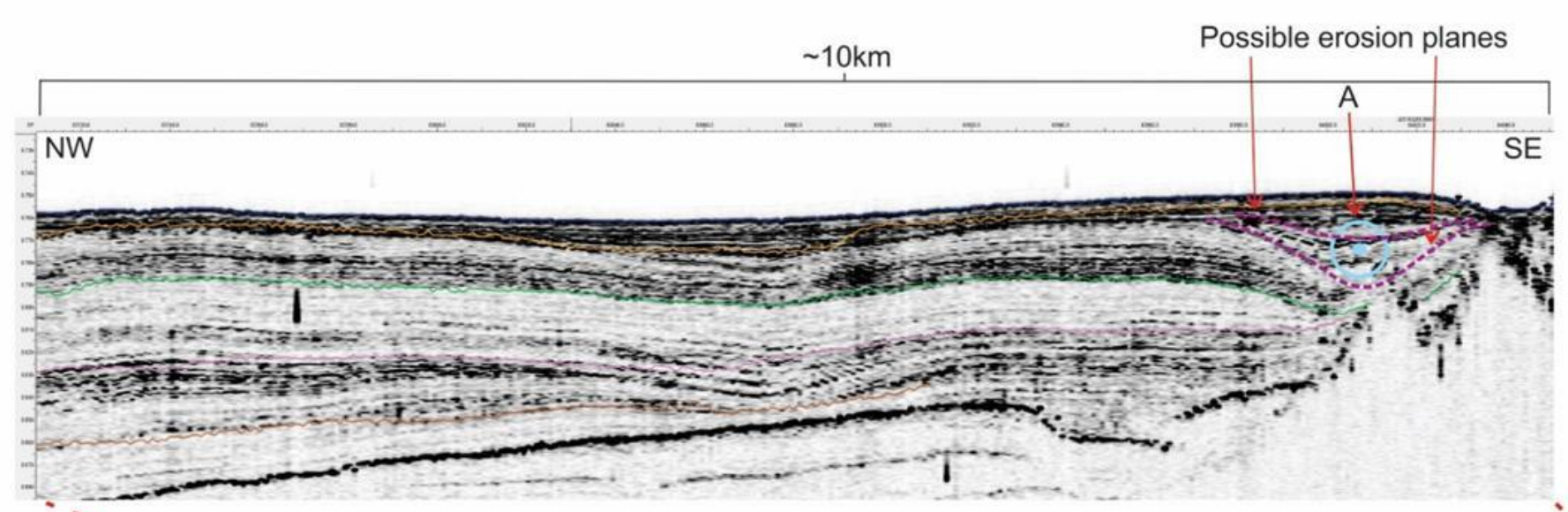

$\because$ Figure 3.15c: Schematic interpretation of possible cause of unit 2a depression/deformation. The blue circle . The purple dashed lines represent possible erosion surfaces from this current. $\sim 38 \mathrm{~km}$

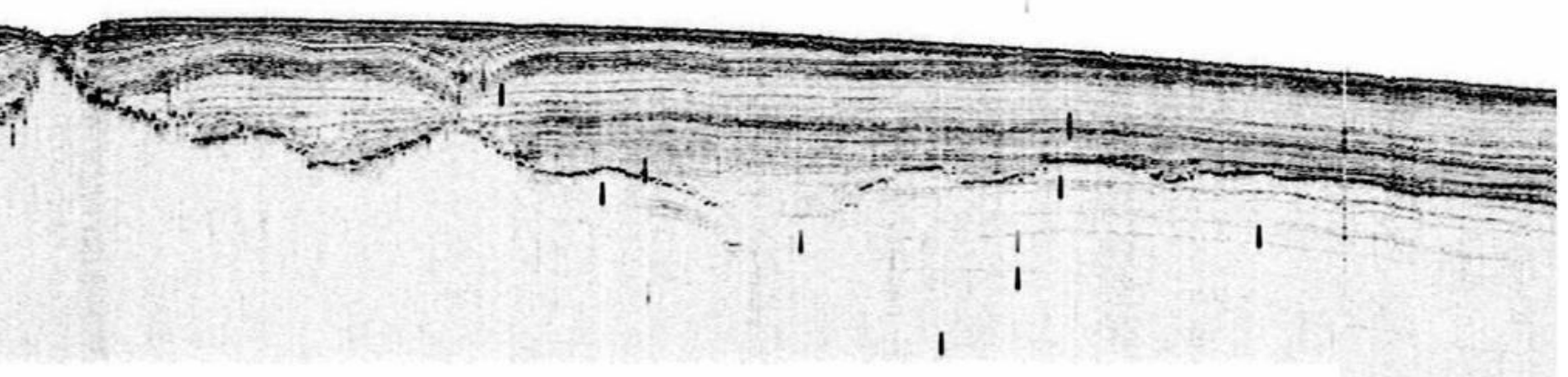

$\sim 10 \mathrm{~km}$

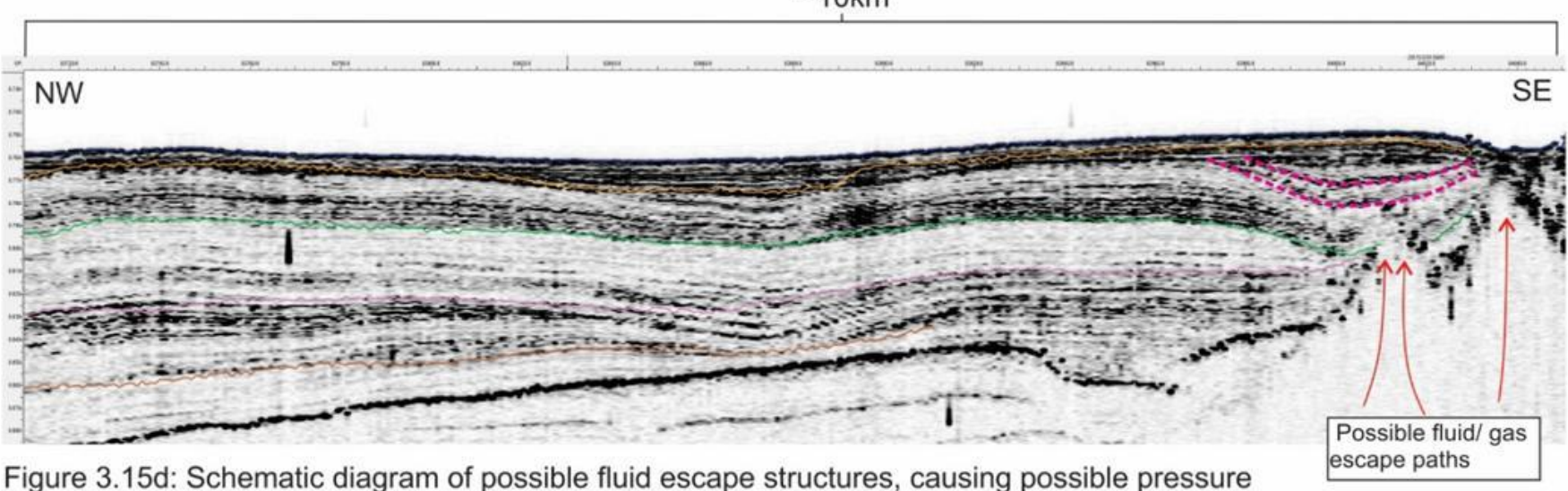

Figure 3.15d: Schematic diagram of possible fluid escape structures, causing possible pressure

escape paths

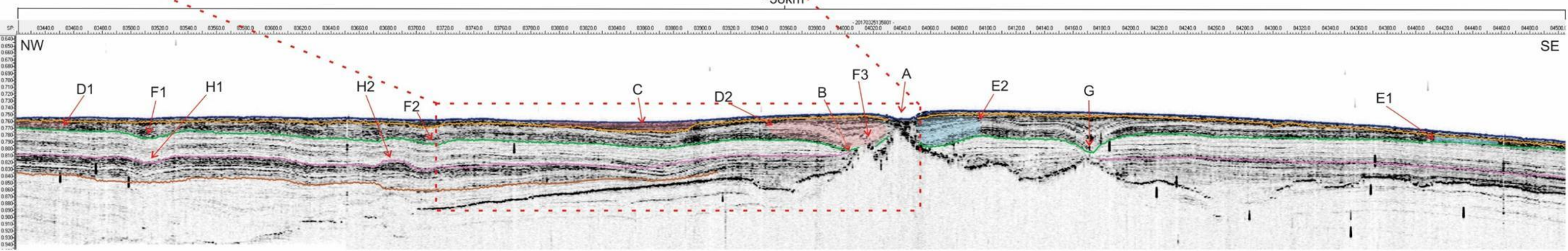

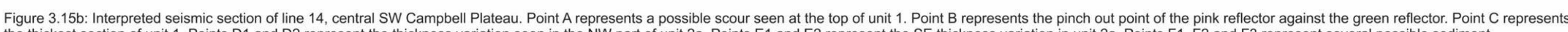
the thickest section of unit 1. Points D1 and D2 represent the thickness variation seen in the NW part of unit 2a. Points E1 and E2 represent the SE thickness variation in unit 2a. Points F1, F2 and F3 represent several possible sediment 


\subsection{4: Interpretation}

The main features of this line are the deposition style of the units and the variation within each unit and the main central structure. Due to the general lack of high amounts of deformation and erosion throughout this line, it could be assumed that much of the units here were deposited in a relatively quiescent environment. Due to the seismic line location of being to the NW of volcanic Campbell Island, it could be assumed that the high amplitude central structures in the middle of the line are volcanic in nature.

With units $2 \mathrm{c}$ and $2 \mathrm{~b}$ being deposited the earliest of the units interpreted in this line. Due to the deformation style of unit $2 \mathrm{a}$ and $2 \mathrm{~b}$ against this high amplitude structure, suggests that this structure intruded after the deposition of unit $2 \mathrm{~b}$ and $2 \mathrm{c}$ but possibly prior to the deposition of units $2 \mathrm{a}$ and 1 . Unit $2 \mathrm{c}$ and $2 \mathrm{~b}$ appear to be uplifted at the edge of the central structure, with units $2 \mathrm{a}$ and 1 appear to be mantling the surface of the structure. The dip of unit 2 a near the edge of the possible volcano suggests a possible paleo-bottom current erosion at the time of deposition of unit $2 \mathrm{a}$ (see figure $3.15 \mathrm{c}$, see point A). However, due to the nature of the change in bedding angle in unit $2 \mathrm{a}$ and the possible volcanic nature of the central figure, these low sections located above the possible volcanic edifices. These may indicate areas of possible influx of volatiles or gas release from these, creating a possible dewatering event within these areas creating a "sag" like structure. This would create more space for the sediments at the time of the gas injection, however, once this gas has passed through the unit the remaining space will be then filled with the sediment, creating a "sag" like structure. This feature is more prevalently seen in the NW section of unit $2 \mathrm{a}$, with a much more defined example (see figure $3.15 b$, point $G)$.

However, another possible theory for the deformation seen in unit 2 a near the possible volcanic edifices is due to current circulation around the edifice at the time of deposition. This would have allowed for the erosion of the unit at the time of deposition, causing the deformation seen in the unit in its present state, due to the possible bottom current at the time of deposition would have caused the winnowing of the unit against the edifice (see figure $3.15 \mathrm{~d}$ ). 
Unit 1 in this line deformation could be tied to the same theories due to its position above the main volcanic edifice. The central dip seen in unit 1 could also possibly be the area that has been scoured by modern day bottom currents, or possibly subject to volatile or gas escape from the immediately below edifice.

\subsection{5: Line 15 (Southwest Campbell Plateau - D)}

\subsection{1: Line Description}

Line 15 is in the southwest section of the Campbell Plateau (see figure 3.1), the line is in NW to SE orientation. Line 15 runs along an upward slope towards Campbell Island, the line appears to be well eroded with a combination of primarily light to moderately reflectors throughout with much of the interpreted units being lightly undulating. All interpreted units in this section also have been eroded obliquely to bedding planes.

\subsection{2: Reflector Descriptions}

Seafloor (Blue reflector): This strong reflector (0.8 to 1A) is moderately undulating throughout. Undulations appear to be smaller to the SE with the NW undulations generally being wider. The Damuth scale seen in this reflector is 1B-B.

Orange reflector: This reflector varies from faintly reflecting a moderately strong reflector ( 0.2 to $0.7 \mathrm{~A})$, the reflector is moderately undulating and largely laterally discontinuous. The reflector follows a similar pattern to that of the blue reflector.

Green reflector: This moderate to strong reflector $(0.5$ to $0.8 \mathrm{~A})$ that is slightly undulating throughout. The reflector is also laterally discontinuous, pinching out against the upper orange reflector.

Pink reflector: This reflector is a moderate to a strong reflector ( 0.5 to $0.8 \mathrm{~A})$ that follows a similar undulation pattern to that of the maroon reflector. The reflector is also laterally discontinuous, pinching about against the orange reflector. This reflector is only present in the NW section of the line.

Brown reflector: The green reflector is a moderate strength reflector ( 0.5 to $0.7 \mathrm{~A})$ that is slightly patchy in terms of amplitude strength; the reflector is also laterally discontinuous with the reflector pinching out against the purple reflector. This reflector is only present in the NW section of the line. 
Purple reflector: Is a faint reflector (0.3 to $0.4 \mathrm{~A})$ that is slightly undulating. The reflector follows the same pattern as above reflectors, with the reflector pinching out against the seafloor/upper units.

Light brown reflector: Generally, this faint reflector increases with strength closer to the surface reflector (from $\sim 0.2$ to $0.6 \mathrm{~A}$ ). The reflector is slightly undulating, pinching out against the surface reflector (blue).

\subsection{3: Unit Descriptions}

Unit 1 (Blue to orange reflector): This unit is the only unit that is present across the entire line, being present mostly in the NW with it being patchier in the SE section of the line. The overall thickness of this line is very thin, with much of the unit having a maximum thickness of 0.002 TWT or $\sim 3 \mathrm{~m}$ at the NW end of the line. This unit is also to be eroded obliquely as the unit thins upslope and then reappears in patches. The unit has possibly faint bedding where sediment thickness is present; however, this is faint in nature: $0.2 \mathrm{~A}$. This unit is also laterally discontinuous across the line.

Unit 2 a (Orange to green reflector): This unit is thinning upwards, with the unit the only being present in a small section of the NW edge of the line. The bedding within this unit is generally quite faint $(\sim 0.3 \mathrm{~A})$ with the unit having a possible fainter central bed ( $\sim .2$ to $0.3 \mathrm{~A}$ ), and with the unit having possibly patchy bedding sections throughout it (see figure 3.16b, point A). The unit is also eroded obliquely to the bedding plane, however, has been eroded the most shallowly. This unit is also laterally discontinuous.

Unit $2 b$ (Green to pink reflector): This unit is also very thin, with the unit having a maximum thickness of $\sim 0.008$ TWT or $\sim 1.2 \mathrm{~m}$ thick at the NW edge of the line. This unit appears to also have been eroded obliquely to the bedding plan with the top maroon reflector of the unit being planned off and overlain by the orange reflector (see figure $3.16 \mathrm{~b}$, point B). Bedding within this unit is patchy but generally has a strong amplitude (0.5 to $0.6 \mathrm{~A})$. This unit is also laterally discontinuous.

Unit $2 c$ (Pink to brown reflector): Unit $2 \mathrm{c}$ is generally a faint unit ( 0.3 to $0.5 \mathrm{~A})$ with isolated regions of high amplitude beds in the top half of the unit. This unit is also seen to be eroded obliquely to the bedding plane, as is the case with all units in this line (see figure 3.16b, point C). The units' thickness is relatively consistent with it having a 
thickness of $\sim 0.03$ TWT or $\sim 46 \mathrm{~m}$. The unit is also laterally discontinuous, being only present in the SE section of the line.

Unit $3 a$ (Brown to purple reflector): This unit has the most well defined beds out of all units seen in this line. The beds in this unit can be generally broken up into two sections; with a top half primarily comprised of relatively strong amplitude beds ( 0.5 to 0.7A), with the amplitudes of these beds generally becoming higher amplitude with a decrease in depth of the unit, with amplitude increasing to $\sim 0.8$ and $0.9 \mathrm{~A}$ (see figure $3.16 b$, point D).

Unit $3 b$ (Purple to light brown reflector): This unit is predominantly faint/low amplitude throughout ( 0.2 to $0.3 \mathrm{~A})$, the unit has faint bedding present throughout, and that is slightly visible at the top of the unit near the surface. This unit slightly varies in thickness, with it having an approximate thickness of $\sim 0.022$ TWT or $\sim 33 \mathrm{~m}$ across the length of the unit. 


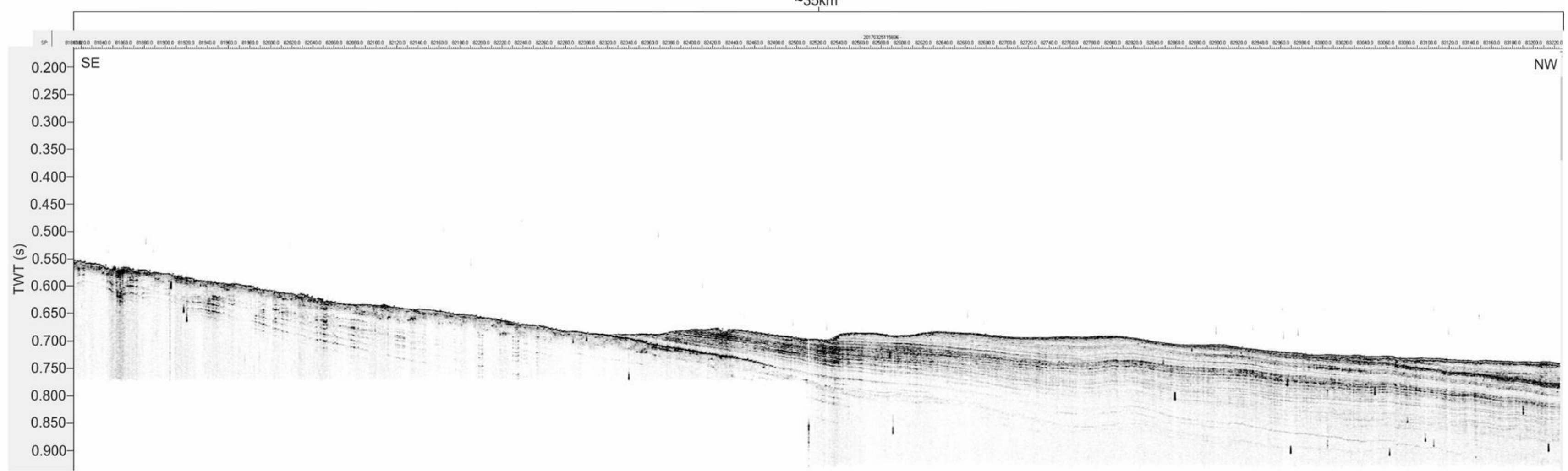

Figure 3.16a: Uninterpreted seismic section of line 15, located in the central southwest Campbell Plateau.

$\sim 35 \mathrm{~km}$

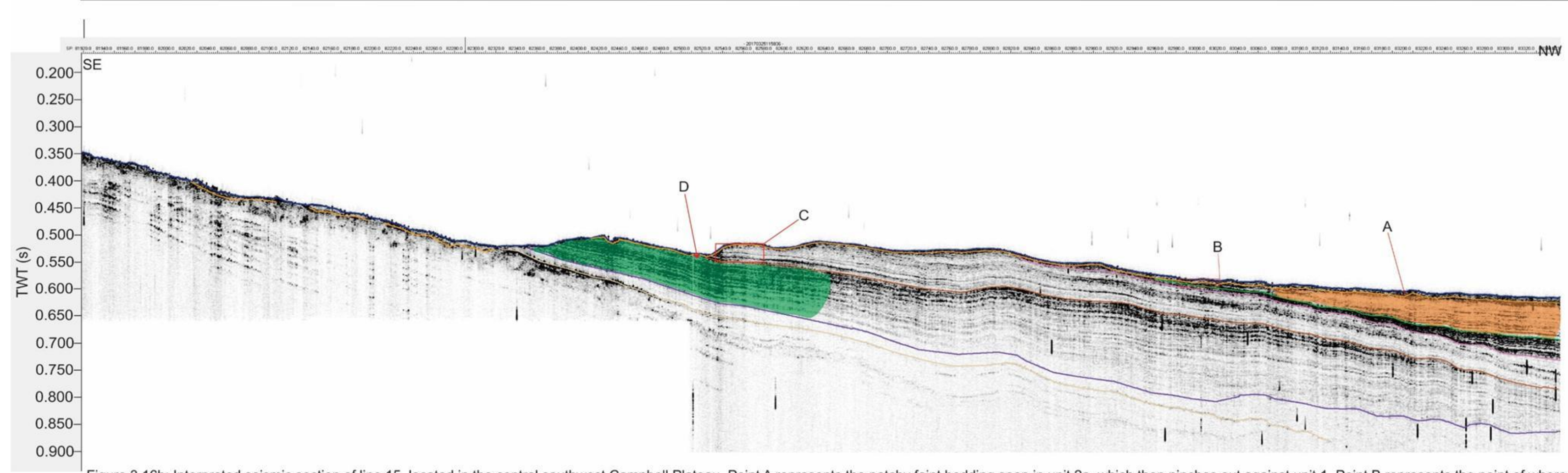

Figure 3.16b: Interpreted seismic section of line 15, located in the central southwest Campbell Plateau. Point A represents the patchy faint bedding seen in unit 2a, which then pinches out against unit 1. Point B represents the point of where unit $2 \mathrm{~b}$ pinches out and is planned off by the above unit $2 \mathrm{a}$. Point $\mathrm{C}$ represents the point where unit $2 \mathrm{c}$ is obliquely eroded against the above units unit $2 \mathrm{~b}$ and $2 \mathrm{a}$. Point $\mathrm{D}$ represents the variation of bedding amplitude seen unit $3 \mathrm{a}$, with this 


\subsection{4: Interpretation}

This line is seen to be generally subjected to the widespread erosion across all units, this could, in turn, be linked to its position of being deposition on the slope edge, or due to the nature of unit 1 (blue reflector to orange reflector) being the primary unit deposited above all units in this line and is the most widespread. The fact that all units in the SE section of the line terminate against this reflector suggests that unit 1 is most likely a large-scale unconformity. This idea is further confirmed through cores ODP1120 and DSDP277 confirming that this unit is part of an unconformable surface ((Carter., et al., 1999; Hollis, 1997). The deposition of this unit further solidifies the theory of a plateau wide event that caused the erosion of the Pliocene sediments.

These units were likely deposited along the edge of soon to be formed Campbell Island if it is assumed that the oldest units $3 a$ and $3 b$ can be tied to units 3 and 4 from ODP1120 core, which would give them the age ranges from Late Miocene to Early Miocene; covering the entire Miocene. With the age of the Campbell Volcanism occurring between from $\sim 11 \mathrm{Ma}$ to $6.5 \mathrm{Ma}$, it could be assumed that the tilting seen across these units could be associated with the development of the Campbell Island via basaltic volcanism during the Late Miocene. However, the theory is unlikely due to for this style of volcanic deformation to occur, this would have to be on a much larger regional scale rather than local. This then leaves the theory of the sediments being deposited after the formation of Campbell Island. This theory would allow for the tighter constraint of the ages of the lower units of this line through having a minimum age of at least $6.5 \mathrm{Ma}$. 
Chapter 4: Discussion 


\section{1: Introduction}

The following discussion is a synthesis and interpretation of the Results. Firstly, an overview of the seismic units each of which is summarised on a regional map. This shows how the units vary with extent, water depth, thickness, and any other relevant features. This will be then discussed to how this adds to the current state of knowledge of the Cenozoic evolution of the plateau. Following on from this overview, a discussion of possible events seen in units, how these link to wider oceanic/climatic events throughout the Cenozoic, in terms of both regional and global scales.

Unit lithologies suggestions, formations and features have been linked to the ODP site 1120 core as the central tie point, with surface cores from previous studies such as Summerhayes (1969) giving supporting evidence into the possible depositional environments of the upper units where applicable.

\section{2: Seafloor and Unit 1 extent and features}

\subsection{1: Seafloor extent and features.}

Much of Campbell Plateaus' surface is gently undulating, the seafloor has an average depth of $\sim 748 \mathrm{~m}$ across the area constrained within the polygon (Summerhayes, 1969). The Damuth scale is a measure of the echo characteristics of subsurface and seafloor, which in turn can be used to understand the surface sediments and processes at play. Approximately $40 \%$ of the all the seafloor reflector is characterised as Damuth scale of 1B-B; characterised as a continuous distinct sharp echo with continuous parallel subbottom reflectors. This echo type of $1 \mathrm{~B}-\mathrm{B}$ is associated with largely undeformed or slightly deformed sediments. The distribution of these reflectors is seen across a large area of the Campbell Plateau in areas with the sediment of moderate thickness, the areas where these reflectors are most prominent are particularly in the eastern and southern areas of Campbell Plateau (see figure 4.1).

Further Damuth scales such as the 1B-C is the second most common echo type. This is found in the SE and NW sections of the study area, it is generally a strong bottom reflector, which may indicate a hard seafloor surface due to the high amplitude response. The position of these echo types in the NW is interpreted to be located below the STF, due to sediment cover here being generally thinner than other areas could the due to its proximity to this front and strong currents. 
The Damuth echo types of the 1A variety are seen typically around the volcanic islands. Echo type $1 \mathrm{~A}$ is seen displaying generally a very strong bottom reflector and little subsurface reflectors. This again indicates a strong seafloor material and the presence of high erosion. Due to these being proximal to the islands, it could be inferred that these are part of wave-cut platforms.

Echo type 2A is seen in areas of steep relief in this study; this has typically hyperbolic sub-bottom echoes associated with it. Damuth (1980) suggests that these areas are typically sea mounds or escarpments and are generally difficult to understand the sedimentary processes when seen on the Campbell Plateau. The nearby ODP site 1121 (see figure 1.7 for location) taken on the "Campbell Drift" shows upper layers of alternating bioturbated sands and silts, with lower layers showing fully pelagic sediment (Graham, Carter, Ditchburn, \& Zondervan, 2004). Damuth (1980) suggest that these echo types related to contourite currents or sediment waves. This aligns with what has seen the upper units of ODP 1120 figure 1.7, which see sediment winnowing that is indicative of current-influenced sedimentation, likely due to the strong influence of the ACC and DWBC on this eastern side of the Campbell Plateau (Neil et al., 2004). 


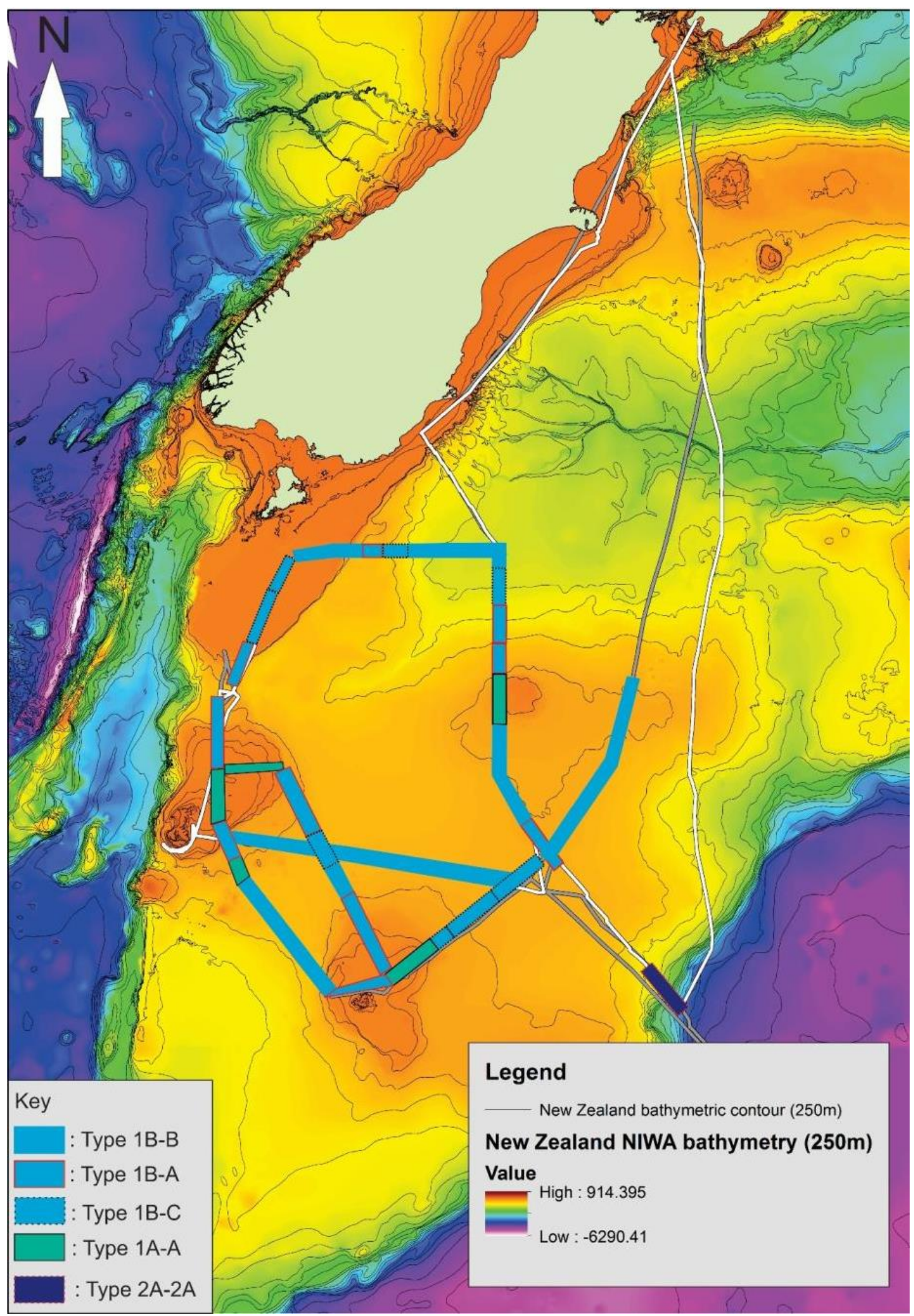

Figure 4.1: Map of the study area showing the variety of Damuth echo types found in the Campbell Plateau's subsurface. Note that type $1 B-B$ is the most common of the echo types found here and is generally found where sediment cover is relatively thick. All of the $1 B$ typed echoes are generally found where sediments are moderately coarse-grained (Damuth., 1980). The 1A sub-bottom echoes display sediments are generally coarse-grained (Damuth., 1980), these are seen predominantly around the volcanic islands. Type $2 A$ is generally hyperbolic (Damuth.,1980, with the example shown on this map generally found along the plateau edge where steepness increases dramatically. 


\subsection{2: Cause of seafloor extent and features}

The sediment extent studies performed by Summerhayes (1969) on the Campbell Plateau showed out of 136 cores gathered by Summerhayes, both surface and sediment, that 66 of these contained Globigerina ooze (see figure 1.9 for map of sediment extents). These areas also aligned with area that primarily have the echo type 1B-B, suggesting that the ooze has a relatively high amplitude. The sediments around the islands interpreted by Summerhayes (1969) show Polyzoan and shell debris on the upper slope and the immediate slopes with the lower slopes of the islands being more glauconitic rich Globigerina ooze. This indicates that the areas around the islands that have Damuth scales of 1B-C and 1A-A are associated with these sediments, however, due to the Damuth scales being primarily associated with mud and silt on the Amazon Delta, it is difficult to assess these in comparison to the biogenic sediments seen on the plateau.

Sediments seen from the Neil et al (2004) study found that sediment along the flanks of the plateau taken in core V1439 (see figure 1.7 for core location) was coarser compared to that of the interior cores such as Y14 which were generally finer grained. The plateau flank material is in line with what is seen in the Damuth echo type 2A. This saw generally coarser grained material and low sedimentation rates seen on the plateau, being 1 to $2 \mathrm{~cm} \mathrm{kyr}^{-1}$ during the LGM and increasing to 2 to $3 \mathrm{~cm} \mathrm{kyr}^{-1}$ during the Holocene (Neil, Carter, \& Morris, 2004). This is shown through strong erosion around the plateau edges such as the SAF on the south and eastern slopes. The presence of finer grained material in the interior and the generally quiescent environment that these sediments were deposited in. This is also in line with the echo type 1B to a certain extent, primarily due to the lack of current-based erosion that allowed the build-up of sediment and is generally seen to be finer grained sediment as was seen in the Damuth (1980) study. 


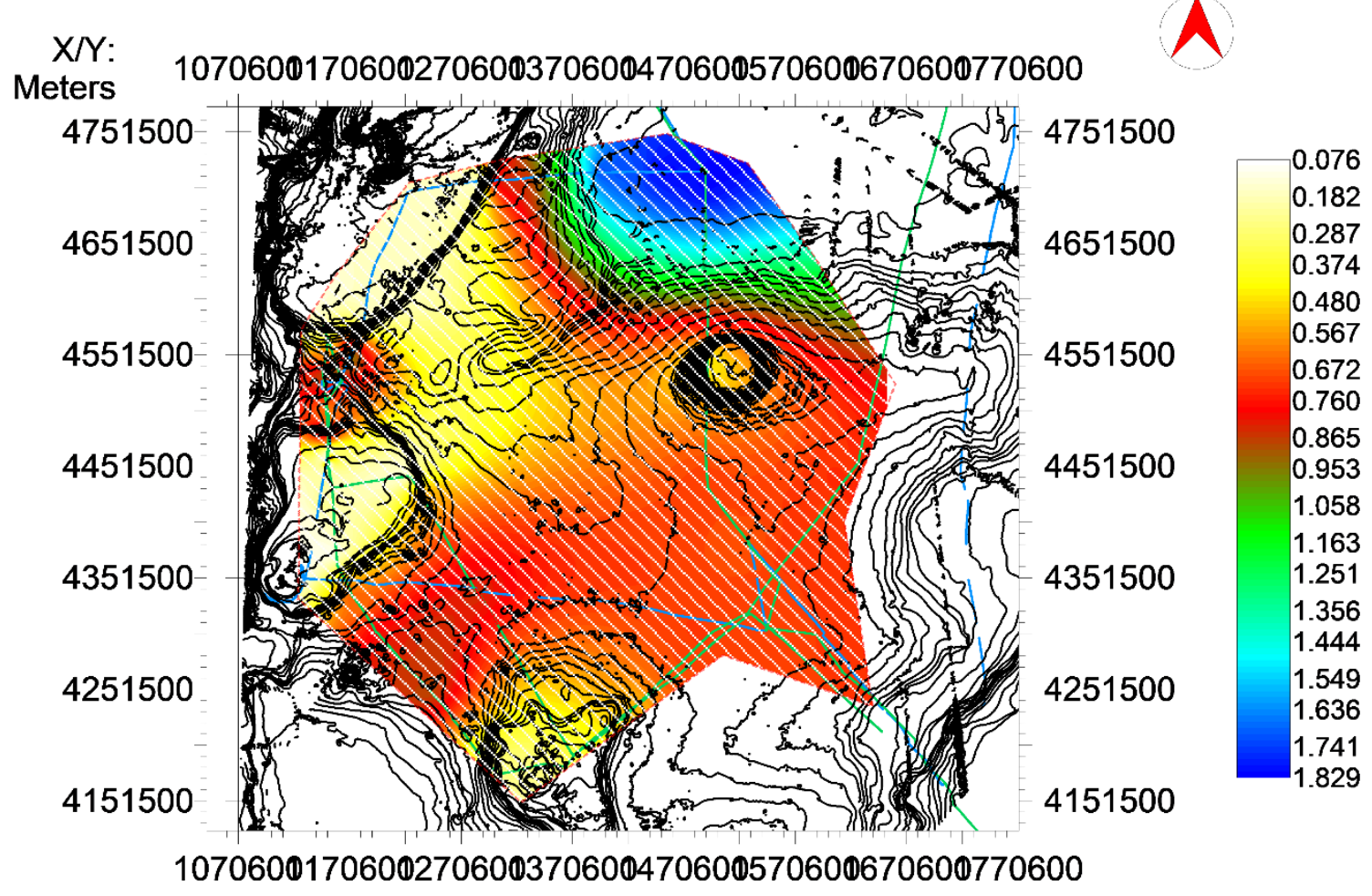

Figure 4.2: Isochron map displaying the difference in TWT depths of Unit 1 across Campbell Plateau. This unit is seen to be deepest across the southern and eastern areas of the plateau, with the unit becoming shallower in the northern and western areas of the plateau, particularly around the islands.

\subsection{3: Unit 1 extent and features}

Unit 1 is the most expansive unit across Campbell Plateau throughout this dataset and the most recorded via interceptions by cores. As it can be seen in figure 4.2, unit 1 covers much of the Campbell Plateau and is recorded within all interpreted seismic lines on most areas of Campbell Plateau apart from locations where erosion is greatest, where it is very shallow, such as near the shelf areas along the Auckland, Campbell Islands and Pukaki Rise. The locations where unit 1 is thickest in the northern section of Campbell Plateau and along the eastern side of the Campbell Plateau. This variation in thickness could be in part due to the variation in the circulation throughout the Pleistocene, particularly during the glacial and inter-glacial periods. The variation caused by the glacial and interglacial periods is likely due to the moving fronts which caused the shifting of the PF and SAF equatorward by $5-10^{\circ}$. This shift then led to the thermal isolation of Campbell Plateau during the LGM, the thickness variation of unit 1 could be due to this increased internal circulation on the plateau during the LGM. Due to the conditions of the LGM with the increase of wind strength and the associated increase of dust deposition from Australia (Carter, Neil, \& McCave, 2000; Durand et al., 2017) in turn led to an increase in foraminifera production, thus leading to an increase in sedimentation with the following interglacial period. 
The variability the thickness changes of unit 1 might also be a contribution from the warming period of MIS 5e which saw a mean annual temperature rise of 0.9 to $1.8^{\circ} \mathrm{C}$ rise through the influx of subtropical water on to the Campbell Plateau. This influx lead to an increased stratification of the ocean and a thermally stratified upper ocean which led to the increased production of coccolithophore production during this time (Duncan et al., 2016). This increase in production in the subantarctic region is tied to the increase in sedimentation across Campbell Plateau during glacials.

With unit 1 being largely dated to Pleistocene as seen in cores ODP Site 1120, DSDP Site 277 and the various surface cores this unit is also acknowledged to have its base as an unconformity surface across the primary cores of the Campbell Plateau (ODP1120 and DSDP277). This unit is seen to be linked to an unconformity between the Miocene layers and the Pleistocene, with the entire Pliocene missing. Due to unit 1 being widespread across Campbell Plateau, and where it is present it has a relatively uniform thickness of $\sim 7$ to $\sim 10 \mathrm{~m}$.

Due to this unit having a relatively consistent thickness variation where present, however its base is defined by an unconformable surface suggests that this unit has been largely affected by the glacial and interglacial variations in currents.

\section{3: Unit 2 extent and features}

\subsection{1: Introduction}

Unit 2 and its associated subunits is the thickest unit on the plateau and its associated subunits are seen throughout the majority of the Campbell Plateau, especially in the eastern, southern and northern sections of the study area. As seen in figure 4.3 the general thickness of unit 2 varies in depth across much of the plateau, with the exception of areas of thicker sediment such as along the northern sections where unit is at a depth of up to $\sim 0.283$ TWT as seen against the NW side of Pukaki Rise (see figure 4.3).. This unit varies between faint reflectors/ or well-defined reflectors. The low amplitude and higher amplitude variants of this unit are likely linked to the variations of lithology within the unit have differing percentages of $\mathrm{CaCO} 3$ versus lithogenic influence on the biogenic ooze. The unit 2 seen in the more southern DSDP site 277 core, this consists of un-varying nannofossil ooze that has common glauconite but is dated to Oligocene in age (Hollis, 1997), while unit 2 in ODP1120 consists of near 
identical lithology, consisting of a nannofossil ooze with aspects of glauconite and pyrite. Due to the distance of the southern lines to the DSDP277 core, further suggesting all ties on the central plateau at this time be made to ODP site 1120. This would suggest that much of $1000 \mathrm{~m}$ contour and shallower is of Miocene aged material, with the Oligocene only preserved in the Tucker Limestone on Campbell Island. Unit 2 when tied to the ODP1120 core is seen to be early Pleistocene in age and with the units below this being Miocene in age shows the bottom of this to be unconformity due to lack of any Pliocene material, this would suggest two unconformities are widespread across the plateau.

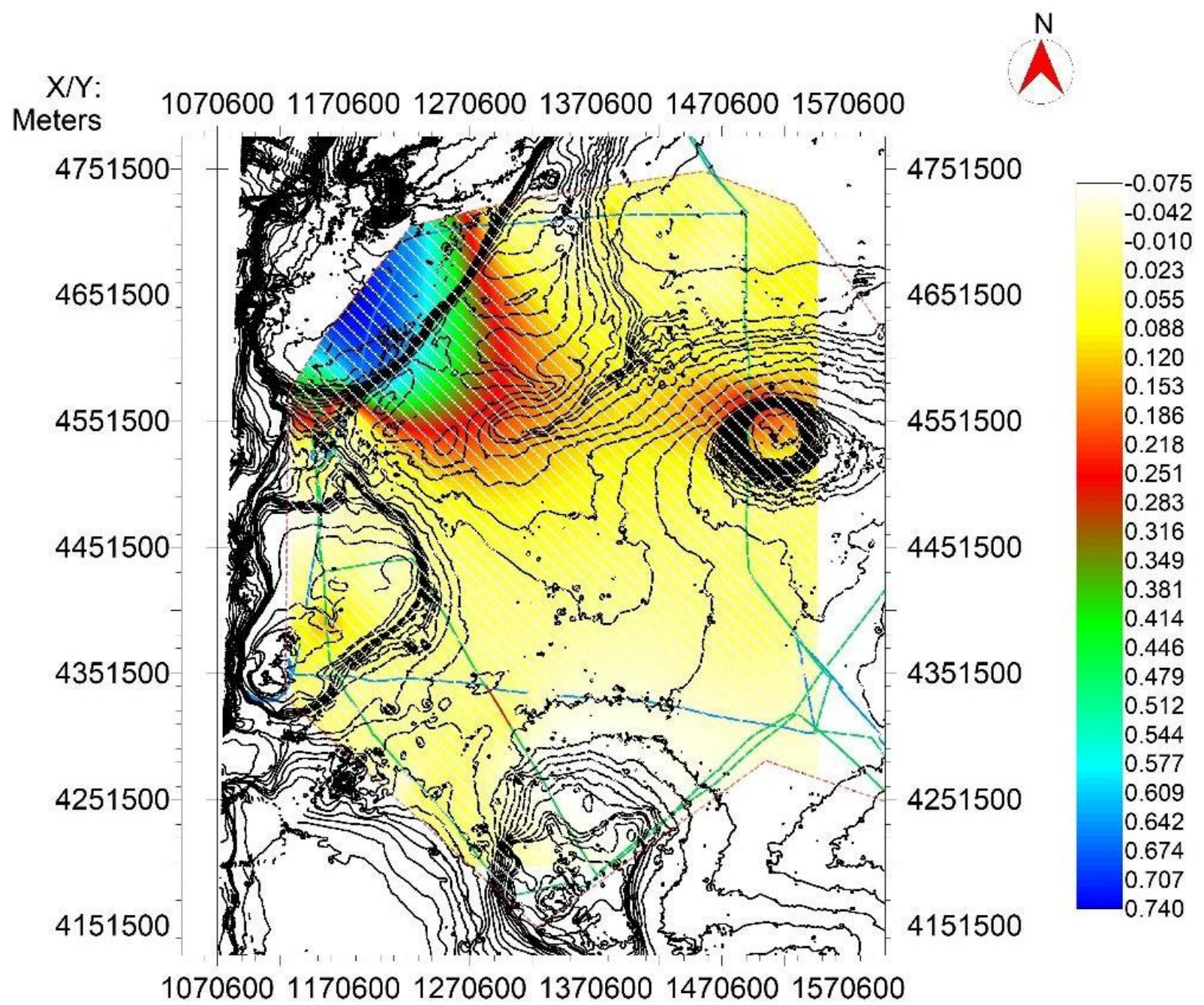

Figure 4.3: Isochron map of unit $2 a$, showing its extent and thickness variation across the Campbell Plateau. Note that Pukaki Rise is in the NW section of the study area. 


\section{4: Unit 3 extent and features}

\subsection{1: Introduction}

Unit 3 across the Campbell Plateau in this study can be split into several subunits that have been tied from the only main core on the plateau, ODP site 1120 . These ties result in unit 3 having differing extents across the plateau. These units are generally well bedded and defined throughout and often display more enhanced deformation compared to that of the upper units.

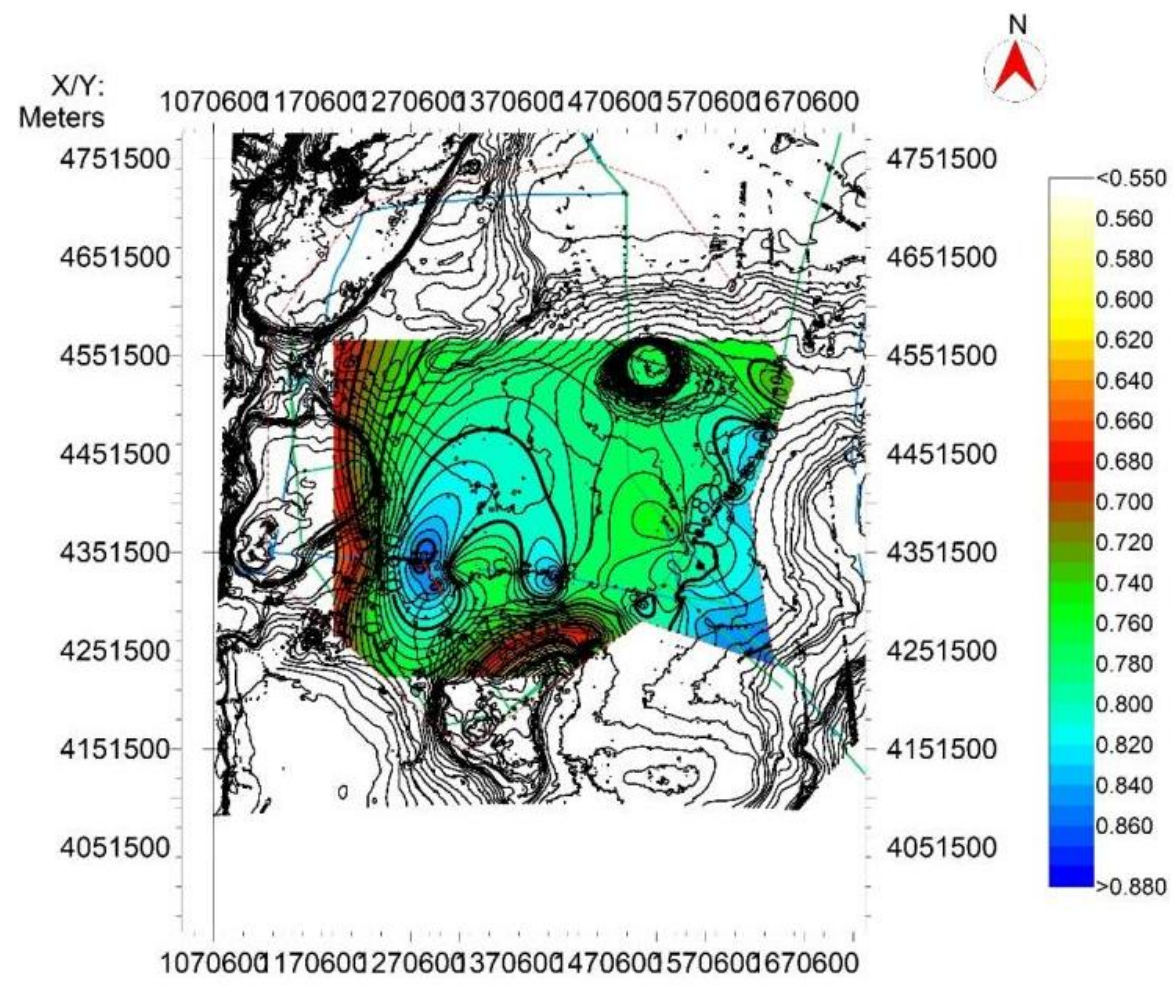

Figure 4.4: Isochron map of depth to ODP1120 unit 3a (in this study), depth is measured in TWT. Note that this unit is primarily located in the southern section of the Campbell Plateau. It is not known however whether the extent of this unit fully continues up into the central plateau with this extrapolated thickness due to lack of data present there.

\subsection{2: Extent and features of Unit 3}

Unit 3 in this study is the more localised of all the units seen on the Campbell Plateau, with the majority of this unit seen to be restricted to the southern and eastern sections of the plateau, however, due to basement penetration generally being present in the shallower sections of the plateau this is uncertain. In the west, north-west sections and 
around the islands of the plateau this unit is generally seen less, due to the lower sediment coverage present in these areas and due to topographic controls on the unit.

The common features of unit 3 seen in lines 3 and 5 is that reflectors within this unit is generally faint. This is also generally is subjected to the most deformation, having the highest folds. These folds were generally, unit 3 is also seen to have structural features that further add to this deformation such as in lines 3 and 5 (see results section; figures $3.4 \mathrm{~b}$ and 3.6b) have the presence of possible submarine volcanism. With the proximity of lines to Campbell Island would suggest that these structural features occurred with the associated volcanism with the creation of Campbell Island, giving these features the likely of age of Middle to Late Miocene (11 to 6.5Ma) (Adams et al., 1979). The further deformation of these units and the beds against the submerged volcanoes (see figure 4.6).

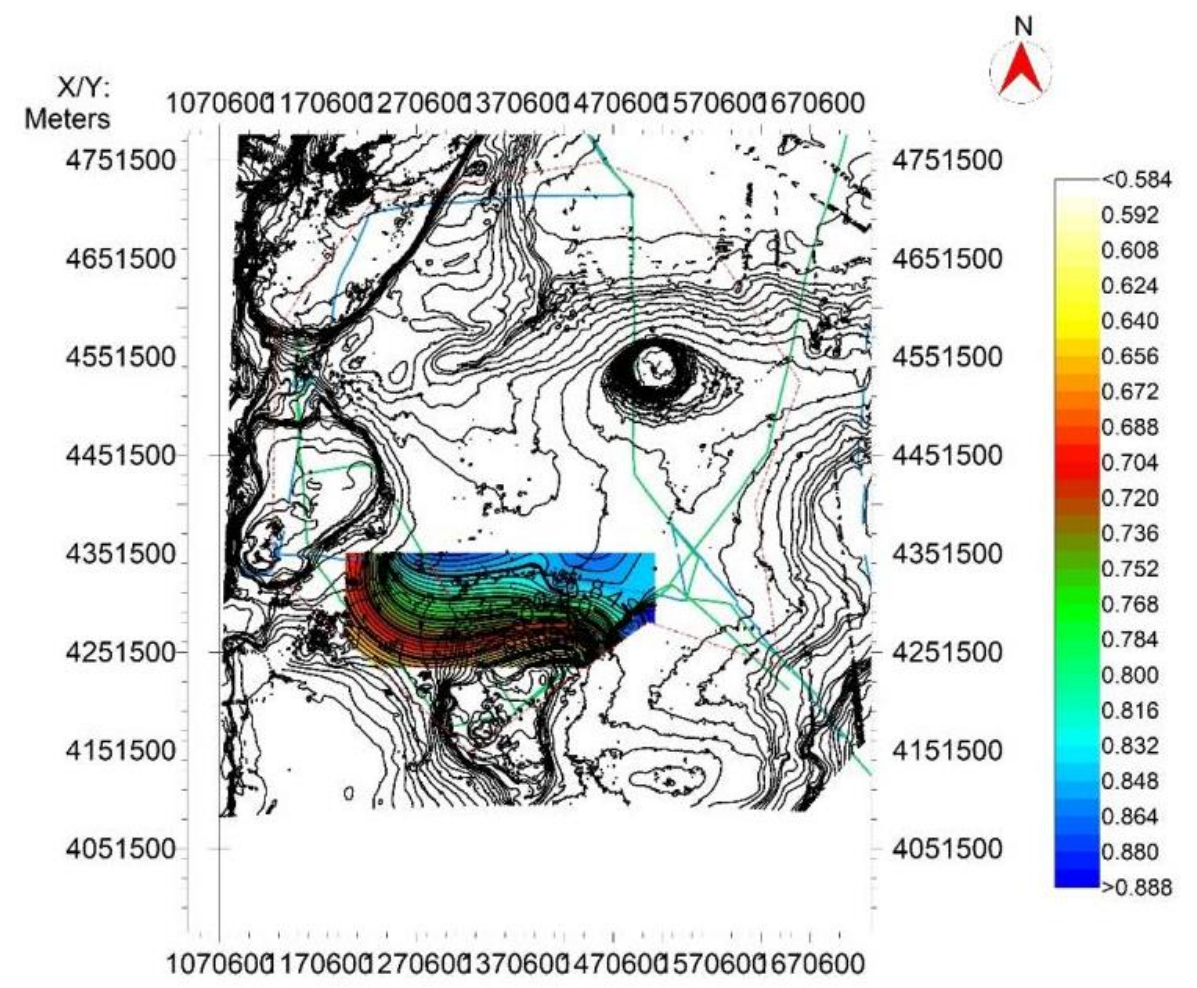

Figure 4.5: Isochron map of the extent and depth of ODP1120 $3 \mathrm{~b}$ reflector (Purple reflector) with depths displayed in TWT. This represents the bottom of unit $3 \mathrm{~b}$ as tied to the ODP1120 core. This section is primarily restricted to the south and southeast in this dataset.

The extent of the unit $3 \mathrm{~b}$ can be seen in figure 4.5 where it is primarily located in the southern section of the plateau. The variation of this unit is heavily influenced by the nearby bathymetry changes caused by the Auckland Islands slope edge and the general increase in sediment thickness in the southern and central sections of the plateau. This 
variation of this unit gives it an average time of $\sim 0.704$ TWT and an average thickness of $\sim 28.7 \mathrm{~m}$ through approximate conversion assuming a velocity of $1600 \mathrm{~m} / \mathrm{s}$ across the area. The extent of this unit also gives an indication of the sediment dispersal. If this unit is extrapolated to be tied back to the deep sea core DSDP277 (see figure 1.7 for core location), the lithology seen is nannofossil chalk with chert nodules that are stiff and semi-lithified with the age of Middle Eocene (Hollis, 1997; Hollis et al., 2015). The date of this unit when tied to the core DSDP277 core is anomalous in comparison to the ODP1120 core to the NE which displays units with a maximum age of Early to Late Miocene in age (Carter et al., 1999). However, due to the bathymetric difference of $\sim 200 \mathrm{~m}$ between the seismic lines and the DSDP277 core location; this may not be a reliable tie with a steep increase in bathymetry from the closest lines to the core. With this unit in the study area having an average thickness of $\sim 30 \mathrm{~m}$ where present, and the unit 3 in the DSDP277 core having a measured thickness of $208 \mathrm{~m}$, it is possible that with the associated change in relief that unit $3 \mathrm{~b}$ in this study may represent the top section of this unit. The lack of this unit in the other sections of the plateau may indicate there was a period of widespread erosion, particularly in the eastern sections of the plateau. This widespread erosion has caused an unconformity regarding the presence of this unit being almost exclusively present in the southern section of the study area. However, without a detailed core log taken in this area, it is difficult to assess whether this unit is part of the DSDP277 core section or simply a continuation of the units seen in the ODP1120 core to the NE.

Further features seen in this unit also show that where this unit is present, that it has a relatively uniform thickness of $\sim 30 \mathrm{~m}$ across its length. The only alterations to this thickness occurring with the bathymetric changes against the volcanic islands, in which the units appear to be banked up or the "pulled up" effect or the opposite which is the "pull down" (Dimitrov, 2002) in relation to the when this volcanism occurred post or pre-deposition (see figure 4.6 for schematic). 


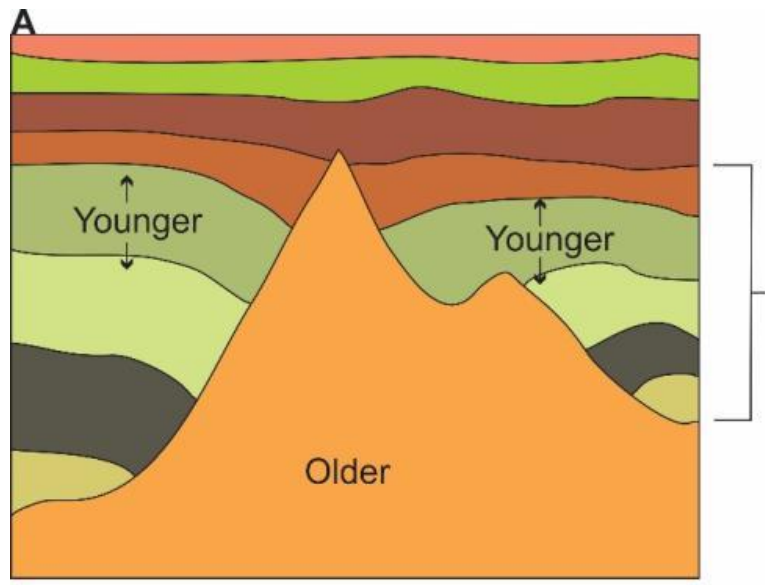

Onlap of sediment against the volcanic centre due to being deposited after the formation of the submarine volcano. Onlap of these sediments is caused by the channelling of bottom currents moving around the volcano and subsequently eroded sediments banked against the volcanoes edge. This is present in line 14 on the older sediments of the central SW Campbell Plateau.

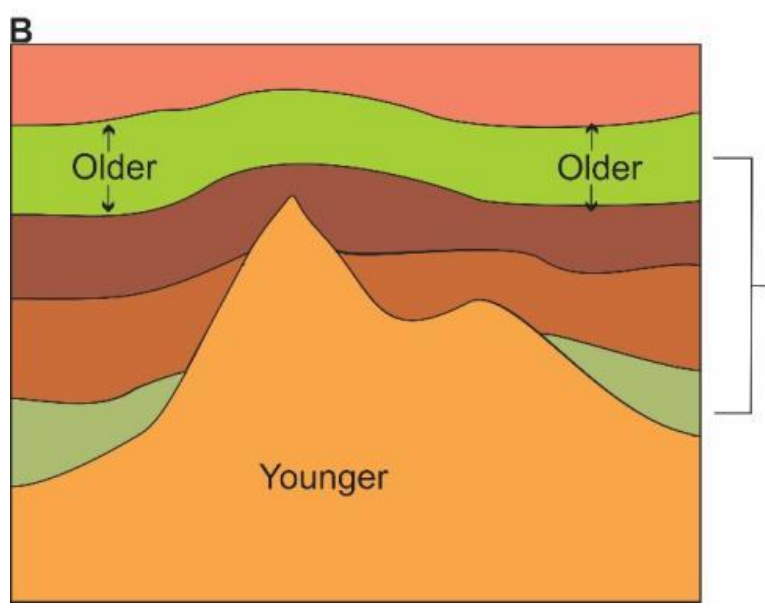

Sediment deformed upward against the edge of the volcanic centre with younger sediments mounting the intrusion. Sediment generally forms wedges against the structure or pinch out sections. This present in to a lesser extent in line 5, SE Campbell Plateau and on the younger sediments of line 14 of the SW Campbell Plateau.

Figure 4.6: Schematic figure of the impacts of submarine volcanism on sediments seen in the study area. Schematic A shows the form of bedding against an already present volcanic edifice, this is primarily seen in the central $S W$ plateau. Schematic B shows the influence of an intruding volcano on sediments after their deposition; note the presence of potential wedging in the lower units of the schematic. Much of the volcanism seen in this study and the plateau is seen near Campbell Island in the SE section of Campbell Plateau.

\section{5: Structural Features of the Campbell Plateau Subsurface}

\subsection{1: Introduction}

The subsurface of the Campbell Plateau displays various structural features that have simply been unobserved prior to this study; an example of this is the various faults and the distribution of faults seen throughout the interpreted units. The spread of these faults can be seen in figure 4.6, which shows these faults localities, the potential style of the fault and whether it is a significant (throw) fault or insignificant (small) fault. This data will then be compared to suggestions made by Summerhayes (1969) regarding the structural geology of the Campbell Plateau. 


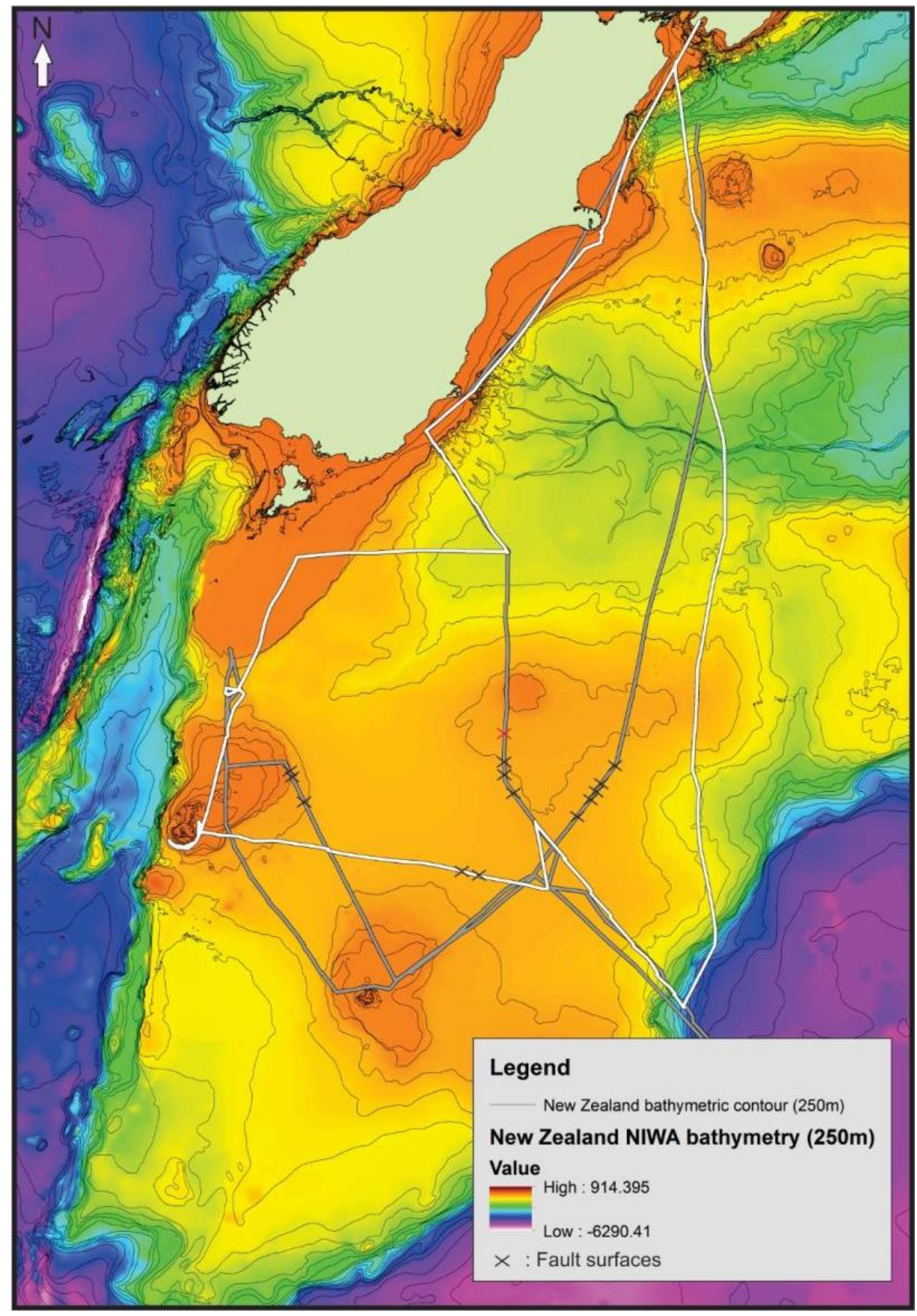

Figure 4.7: Map showing locations of faults interpreted in this study on the Campbell Plateau. Black crosses indicate areas of significant faulting within the units, with the red crosses indicating minor faulting seen in only within individual units. The white lines present seismic lines from TAN1804; the grey lines represent lines from TAN1703 voyages. 


\subsubsection{The subsurface structural geology of Campbell Plateau}

The structural geology the Campbell Plateau can be seen through its distribution of faults and units that they cut through. The distribution of these faults is generally seen to be in the central part of Campbell Plateau, this distribution along with much of the lines these faults are associated with showing a degree of folding that ranges from moderate to high in folding. This range of folding suggests that these faults may be compressional in nature; shown in the general profile of the faults. Although there can be no full interpretation be made on the style of faulting, due to the lack of cross-cutting seismic lines, it can be assumed that due to the compression seen across a large portion of the Campbell Plateau that these are possibly reverse or dip slip faults.

The structures are significantly different from the previous Campbell Plateau assessment of structures by Summerhayes (1969). The structural interpretations made by Summerhayes (1969) were made off inferences from the variations seen in the topographic highs and lows. Based on this interpretation Summerhayes (1969) inferred the presence of two main anticlines that are formed over Campbell Island and Pukaki Rise, with the syncline in the topographic low (see figure 4.8). However, based on the faults interpreted in this study, these patterns are not conclusive of what is seen in this study, there is no presence of large folds in the study area. Although due to the large gap in seismic data in the centre of the plateau this cannot be fully confirmed or denied. 


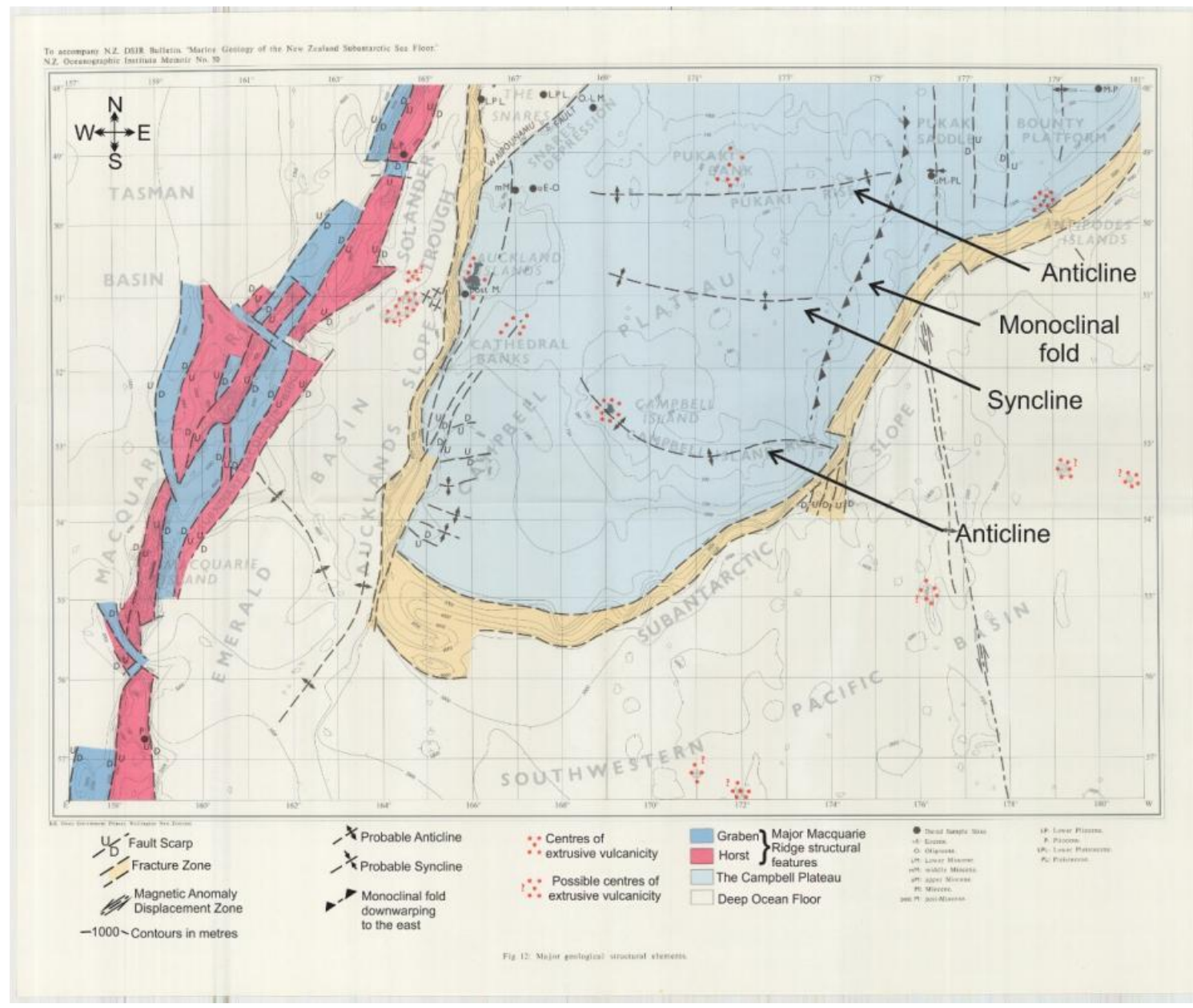

Figure 4.8: Structural interpretation of the Campbell Plateau by Summerhayes (1969). The area highlighted in light blue represents what is interpreted to be the top of the plateau. The area highlighted in light brown indicates the Campbell Plateau slope edge/deep ocean floor. The blue and red area to the west indicates the Macquarie Ridge structural features; with blue being graben structures and red being horst structures [this area is not included in this study] (Modified from Summerhayes., 1969).

\subsubsection{Extent and amplitude and timing of faulting}

Significant faulting (black crosses) seen on the Campbell Plateau is seen predominantly within units 2 and 3 and their associated sub-units, with the exception to minor faulting (red crosses), which is seen within primarily within unit 2 and its associated sub-units (refer to figure 4.6). The significance of these faults being primarily found within units $2 b$ through to $3 b$ and $3 c$, with the ages of these units being tied to Miocene in age (when extrapolated from the ODP1120 core). These faults have an average offset of $\sim 10 \mathrm{~m}$ across the plateau, with much of the faulting being constrained to the northern half of Campbell Plateau. 


\subsubsection{Possible causes of structural geology}

Due to the faulting seen to be relatively minor when set to the scale of the Campbell Plateau and the potential timing of these faults forming during the Miocene epoch, it would suggest that the potential deformation seen in the central plateau could be linked to the general movement of Campbell Plateau with associated deformation of Zealandia.

During the Miocene Zealandia and the Campbell Plateau was largely seen to have continued to spread from Antarctica at a rate of $15 \mathrm{~mm} / \mathrm{yr}$ (Cook et al., 1999). Due to the locations of all these faults being in the northern half of the plateau; primarily the northern central areas this minor internal deformation could be simply part of the transition from extensional to strike-slip movement southward, as was the case with southern Zealandia (Cook et al., 1999). In the northern Great South Basin, this transition from extensional to strike-slip is seen from the Miocene through to the present (Cook et al., 1999). However, this is not seen on the Campbell Plateau with the units that have been dated to Pleistocene and younger to have no evidence of faulting. This evidence suggests that the minor deformation seen on Campbell Plateau during the Miocene possibly moved northward.

\section{6: Features of subsurface Campbell Plateau}

\subsection{1: Introduction}

Due to the relatively unexplored nature of the Campbell Plateau's subsurface, there is little understanding of the nature of it, with knowledge only coming from the sediment cores drilled on the plateau. These sediment cores, such as ODP1120 and DSDP277 allowed for insights into the composition of the majority of the plateau and possible events that altered the sediment record. This study, however, shows that the Campbell Plateau has a reasonably complex subsurface history, with a variety of subsurface structures.

The Campbell Plateau can be broken up into sections that represent different areas of subsurface features. In the northern section of the plateau there is the presence of contourites near the edge of the slope of the South Island and Stewart Island (see figure 4.9). In the southern and central sections of the plateau, there is evidence of volcanism and biogenic gas seen within much of the units in this area of Campbell Plateau. Volcanism is generally seen within the central and south-eastern sections of the study 
area (see figure 4.9). The volcanism interpreted in these areas is found in the areas of the traditional volcanism on the plateau, near the volcanic centres of Auckland and Campbell Islands.

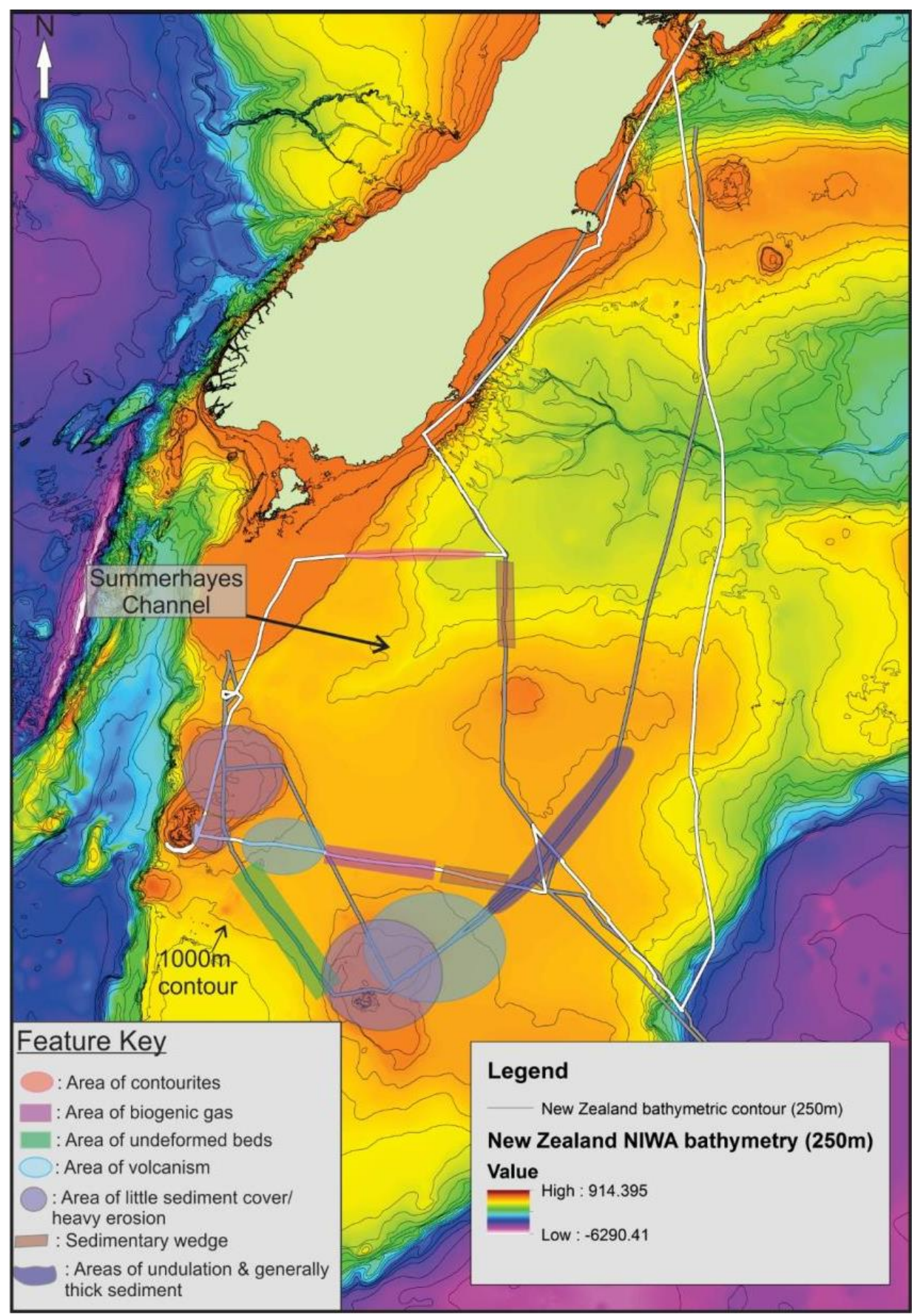

Figure 4.9: Map of the Campbell Plateau displaying the location of the main features of the subsurface. 


\subsection{2: Contourites}

These sections display features that are primarily formed by oceanographic and sedimentary means. This is shown through the presence of contourite current formations in Line 7 (see figure 3.8b) and sedimentary wedges in the north such as in Line 8 (see figure $3.9 \mathrm{~b}$ ). The eastern section of the study area displays pockets of possible gas escape structures such as in Line 10 (see figure 3.11b) with also anomalous seismically opaque features that are seen in both the east at Line 1 and in the north in Line 7 (see figures $3.2 \mathrm{~b}$ and $3.8 \mathrm{~b}$ respectively).

The bottom currents seen in the northern area of the study area are located to the east of Snares Plateau and the continental slope edge of the South Island. This line crosses the path of the modern-day STF and the SC (see figure 1.16). The profile of these currents likely represent small patch drift deposits that are elongate (Stow \& Faugères, 2008). The largest of these drifts having a length of $\sim 10 \mathrm{~km}$ and a height of $\sim 0.055$ TWT or $\sim 84 \mathrm{~m}$, however, the overall geometry of these cannot be attained due to a lack of crosscutting seismic lines. The closest analogue for these contourite currents can be found to the north at ODP site 1119 in the Canterbury basin and also at IODP Site U1352 (Fulthorpe, Hoyanagi, Blum, \& Expedition, 2011). The contourites found in Canterbury Basin are made up of terrigenous silt and fine sand which are representative of glacial and interglacial cycles throughout MIS 1-7 in unit A in the ODP 1119 core (Carter, Fulthorpe, \& Lu, 2004). The formation of the contourites in this area is seen to be deposited from the northward flowing SAMW at 250 to $800 \mathrm{~m}$ depth and the AAIW at $\sim 800$ to $1100 \mathrm{~m}$ depth. These contourites transitioned from elongate large drifts to smaller and higher-energy drifts after $\sim 3.25 \mathrm{Ma}$ and are interpreted as a change from the AAIW to the beginning of the SAMW northward flow (Carter et al., 2004). This change drift style also saw an associated increase in production of planktonic calcareous fauna, further emphasising the transition of glacial to interglacial periods (Carter et al., 2004). If the contourites seen in the northwest section of the study area share a similar profile and formation as the Late Pliocene ( $\sim 3.25 \mathrm{Ma})$, this would give further evidence of the contourites discovered in this study to be likely formed by the northward-flowing SAMW, which was driven by the SC. When NW section of the study area are overlain with the sediment maps compilated by Bostock et al. (2018), the dominant lithology of the seafloor is carbonate, having a composition of $\sim 80 \%$. This high percentage of 
carbonate in this area is in accordance with the rest of the seafloor of the Campbell Plateau, this could also be associated with the increases in planktonic production from 3.25Ma seen in Canterbury Basin. The closest surface cores to this area, Y17 and D134 (see figure 1.7 for both core locations) show $223 \mathrm{~cm}$ of foraminifera mud and phosphatised foraminifera ooze respectively (Carter et al., 1999; Summerhayes, 1969). With only the D134 core being dated, having a date of Mid to Late Oligocene - Early Miocene (Summerhayes, 1969) is therefore ruled out due to this likely being an eroded section of sediment. Being to the south of this seismic line possibly shows that these newly discovered contourites could suggest the surface sediment age-aligned with this, rather than the Pliocene ODP 1119 contourite/drift deposits. During the Mid to Late Oligocene to Early Miocene, the palaeoceanography reconstructions show with the establishment of proto-fronts only beginning to develop within the Oligocene with the leaking of Tasman Gateway and the initiation of the ACC (Campbell S. Nelson \& Cooke, 2001; J. C. Zachos et al., 1993). However, in the Early Miocene the establishment of a subtropical climate with the movement northward of the AAPF, which in turn led to an increase in planktonic production, this could be associated with the widespread carbonate dominate D134 core. However, due to these contourites overlaying unit 1 , given the age of unit 1 being at least Pleistocene in age can be assumed that these are Late Pleistocene and younger.

\subsection{4: Northern sedimentary wedge- Pukaki Rise.}

The wedge formations are seen to the north of Pukaki Rise such as in line 8 (see figure 4.9 and figure 3.9b: chapter 3) are definitive of typical sedimentary wedge features. As these seismic lines are orientated N-S, the wedge discovered in this study trends along slope increasing toward Pukaki Rise. Nearby core, F106, taken directly south of Pukaki Rise suggests that sediment within the $250 \mathrm{~m}$ to $500 \mathrm{~m}$ contour is Pliocene to Pleistocene in age (Summerhayes, 1969). This wedge has a length of $\sim 12 \mathrm{~km}$ and has the appearance of an onlap fill surface. This feature is well stratified, appearing indicative of a possible lowstand onlap surface. The wedge itself has a thickness of $\sim 0.043$ TWT or $\sim 66 \mathrm{~m}$. Given the nature of the surrounding sediments in the area and ties to the few deep-sea cores on the plateau, this is likely to consist of carbonates/nannofossil ooze. 


\subsection{5: Anomalous/unknown features}

These features seen in the eastern section of the plateau, as seen in Lines 1 and 7 (see figures $3.2 \mathrm{~b}$ and $3.8 \mathrm{~b}$ respectively). In Line 1 this feature is seen in the bottom of the unit $2 \mathrm{c}$ and is a relatively large structure that is $\sim 1 \mathrm{~km}$ in width, the feature displays a large drop in amplitude in between otherwise continuous bedding within unit 2c. As stated previously, this formation is unlikely to be volcanic in nature due to lack of the typical high amplitude characteristics outlining the general form of the volcanic edifice.

Line 7 also displays anomalous material in the western section of the line there are two low amplitude rounded structures that are $\sim 20 \mathrm{~m}$ in height and width of $\sim 1 \mathrm{~km}$ at largest. Without sediment samples or sufficient survey data to outline the morphology and orientation of the mounds, their origin is a matter of speculation. Firstly, the mounds have irregular relief, likely linked to the normal faulting seen below these. They also appear to be deposited to active bottom currents judging by the distribution of unit 1 sediments on the largest mound which appears show erosion or non-deposition on what is here interpreted to be the up-current side of the mound with deposition in the leeward side (see figure $3.8 \mathrm{~b}$ ). The overlapping unit 1 buries the smaller mounds. TOPAS profiles reveal a well layered internal structure.

Their lack of any regularity in relief together with their layered internal structure suggests the mounds are unlikely to be current induced sand waves, which tend to some regular relief and, more importantly, display foreset-like internal bedding e.g. Berne et al. (1988). More likely, the mounds are bioherms formed by cold-water corals. Highresolution seismic profiles presented by Correa et al. (2012) show similar internal structure, which is consistent with the thicket-like structure of such bioherms. Furthermore, the irregular intertwining structure of cold-water corals provides some resistance to bottom currents. Finally, cold-water coral reefs are well established in the New Zealand region including Campbell Plateau (Roberts et al., 2006) 


\subsection{7: Southern and western features of the Campbell Plateau}

These sections of the study area generally show the variations of the volcanism seen across the study area. The west displays features that are indicative of heavy erosion in the shallower sections of the plateau.

The southern sections of the Campbell Plateau are where much of the volcanism is seen, adjacent to the volcanic Auckland and Campbell Islands. Although there is volcanism seen in the west (as seen with the Auckland Islands), volcanism in this study is primarily seen in the south and southeast sections around Campbell Island.

The volcanism seen in Line 5 to the NE of Campbell Island is an example of this (see figure 3.6b). The sub-surface volcanism seen in this study further confirms the extent of the volcanism on the Campbell Plateau, with the locations of these lines relative to Campbell Island also further confirms the northward movement of volcanism throughout the Cenozoic on the Campbell Plateau (Adams, 1981). However, the overall extent of these sub-surface volcanoes cannot be fully assessed due to the lack of perpendicular seismic lines across the structures. Further volcanism is also seen in the central southwest section of the study area (see figure 3.15b; Chapter 3).

\subsection{8: Western erosion and features}

The western section of the study area exhibits the areas of thin sediment cover and erosion seen on the shelf areas of the plateau. In the central western areas, this transitions less erosion, thicker sediment and examples of possible areas of biogenic gas seen within some seismic sections.

Much of these erosive features are seen along the shelf edge of the study area, around the Auckland Islands and further north. These seismic sections generally only show one unit with areas of sediment pockets.

An example of this thin sediment cover is seen in Line 6 located directly east of the Auckland Islands (see figure 4.7b). These high levels of erosion are likely a combination of being in relatively shallow water $\sim 300 \mathrm{~m}$ and strong bottom currents that have caused the scouring of these platform areas, this, in turn, has allowed for little sediment to be deposited over these areas. These regions would have been significantly shallower during the glacials when sea level was $\sim 120$ m lower than the present. This 
would leave the course of this high erosion to storm waves as this region experience significant wave heights of $10 \mathrm{~m}$, this is further evidenced by the high amount of strongly reflective eroded material seen in the northern and southern sections of line 6 for example.

\section{7: Comparisons with global \& regional events}

\subsection{1: Pliocene Unconformity}

Throughout the Cenozoic much of the surrounding oceanography and geology of the Southern Ocean and Southern New Zealand changed in relation to the movements Antarctica and tectonic movements of Zealandia as a whole (King, 2000). Since the Campbell Plateau is an original piece of Gondwana it has been through the entire Cenozoic evolution of Zealandia. The drilling of the ODP 1120 core discovered that units 1 and 2 lie unconformably above unit 3, with unit 1 and 2 being dated to Pleistocene in age, while unit 3 being Late Miocene in age (Carter et al., 1999). This unconformity suggests a regional wide erosional event of the Pliocene across the plateau. This study found that unit 1 of the ODP1120 core is traceable along the outside of the plateau with it also being present in the centre of the plateau where data is available. Due to the timing of this unconformity, the disappearance of the Pliocene across the study area and planar nature of the base of unit 2 above unit 3 gives the prospect of an intense scouring across much of the plateau during the Late Pliocene/Early Pleistocene.

In this time frame the only event that appears to impact the Campbell Plateau a significant way is the movement of the Polar Front Zone northward at $\sim 2.4 \mathrm{Ma}$ (see figure 4.10 and 4.11) (Hodell \& Warnke, 1991). The significance of this movement on the plateau is that due to the movement of the PFZ northward which in turn led to an increase in glaciation due to the associated cooling with subsequently increasing wind vorticity across the Southern Hemisphere, impacting the Campbell Plateau (Carter et al., 2002). The northward movement of the PFZ causes an associated shift with other fronts and water masses in the Southern Ocean and Subantarctic New Zealand, which had a temporary movement of $5-10^{\circ}$ north. Past studies debate whether this shift was enough 
for the SAF/PFZ to overcome the topographic constraint of the Campbell Plateau (Campbell S. Nelson \& Cooke, 2001). This shift northward of the southern water masses with the combination of the topographic constraint of the Campbell Plateau shows an increase in the circulation speeds of the ACC/SAF against the edges of the plateau (Morris et al., 2001). This increase in current speed and strength likely had an impact on this widespread nature of the unconformity, as seen throughout the LGM. The north-west section of the unconformity is likely to be eroded by a splay of the now more northward ACC/SAF and STF. This erosion seen in this study suggests that this splay is linked to the ACC flowing through the gaps in the Macquarie Ridge and through the Snares Depression to flow to the immediate north of the Auckland Islands gives a possible cause of both the unconformity and the contourite formations seen in this NW section. The evidence of a paleo-channel to the NNE of the Auckland Islands is also evidence of this (see figure 4.9 and 4.10). The presence of features such as the sedimentary wedge seen to the north of Pukaki Rise seen in line 11 could likely be formed from this new suggested glacial current pathway along, also forming paleochannel which will be referred to the Summerhayes Channel (see figure 4.9 and 4.10).

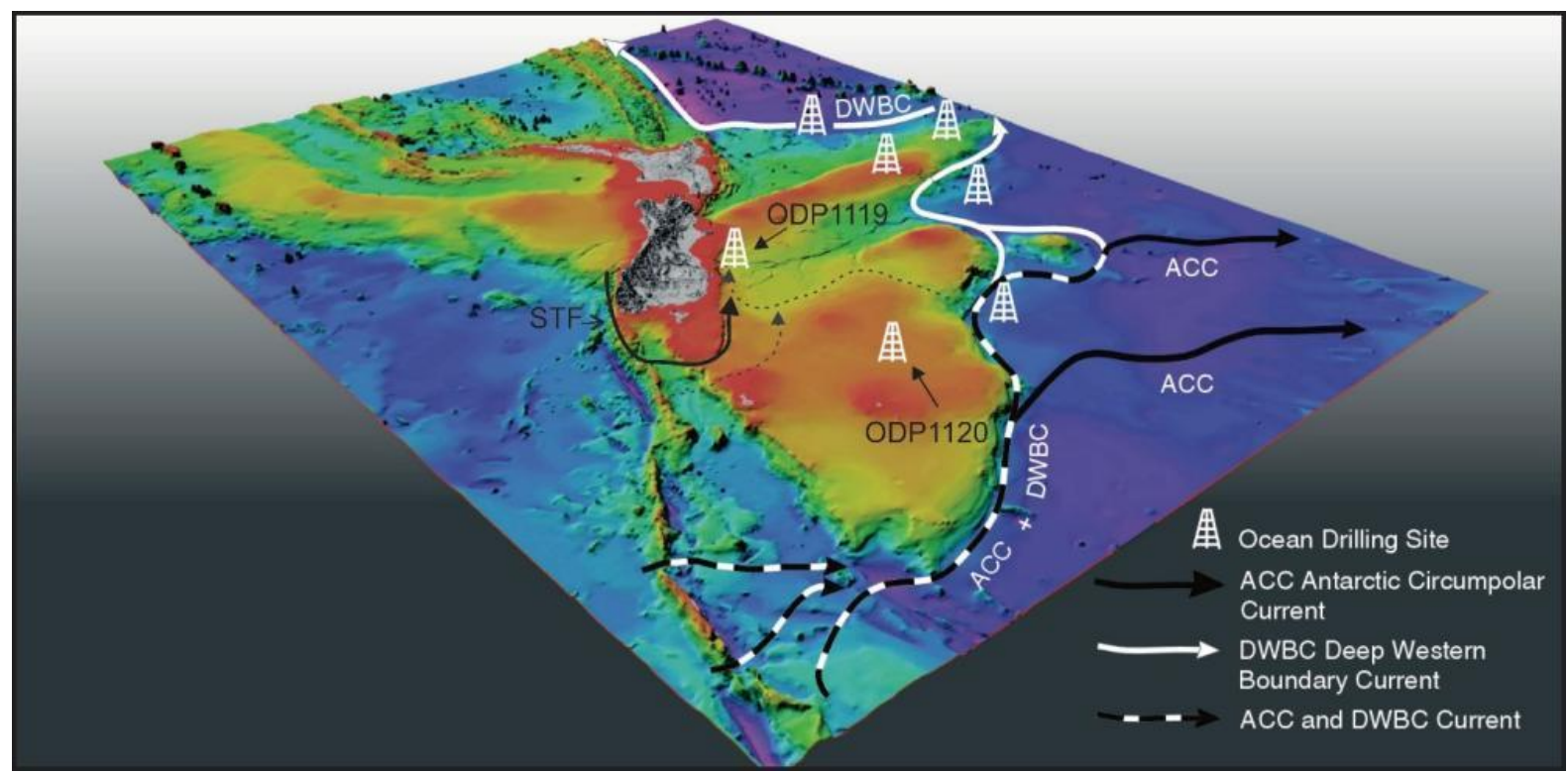

Figure 4.10: Oblique Map view of Zealandia and Campbell Plateau showing the modern-day Southern Ocean Circulation regime. The dashed lines represent suggested paleo-currents during the LGM based on findings in this study, e.g. the Summerhayes Channel. The Ocean Drilling sites marked are drill sites that were used in this study, with all other drill sites representing sites drilled on ODP leg 181 (adapted from NIWA UnderSea New Zealand, L. Carter 2019, pers. comm., 6 May). 


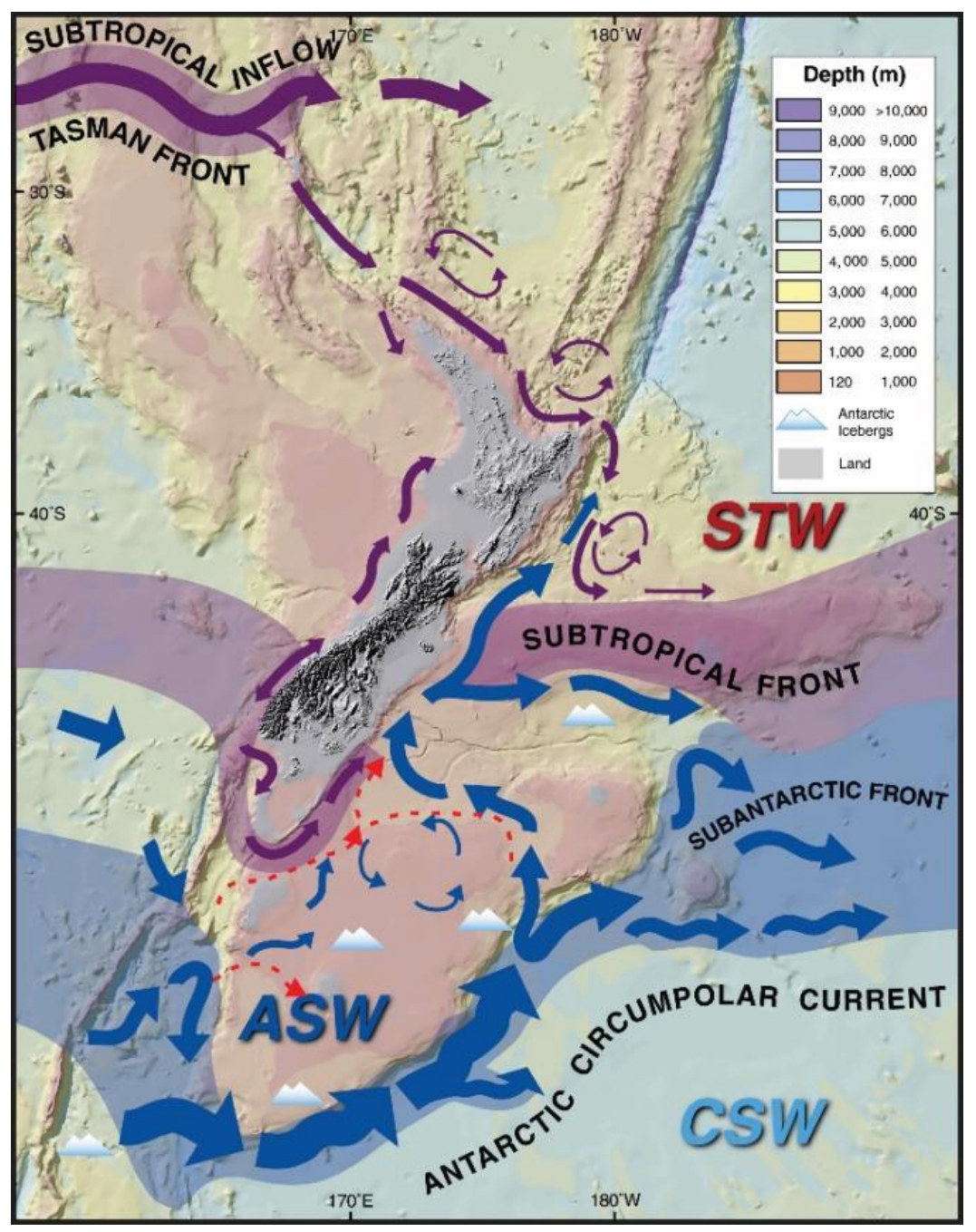

Figure 4.11: Circulation map of New Zealand during the LGM. Arrows seen on this map indicate water mass pathways during the LGM. The red dotted arrows show the suggested modified pathways of these currents around the Campbell Plateau, based on evidence seen in this study. During the LGM all water masses were invigorated due to the increase in wind strength and movement forward of southern water masses, which further amplifies the impact of the bathymetric constraint of the Campbell Plateau on the ACC subsequently increasing its strength. The presence of Antarctic icebergs on the plateau is also evidence of this northward shift of the ACC/SAF during the glacial periods. (Modified from Carter et al., 2000) 


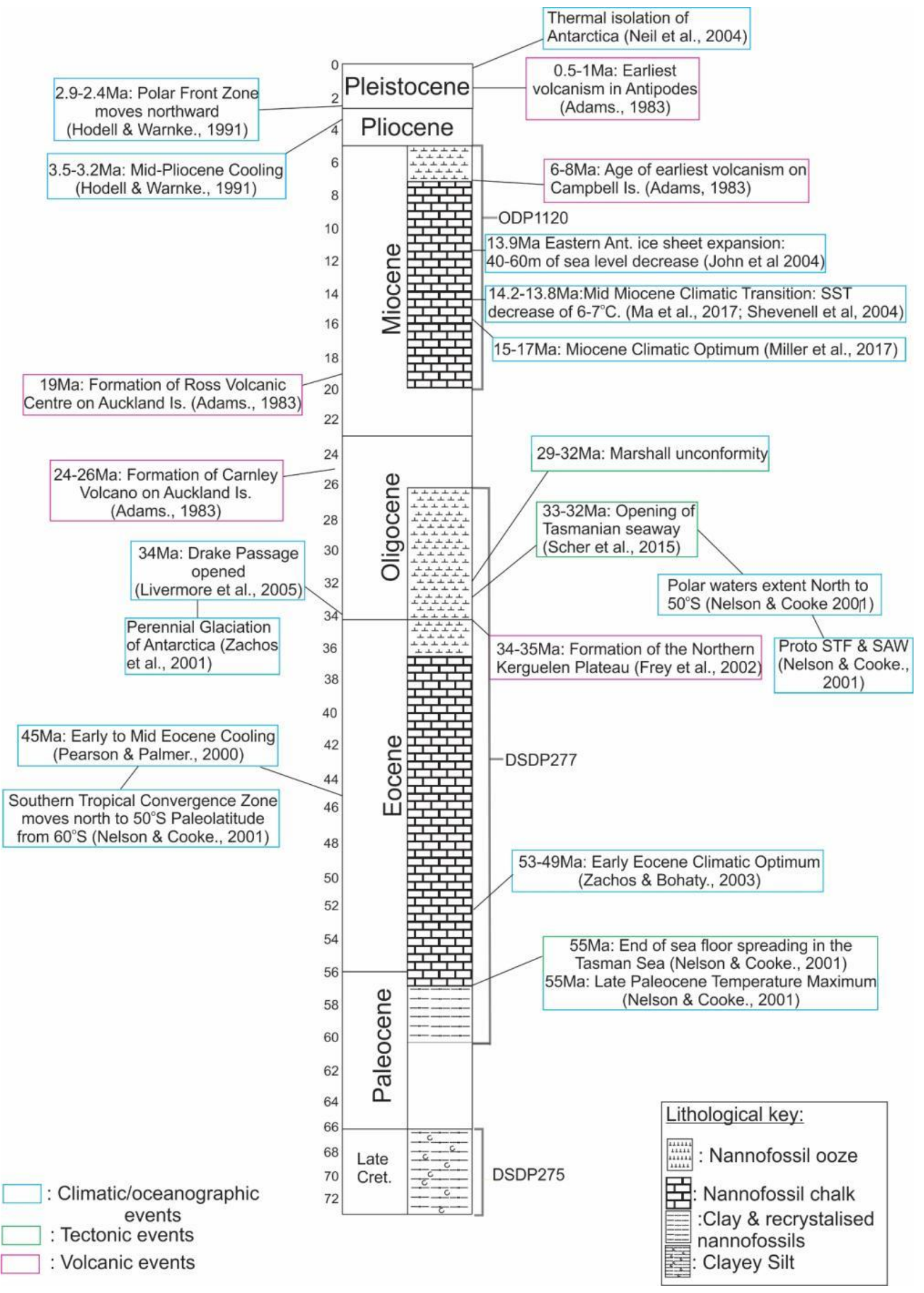

Figure 4.12: Schematic measured section of the Cenozoic ( 72Ma to present) with events that have been characterised by their type: volcanic, climatic or geologic, that have impacted the Southern Ocean and the Campbell Plateau. Column also shows the epochs within the Cenozoic and the deep-sea cores that penetrate these and their associated lithologies on the Campbell Plateau. 
The palaeo-channel to the NNE of Auckland Islands (see figure 4.7 and 4.8), in this study, will be referred to as the Summerhayes Channel likely had the palaeoconditions that reflect the Pliocene and Pleistocene unconformities, such as the Pliocene unconformity seen in ODP1120. Due to the widespread nature of these unconformities across the Campbell Plateau would suggest a large oceanographic event. The modelling performed by Hodell et al (1991) suggests a 5-10 latitude shift northward of the ACC during the Pliocene, which suggests to have been a response to substantial ice sheet growth in Antarctica during this time. This northward shift also likely influenced western New Zealand and the western edge of the Campbell Plateau due to no major submarine topography would affect this migration. This would allow the SAF of the ACC to find gaps within the northern section of the Macquarie Ridge and move towards the channel between the Auckland Islands and Snares Platform, which in turn leads to the Summerhayes Channel. This mechanism could be the driver for the erosion of the entire Pliocene on the Campbell Plateau, as a similar mechanism is seen with the erosion of the Solander Fan with the ACC flowing through the central sections of the Macquarie Ridge (Carter \& McCave, 1997). This mechanism could also function during glacial cycles that caused the production of the Pleistocene unconformity seen across the plateau.

\subsection{2: Subsurface Oligocene Campbell Plateau}

The sediments that have been dated to Oligocene in age are seen on the Campbell Plateau, however, examples of these are only seen in the volcanic islands where it is seen above sea level such as the Tucker Limestone on Campbell Island (James P Kennett et al., 1975). It is possible that the limestone seen on the volcanic islands is preserved due to the uplifting of these islands with the associated volcanism during the Miocene. However, in the subsurface is only seen in the DSDP277 core, located $\sim 200 \mathrm{~km}$ south of the closest seismic line in the study area. The section of Oligocene that is seen in the DSDP277 core, unit 2, has a thickness of 233m ranging from Middle-Late Oligocene through to Early Oligocene (Hollis, 1997), with a topographic difference of $<\sim 225 \mathrm{~m}$ it is possible this unit could be preserved within the deeper sections of the 
Campbell Plateau. The Oligocene not being present in the south of the Campbell Plateau can likely be linked to increases in the oceanography at the time of deposition. During the Oligocene the presence of the proto-SAF and the AAPF with the general intensification of these with the more open seaway at this time (Campbell S. Nelson \& Cooke, 2001). This, in conjunction with the position of the plateau being further west and north (P. R. King, 2000) suggests these units have been possibly eroded by an intensified proto-SAF flowing across the southern Campbell Plateau. However, without solid evidence through sediment cores associated with the sub-bottom profiles in this southern section of the study area, this is yet to be confirmed. 


\section{Chapter 5: Conclusions}

\section{1: Summaries of key findings}

This summary of the key findings of this study will be presented in order of geological time to represent the order of evolution of the Campbell Plateau throughout the Cenozoic.

The presence of several basement highs seen in the Campbell Plateau subsurface suggests that it has undergone several periods of large-scale erosion and faulting during its Cenozoic transition from Gondwana to its current day position. This observation compared to the flat surface expression of the plateau displays that during the Cenozoic that these areas have been largely infilled with sediment.

Past structural interpretations by Summerhayes (1969) are also seen to be valid, this study further validates the presence of anticlines and synclines across the plateau on such a large scale and in more detail (see figure 4.7). The majority of structural deformation that is seen in the subsurface Campbell Plateau seen to be slightly more minor compared to the interpretations made originally by Summerhayes (1969).

The Miocene appears to be the period highest sedimentation across the Campbell Plateau, shown through the thickness of the Miocene sediment seen through the thickness of the Miocene section of the ODP1120 core, having a thickness of $\sim 188 \mathrm{~m}$. The sediment thickness is further suggested by the rather high sedimentation rate of $\sim 20 \mathrm{~m} / \mathrm{m}$.y. in the Early to Late Miocene, with this decreasing to $\sim 5 \mathrm{~m} / \mathrm{m}$.y. (Carter et al., 1999).

This study further confirmed the vast extent of the Pleistocene unconformity found in the ODP 1120 drill site, which is found across the entire plateau. This unconformity is likely caused by the extension of an intensified proto-SAF/ACC during the glacial periods over the Campbell Plateau. This intensification is also further caused by the topographic constraint of the plateau itself, which increases the likelihood of the suggested pathways of currents where the extent of the Pleistocene unconformity is seen.

The new suggested glacial current pathways are aligned with both the extent of this main unconformity and further features found in this subsurface study such as sediment wedges. These new suggested glacial current pathways suggest a tighter pathway 
around the northern edge of the Campbell Plateau, with this travelling generally further across to the west and following the continental shelf northward with the STF (see figures 4.7 and 4.8). The suggestion of glacial currents flowing through gaps in the Macquarie Ridge and over the Snares Depression in the NW is theorised due to the presence of newfound sedimentary formations such as contourite structures, general heavy erosion and the paleo-channel seen running into GSB is further evidence of this modified current direction during the LGM (see figure 5.7).

\section{2: Future work on the study area}

While this study has significantly improved our understanding of the sub-seafloor history on the Campbell Plateau, the interpretation of the data was significantly hampered by the lack of drill cores on the plateau to tie the reflectors too. Below are a number of suggested future work projects that are needed to further improve our knowledge of the sub-seafloor history and Cenozoic evolution of this part of Zealandia.

- A wider array of cores, especially deep drill cores, taken on the plateau to increase the sub-surface information and having more possible tie points for subbottom profile data.

- Taking a larger grid of sub-bottom profile data, to increase the amount of crosscutting lines and to fill in the large gaps with no seismic information, especially across the centre of the plateau.

- Improved understanding of the sedimentary structures on the plateau such as the wedges, contourites and unknown blobs, through improved coverage of subbottom profiles and sediment and drill cores.

- Further studies investigating the unconformity and the lack of sediment deposition during the Pliocene evident at ODP1120 core site and across the majority of the plateau from sub-bottom profiles.

- More work on the sediment cores to understand the paleoceanographic changes on the Campbell Plateau, how these relate to the larger scale changes in the Southern Ocean during the Cenozoic. A future International Ocean Discovery Program (IODP) expedition 378 focussing on the South Pacific Paleogene 
Climate is scheduled for January to March 2020 will be revisiting DSDP core site 277. Thus, it is likely that there will be more focus on the Cenozoic changes in this region in the future with this freshly drilled core. 


\section{$\underline{\text { References }}$}

Abreu, V. S., \& Anderson, J. B. (1998). Glacial eustasy during the Cenozoic: sequence stratigraphic implications. AAPG BUl et n82 (7), 1385-1400.

Adams. (1983). Age of the volcanoes and granite basement of the Auckland Islands, Southwest Pacific. Nera lad Jd fo Gebgrd Geb doi:10.1080/00288306.1983.10422237

Adams, Morris, P., \& Beggs, J. (1979). Age and correlation of volcanic rocks of Campbell Island

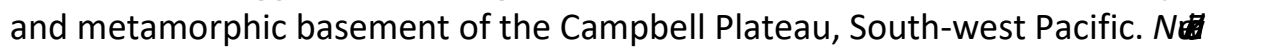
$J d f$
Gebged
Gep
(6), 679-691.

Adams, C. (1981). Migration of late Cenozoic volcanism in the South Island of New Zealand and the Campbell Plateau. NG, $294 \quad$ (5837), 153.

Barron, J. A., Baldauf, J. G., Barrera, E., Caulet, J.-P., Huber, B. T., Keating, B. H., . . Wei, W.
(1991). Bi o
Bd
h
Paper presented at the Barron, J.,

Larsen, B., et al., Proc. ODP, Sci. Results.

Barrows, T., Juggins, S., De Deckker, P., Thiede, J., \& Martinez, J. I. (2000). Sea-surface temperatures of the southwest Pacific Ocean during the Last Glacial Maximum.
Pdeo
(1), 95-109.

Beggs, J. M. (1978). Geology of the metamorphic basement and late Cretaceous Oligocene sedimentary sequence of Campbell Island, Southwest Pacific Ocean. Jd $6 \mathrm{~h}$
$R \not$ So
(2), 161-177. doi:10.1080/03036758.1978.10429389

Belkin, I. M., \& Gordon, A. L. (1996). Southern Ocean fronts from the Greenwich meridian to Tasmania. Jd 6 Geb $\quad$ (C2), 3675-3696.

Bishop, D. (1974). Stratigraphic, structural, and metamorphic relationships in the Dansey Pass area, Otago, New Zealand. New Ed dod Jd $f$ Gebgyd Geb 301-335.

Bostock, H. C., Barrows, T. T., Carter, L., Chase, Z., Cortese, G., Dunbar, G., ... Neil, H. (2013). A review of the Australian-New Zealand sector of the Southern Ocean over the last 30 ka (Aus-INTIMATE project). Qmensc , 35-57.

Bostock, H. C., Hayward, B. W., Neil, H. L., Sabaa, A. T., \& Scott, G. H. (2015). Changes in the position of the Subtropical Front south of New Zealand since the last glacial period.
Pdeo
$p$
(7), 824-844.

Bostock, H. C., Sutton, P. J., Williams, M. J., \& Opdyke, B. N. (2013). Reviewing the circulation and mixing of Antarctic Intermediate Water in the South Pacific using evidence from geochemical tracers and Argo float trajectories. DeeseaResc Oc , 84-98.

Carter, L., \& McCave, I. (1997). The sedimentary regime beneath the deep western boundary current inflow to the southwest Pacific Ocean. Ja d $6 \mathrm{Sed}$ 1005-1017.

Carter, L., Neil, H., \& McCave, I. (2000). Glacial to interglacial changes in non-carbonate and carbonate accumulation in the SW Pacific Ocean, New Zealand. Pd cegegh Pd ceo 162(3-4), 333-356.

Carter, L., Neil, H. L., \& Northcote, L. (2002). Late Quaternary ice-rafting events in the SW Pacific Ocean, off eastern New Zealand. Má eGebgy191 (1-2), 19-35.

Carter, R., Fulthorpe, C. t., \& Lu, H. (2004). Canterbury drifts at Ocean Drilling Program Site 1119 , New Zealand: climatic modulation of southwest Pacific intermediate water flows since 3.9 Ma. Gebg/32 $\quad$ (11), 1005-1008.

Carter, R. M., McCave, I.N., Ritcher, C., Carter, L., et al.,. (1999). Site 1120: Central Campbell
Plateau. Po
$c$
, 77.

doi:10.2973/odp.proc.ir.181.104.2000 
Chiswell, S. M., Bostock, H. C., Sutton, P. J. H., \& Williams, M. J. M. (2015). Physical

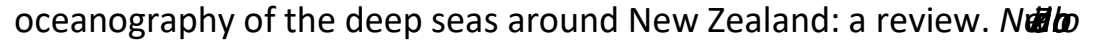
Má $\boldsymbol{\theta}$ ad

(2), 286-317. doi:10.1080/00288330.2014.992918

Cook, R. A., Sutherland, R., \& Zhu, H. (1999). Cretaceous-Cenozoic Geology And Petrom Systems Of The Great South Basin, New Zealand.

Cortese, G., Dunbar, G., Carter, L., Scott, G., Bostock, H., Bowen, M., . . . Martínez, J. I. (2013). Southwest Pacific Ocean response to a warmer world: insights from Marine Isotope Stage 5e. Pdeo

(3), 585-598.

Damuth, J. E. (1975). Echo character of the western equatorial Atlantic floor and its relationship to the dispersal and distribution of terrigenous sediments. Má $\boldsymbol{\theta}$ Gebgy $18 \quad$ (2), 17-45.

Deacon, G. E. R. (1937). The hydrology of the Southern Ocean. Di 6 , 3-122.

Dimitrov, L. I. (2002). Mud volcanoes - the most important pathway for degassing deeply buried sediments. Ech $-S c \quad(1-4), 49-76$.

Duncan, B., Carter, L., Dunbar, G., Bostock, H., Neil, H., Scott, G., . . Sabaa, A. (2016). Interglacial/glacial changes in coccolith-rich deposition in the SW Pacific Ocean: An analogue for a warmer world? Gl b d d d , 252-262.

Forcén-Vázquez, A., Williams, M. J., Bowen, M., Carter, L., \& Bostock, H. (2018). Campbell Plateau: A major control on the SW Pacific sector of the Southern Ocean circulation.

Fulthorpe, C. S., Carter, R. M., Miller, K. G., \& Wilson, J. (1996). Marshall Paraconformity: a mid-Oligocene record of inception of the Antarctic Circumpolar Current and coeval glacio-eustatic lowstand? Má ead 11$), 61-77$.

Fulthorpe, C. S., Hoyanagi, K., Blum, P., \& Expedition, I. (2011). IODP expedition 317: Exploring the record of sea-level change off New Zealand. Sc , 4-14.

Gille, S. T. (2003). Float observations of the Southern Ocean. Part I: Estimating mean fields, bottom velocities, and topographic steering. Jd $f P h \quad g p$ 1167-1181.

Glasby, G., \& Wright, I. (1990). Má eimed th d $i$ iNeled al

ธ่) вec

B Paper presented at the Offshore Technology Conference.

Graham, I., Carter, R., Ditchburn, R., \& Zondervan, A. (2004). Chronostratigraphy of ODP 181, Site 1121 sediment core (Southwest Pacific Ocean), using 10Be/9Be dating of entrapped ferromanganese nodules. Má $\boldsymbol{\theta}$ Gebg/205 (1-4), 227-247.

Greenwood, D. R., \& Wing, S. L. (1995). Eocene continental climates and latitudinal temperature gradients. Gebg/23 (11), 1044-1048.

Hesse, P. P. (1994). The record of continental dust from Australia in Tasman Sea sediments.

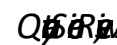

(3), 257-272.

Hodell, D. A., \& Warnke, D. A. (1991). Climatic evolution of the Southern Ocean during the Pliocene epoch from 4.8 to 2.6 million years ago. Quensc 205-214.

Hollis, C. (1997). Integrated Paleogene biostratigraphy of DSDP site 277 (Leg 29): foraminifera, calcareous nannofossils, Radiolaria, and palynomorphs. It Geb. $\mathrm{Na}$ 97/07, 1-87.

Hollis, C., Hines, B., Littler, K., Villasante-Marcos, V., Kulhanek, D., Strong, C., . . Phillips, A. (2015). The Paleocene-Eocene Thermal Maximum at DSDP Site 277, Campbell Plateau, southern Pacific Ocean.

Huber, M., Brinkhuis, H., Stickley, C. E., Döös, K., Sluijs, A., Warnaar, J., . . Williams, G. L. (2004). Eocene circulation of the Southern Ocean: Was Antarctica kept warm by subtropical waters? Pdeo

Jenkins, D. G. (1993). The evolution of the Cenozoic southern high-and mid-latitude planktonic foraminiferal faunas. Th Pepc PdTw , 175-194.

Katz, H.-R. (1974). Margins of the southwest Pacific. Th

I $\operatorname{ag}$ \& (pp. 549-565): Springer. 
Kennett, J. P., Houtz, R. E., Andrews, P. B., Edwards, A. R., Gostin, V. A., Hajós, M., . . Ovenshine, A. T. (1975). Cenozoic paleoceanography in the southwest Pacific Ocean, Antarctic glaciation, and the development of the Circum-Antarctic Current. In $t \boldsymbol{d}$ Anth , 1155-1169.

Kennett, J. P., Houtz, R. E., Andrews, P. B., Edwards, A. R., Gostin, V. A., Hajos, M., . . PerchNielsen, K. (1975a). Site 275. In ti d h $\mathrm{bad}$, 19. doi:DOI: 10.2973/dsdp.proc.29.102.1975

Kennett, J. P., Houtz, R. E., Andrews, P. B., Edwards, A. R., Gostin, V. A., Hajos, M., . . PerchNielsen, K. (1975b). Site 276. In $t d d h$ doi:DOI: 10.2973/dsdp.proc.29.103.1975

Kennett, J. P., Houtz, R. E., Andrews, P. B., Edwards, A. R., Gostin, V. A., Hajos, M., . . PerchNielsen, K. (1975c). Site 277. In $t d d h$ , 45 . doi:DOI: $10.2973 /$ dsdp.proc.29.104.1975

Kennett, J. P., Houtz, R. E., Andrews, P. B., Edwards, A. R., Gostin, V. A., Hajos, M., . . PerchNielsen, K.. (1975). Site 278 lin $t d$ h $h$ , 121-189. doi:10.2973/dsdp.proc.29.105.1975

King, P. (2000). New Zealand's changing configuration in the last 100 million years: plate ec i $g$ Paper presented at the 2000 New Zealand Petroleum Conference Proceedings.

King, P. R. (2000). Tectonic reconstructions of New Zealand: 40 Ma to the present. New Ed d d Jd $f \quad$ Gebged Geb $\quad$ (4), 611-638.

Kongsberg. (2018). TOPAS PS 18: Parametric sub-bottom profiler. Paib $c \quad$-Btn Pfi ler (25/03), 2. Retrieved from Kongsberg Sub-bottom profiler, Parametric website:

https://www.km.kongsberg.com/ks/web/nokbg0397.nsf/AllWeb/455815DCF4E3BEC3 C125782D0042F091/\$̧file/TOPAS-PS-18-data-sheet.pdf?OpenElement

LeBlanc, L. R., Mayer, L., Rufino, M., Schock, S. G., \& King, J. (1992). Marine sediment classification using the chirp sonar. Th 91(1), 107-115.

Lowrie, W. (2007). Fd Cambridge university press.

Markwick, P. J. (1998). Fossil crocodilians as indicators of Late Cretaceous and Cenozoic climates: implications for using palaeontological data in reconstructing palaeoclimate. Pd cegegh ceo (3-4), 205-271.

McCartney, M. (1977). Subantarctic Mode Water. In. A Vqef Di o Resc , 103-119.

McCartney, M. S. (1982). The subtropical recirculation of mode waters. J. Ma Res40 (427.4), 64.

McCave, I., Carter, L., \& Hall, I. R. (2008). Glacial-interglacial changes in water mass structure and flow in the SW Pacific Ocean. Qceanc

(19), 1886-1908.

Miller, K. G., Browning, J. V., Aubry, M.-P., Wade, B. S., Katz, M. E., Kulpecz, A. A., \& Wright, J. D. (2008). Eocene-Oligocene global climate and sea-level changes: St. Stephens Quarry, Alabama. Gebg $c$

(1-2), 34-53.

Morris, M., Stanton, B., \& Neil, H. (2001). Subantarctic oceanography around New Zealand: Preliminary results from an ongoing survey. Need ad Feb $\quad$ (3), 499-519. doi:10.1080/00288330.2001.9517018

Mortimer, N., Rattenbury, M., King, P., Bland, K., Barrell, D., Bache, F., . . Crampton, J. (2014). High-level stratigraphic scheme for New Zealand rocks. Ne d d d J $f$
Gebged
Gep
(4), 402-419.

Neil, H. L., Carter, L., \& Morris, M. Y. (2004). Thermal isolation of Campbell Plateau, New Zealand, by the Antarctic Circumpolar Current over the past $130 \mathrm{kyr}$.
Pd eo
(4). doi:10.1029/2003pa000975 
Nelson, C., Hendy, C., \& Cuthbertson, A. (1994). Oxygen isotope evidence for climatic contrasts between the Tasman Sea and Southwest Pacific Ocean during the late Quaternary.

Ebtu $\phi$ h , 181-196.

Nelson, C., Hendy, I., Neil, H., Hendy, C., \& Weaver, P. (2000). Last glacial jetting of cold waters through the Subtropical Convergence zone in the Southwest Pacific off eastern New Zealand, and some geological implications. Pd cegegh
Pd ceec
(1), 103-121.

Nelson, C. S., \& Cooke, P. J. (2001). History of oceanic front development in the New Zealand sector of the Southern Ocean during the Cenozoic - a synthesis. Neld ad Jd f Gebged $\quad$ (4), 535-553. doi:10.1080/00288306.2001.9514954

Nelson, C. S., Cooke, P. J., Hendy, C. H., \& Cuthbertson, A. M. (1993). Oceanographic and climatic changes over the past 160,000 years at Deep Sea Drilling Project Site 594 off southeastern New Zealand, southwest Pacific Ocean. Pd eo (4), 435458.

Nodder, S. D., \& Northcote, L. C. (2001). Episodic particulate fluxes at southern temperate midlatitudes (42-45 S) in the Subtropical Front region, east of New Zealand. Deeßsea Resc

(3), 833-864.

Ohshima, K. I., Fukamachi, Y., Williams, G. D., Nihashi, S., Roquet, F., Kitade, Y., . . Field, I. (2013). Antarctic Bottom Water production by intense sea-ice formation in the Cape Darnley polynya. Nat Ges (3), 235.

Oliver, R. L., Finlay, H. J., \& Fleming, C. A. (1950). Th ell Isad : Department of Scientific and Industrial Research.

Orsi, A. H., Whitworth III, T., \& Nowlin Jr, W. D. (1995). On the meridional extent and fronts of the Antarctic Circumpolar Current. DeepseaResc

$P$ cos $42 \quad$ (5), 641-673.

Rintoul, S. R., \& Bullister, J. L. (1999). A late winter hydrographic section from Tasmania to Antarctica. Deeßs eaResc

(8), 14171454.

Rintoul, S. R., \& England, M. H. (2002). Ekman transport dominates local air-sea fluxes in driving variability of Subantarctic Mode Water. Jd $f P h$

œp 32(5), 1308-1321.

Shakleton, N., \& Kennett, J. (1975). Paleotemperature history of the Cenozoic and the Initiation of Antarctic Glaciation: Oxygen and Carbon isotope analysis in DSDP Sites 277, 279 and 281. In $t$ RepDeedaDi lli gPjec $\quad t 29,743-754$.

Sikes, E., Howard, W., Samson, C., Mahan, T., Robertson, L., \& Volkman, J. (2009). Southern Ocean seasonal temperature and Subtropical Front movement on the South Tasman Rise in the late Quaternary. Pdeo

Smith, R. O., Vennell, R., Bostock, H. C., \& Williams, M. J. (2013). Interaction of the subtropical front with topography around southern New Zealand. DeepseaResc

Oc , 13-26.

Sokolov, S., \& Rintoul, S. R. (2007). Multiple jets of the Antarctic Circumpolar Current south of Australia. Jd $6 P h$

(5), 1394-1412.

Sokolov, S., Rintoul, S. R., \& Wienecke, B. (2006). Tracking the Polar Front south of New Zealand using penguin dive data. DeepseaResc $\quad: O c$ Pc⿻5 53 (4), 591-607.

Stanton, B. R., \& Morris, M. Y. (2004). Direct velocity measurements in the Subantarctic Front and over Campbell Plateau, southeast of New Zealand. Jd f Gep $\begin{array}{lll}\text { Resc } & c & (\mathrm{C} 1) \text {. }\end{array}$

Stow, D., \& Faugères, J.-C. (2008). Contourite facies and the facies model. Ded fit $n$ Sed , 223-256.

Summerhayes, C. P. (1969). Má $\theta$ Gebgght Wellington: Government Printer. 
Sutton, P. J. (2003). The Southland Current: a subantarctic current. Need ad Má ed $\quad$ (3), 645-652.

Timm, C., Hoernle, K., Werner, R., Hauff, F., van den Bogaard, P., White, J., . . GarbeSchönberg, D. (2010). Temporal and geochemical evolution of the Cenozoic intraplate volcanism of Zealandia. Ech -SC (1), 38-64.

Watkins, N., Ledbetter, M., \& Huang, T. (1982). Antarctic glacial history using spatial and temporal variations of ice-rafted debris in abyssal sediments of the Southern Ocean. Att , 1013-1016.

Weaver, P. P., Carter, L., \& Neil, H. L. (1998). Response of surface water masses and circulation to late Quaternary climate change east of New Zealand. Pd eo 83.

Whitworth III, T., Warren, B., Nowlin Jr, W., Rutz, S., Pillsbury, R., \& Moore, M. (1999). On the deep western-boundary current in the Southwest Pacific Basin. Pges $n$ Oc (1), 1-54.

Wilson, G. J. (1967). Microplankton from the Garden Cove Formation, Campbell Island. New $\begin{array}{lll}\text { Ed ad } & \text { (2), 223-240. }\end{array}$

Wise, S. (1991). Paleogene glacial history of Antarctica. Cis es ith ,133171.

Zachos, J., Pagani, M., Sloan, L., Thomas, E., \& Billups, K. (2001). Trends, rhythms, and aberrations in global climate $65 \mathrm{Ma}$ to present. $6 \quad$ 2(5517), 686-693.

Zachos, J. C., Dickens, G. R., \& Zeebe, R. E. (2008). An early Cenozoic perspective on greenhouse warming and carbon-cycle dynamics. N\& 451 (7176), 279.

Zachos, J. C., Lohmann, K. C., Walker, J. C., \& Wise, S. W. (1993). Abrupt climate change and transient climates during the Paleogene: A marine perspective. Th 101(2), 191-213. 